\title{
Architecture for the Poor and Unprivileged of Jakarta
}

By

\author{
Patrick Waller
}

\section{A 120-point thesis}

submitted to the Victoria University of Wellington

in partial fulfillment of the requirements for the

degree of Master of Architecture (Professional)

Victoria University of Wellington

Scchool of Architecture 


\section{Acknowledgments}

Firstly I would like to thank my supervisor Fabricio Chicca for his endless guidance, knowledge and support throughout the year. He always gave me useful advice and taught me to have a confidence in my own work.

I would like to make a special acknowledgement to all my friends I have made throughout my five years at VUW School of Architecture. Especially Sarah who's constant cheerfulness and relaxed attitude made the long hours and late nights a bit easier. I would also like to thank my Mum and Dad for their constant support and for always helping me manage my finances. 
As the world becomes increasingly urbanised, cities are forced to manage significant population increases. Jakarta, in Indonesia, has a significant population that is visibly living below the poverty line which suggests the city was not fully prepared to accommodate the radical growth. With such a large number of people living in poverty, and there being a lack of affordable housing Jakarta faces an issue where a significant number of these people are forced to live in informal settlements, which are spread throughout the city. These informal settlements, known as Kampungs are typically made up of dense clusters of single or two story residential structures packed together in communal areas. The erection of these houses often results in unplanned but functional networks of footpaths. These urban arrangements normally have a lack of sanitary infrastructure. The government's current plans to mitigate this issue are by forced evictions, and moving the informal settlement residents into subsidised social housing apartment buildings. Generally, people are against these forced evictions and in many cases they are forced to leave, or simply rebuild on top of the rubble of their old homes.

How can architecture support the existing social connections within the community, while improving the living conditions of the residents in the informal settlements of Jakarta?

This research proposes a community centre design which is able to provide necessary facilities to the informal settlements. Although the residents are not in need of a new housing design, this research focuses on providing facilities to improve the quality of life. The research takes into account extensive site, literature, and precedent analysis; to develop a design criteria which aims to produce positive neighbourhood development. Traditional Indonesian architecture has a heavy influence on the form and construction material, with the intention to give the opportunity for the community to get involved in the construction and maintenance of the building. The final design result is a community centre with a large auditorium space for community gatherings, and support spaces which include emergency accommodation, teaching facilities, exhibition space, workshop space, sanitary facilities, recycling management centre, and retail spaces. This architectural intervention provides a place for the community to come together and to have a better quality of life while still being able to live in their personally constructed and designed homes. 


\section{Table of Contents}

Acknowledgments

Abstract

Table of Contents

\subsection{Introduction}

Research Problem

Research Question

Thesis Direction

Aims

Objectives

Reseach Methodology

\subsection{Site Analysis}

Initial Site Investigation

Informal Settlement Spread

Elevation Below Sea Level

City Waste Management

Jakarta Different Scales

Kampung Luar Batang

Climate Analysis

Surrounding Site Context

Luar Batang Informal Footprints

Site Sections

Public/ Green Space

Education Facilities

Inside Luar Batang

Kampung Akuarium

Existing Housing Types

Existing Site Conditions

Existing Site Conditions

Existing Site Conditions

\subsection{Literature Review}

Introduction
Urban Development

Social Sustainability

Community Resilience

Conclusion

\subsection{Precedents}

Mumbai Incremental Housing

Rafael-Unido Neighbourhood plan

Low Cost Housing for South Afrcan Slum

Alok Shetty's Slum Dwelling Design

Klong Toey Community Lantern

Waterhubs: Infrastructure for Urban Slums

Useful Systems

Cleantech Solutions to Waste Management

Initial Sketches

Initial Sketches

Initial Sketches

Chapter Conclusion

\subsection{Detailed Case Studies}

Chamanga Cultural Center

Center for Culture and Ecology Quiane

Renacer de Chamanga Community House

Black Bamboo Community Center, Yogyakarta

Designing for Flooding

Conclusions

\subsection{Initial Design Investigations 83}

Initial Sketch Ideas

Initial Sketch Ideas

Digital Mass Explorations

Digital Mass Explorations

Conclusion 


\subsection{Material Study}

Bamboo

Bamboo

Traditional Betawi Architecture

Bamboo Architecture

Digital Material Exploration 1

Digital Material Exploration 2

Digital Material Exploration 3

Digital Material Exploration 4

Waterproofing Bamboo Roofs

Conclusions

\subsection{Concepts}

Concept 1

Concept 2

Concept 3

Concept 4

Concept 5

Concept 6

9.0 Developed Design

Concept Position on Site

Jakarta Pevailing Wind

Interior Spatial Development

Initial External Form Devlopment

Dry Zones

Design Development - Base

Design Development - Roof

Design Development - Roof Support

Design Development - Exterior Walls

Solar Power

Design Development - Programme

Design Development - Openings

Spatial Planning
Spatial Planning

Spatial Planning

Design Development - Interior Form

150

Design Development - Structure

Rainwater Management

153

Structural Sections

154

Bamboo Construction Detail - Foundation

156

Construction Technique 157

Bamboo Construction Detail - Roof

158

Construction Technique

Conclusion

\subsection{Final Design}

Ground level

level 1

166

level 2

Section

170

Section

172

3D Visualisation

\subsection{Conclusion}

Findings

Critical Reflection

Critical Reflection

Potential Applications

Limitations

Conclusion

Works Cited 
Fig 1.1. Jakarta City 
1.0 Introduction 
Rapid urbanisation and population growth has resulted in the emergence of informal settlements in cities which were poorly prepared for significant population increases, such as Jakarta in Indonesia (Alzamil, 2017). Jakarta is a city which has over 2 million people that live below the poverty line, these people are generally concentrated in unplanned slums that have high population densities, substandard dwellings, and inadequate infrastructure (Hadiwinoto \& Leitmann, 1994); Simone, 2014). The informal settlements of Jakarta are spread throughout the city, where residents are making the most of any land and resources that are available.

Similar to many cities in developing countries, Jakarta is full of deceptive appearances. Large numbers of people are facing constant scarcity and are caught in the daily struggle to put food on the table. At least two million Jakarta residents live in substantially deteriorating conditions (Simone, 2014). The people who live collectively in questionable conditions live in the informal settlements, referred to as Kampungs. A kampung is a slum, considered to be an urban version of a rural village, typically made up of a dense cluster of single, or sometimes two storey residential structures packed together in a communal area. The erection of these houses results in unplanned networks of footpaths, and a lack of sanitary infrastructure (Irawaty, 2018). The housing backlog is an enduring problem in Indonesian cities, and the kampungs are the current solution, able to make a significant contribution towards the way the urban poor were accommodated in the city. The Jakarta government considers the informal kampungs as problematic spaces and the antithesis to modernity. In the early 1980's rapid modernization of the city meant urban planners began to view the kampungs as anomalies, and pushed for their demolition, forcing evictions and moving the residents into social housing (Irawaty, 2018). It has become a known problem in Jakarta that a majority of the time relocated communities are rehoused in accommodation that breaks down their networks and coping strategies when facing social and environmental threats (Baldwin, King, and King, 2018). The poor people of Jakarta tend to have poor living conditions, lacking basic infrastructure and services needed to meet basic human needs. However some victims of the forced government evictions have such a love for their homes that they reclaim their old plots of land and rebuild on top of the rubble. They decline the offer of social housing because the small high rise studios that are offered tend to be far away, and relatively expensive to rent, and with no space to run a home business. A complete disconnection from the existing way of life in the informal settlements (Tilley, Elias, and Rethel, 2017).

The informal kampung settlements of Jakarta not only house residents in poor living conditions, but the lack of infrastructure makes them vulnerable to environmental threats of the area, most significantly flooding (Hadiwinoto \& Leitmann, 1994). It is considered to be the role of a city government to adequately house its citizens, rather than leaving a substantial amount of the population to service in a permanent state of insecurity. With the current government solution proven to be insufficient, it leads to the question of how the living conditions of the kampung residents can be improved while maintaining the important social connections of the community. 


\section{Research Question}

How can architecture support the existing social connections within the community, while improving the living conditions of the residents in the informal settlements of Jakarta?

\section{Thesis Direction}

The focus of this research centres on the living conditions of the residents of the informal settlements in Jakarta, known as kampungs. Specifically the community of Kampung Luar Batang, one of the oldest and most vulnerable informal settlements in Jakarta (Subroto, 1993). This thesis proposes an analysis of the residents living in the informal settlements, understanding their needs and their way of life, in order to investigate how an intervention can successfully improve the current living conditions. An alternative to the government's current plans of forced relocation to social housing, and the demolition of the kampungs to make land available for developers. Although the kampung residents have a deep love for their homes and community, they are living in conditions which lack basic infrastructure and public facility to meet basic human needs (Hadiwinoto \& Leitmann, 1994).

The initial intended result of the research at the earlier stages was a housing typology design. Intending to improve the living conditions of the residents while maintaining their community ideals. As the research continued it became clear that a housing design was not necessary and it was more important to provide facilities to aid and support the community as a whole. Therefore the new direction was towards the design of a community centre that would be able to provide necessary facilities that are currently lacking, and increase the social capital.

Fig 1.2. Kampung Luar Batang architecture 


\section{Aims}

- To investigate how an architectural design can improve the current living conditions in the informal settlements while avoiding forced relocation of the current residences.

- Investigate ways to in which architecture can support the social connections between the current residents.

_ To investigate what services the informal community would most benefit from.

_ To investigate materiality, design using suitable natural materials that can be locally sourced in an abundance.

_ To investigate how services and facilities can be multi-use to meet specific community needs.

\section{Objectives}

- Critically explore through design achievable needs of the residents in the informal residents of Jakarta.

- Critically explore through design the extensive use of natural materials to achieve the desired architectural form. 

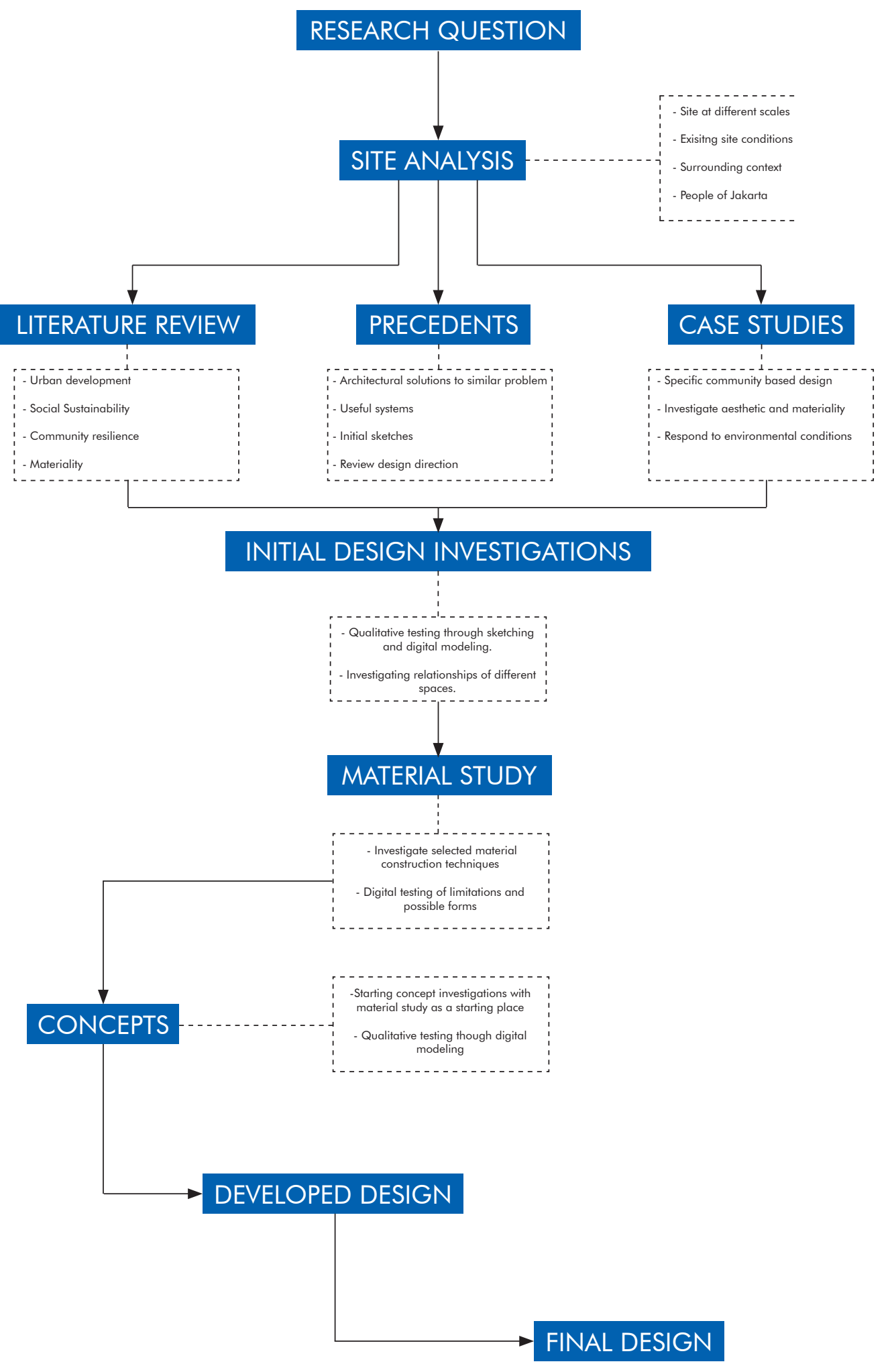

Fig 1.3. Research Methodology Diagram 


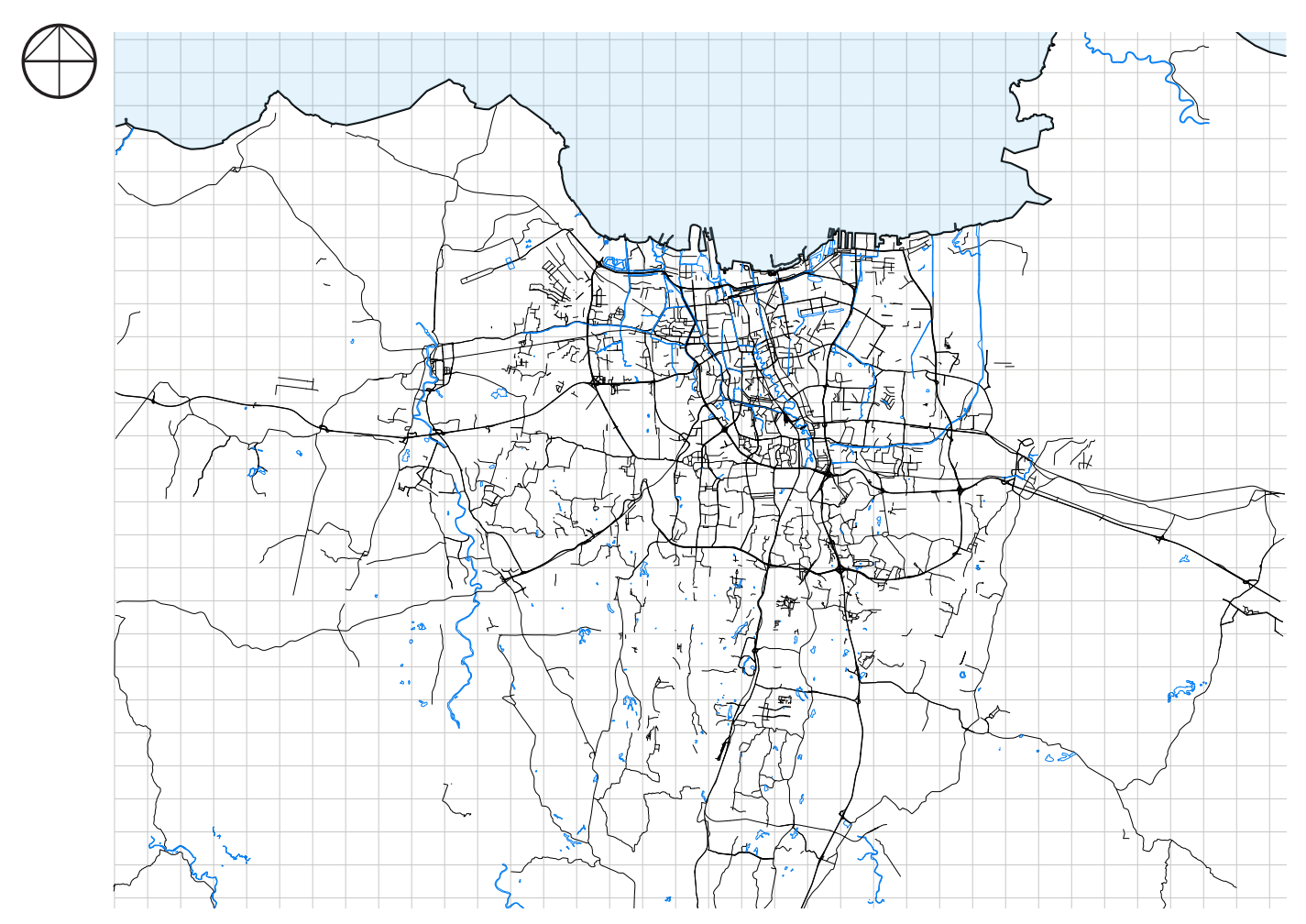

Fig 2.1. Jakarta City Map 
2.0 Site Analysis 


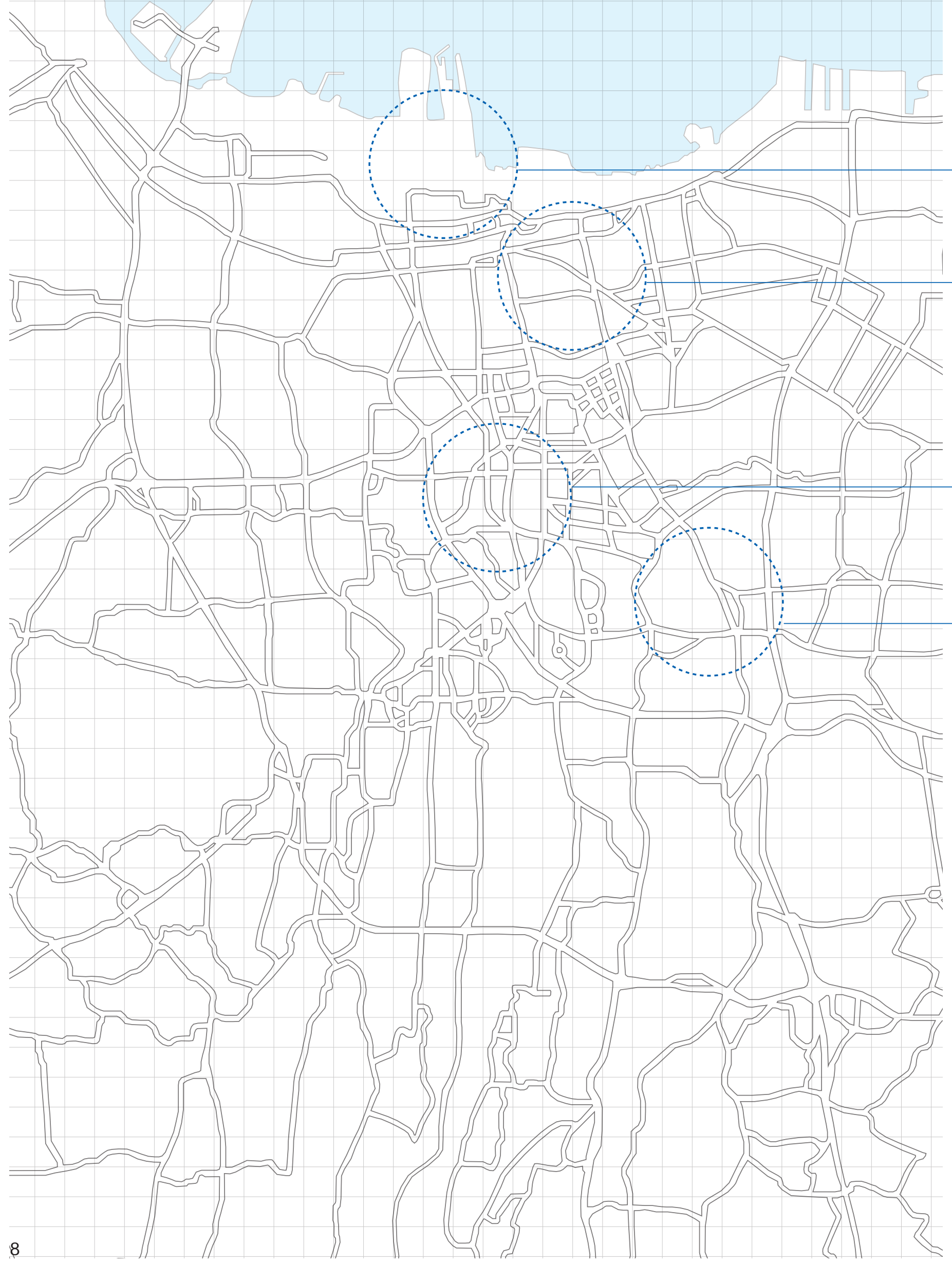




\section{Initial Site Investigation}

\section{Kampung Luar Batang}

- Located near the Ciliwung River.

- Common building materials in this settlement include wood and bricks.

- Common features received from residential respondents include:

Deteriorating housing, shortage of housing spaces, lack of services, forms of electricity connection, gas systems, and rainwater drainage. (Alzamil, 2017).

\section{Kampung Bandan}

- Densely populated Bordering North Jakarta and Central Jakarta.

- Most common building materials are wood, Iron sheets, and brick.

- Common features received from residential respondents include:

Deteriorating housing, shortage of housing space, lack of housing services, lack of waste water sewage utilities, lack of rainwater drainage. (Alzamil, 2017).

\section{Kebon Melati}

- Considered to be of the most vulnerable informal settlement almost all of it has been destroyed by urban development (Oktarina, 2018).

\section{Kampung Pulo}

- Formally the government deems Kampung Pulo as an illegal settlement, and has been scheduled to be razed to the ground (Van Voorst \& Padawangi, 2015). 


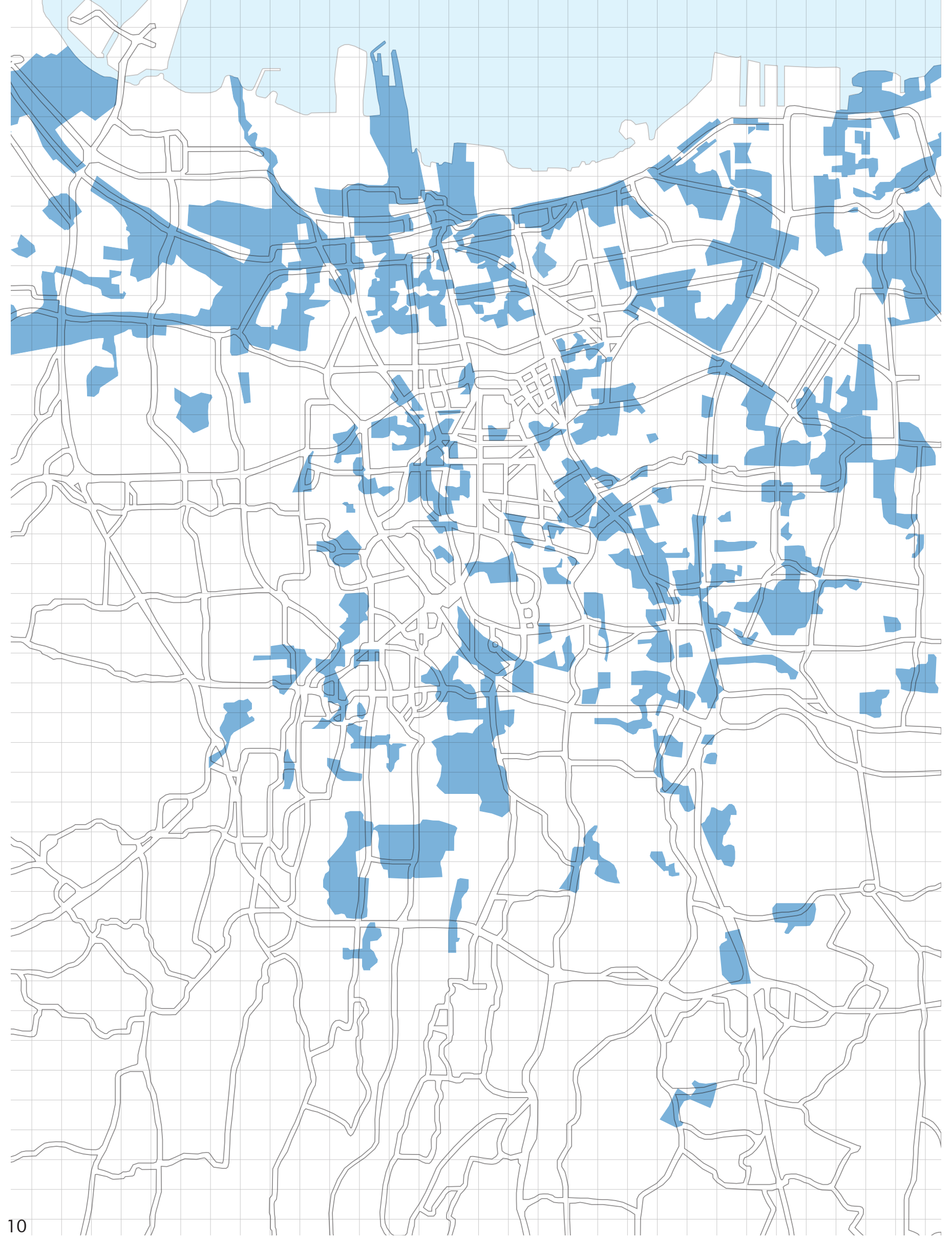

Fig 2.4. Jakarta informal settlement distribution 


\section{Informal Settlement Spread}

The distribution of slum villages throughout Jakarta:

\begin{tabular}{l|c|c} 
Municipality & Sub-Districts & Villages \\
\hline North Jakarta & 6 & 21 \\
\hline South Jakarta & 7 & 15 \\
\hline Central Jakarta & 7 & 15 \\
\hline West Jakarta & 4 & 8 \\
\hline East Jakarta & 10 & 19
\end{tabular}

(Gasper, 2015.)

Data for this graphic was sourced from (Google Maps, 2019) (Gasper, 2015). 
JAKARTA BAY

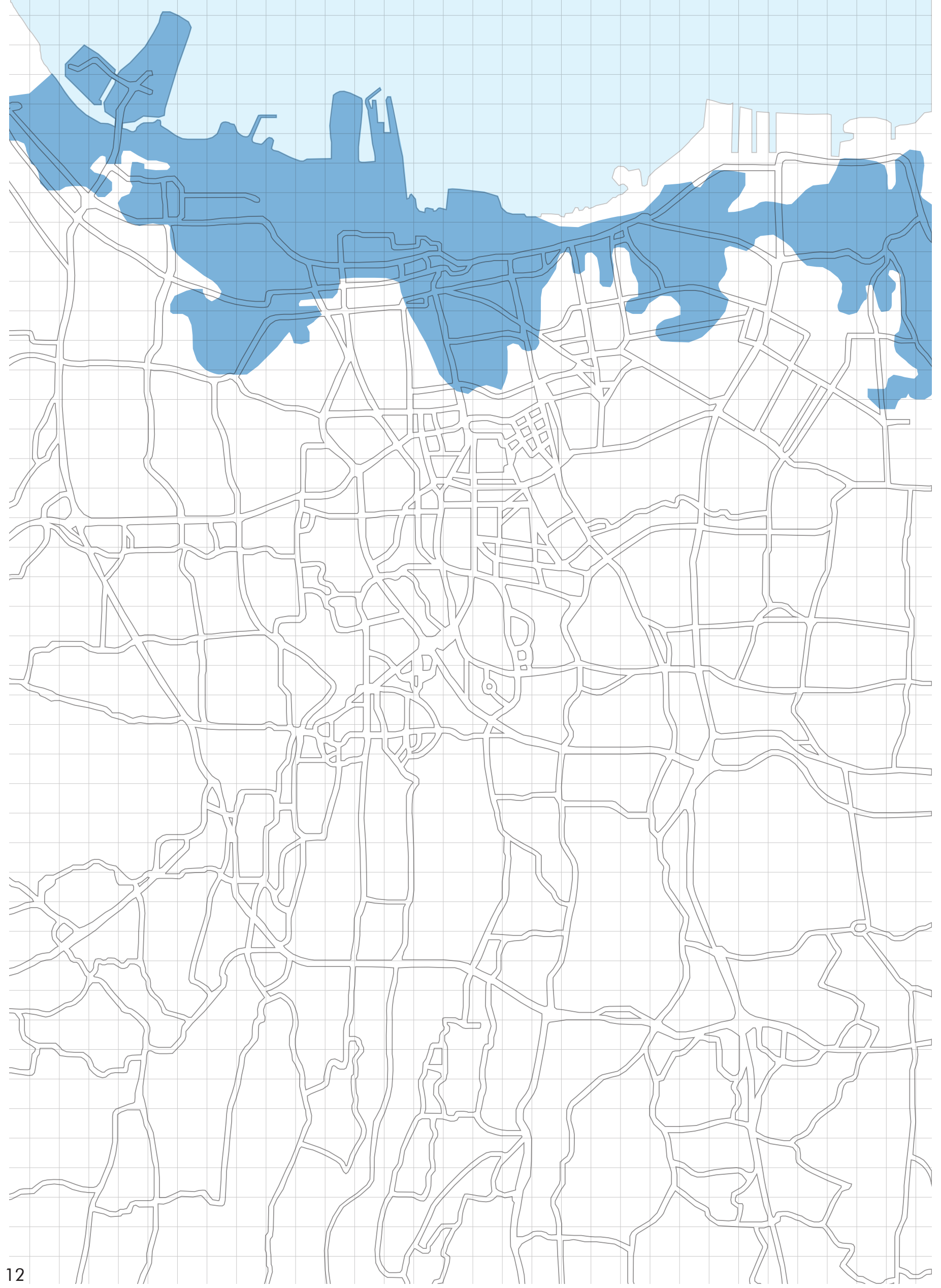




\section{Elevation Below Sea Level}

The informal settlements of Jakarta that are positioned in the northern coastal area face a more unique threat than those positioned further south. The issue is that the city is sinking at an alarming rate, resulting in a significant amount of the northern area of Jakarta to have an elevation which is below the mean sea level (Jakarta Post, 2015). The main reason for the land sinking is the informal settlements themselves. Because the communities do not have access to necessary infrastructure, such as piped water, residents are forced to dig illegal wells. These wells are draining the underground aquafiers which the city rests on. Hydrologists say the city has roughly a decade to stop the sinking, if not the north of Jakarta will end up underwater (Kimmelman and Haner 2017). It is clear that the way to mitigate the sinking of the land is to improve the infrastructure in the area. The population should not need to dig the illegal wells to obtain fresh water.

Data for this graphic was sourced from (Google Maps, 2019)

(Kimmelman and Haner, 2017). 


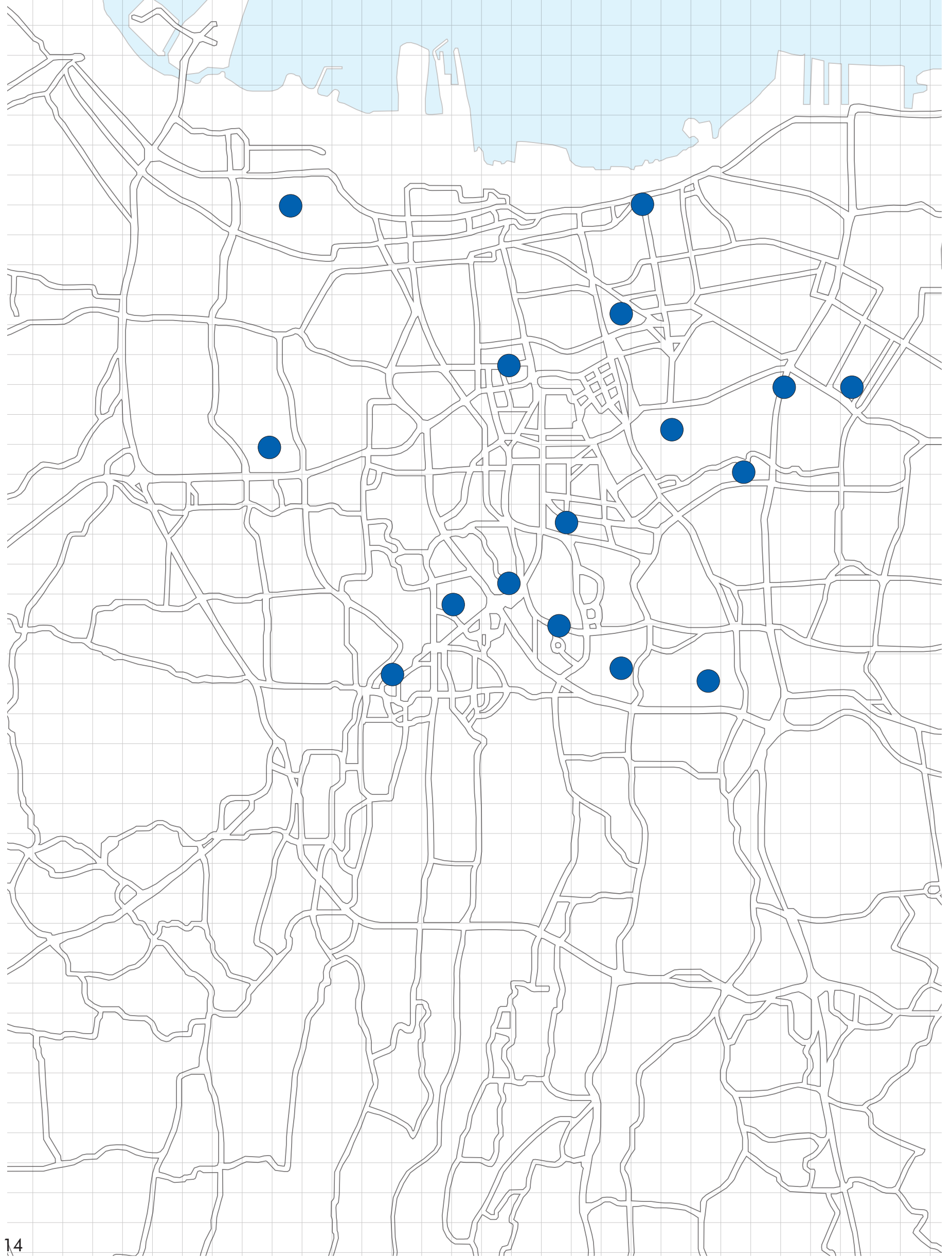




\section{City Waste Management}

In Jakarta there are a lot of waste management services scattered throughout the city, however a dangerously large amount of waste is dumped into the water bodies and the makeshift landfills which appear amongst the settlements (Parvin \& Begum, 2018). For lives to be improved in the informal settlements, it is very important that there is an effective waste management system. The main issue at the moment is that the streets and pathways within informal settlements are too narrow for vehicles to drive in between the houses, making waste collection too challenging and inefficient (Parvin \& Begum, 2018).

Data for this graphic was sourced from (Google Maps, 2019) 


\section{Jakarta Different Scales}

$\ominus$
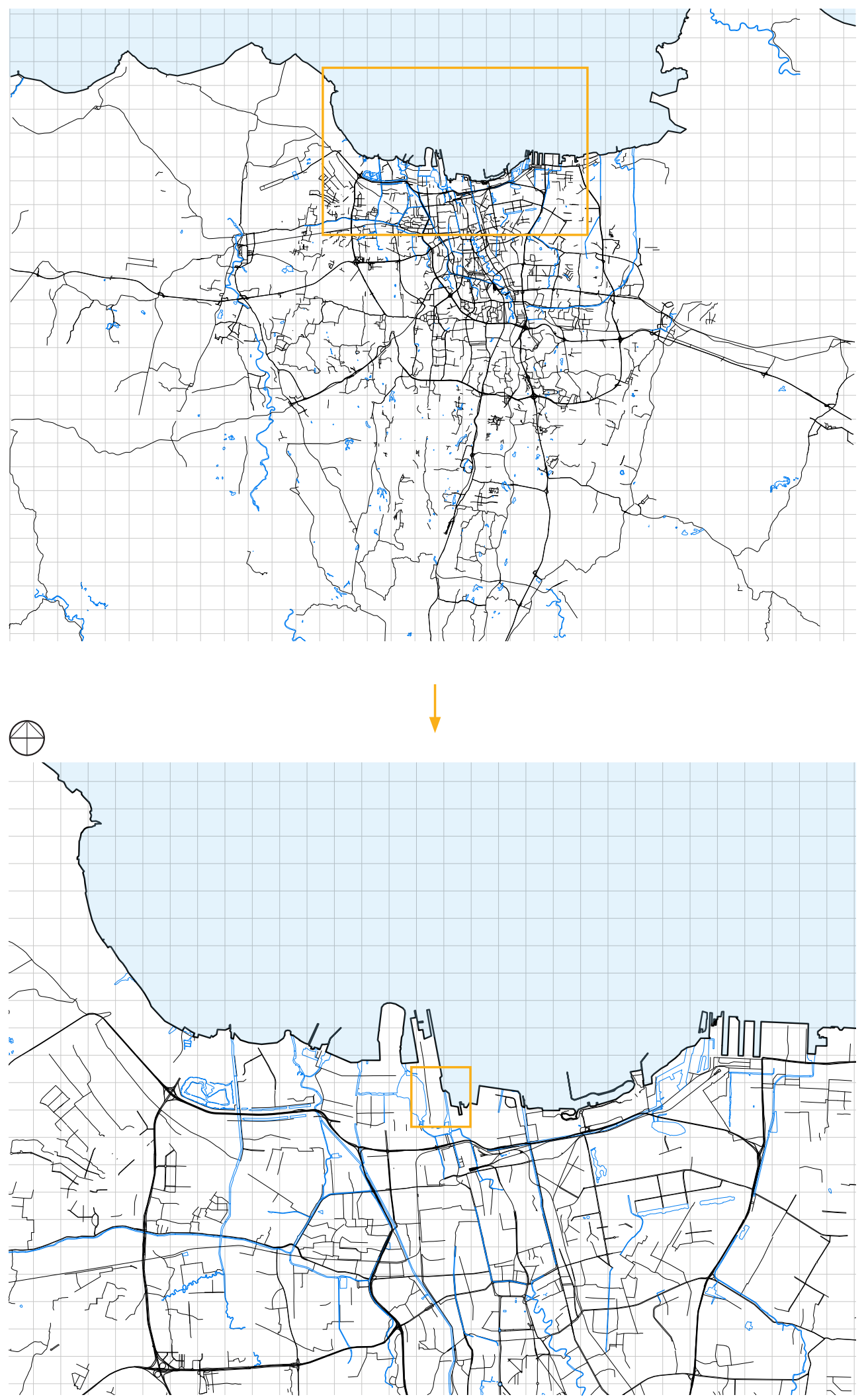

Fig 2.7. Jakarta Different Scales 


\section{Kampung Luar Batang}

\section{Selected Site}

\section{$\theta$}

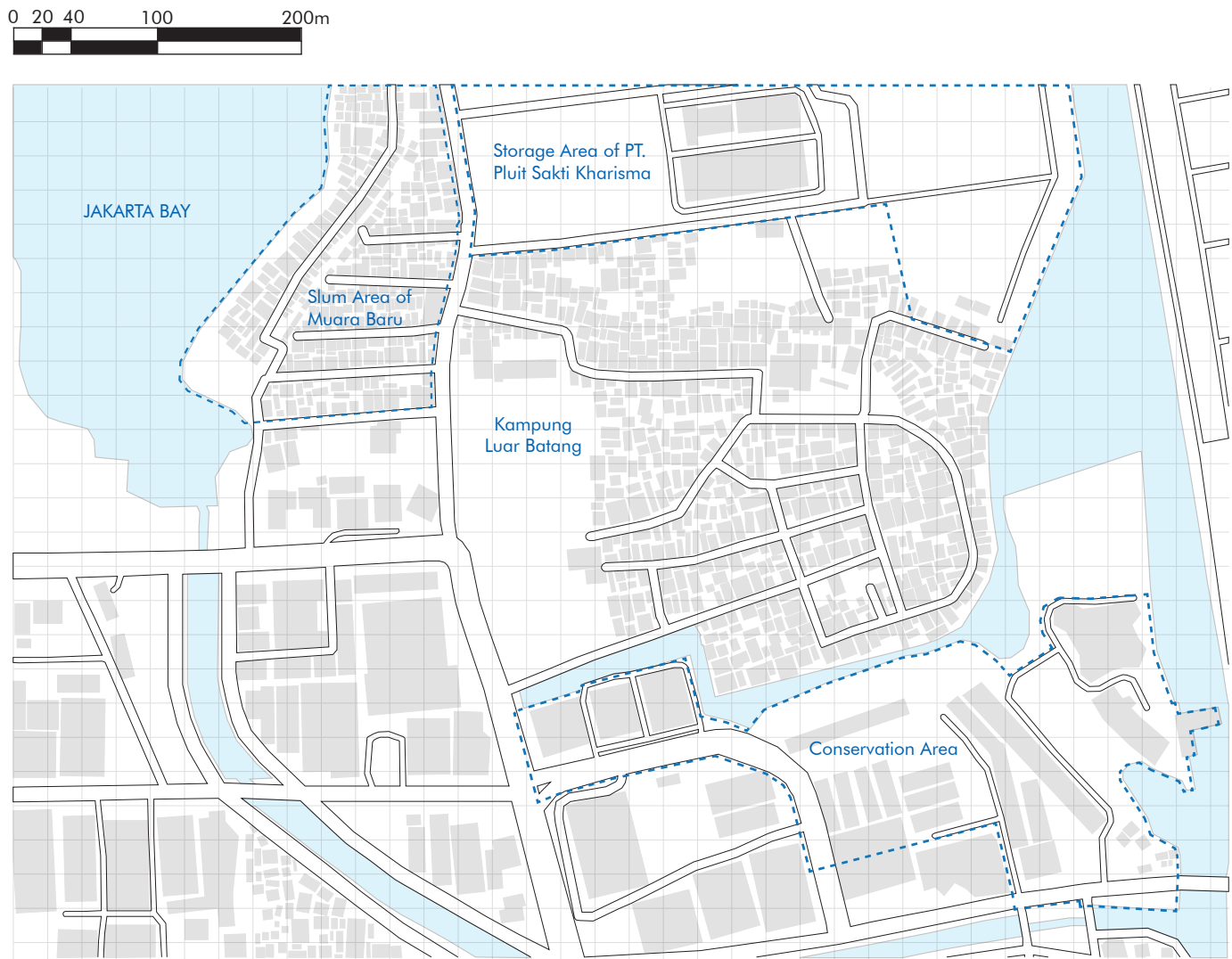

Fig 2.8. Kampung luar Batang 


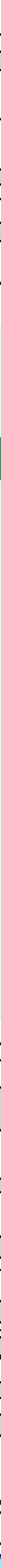




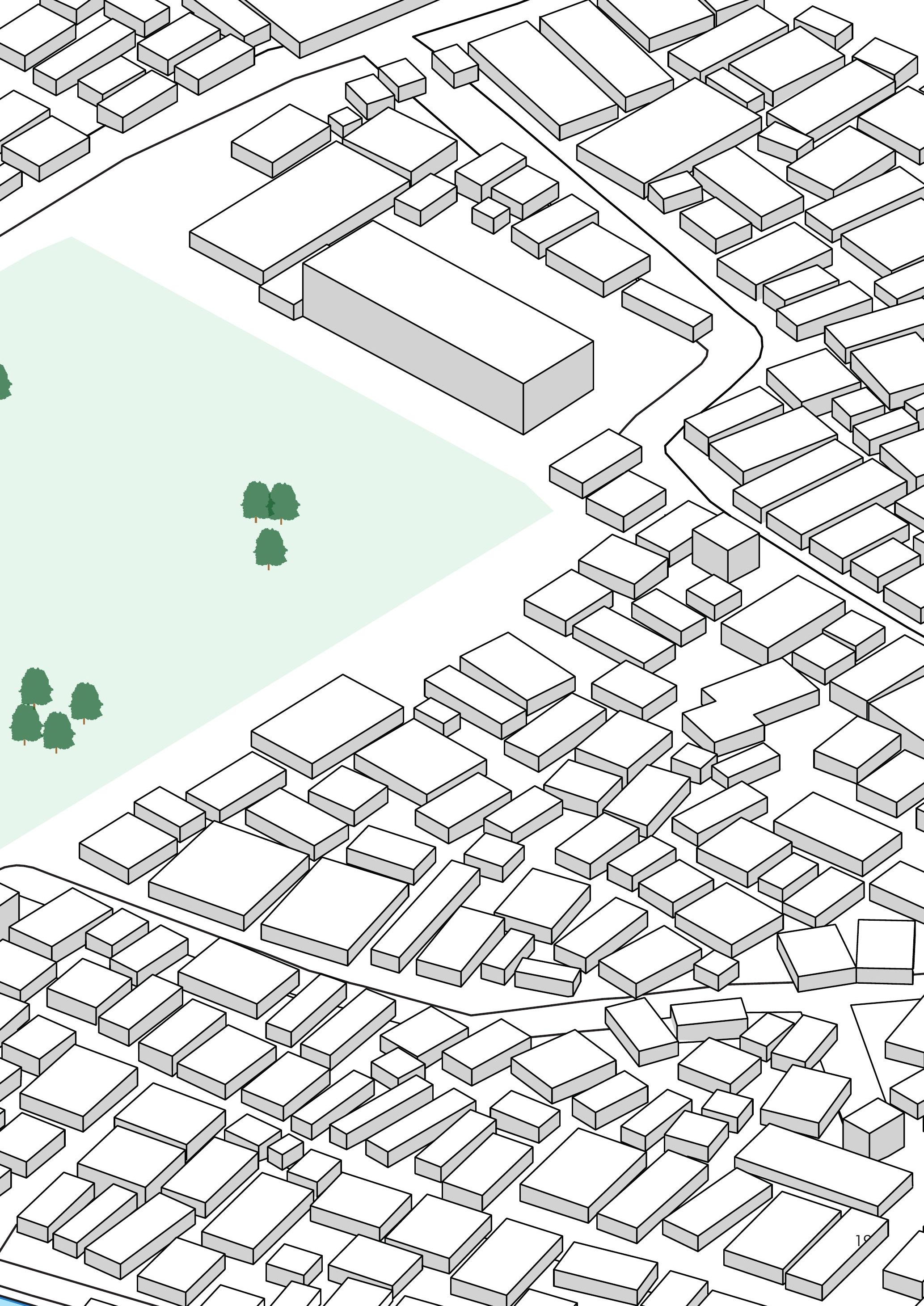




\section{Climate Analysis}

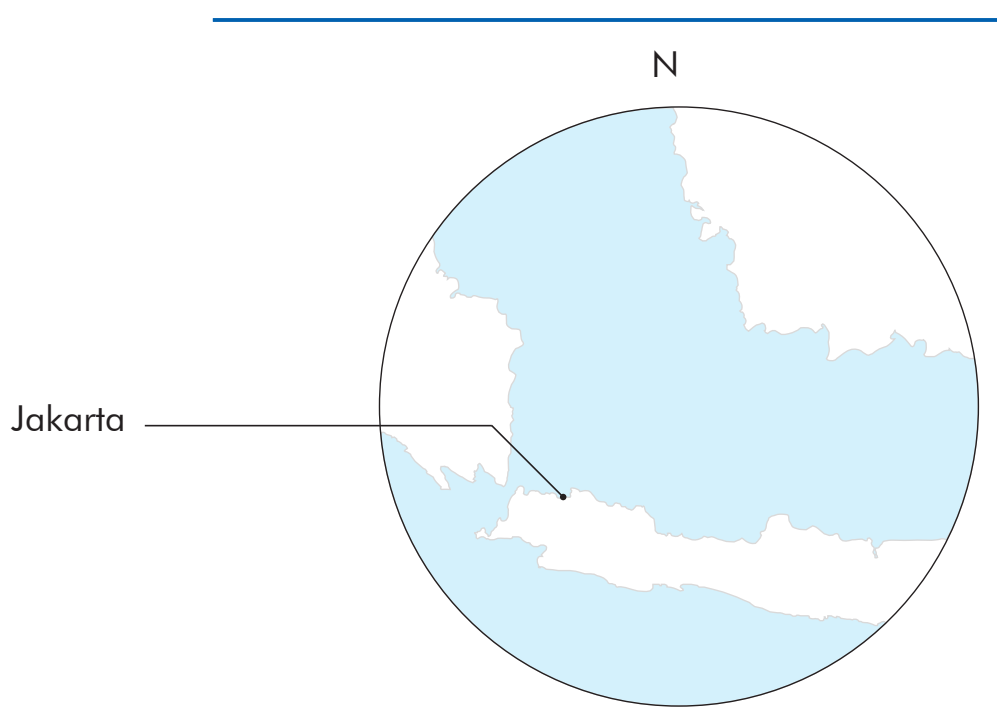

SUN PATHS
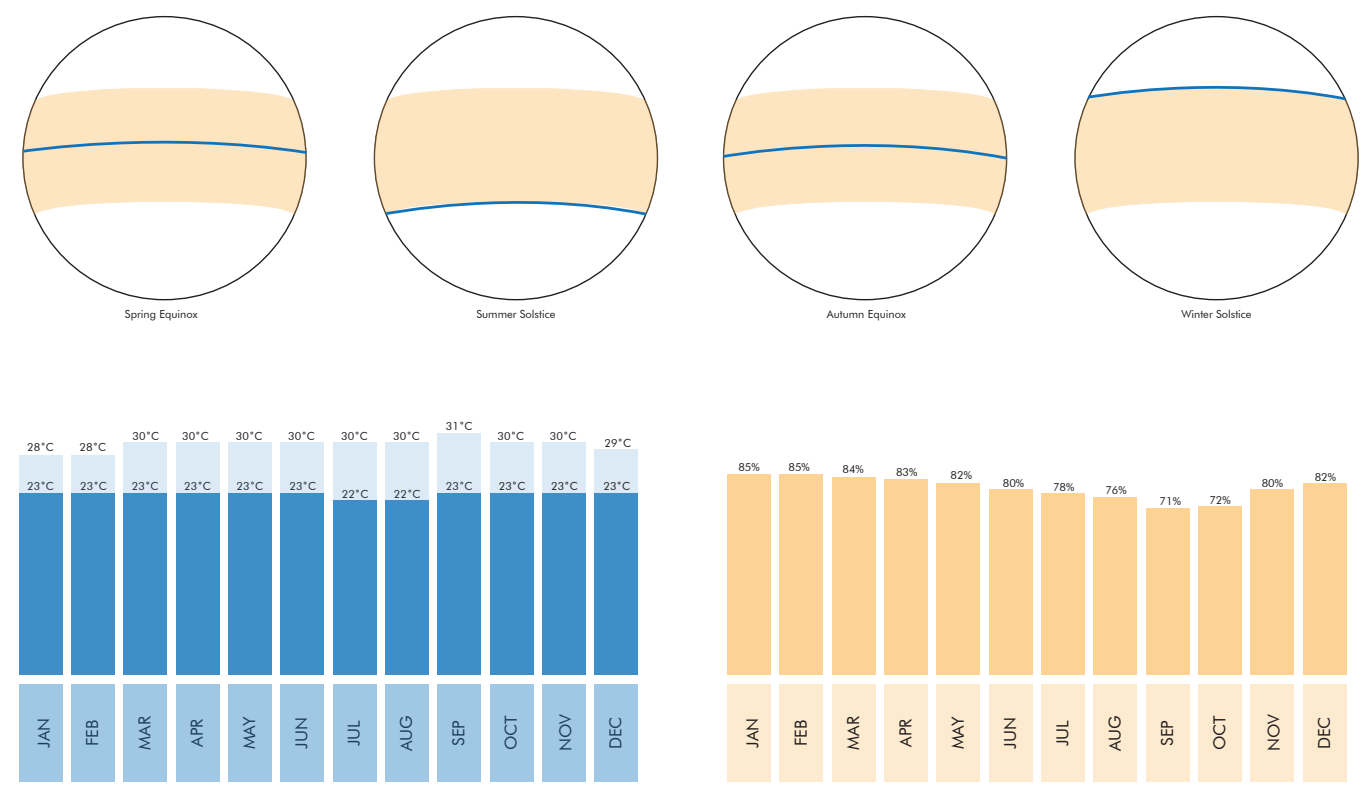

TEMPERATURE

HUMIDITY
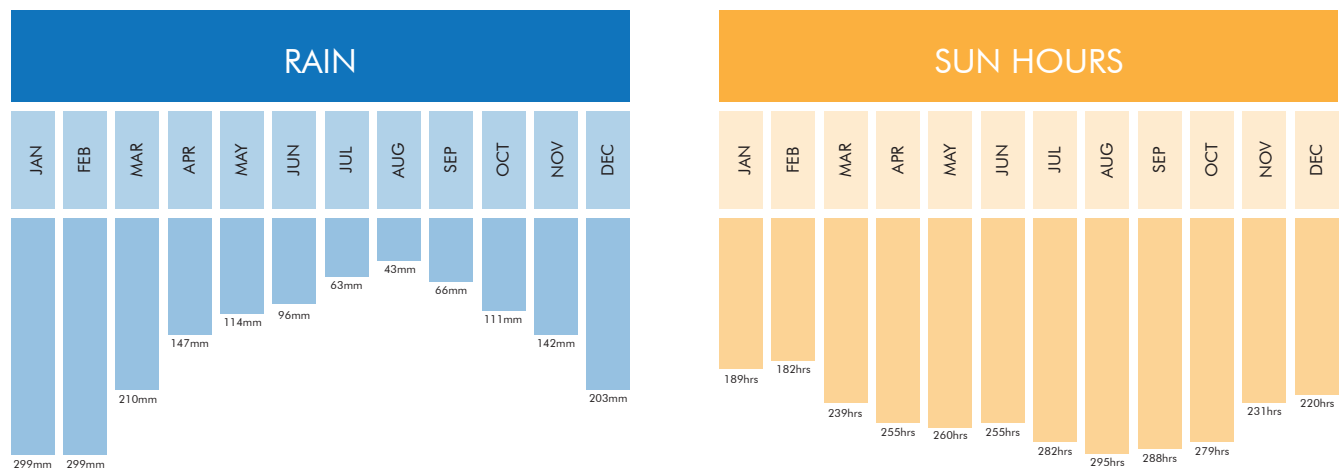

Fig 2.10. Jakarta Climate Analysis 


\section{Surrounding Site Context}

$\bigoplus$

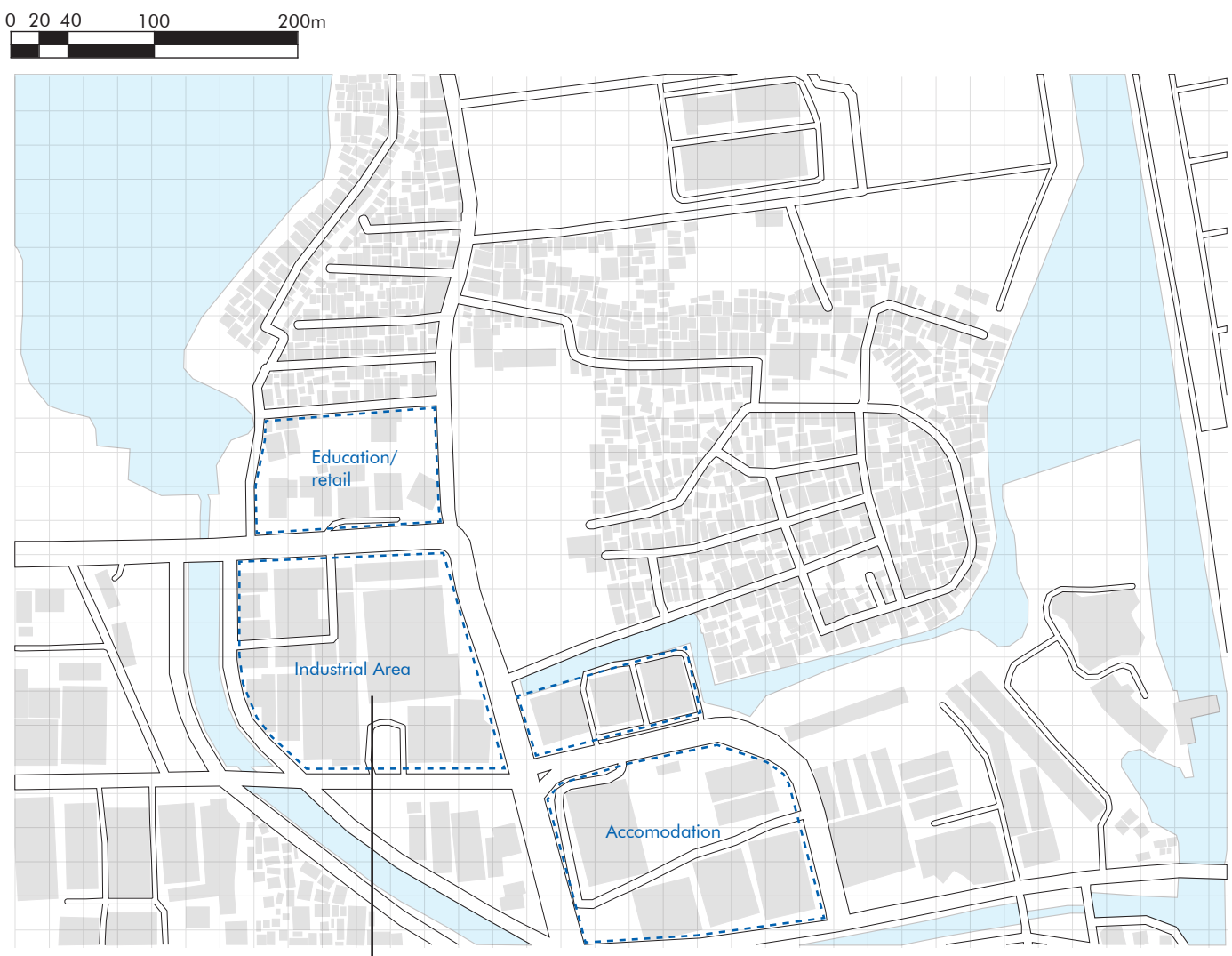

Fig 2.11. Luar Batang Surrounding Context

Fig 2.12. AKS Head office - produce plastic manufacturing machines 


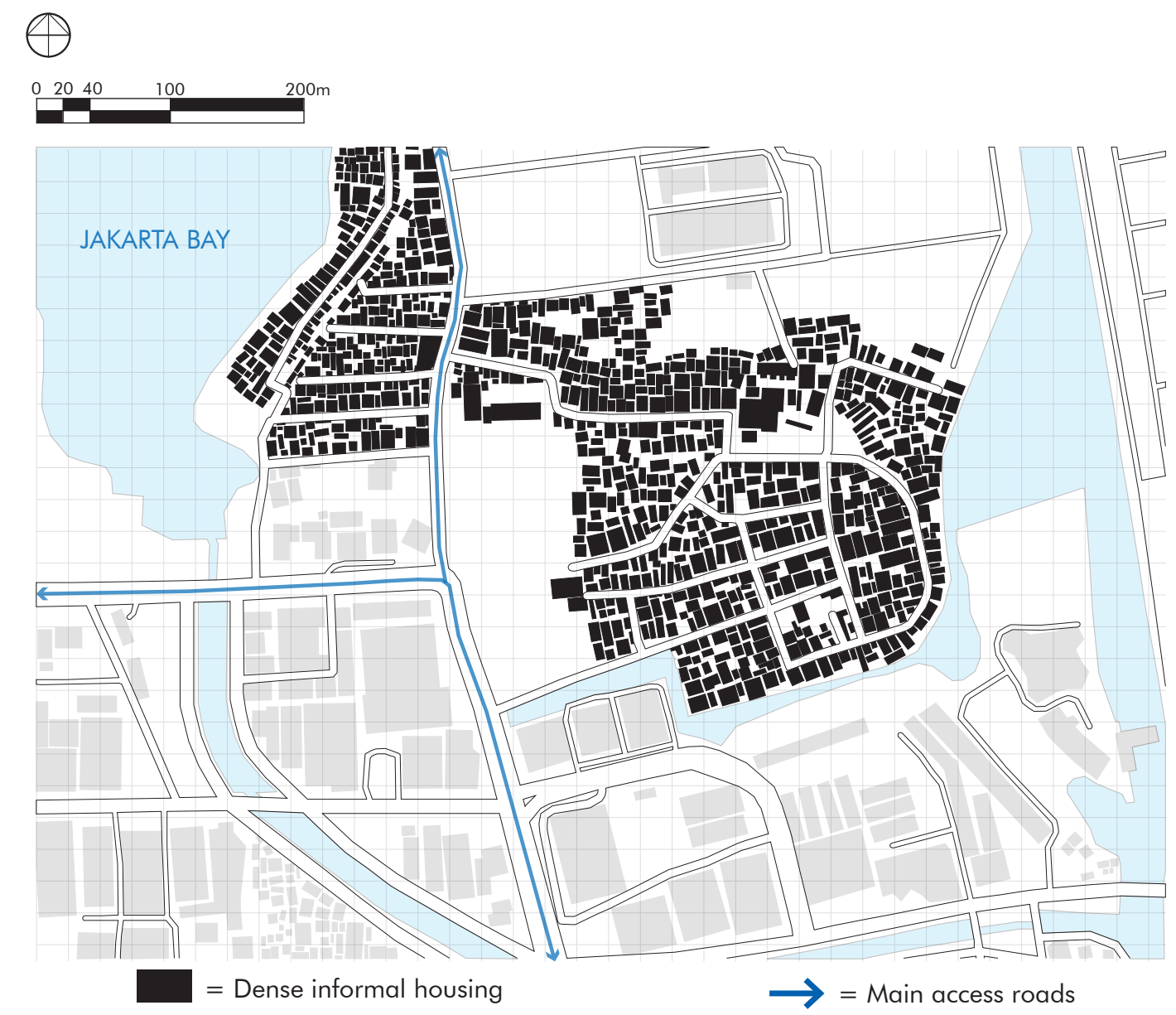

Fig 2.13. Luar Batang Informal housing 


\section{Luar Batang Informal Footprints}

Kampung Luar Batang is one of the oldest historical informal settlements in jakarta, constantly facing dilemmas with the growth and expanding of Jakarta into a giant metropolitan. Positioned on the waterfront, Luar Batang sits on some very popular land which investors want to purchase, a promising opportunity for development. This puts the current residents at a serious risk of forced government eviction (Subroto, 1993). Many people live in unhealthy environments, which are heavily polluted, and lack clean water, while the houses are much deteriorated. Most Inhabitants work in the industrial areas nearby, or in the Sunda Kelapa Harbour. The architecture in the settlement has a lot of variation, they are small scale and built up of different expressions. The spontaneous urban growth resulted in narrow winding roads, which combined with specific forms of traditional houses, and resulted in Luar Batang to be an original example of the kampung settlements in Indonesia (Subroto, 1993).

Density: Roughly 700 people/Ha (Subroto, 1993).

Traditional architectural Betawi house characteristics still exist in Kampung Luar Batang. However it mostly consists of the standard kampung houses which can be seen in any other kampung in Jakarta, and there are few houses with traditional Betawi characteristics. It is very importantant to preserve traditional charater and Kampung Luar Batang is at risk of losing that (Funo, Ferianto, \& Yamada, 2005). 


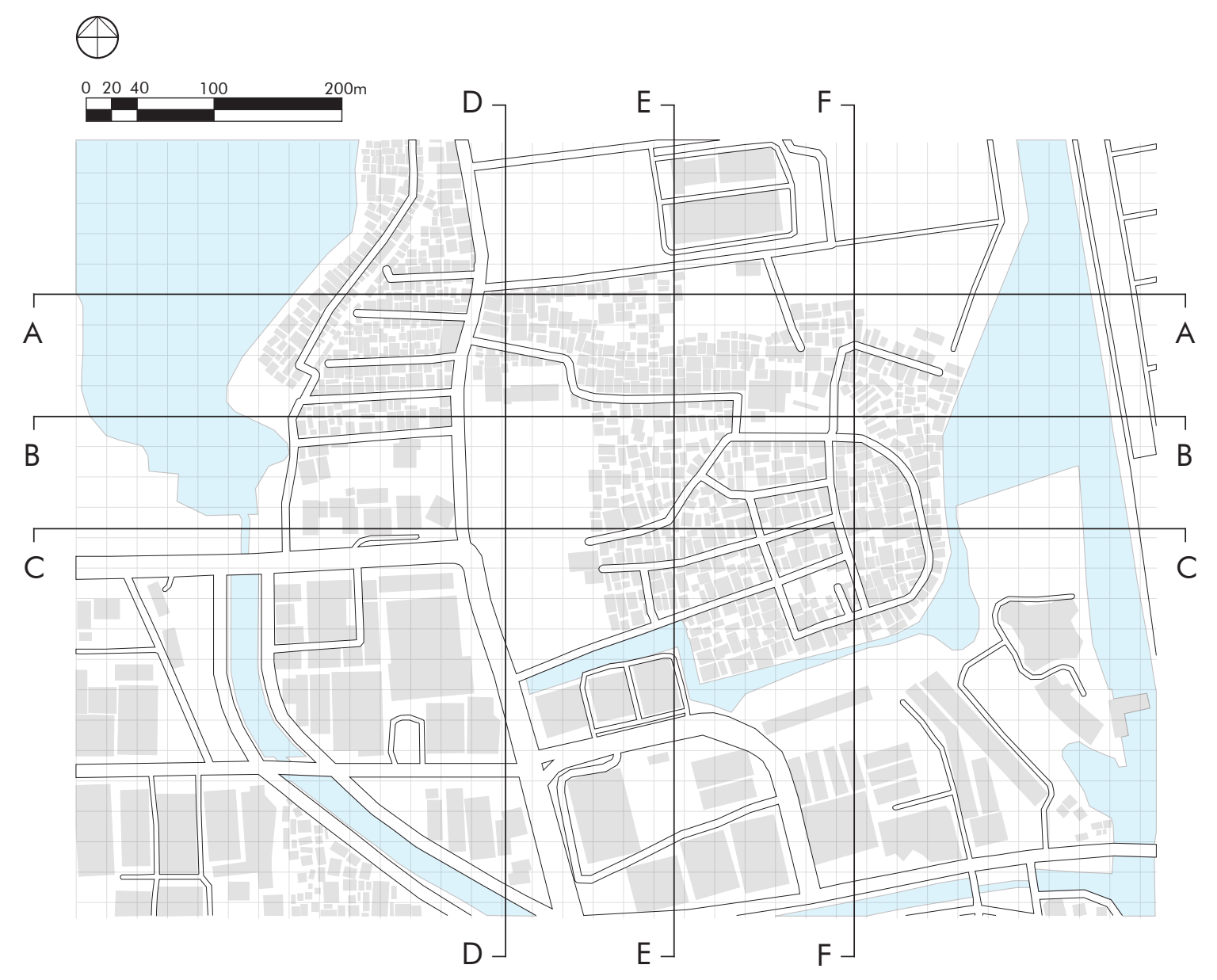

Fig 2.14. Luar Batang Site Section Cuts 


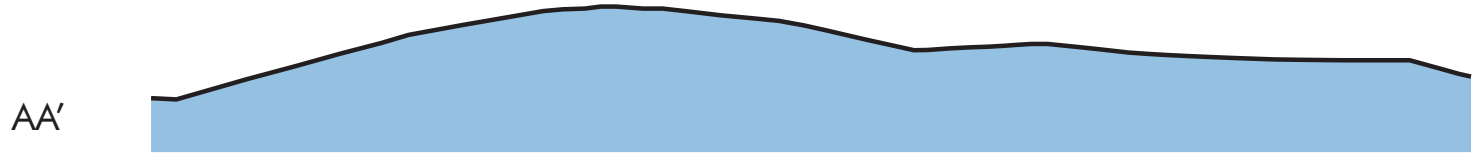

$\mathrm{BB}^{\prime}$

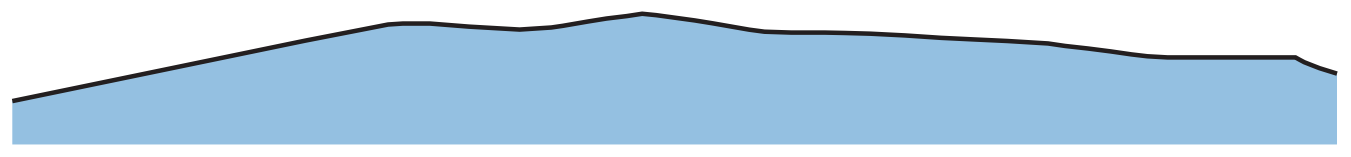

$\mathrm{CC}^{\prime}$

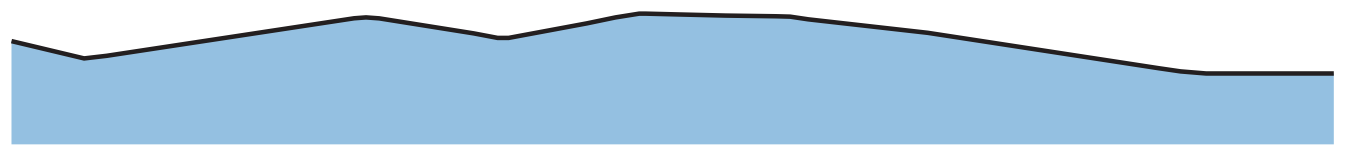

$\mathrm{DD}^{\prime}$

EE

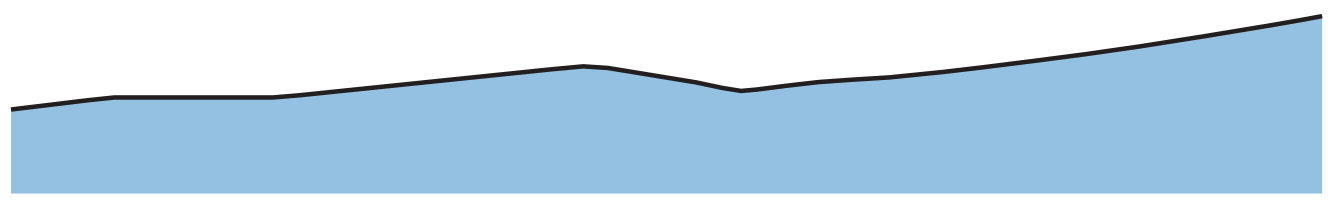

$\mathrm{FF}^{\prime}$

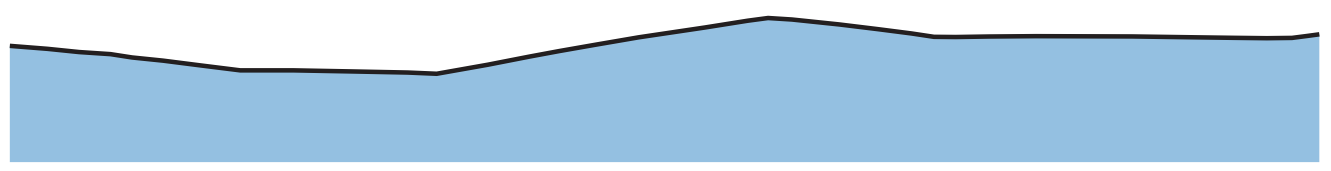

Fig 2.15. Luar Batang Site Sections

Data for this graphic was sourced from (Google Earth, 2019). 


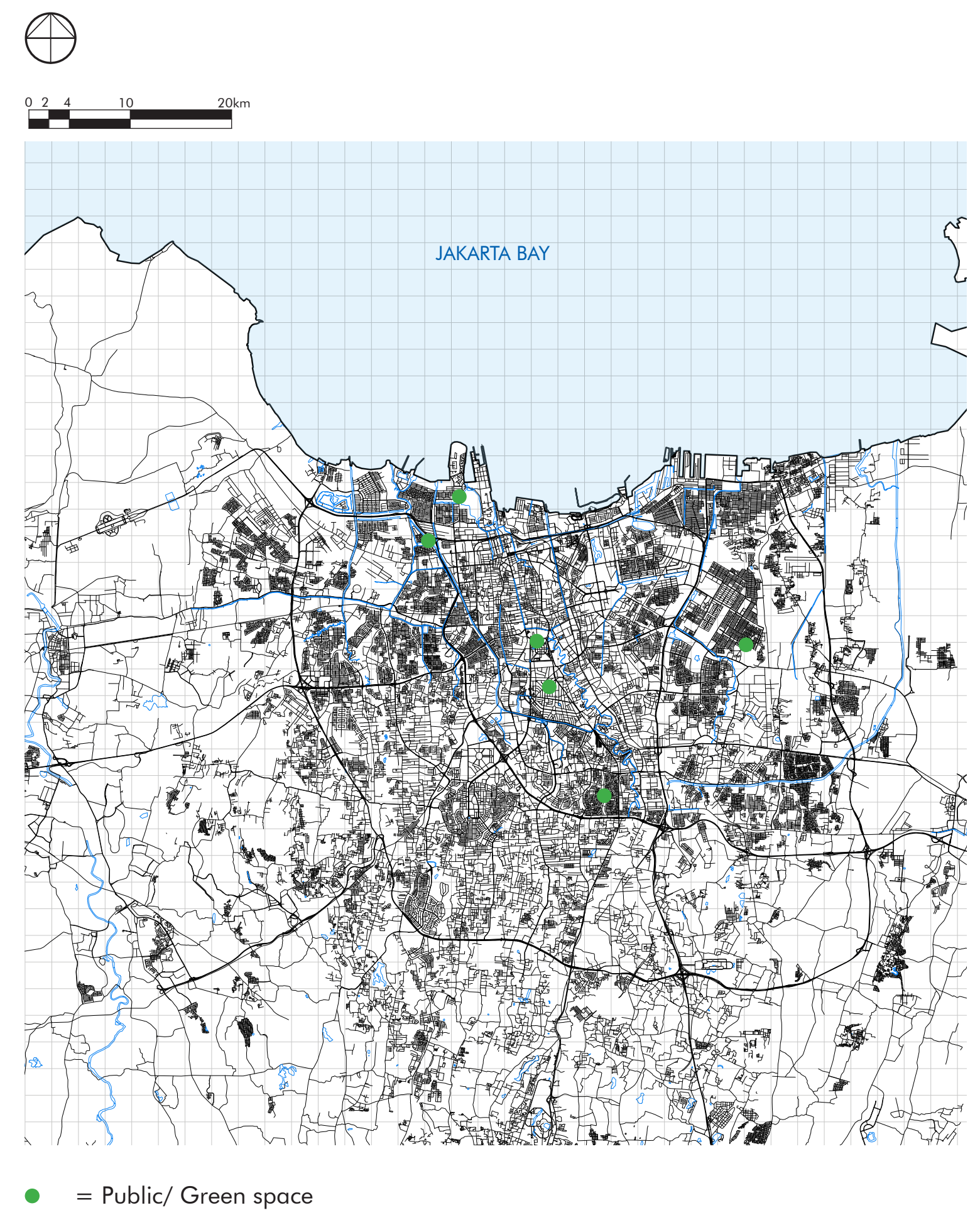

Fig 2.16. Jakarta Significant Public Area and Green Space 


\section{Public/ Green Space}

This is an analysis of the easily accessed public areas that are of a significant size. Due to the rapid population growth and the sudden rise of informal settlements there are a relatively small amount of open public and green space available throughout the city. The public parks that are available are an unsuccessful attempt to provide public space to the cities. The public parks that bear the names of national heroes clash with the remnants of old construction, such as, residences, workshops, sheds, and dead-end streets. These also meet head on with the intricate construction of informal dwellings whose unfinished upper stories which are intertwined with pylons and wires and planks that act as alternative thoroughfares to the paths at street level (Simone, 2014a).

The lack of open public space in the cities such as Jakarta, is due to the unplanned nature of the inner city informal settlements, where any available land is occupied by those desperate for accommodation (Winayanti \& Lang, 2004). 


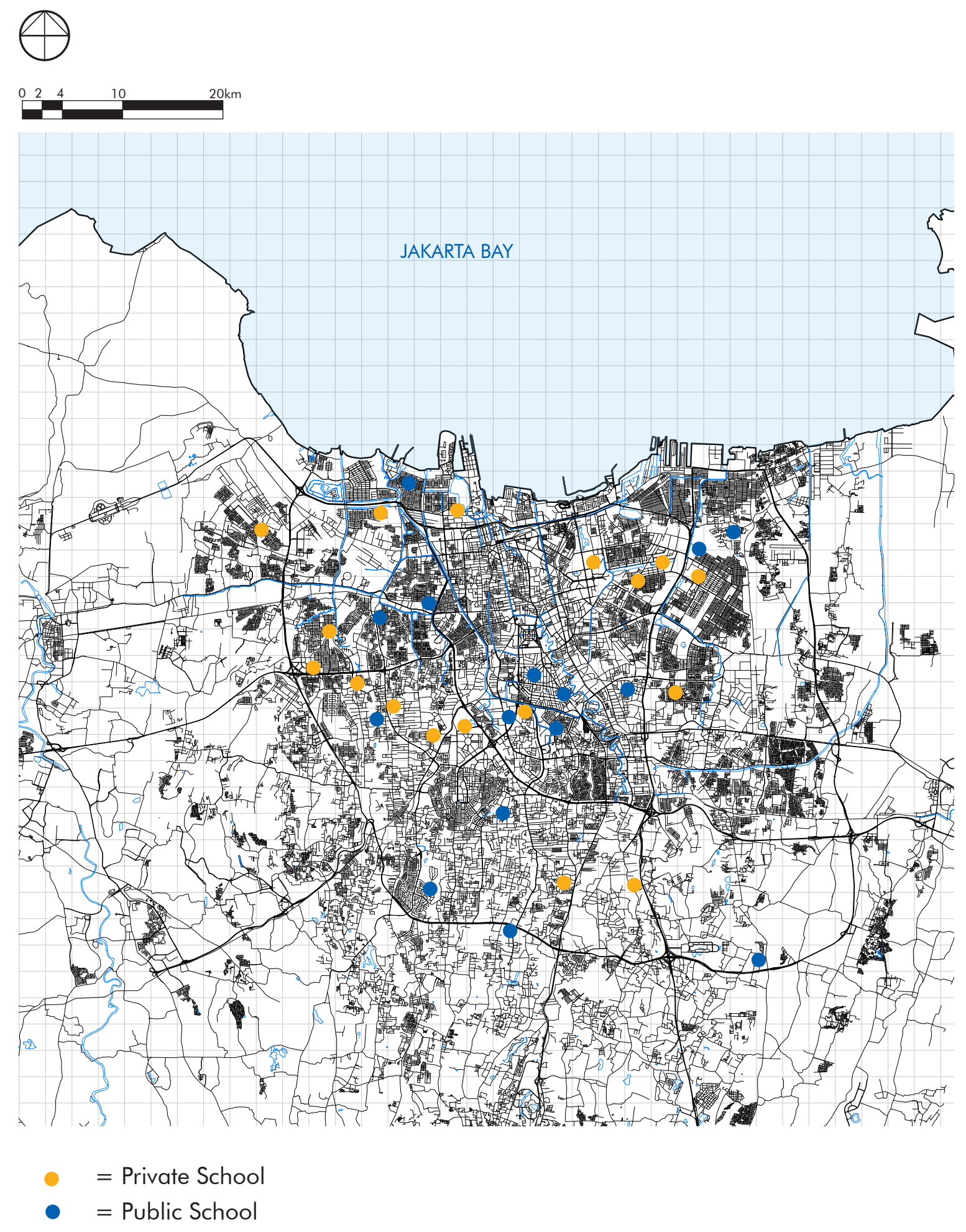

Fig 2.17. Education Facilities 


\section{Education Facilities}

This is a documentation of the secondary school education facilities, there is a relatively even spread across the city. Having easy access to education facilities increases the chance of finishing schooling. Finishing secondary school level education has a direct relationship to a successful transition into full time stable employment (Absor \& Utomo, 2017). 
Fig 2.18. Pasar lkan Protests

Fig 2.19. Rubble of Pasar Ikan 


\section{"Don't destroy our village with the power of money"}

(Gabriel, 2016, para. 6)

Kampung Luar Baang is at the forefront of the fight to remove Jakarta Governer Basuki Tjahaja Purnama from office. The Kampung residents of north Jakarta began to revolt against the governor as a result of his plans to evict roughly 1000 residents on the bases that the communities are prone to flooding. The flooding being a result of rising sea levels, and the fact the city is sinking (Gabriel, 2016).

The governor planned to demolish the sea side communities in an attempt to promote the city's maritime heritage and the area surrounding the historic Luar Batang Mosque, tied into an overall plan to boost tourism and reduce flooding. The significant issue is residents don't want to leave. Observing a nearby case, in the village of Pasar Ikan, residents were evicted from their homes after weeks of protest, and much of the community was turned to rubble (Gabriel, 2016).

The eviction of Luar Batang was put on hold only because of the delay in construction of the subsidized apartments that the evicted residents were going to be forced to move in to. In Pasar lkan, residents had such a love for their homes, and were so against the forced evictions that some would construct make shift shelters on top of the rubble of their old homes. (Gabriel, 2016). This shows just how strong the connection the current kampung residents have to their homes, and how forcing people into apartment buildings is not a valid housing alternative for them. 
Fig 2.20. Construction on the rubble of Kampung Akuarium 


\section{Kampung Akuarium}

With large populations of people facing constant deprivation, struggling daily to put food on the table, Jakarta is a city full of deceptive appearances. At least two million Jakarta residents live in conditions which are deteriorating and they can do little about it (Simone, 2014b). The government driven mega developments work their way across the regions promising all in one living conditions, designed to concentrate the accumulation of the growing middle class. Forcing the eviction of informal settlement residents who have been living in the same place for generations. It is important to understand how residents from different walks of life consider each other, how they work together or keep their distance in order to make their districts in which they live endurable (Simone, 2014b).

Localized eviction regimes in Jakarta have resulted in urban ruin. These ruined neighbourhoods become places of unexpected political projects. Kampung Akuarium was once an old established neighbourhood consisting of two and three-story houses which had shops and workshops integrated within them. Kampung Akuarium now lies in ruins, razed to the ground by the Jakarata City government. The residents who were evicted return to live on the debris of their former homes (Tilley et al., 2017). Dina, who was an established member of Akuarium community, remade her life on the plot of her old home. Maintaining the position on her plot of land where she has been for many years, keeping her daughter in the nearby school, and selling snacks and sachet based ice drinks. Ibu Dita is another recent evictee who lived in a 6 room house for a three-generation family of nine. She had also integrated a business as part of her home, which made a reasonable income. She has now re pitched her stall on top of the old rubble where her old shop was, and earns half as much (Tilley et al., 2017).

When investigating the reported actions of residents after they have been forcefully evicted, it is clear that they all have similar views, and tend to act in the same way. For most residents in the informal settlements, their homes are a result of overcoming previously difficult or unpleasant living situations and are generally their most valued possession. 


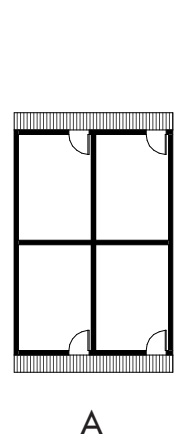

A

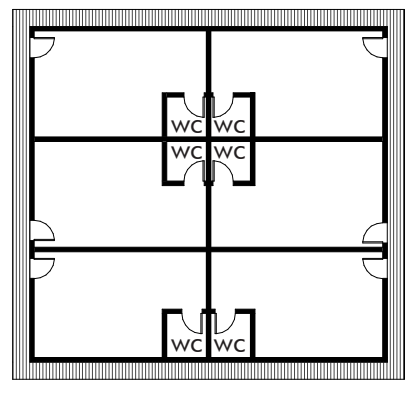

B

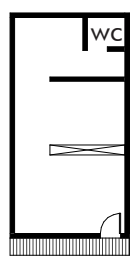

C

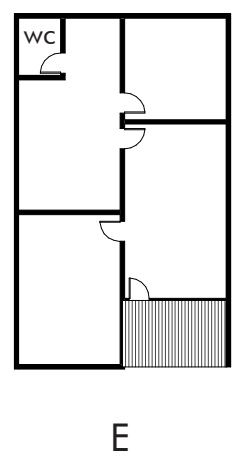

Fig 2.21. Existing Housing types 


\section{Existing Housing Types}

Houses in Luar Batang were not built according to a predetermined plan, but evolved through additions and alterations over time. The houses could be classified under five distinct types based on their space articulation (Funo et al., 2005).

A type house: Single occupancy house with a room layout which differs depending on the needs of the occupant. It is only a single room however wooden partitions are used to divide the space and allow for a guest room. The single multiuse room is also used as the dining room. There is no specific size for this house type, however they usually measure $3 \times 4$ square meters, and does not include an on-site toilet facility. Occupants tend to rely on the nearby shops for their toilet facilities, these shops are abundant within the Kampung (Funo et al., 2005).

B type house: These types of house are intended for families, and are bigger than type A, with toilet facilities in the back corner. A generic size for this type is $3 \times 6$ square meters. Occupants also divide the single space with wooden partitions (Funo et al., 2005).

C type house: This house type is a derivative of house type $B$, with an addition of a kitchen space. It consists of a large room at the front followed by a separated kitchen space and toilet facilities (Funo et al., 2005).

D type house: A popular house type in Kampung Luar Batang, usually has a guest room which also functions as a dining or living room, located at the front of the house. The WC adjoins the kitchen (Funo et al., 2005).

E type house: This house type is considered to be the standard. It consists of four rooms plus a toilet facility. The guest room and dining room are properly separated by doors (Funo et al., 2005).

All house types are often completed with a front or back terrace. In smaller houses the rear terrace can sometimes function as a kitchen space or even a toilet facility (Funo et al., 2005).

These housing types are all simplifications, but it is clear that the key feature of these dwellings in Kampung Luar Batang is the adaptive nature of the houses, changing and developing based on the family size and occupancy needs. 
Existing Site Conditions 
Existing Site Conditions 
3.0 Literature Review 


\section{Introduction}

Due to the self-perpetuating growth of cities, the earth has urbanized even faster than originally predicted. In 1950 there were only 86 cities in the world which had a population of more than one million, today there are at least 550. Rapid urban growth in the circumstances of structural adjustment, currency devaluation, and cost cuts due to economic difficulty has been an inevitable recipe for the mass production of slums. (Davis 2006). Cities are expanding faster than what the current infrastructure and housing is intended to accommodate for. People moving to the cities in search of work, as a result of economic difficulty are unable to afford any other form of accommodation and are forced into informal and unplanned settlements. As these informal settlements come into existence faster than governments can plan for, the living conditions are poor with a significant lack of infrastructure and services that basic human needs.

This literature review is intended to investigate a range of relevant theory and information, which will be able to guide the research through the design process. The intention is to be able to develop a design response to the complex social and environmental issues that are faced by the informal settlements of Jakarta. Examples of architectural design theory will be investigated, and the conclusions made will drive the design intending to develop strategies that seek to improve the lives of the residents of informal settlements in Jakarta.

Cathy Baldwin and Robin King's book, "Social Sustainability, Climate Resilience and Community-Based Urban Development: What about the people?" Unites three major strands of research and policy of cities; Urban Development, Social Sustainability, and Community Resilience. They explore the influence of urban planning, design and the development of urban built environments on the residents' pro-community behaviours. Urban social networks of residents or communities need to develop their capacity for pro-community action more than ever due to the urgent issue of climate change. Baldwin and King believe that the urban sector can contribute to the development of capacity of procommunity behaviours by creating built environments that encourage and support them. The chapter linking social sustainability and urban development considers how ideas of social sustainability have been translated into city frameworks and incorporated into urban design, and the resulting influence on pro-community behaviours. The chapter reviewing the concept of community resilience defines the subject as the existence, development, and engagement of community resources by community members to thrive in an environment characterised by change and unpredictability (Baldwin and King, 2018).

Throughout the design process, I will be applying the ideas of Baldwin and King directing them towards improving the lives of the urban poor. By incorporating the theory of uniting three major strands of research and policy of cities, the essential starting points that need to be addressed in order to make improvements to the current informal settlements can be realised. A comprehensive approach to coming up with a design intervention, would be to analyse the informal settlements in their current situation through Baldwin and King's theory. Investigating how the current informal settlements achieve urban development, social sustainability, and community resilience. Throughout the design process I will also be considering construction techniques and material choice. Oscar Lopez in his book "Manuel de Construccion con Bambu" has an extensive material study of bamboo construction (Lopez, 1981). 


\section{Urban Development}

Urban development is a very important area of overall city development when referring to informal settlements. Goal or dimension-orientated policy frameworks offer a vision for cities. Development or regeneration at neighbourhood level can impact community social resources in a positive way (Baldwin \& King, 2018). One direction to take is a people orientated approach which is consistent in the attention to detail when providing a designed built environment that is supportive of community bonds and interaction. The aspects of the neighbourhood which are associated with urban development are; Architecture and site design, density and scale, streets, public space, and mixed land uses. Along with the people orientated development approach, there is also organic growth and evolution. Informal settlements incorporate some of these design aspects but in contrasting ways to the formal planned approaches (Baldwin \& King, 2018). Slums often begin with bad geology, as residents are just looking for any available land to build on. The natural hazards are magnified by urban poverty, and entirely new artificial hazards are created by poverty's interaction with toxic industries, intemperate traffic, and collapsing infrastructure (Davis, 2006).

Ghulam Akhmat and Muhummad Khan discuss in their paper, "Key interventions to solve the problems of informal abodes of the third world, due to poor infrastructure", possible intervention directions to take in order to head towards positive urban development of informal settlements. These interventions include; Progressive improvement of infrastructure, new type of settlement master plans, and strong commitment and involvement of the communities (Akhmat \& Khan, 2011).

A people orientated approach has a significantly positive impact in terms of improving the urban development of cities as the resident's needs are taken into account when designing. Without being able to able to physically interview the people of the informal settlements in Jakarta, it becomes important to look at other studies done in the area. This way an accurate understanding of how to achieve positive urban development that meets the needs of the people can be attained. Lisa Tilley studied the ruination in Jakarta and how to undo it. She observed informal settlement residents, and their reactions to the government's urban development plans. This involved forced resident evictions as the informal settlements were razed to the ground. She noted that rubble acquired a political life of its own as unhappy residents reconstructed make shift homes on the rubble of their old ones, in preference to living in a subsidized apartment complex (Tilley et al., 2017). A people orientated approach to urban development means it will be clearer on how to meet the social and physical needs of the community. 
Socially aware planning involves objectives being incorporated into building or regeneration schemes with intentional positive impact. Ideas of social sustainability need to be closely linked with the urban design in order to have a positive impact on pro-community behaviours. In the planning sector, the concept of social sustainability is often considered 'softer' but is harder to achieve than other concepts associated with urban development (Baldwin \& King, 2018). Developing social sustainability is an inherently political process, non-government organisations now have the power to direct communities affected by poverty towards self-help, social capital and the strengthening of civil society (Davis, 2006). The key to successfully applying the concept of social sustainability to urban development is community participation in the planning and design process (Baldwin \& King, 2018).

Ideal collaboration takes the ideas from social scientists, planes, designers, and other physical environmental specialists, along with standard citizens of the area (Baldwin \& King, 2018). Baldwin and King believe incorporating the concept of social sustainability into the design process is best accomplished through participatory or co-design approaches to encourage community participation in the planning and design process. Although achieving a level of social sustainability would be beneficial to informal settlements, a co-design approach would not be suitable for this thesis. As a compromise to inform the design process, it will be important to look at already registered views of existing residents, and use them to inform the design.

Research has found that communities lacking in social capital retreat into the private sphere, as the responsibility falls on the individual actions of community members rather than working together as a whole. Informal settlements that lack social capital fail to organize and address basic neighbourhood needs, such as street cleaning and public space maintenance (Lastra \& Pojani, 2018). Improving social capital plays a direct part in achieving social sustainability. One component of social capital is social trust; which is an individual's belief that others will not knowingly or willingly do him/her harm, instead preferably act in his/her interests. Based on the 'eyes on the street' theory, a level of social control is provided casually, voluntarily and even unconsciously by locals within strong communities, which constitutes a better form of surveillance than official policing (Lastra \& Pojani, 2018). For an architectural design to increase the social capital of a neighbourhood, it is important to provide a space that allows for residents to be a community presence without actively having to make a conscious effort. Increasing social capital makes a direct contribution to achieving social sustainability.

Community involvement in the construction of the design would be a positive contribution to improving social capital of the residents, therefore it is important for the construction materials and methods to be easily taught and understood by those with no extensive training. In the Lopez's book "Manuel de Construccion con Bambu", there is extensive detail on different bamboo construction techniques with clear diagrams and explanation of methods (Lopez, 1981). Simple bamboo construction techniques could be successfully utilised in the design process to encourage community engagement in the construction and maintenance of the building. 


\section{Community Resilience}

Community resilience is an idea that has developed from two different academic fields. First is socio ecological, where a system is able to absorb shocks, sustain, renew, and transform itself afterwards. The second is personal psychology and mental health, referring to an individual's ability to recover from trauma. Everyday social sustainability sits on a continuum with resilience, centred on the shared and similar social resources that communities develop, and then harness to respond to specific events (Baldwin \& King, 2018). In AbdouMaliq Simone's book, "Jakarta, Drawing the City Near", methods of endurance are discussed. Within informal settlements, a great deal of individual resilience and street smarts are demonstrated under otherwise debilitating conditions. In some cases of cities which have a significant informal settlement population, such as Caracas and Karachi, individual residents notions of resilience seem to be depended on the individuals capacity to remain almost invisible. In these cities if a person tries to be or have something of any significance, it is bound to attract all kinds of unwanted criminal attention (Simone, 2014a).

Community resilience in the face of environmental threats can be assessed by five different capitals; natural, physical, social, economic, and governance. The most significant environmental threat in Jakarta is flooding, so each of these capitals have a number of variables in terms of developing community resilience towards floods. Improving the natural capital refers to the variable of ecosystem services, such as quality of drinking water, quality of air, and existence of drainage. Physical capital variables include access to electricity, water, sanitation, and accessibility of roads during floods. Social capital variables refer to the public participation in decision making, education and awareness, heath, and community preparedness. Economic capital refers to the variables of employment, household assets, finance, and subsidy. Improving the governance capital refers to mainstreaming of flood resilience through local strategies, good governance, effectiveness of city's crisis management, and collaboration during floods with organisations (Kamh, Khalifa, \& El-Bahrawy, 2015). Identifying the different capitals of community resilience allows for the areas of vulnerability to be realised.

\section{Conclusion}

This literature investigates a range of relevant theory and information which will be able to guide the research through the design process. Focusing on the ideas of Baldwin and King, incorporating the theory of uniting the three major strands of research and policy of major cities in an attempt to improve the lives of the urban poor. Baldwin and King's theory can be used to evaluate design ideas, resulting in the development of a design criteria based on the literature related to the three major research strands of urban development, social sustainability, and community resilience. By approaching the informal settlement improvement through this process, designers will be able to completely understand the needs of the community, what areas to prioritize. This project will use this resulting design criteria in sketch and digital design experiments with the aim at producing a comprehensive architectural intervention that improves the lives if the informal settlement residents. 
4.0 Precedents 


\section{Mumbai Incremental Housing}

Mumbai Incremental Housing Strategy developed by architects Filipe Balestra and Sara Gornasson. This strategy involved fostering communal values through the ongoing community engagement when creating housing prototypes. In an attempt to find solutions for housing and infrastructure issues experienced by the urban poor. Three strategies were created which allow for versatility by providing the opportunity for vertical expansions and openings at various levels. It was agreed that the most successful of the three prototype designs was the option which created an open ground floor space. For use such as, a garage or a shop front, allowing for economic mobility and providing space for families to earn an income (Fairs, 2009). This strategy allows for the house owners to still have control of their home but are given the structural start needed to improve the living conditions. It would be beneficial to incorporate some of these ideas into my design, as it is important to allow for flexibility due to the unique needs of each slum resident. 
Fig 4.2. Rafael-Unido Neighbourhood plan 


\section{Rafael-Unido Neighbourhood plan}

The San Rafael-Unido neighbourhood plan is driven by the Caracas based firm Arqui 5. The design is for a new "Urban Façade" that offers stabilisation and commercial development. The plan involved the design of preschool, apartments, and a community centre (Wethmann \& Beardsley, 2008). This is an example of design which attempts to improve the social and environmental conditions through the infrastructure, as well as housing. Attmepting to improve the informal settlements physically without disrupting them socially. Arqui 5 improved the infrastructure through paving and adding hand rails. These are subtle but effective ways of improving the living conditions in the informal settlements, however the idea of commercial development has risk of disrupting the existing social fabric, in the context of the kampungs in Jakarta. 
Fig 4.3. Empower Shack by Urban-Think Tank 


\section{Low Cost Housing for South Afrcan Slum}

Urban-Think Tank came up with a design strategy to bring safe low-cost housing to the residents of South Africa's informal settlements. Focusing on Cape Town's second largest township, Khayelitisha, the first four prototypes for alternative slum housing were designed and built in 2012. The goal of Urban-Think Tank was to demonstrate an adaptable method of designing safe and accessible housing units with urban plans. The final design, a result of the design process, were low cost buildings that occupy a smaller portion of the usual slum dwelling footprint. Leaving fire break spaces that give emergency services easy access. The dwellings are designed so a second or third storey can be added to accommodate different family sizes (Block, 2017). By having a more vertical focus, these house designs are able to use the land space more efficiently. This means the residents are able to stay on the same sites that their previous slum dwelling was on, allowing for them to maintain their important social connections. 
Fig 4.4. Slum Dwelling Design 
Alok Shetty addresses the housing conditions of the urban poor. He designed an improved slum dwelling for Bangalore's LRDE settlement, which houses approximately 2000 residents. The low cost housing model is a response to the poor living conditions in the area, which are affected by flooding, and cramped, unventilated spaces. Shetty's housing design is built in response to the harsh environmental conditions brought by the monsoon flooding, with raised framework constructed above the ground and a sloping roof to allow residents to collect the runoff water. The design accommodates for the lack of space by splitting up the 100 square foot dwelling into two units, divided by a corridor which provides an open space for cooking. The design also features a raised roof to allow natural ventilation (Walker, 2016). This housing design is an example of how simple features can account for harsh environmental conditions. The site of Kampung Luar Batang has similar environmental threats, so it would be beneficial to take a similar approach. 
Fig 4.5. Klong Toey Community Lantern 


\section{Klong Toey Community Lantern}

TYIN Tegnestue, a Norwegian firm collaborated with local students to give back to the residents of the Klong Toey community in Bangkok. TYIN Tegnestue worked with the community to design and build a space that would help the areas residents. The result was a small multi-use social centre which included facilities such as a stage, a community centre, a reading room, a sports court, a climbing area, and a meeting place. Klong Toey is the largest and oldest area of slum dwellings in Bangkok. The goal of the design process was to have a positive impact on the community by improving social sustainability, and encourage community interaction. The design uses a simple, durable, and repetitive logic to ensure it will be a long term feature in the community for years to come. It also encourages adaptions as the community sees fit over time (Meinhold, 2012). This is an example of how to relieve social stress in a slum community through architecture directed at the community, rather than individual housing. Improving social sustainability would be an appropriate goal in my design, however this would be difficult to achieve with just a housing design. 
Waterhubs is a modular water sanitation infrastructure solution for urban slums. Due to the way the world is dynamic and quickly changing, there is an emphasis on the need to evolve the way we plan and develop cities. The design behind Waterhubs integrates modular blocks of sanitation, water treatment, water supply, organic waste processing, energy, and nutrient recovery. The idea is to close metabolic loops of material flow, saving resources and reducing waste. The solution is co-created with the community and provides functions like; community services (toilets, showers etc.) biological sewerage treatment and water recycling, waste processing, electricity access, and agricultural production (Saraf, 2015). This design identifies the different services that would successfully improve the infrastructure for urban slums. Improving the infrastructure of the slum areas plays a significant part in improving the living conditions of residents, as most lack basic resources. 


\title{
Useful Systems
}

\author{
Metabolic Network Reactor
}

Metabolic Network Reactor: This is integrated fixed film activated sludge water treatment technology. The underlying principal behind the technology is a natural occurrence, where microbial biofilm develops on the roots of aquatic plants. Advantages of using this system for water treatment include; odour free, stable and reliable, small physical footprint, economically viable, and is technically effective. This system can be used to treat municipal wastewater, industrial wastewater, and urban waterbodies (Biopolus, 2018).

Fig 4.7. Metabolic Network Reactor Diagram

Slum Drain Design

Problems caused by the rapid growth of cities and their social and environmental impacts, has led to solutions which require an integrated and systematic approach. Because the informal settlements are constructed in an organic or unplanned way, improvements must be made from thinking from the ground up. In this kind of approach it is important for community participation to combine with technical and financial support from local governments to help provide clean drinking water, sanitation and drainage to the urban poor. Oarno and Cairncross have formulated several low cost drainage designs for the use in informal settlements. These drain designs have already been successfully produced in the Brazilian City of San Salvador. The drainage problems of small communities are related to the poor drainage across the whole city, so these simple drainage designs help to mitigate the issue (Das, 2012). 


\section{Cleantech Solutions to Waste Management}

Traceability is a key operational component when it comes to waste management of informal settlements. This is important because a lot of the waste is irregularly disposed of, and no one accounts for it, with much of it ending up in rivers and other fresh water sources.

Looking into ideal waste management solutions for informal settlements, introducing the following elements are considered important:

1. Campaigning for waste segregation: at the domestic, commercial and institutional level, it is important to separate the waste into four groups (organic, glass based, paper based, and plastic waste). This makes it easier for waste collectors to transfer waste to recycling points, also meaning less waste goes to landfills.

2. Digital geo-spatial mapping: digitized zoning of waste aggregation centres, transit points and landfills for ease of resource optimization and redistributed by municipal authorities.

3. Forging municipal synergies with informal waste collectors and private operators: Aligning informal waste pickers operations with that of the municipal authorities which yield higher logistical strength.

4. Mapping of transit routes for waste: and redistribution to places of need such as recycling plants.

(Ochieng, 2015).

In Jakarta there are a lot of waste management services scattered throughout the city, however a dangerously large amount of waste is dumped into the water bodies or in makeshift landfills amongst the settlements. For the improvement of live in the informal settlements it is vital that there is an effective waste management system. the main issue at the moment is the streets are too narrow for vehicles to drive in between the houses making waste collection challenging. 


\section{Initial Sketches}

The method of design experimentation through sketches, diagrams, and digital modelling has been applied throughout the research. This method was chosen because in the initial design phase, the visualisations produced help to identify design errors before refining the experiments through prototyping. By producing a range of digital prototypes it is then possible to test if designs respond to their intended performance through a qualitative analysis. A strength of using this method is there are no physical limitations on the forms that are produced, there is freedom to explore form in any direction. The weakness of using digital modelling is the scale can be easily lost, therefore it is important to include site context to keep an idea of scale.
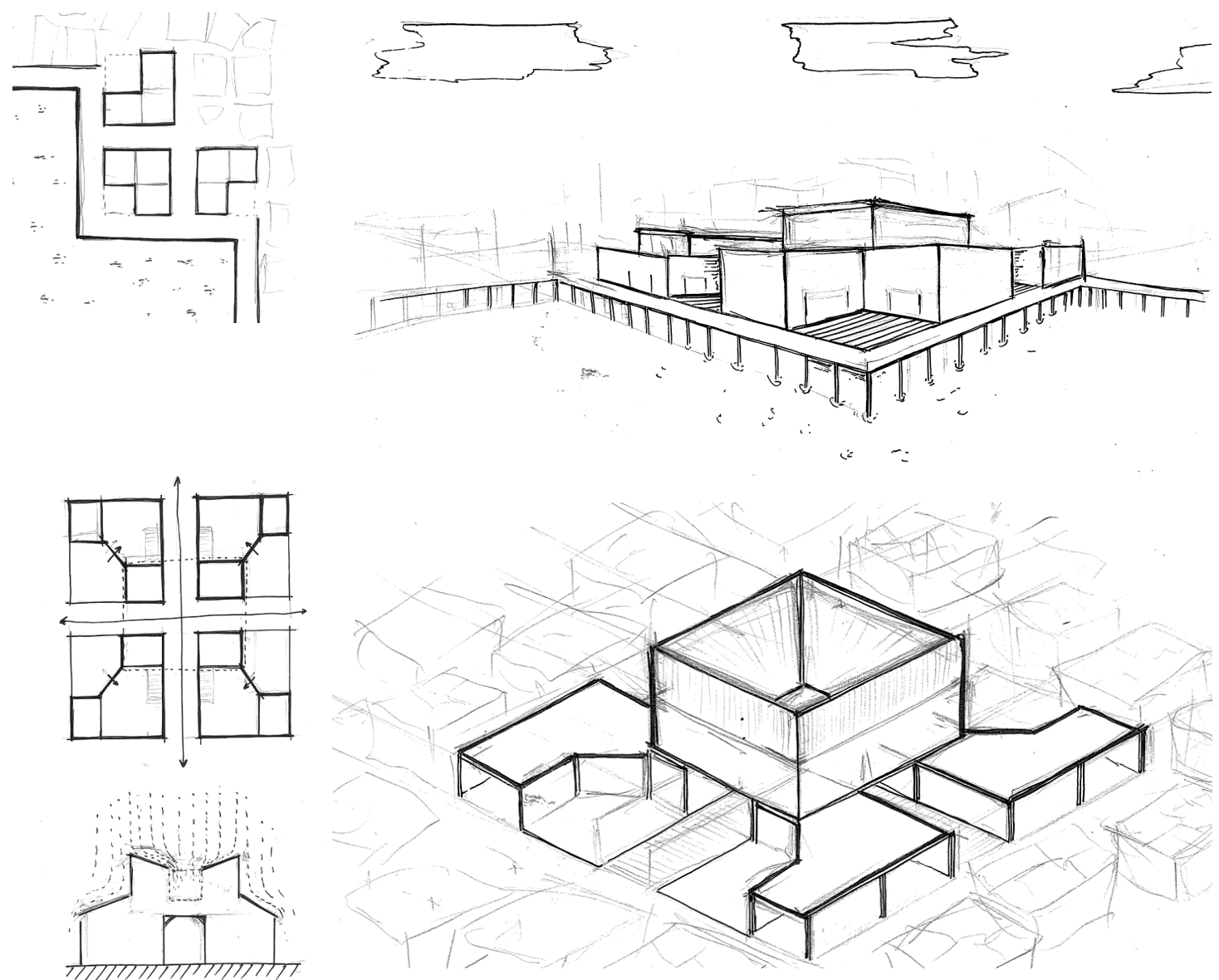

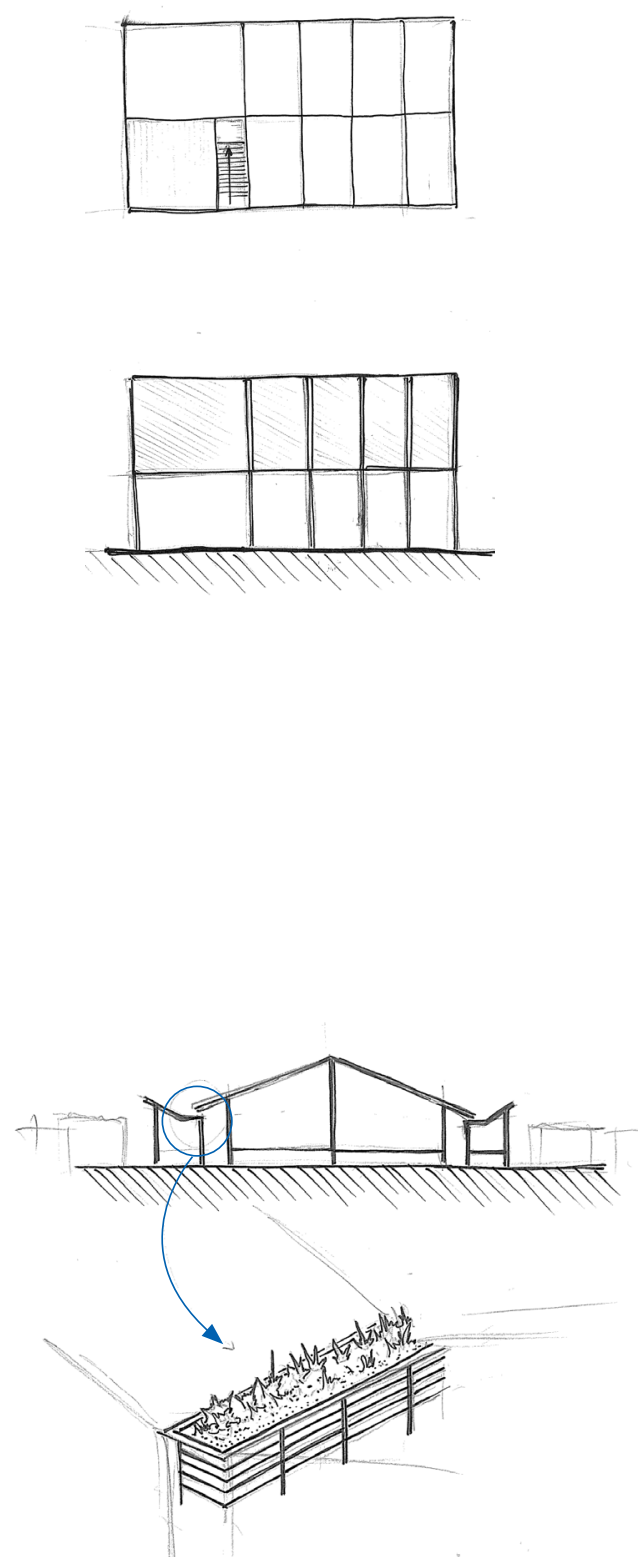
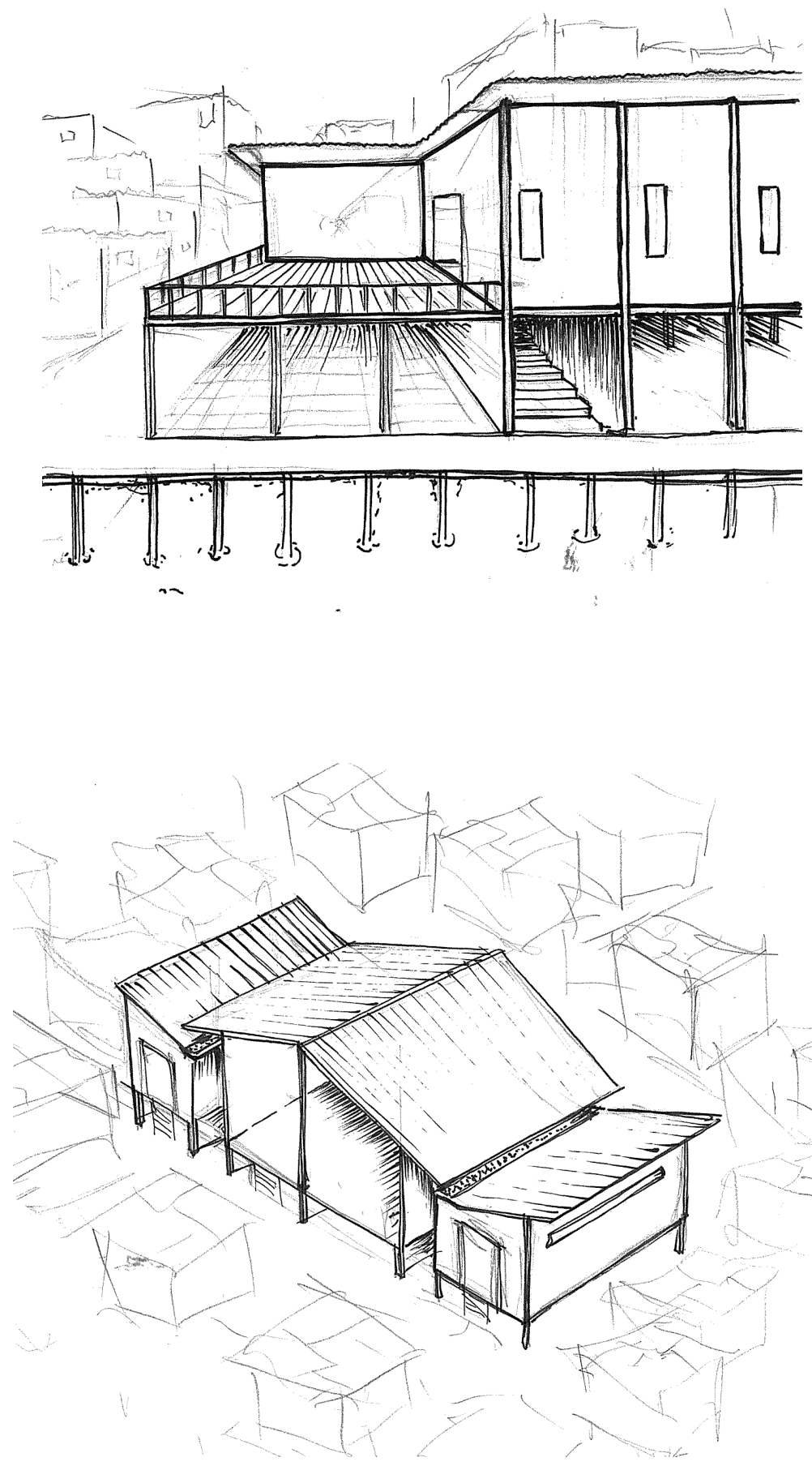

Fig 4.10.Initial Sketches 
Initial Sketches
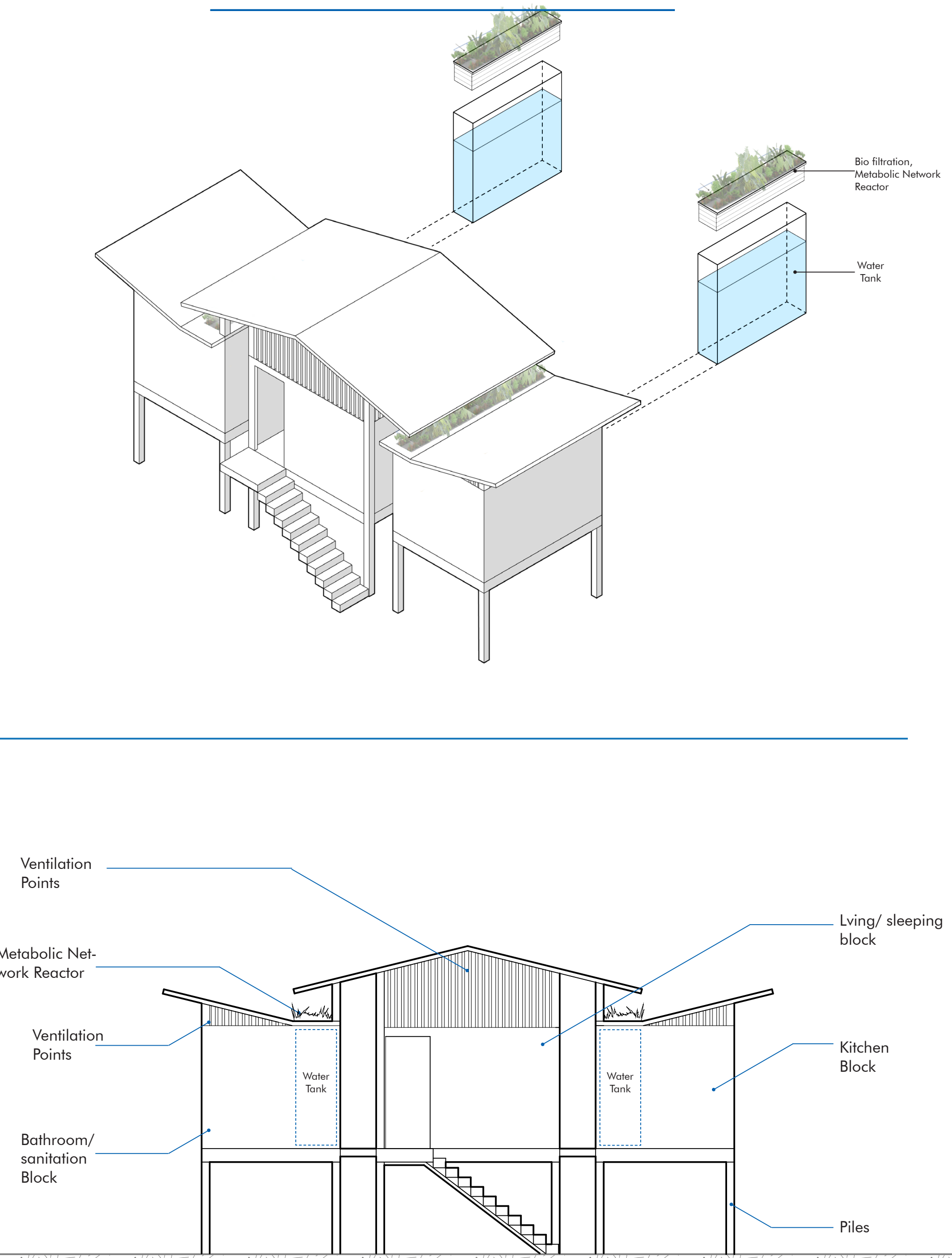

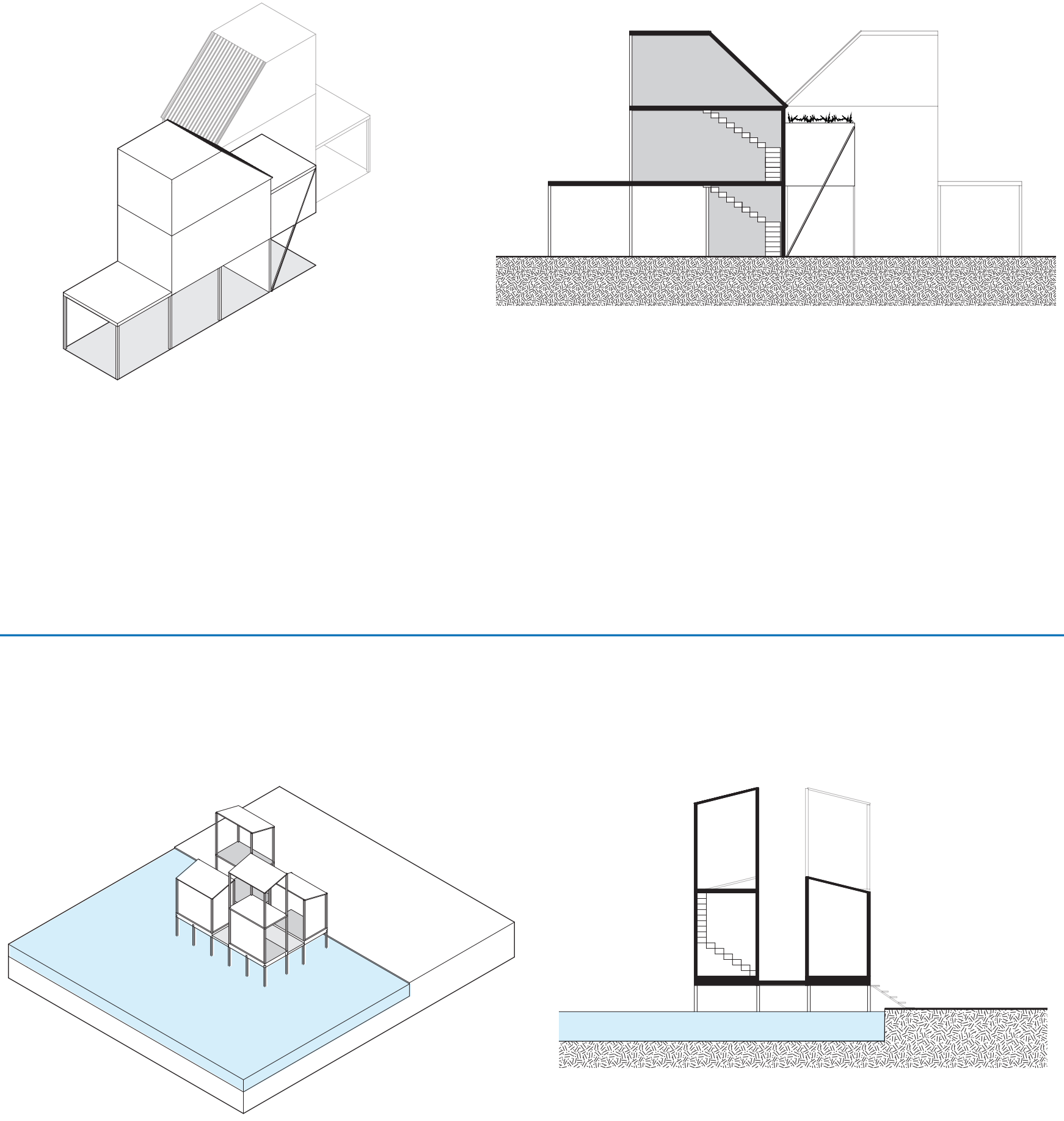


\begin{tabular}{|c|c|c|c|c|c|c|}
\hline $\begin{array}{c}\text { Site } \\
\text { Analysis }\end{array}$ & + & $\begin{array}{c}\text { Literature } \\
\text { Review }\end{array}$ & + & Precedents & + & 1st Design \\
\hline
\end{tabular}

Fig 4.12.Design Criteria Diagram 


\section{Chapter Conclusion}

Initially when beginning this thesis, the assumption was to relieve the social stress in the informal settlements through an improved housing design. However after an in depth analysis of Jakarta through site, people, literature, and the first design review, it became clear that to come up with a housing design to replace existing dwellings would not be effective in supporting the existing social connections within the community.

After an extensive site analysis, understanding the environmental conditions as well as the people that are living in the informal settlements, it became clear that for the current residents, their homes are their most valued possession, and they are constructed in the precise way to meet their immediate needs. Instead of a housing solution, important issues in the Luar Batang community include, lack of infrastructure, access to sanitary facilities, waste management, and a safe place for the community to come together. Reviewing relevant literature, and precedents of how other designs address the same issues within informal settlements, some initial sketch explorations were produced and then then reviewed by an internal panel within the faculty. It was clear from comments made that housing was the wrong direction to take in terms of an architectural solution.

This directed me to change my focus and approach, from a housing solution to one orientated towards the community as a whole. With an emphasis on shared facilities which encourages community interaction, strengthening social connections which are a so important to the way of life of the residents in the informal settlements of Jakarta. Instead of destroying what exists on site resulting from years of natural development, the architectural intervention should support what exists and be able to adapt to further needs.

Based on the Site analysis, Literature, Precedents, and first design review, the following design criteria was developed:

- Provide necessary infrastructure improvements.

- Address the existing architecture, including the traditional features.

- Provide facilities to be available and of benefit to the community as a whole.

- Give opportunity personalisation of space, an adaptive area that can be manipulated depending on the user's needs.

- Assist in social sustainability of the community in the face of environmental threats. 
5.0 Detailed Case Studies 


\section{Chamanga Cultural Center}

Developed by the Centre for Public Interest Design (CPID), The Chamanga Cultural Centre was planned and built by students and teachers from the three universities. Located in San Jose de Chamanga, Ecuador. The design is in response to the earthquake in the spring of 2016, which damaged over $80 \%$ of the buildings in the fishing community of Chamanga. The focus was to use culture to provide positive alternatives to the youth. In workshops run by Ecuadorian Architects Ararraya, expectations and possible design options were discussed, particular care was taken to endure a participatory decision making process, in which various stakeholder groups were herd ("2018 SEED Awards," 2018).

The design consisted of an auditorium that might be extended to the street, a dance studio, a library, and audio-studio, and an office that could accommodate a guest for a couple nights. This spatial layout has to fit into a $135 \mathrm{~m} 2$ plot, and is intended to be as flexible as possible. A solution for bathrooms had to be found, as there is no water treatment in Chamanga ("2018 SEED Awards," 2018).

This is not only an example of cheap construction using locally found materials, but it also sets a guideline for what facilities would help in maintaining social sustainability within a community in the face of the environmental threats. Providing a space to enhance the community connection and be a place where people come together is a key feature of this case study. 


\section{Center for Culture and Ecology Quiane}

Planned and built in the community of Santa Quianne, this project was developed in collaboration with the Mexican governmental organisation CAMPO. The new centre creates a space for working, learning, and recreation. The project supports the sustainable and ecological management of the land and promotes traditional and contemporary culture. The design includes halls, workshops, a nursery garden, gardens for local plant species, and a communal kitchen. Santa Catrina Quianne is a small rural community in Oaxaca. It is one of the poorest states of Mexico and faces social issues of rural exodus, poverty migration, and the loss of cultural identity. Oaxaca also faces the environmental threat of earthquakes. The community has a wellorganized civil society and a vibrant culture, but nowhere to practice them (Designbuild X Change, 2018).

The design intends to create a meeting place for the inhabitants of Santa Catarina Quiane, a place for dancing, working, learning, playing, cooking, and eating. So far the first phase is complete with a large aula and the sanitary building which has an organic water treatment plant, and a constructed wetland for wastewater (Designbuild X Change, 2018).

Like the Chamanga Cultural Centre, the intention is to provide a space where the community is able to come together. The inclusion of a workshop and learning space gives the community a central meeting place where they are able to learn skills to further give back to the area, also giving the residents more reason to stay in the area. 
Also located in San Jose de Chamanga, the project was developed as a response to the spring earthquake. The area where the project is settled corresponds to community land that was donated to the neighbourhood, the space is home to 30 families, with a total of 170 people. The designs purpose is to host a variety of collective activities. Community workshops were developed to prioritize people's needs, this served as the base for design. The idea for the project was to design a wide roof that allows for a range of activities planned by the community. The basic intentions were to revalue local materials and the safe construction systems, also to empower the people through collective work during the building period. (Konovas, 2016)

For construction, a guadua cane structure was proposed, which were assembled by simple joints with nuts and threaded bar. The structural configuration was given by two planes of crossed canes that are constructed to support the roof. The foreground corresponds to the front façade with $4.08 \mathrm{~m}$ (height) by $20 \mathrm{~m}$ (length) and the background corresponds to the rear façade with $3.20 \mathrm{~m}$ (height) by 18m (length) (Konovas, 2016).

This is an example of how a simple intervention can make a significant impact. The simple structure made by community contribution and from local materials is able to improve the situation of the residents of the area substantially. The roof structure provides shelter from the environmental conditions, and is an area where the community can maintain their social connections in the face of a natural disaster (Konovas, 2016). 


\section{Black Bamboo Community Center, Yogyakarta}

This community centre is for the daily meetings of the villagers of Kampung Pakuncen in Yogyakarta. It is nested over the drainage channel and is made of locally found black bamboo. It was built by community volunteers with the help of bamboo specialists Andrea Fitrianto and Jasri Mulya, and non-profit organisation 'Architecture in Development'. The basic need for the community centre was initiated as a result of scarcity of space and money (Chandel, 2013). In informal communities it is important to have a gathering place where regular meetings can be held. Bamboo is a versatile and strong construction material, and regular harvesting improves its vitality and productivity. It is the perfect construction, material for the warm climate conditions of Yogyakarta, which is situated in the centre of Java Island. This is what drove the design to be an open air structure, and its high elevated position is to provide protection against floods (Chandel, 2013).

The total cost of the construction was only $\$ 2500$, and is a good example of 'climate proof architecture' with its response to the environmental conditions of the site (Chandel, 2013).

This design responds to very similar architectural conditions that my site faces. Aspects that would be beneficial for my design would be the open air structure to allow for maximum ventilation in the warm climate, and the elevated position to give some resistance to flooding.. 
The selected site in Kampung Luar Batang is highly prone to flooding, therefor this environmental threat must be accounted for when coming up with design ideas. The first step in resilient flood design for areas that are positioned right on the coast, is to identify and map areas of any existing natural features that provide ecosystem services in absorbing rainfall. Then to develop a plan that restores and improves these features.

Features Include:

Swales, Depressions, and flow Pathways. Understanding the movement of water through the area, looking at aerial photos is a technique to identify wet areas and flow pathways.

Wetlands, and stream systems. Identify locations where surface water is able to leave the site, and understand where it goes.

Vegetation. Understand the type of vegetation that would thrive if human influences were not present.

Geology, Soils, and Slopes. Understand the underlying conditions.

For the Luar Batang site it is important to allow for surface water to drain, this means the eventual design intervention needs to reduce impervious land cover. There are two opportunities to do this, the first is to reduce the footprint, and the second is to use porous pavements (Watson and Adams 2011).

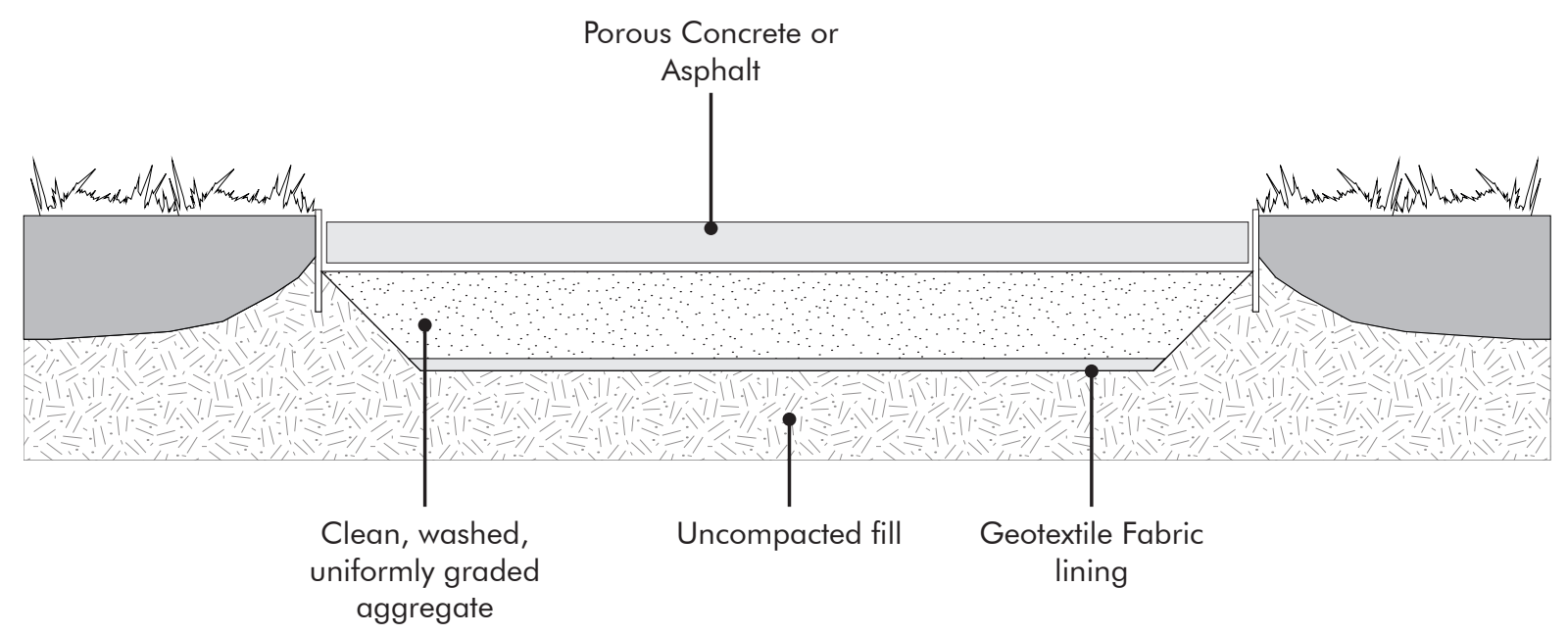




\section{Conclusions}

Revising the research direction to focus on community orientated architecture rather than housing. These case studies all use architecture as a way to bring the community together by providing facilities that would otherwise not be available. The communities these case studies are involved with are all in a state of poverty and are closely related to Kampung Luar Batang in terms of the community needs. The use of natural construction materials in these case studies are important parts of their designs, as they are cheap and easily accessible and local residents can learn from the construction techniques and use them on their own homes. The Black Bamboo community Centre is in Indonesia and has shown many benefits using bamboo, these benefits would also be realised in Luar Batang as the site conditions are so similar. These case studies offer an idea of what facilities are necessary in communities struggling with poverty, and should be considered in my design.

Potential Facilities:

- Auditorium, open indoor space, maybe extended outdoors.

- Office space.

- Emergency sleeping accommodation.

- Sports facility.

- Toilet facilities.

- Services (cooking space).

- Onsite water treatment.

\section{- Education facilities}

To further understand the how these potential facilities can be arranged initial design investigations are needed through sketches and digital mass modelling.

All these examples of community orientated architecture have different aspects that helped to influence my final design. The interior facilities of these case studies are what have been included in the final design. They have proved to be successful in these case studies showing their importance in a similar environment to my site. They also had similar aesthetics using lightweight natural materials that were found locally. Renacer de Chamga Community House, and the Black Bamboo Community Centre, are both open air structures made completely from locally sourced bamboo. Open to all members of the community to use at all times. These forms are where the open air structure feature in my final design was first realised. 
6.0 Initial Design Investigations 


\section{Initial Sketch Ideas}
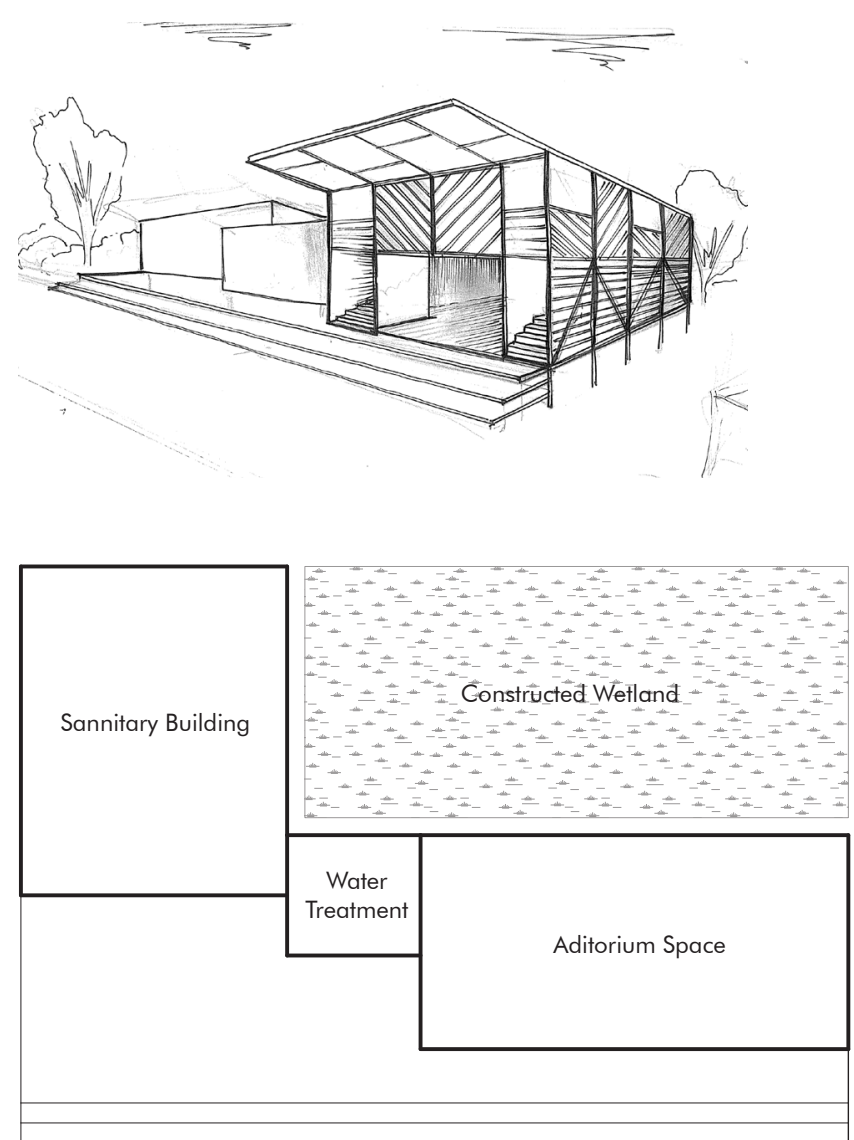

Intended Features:

- Exploring the possible aesthetic and materiality.

- Thinking about the necessary spaces.

- Includes sanitary building for public use.

- Includes on site water treatment.

- Includes Constructed wetland for waste water from the facility.

Critical Review:

- Spaces have poor connections with each other.

- The spread of the spaces result in a large and uneccessary building footprint, more thought needs to go into the layout of the spaces which will effect the overall aesthetic of the design.
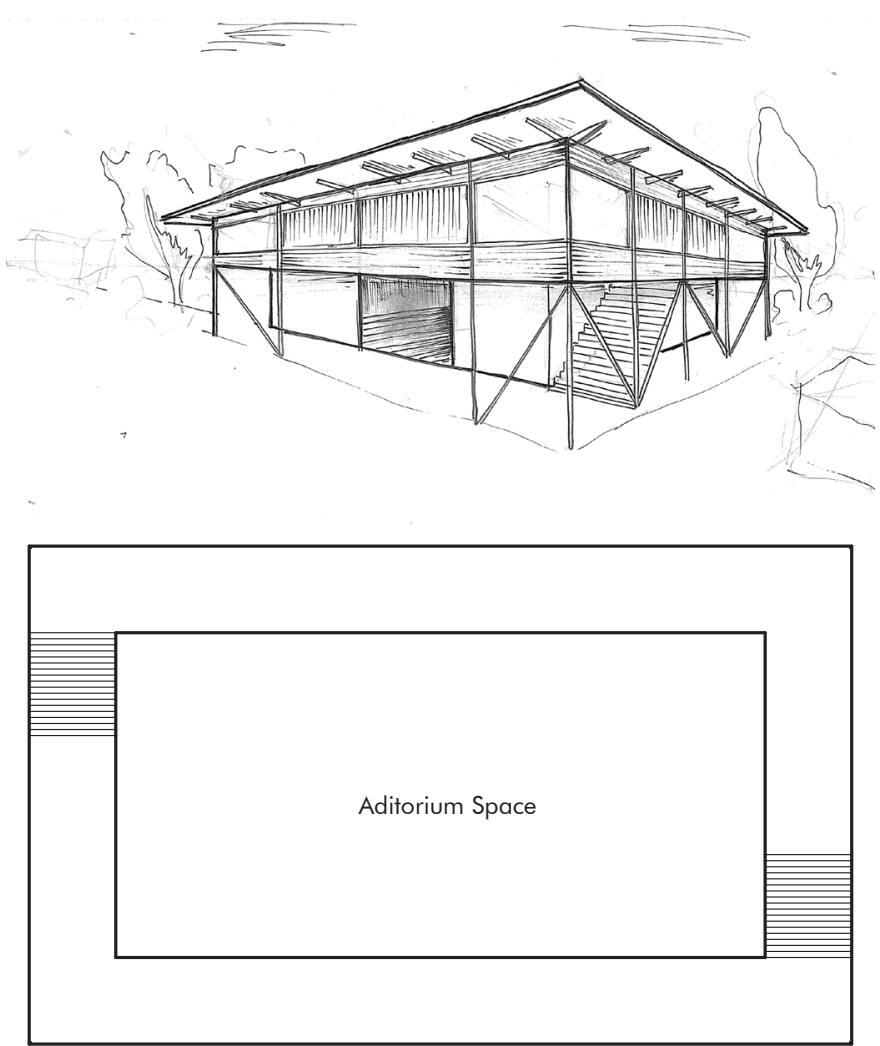

Intended Features:

- Exploring verticality.

- Acknowledging the environmental conditions of the site (prone to floods).

- Includes large auditorium space intended for a variety of uses.

\section{Critical Review:}

- Needs more spaces to support the auditorium, such as sanitary facilities.

- Design has no exploration of form, other than looking into verticality, more thought needs to go into how the space would be accessed and the specific uses, such as community gatherings and sports games. 


\section{Initial Sketch Ideas}
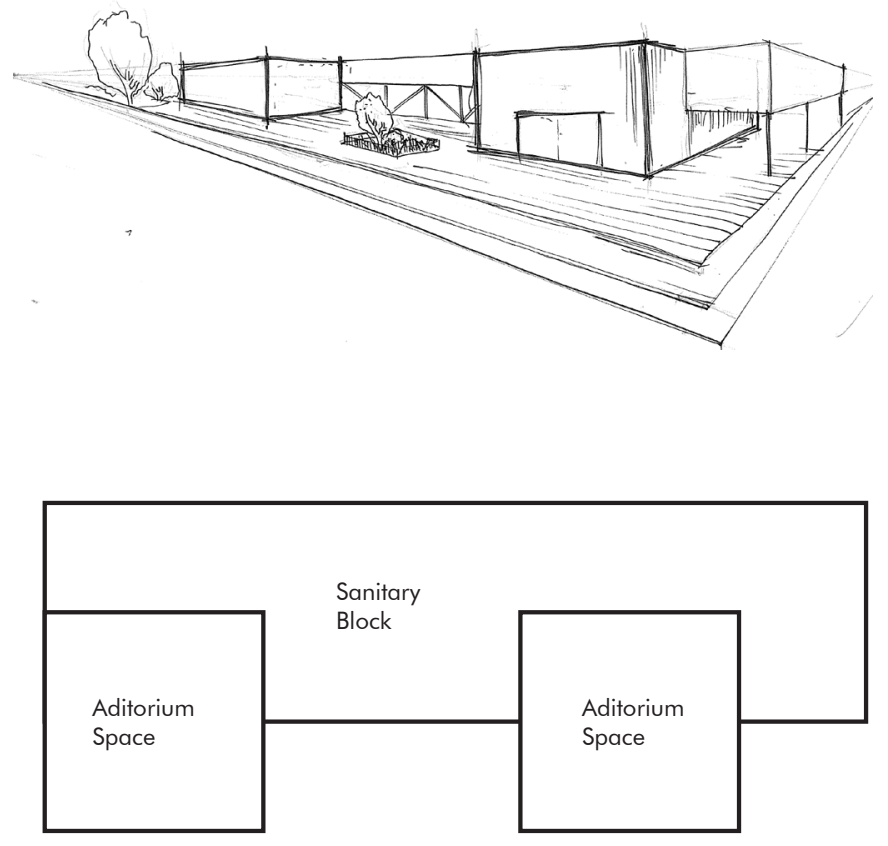

Intended Features:

- Two auditorium spaces for multiple uses at the same time.

- Sanitary block raised off the ground to enable continued use for the public in the case of a flood.

Critical review:

- Might be of more benefit for the two auditorium spaces to be of different sizes so the spaces can be more accommodating for the different uses.

- The roof form will be an important factor to consider, to make sure the runoff does not affect the design and provide the opportunity for the water to be collected
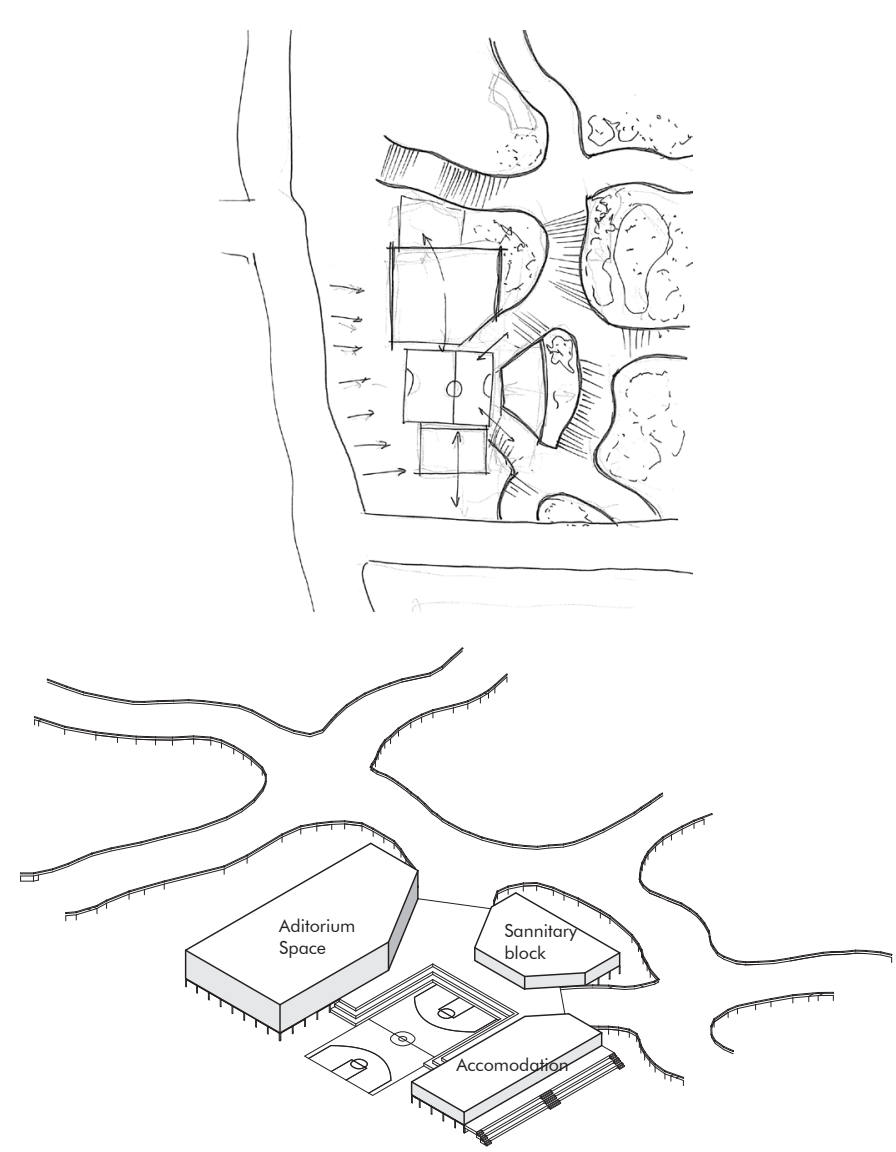

Fig 6.2. Initial Sketches
Intended Features:

- Focuses around an outdoor space, which could be used for gatherings or allow people to play sports.

- Linked with a constructed wetland and walkway which could be used to help connect the Informal settlement roads to the main road.

- Building raised on stilts to avoid flooding.

Critical review:

- Larger auditorium block could be extended out into the sports space, but the different levels would make this difficult.

- Water drainage from the roof and flat surfaces need to be accounted for, if water is unable to drain off the roof effectively water could pool and cause damage. 

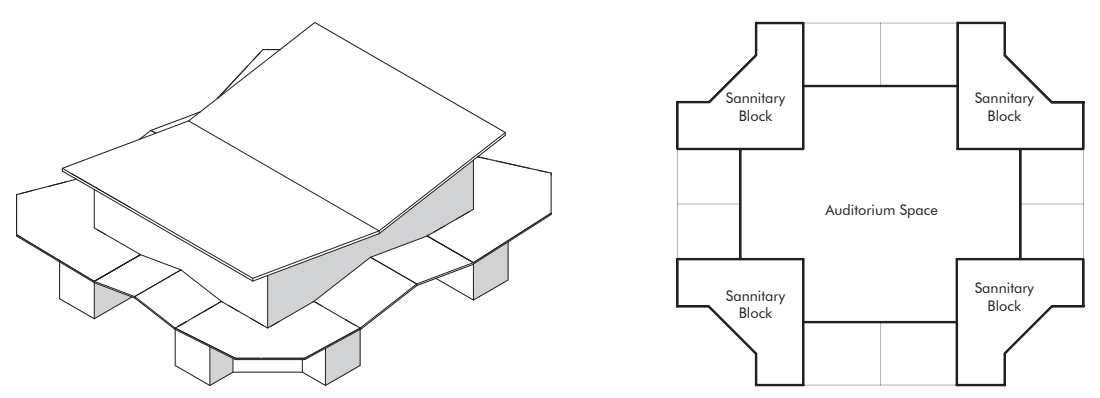

- Exploring an arrangement of space with multiple entrance points, allowing for the space to be welcoming from all directions.

- Thinking about roof angles and the direction of water run-off.
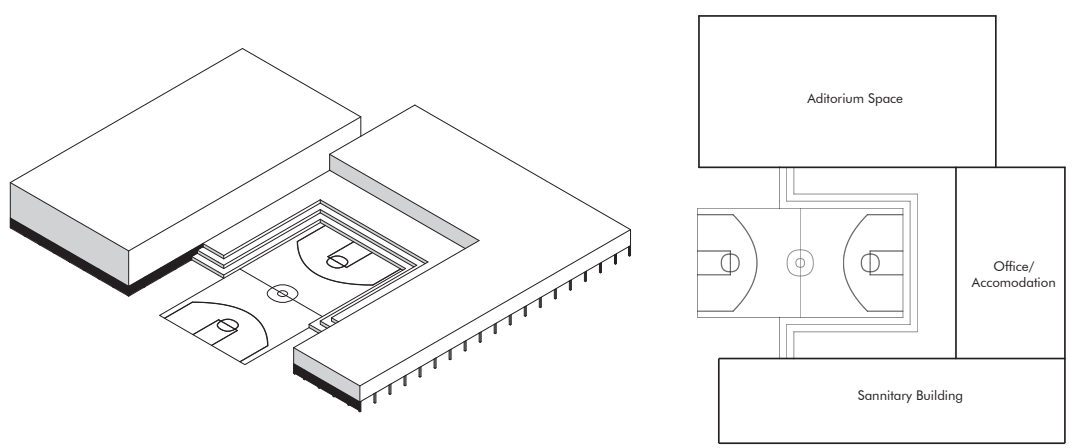

- Different mass sizes based around an open outdoor space which could be used for sports. With some bleachers to form an outdoor amphitheatre, creating a multi-use space.

- Raised above the ground to acknowledge flood prone site conditions, but no considerations of roof design.
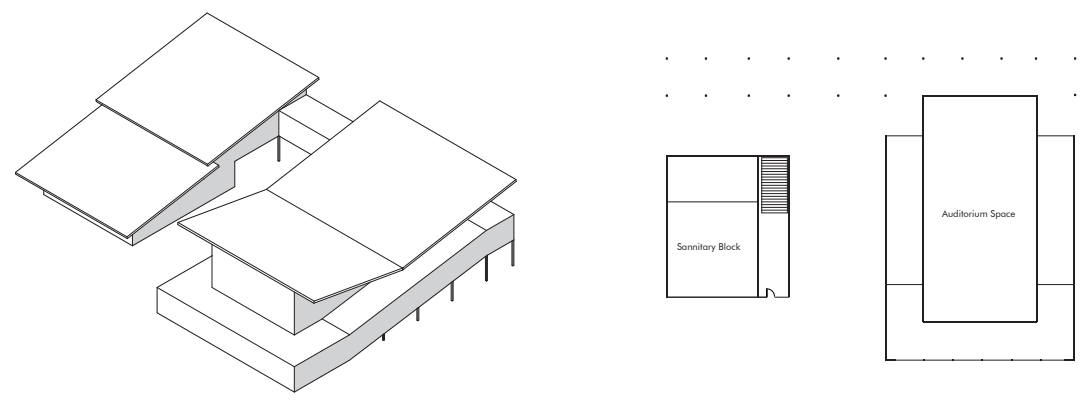

- Investigating how the different spaces with different uses might be connected.

- Exploring the use of different heights, allowing a smaller footprint on the ground and encouraging people to interact with the site. 


\section{Digital Mass Explorations}
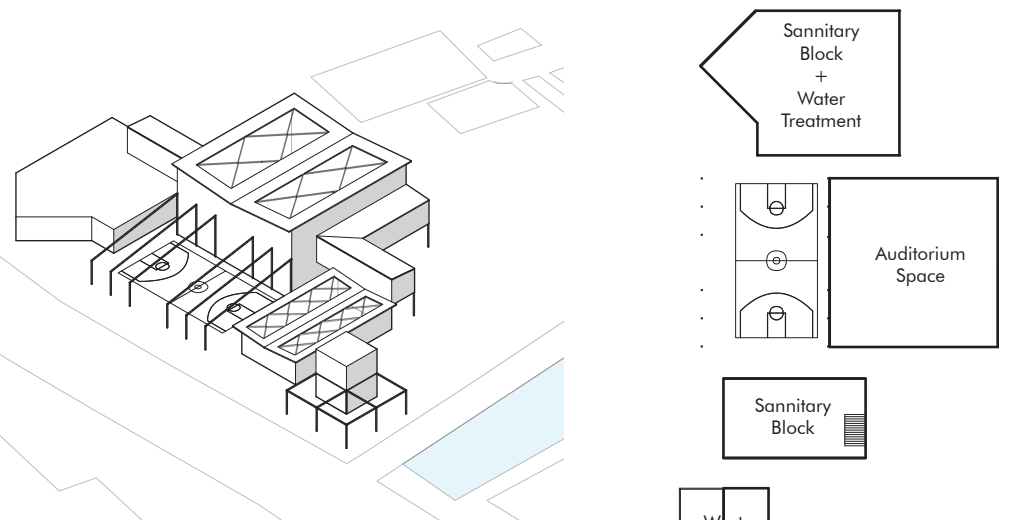

- Thinking about how the design might interact with the site location, with the waste management station on the corner of the main road and the informal road.

- Thinking about how the community might personalise the
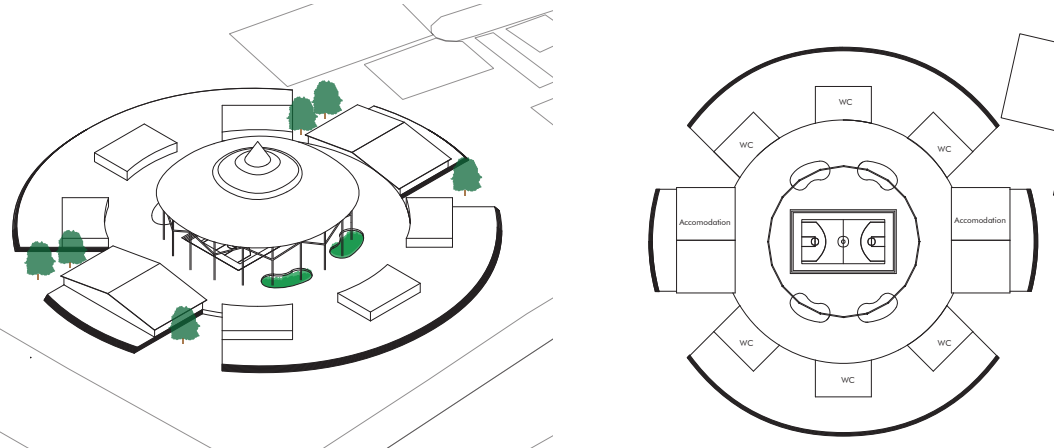

- Exploring how the design could be accessed from multiple directions.

- Focusing around a central open space which could be used for community meetings or sports activities.

- The pitch of the roofs are intended to direct the runoff to green wetland areas.

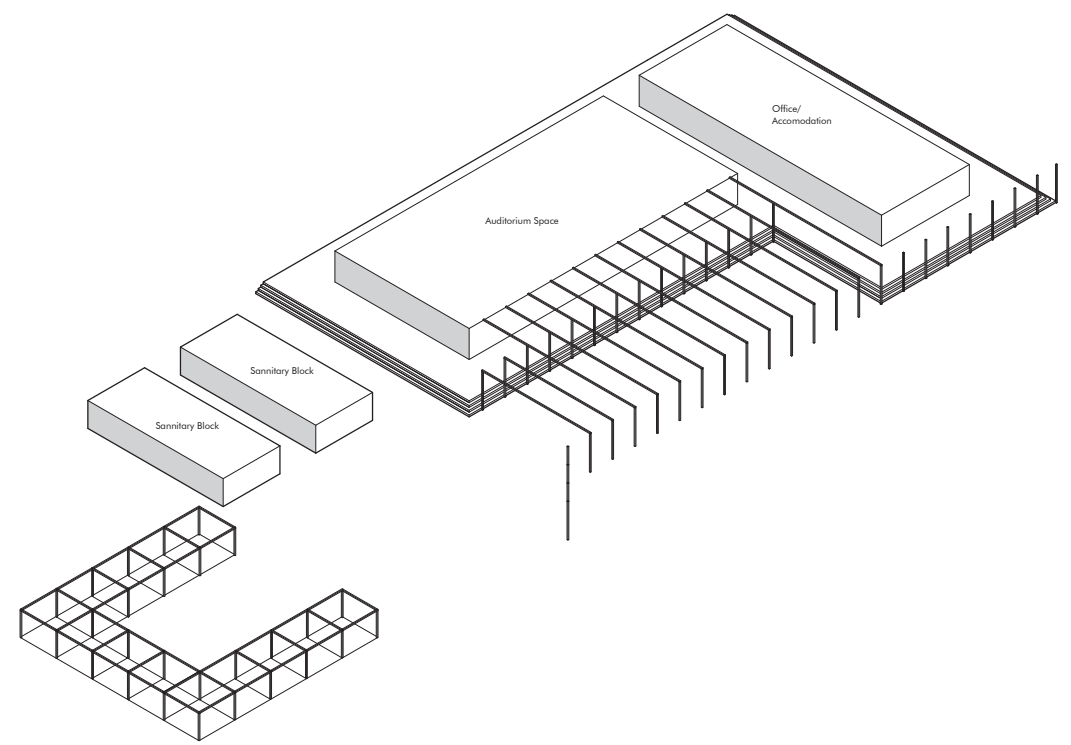

- Allowing for the users of the design to have the freedom to personalise the space to fit specific needs. Providing the initial structure and allowing for the freedom of alterations.

Fig 6.4. Initial Digital Masses 


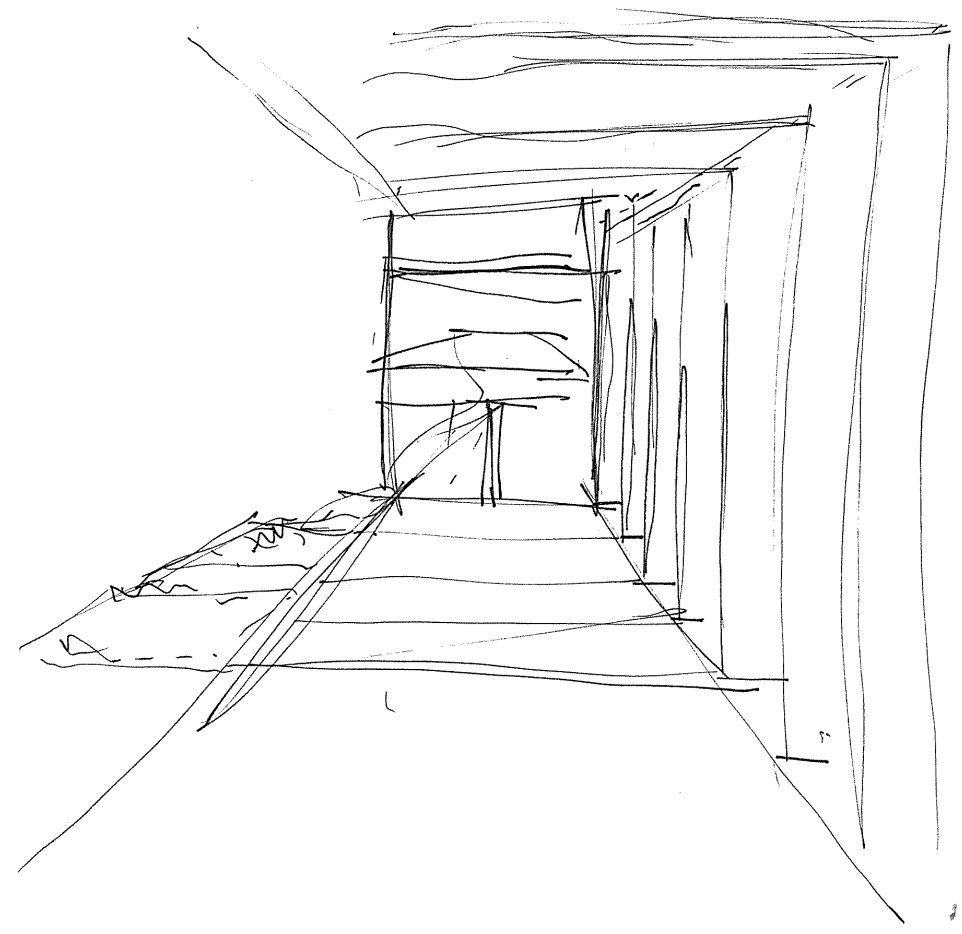

Fig 6.5. Experimental sketch 


\section{Conclusion}

Sketches were used to quickly explore possible aesthetics that were influenced by the case studies. And the possible spatial arrangements. These sketches were useful when visualising initial relationships between the exterior form and the functionality of the design. All investigated forms were simple and only diagrammatic visualisations. The main focus of all sketches was a large communal auditorium space, as this was the most important feature I gathered from the case studies.

Digital mass Explorations helped to further visualise the space relationships. Using the auditorium space a starting point and arranging other facilities to support it. To further develop from digital massing and investigate an external aesthetic, materiality needs to be understood. Different materials will have different limitations and properties. 


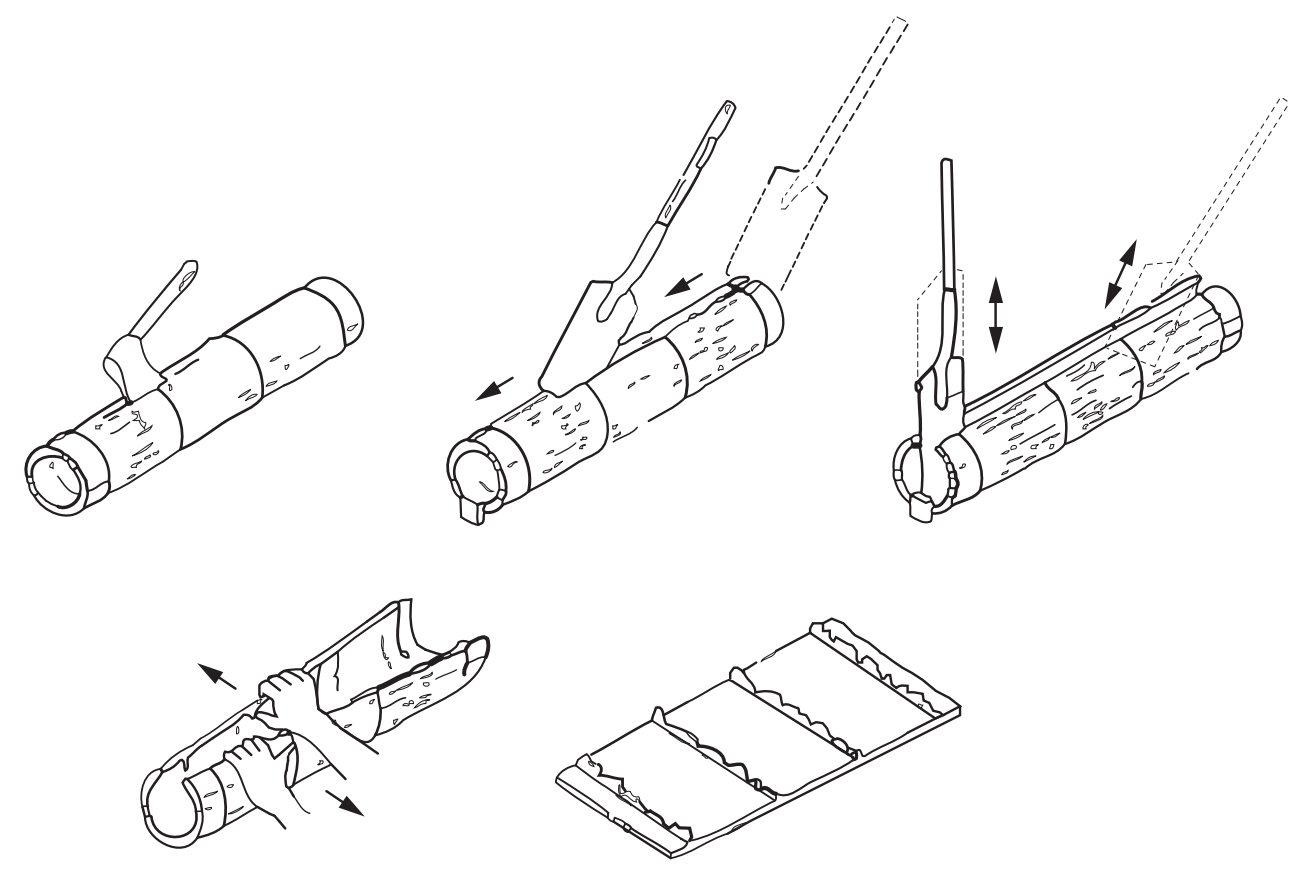

Fig 7.1. Bamboo construction technique Diagram 


\section{Bamboo}

Bamboo is a versatile and strong construction material which grows naturally and in an abundance in Indonesia, and regular harvesting improves its vitality and productivity (Chandel, 2013). It is the perfect material for the warm climate conditions of Jakarta. There are various construction techniques developed in various parts of the world that make the design possibilities vast. Such as in FIG, which turns a piece of bamboo into a sheet (Lopez, 1981).

Bamboo has unique physical qualities and by applying certain techniques, designs with organic forms are able to be achieved as well as rigid structures. Although bamboo has a limited natural curvature there are some bamboo construction techniques which allow for expected curvatures to be reached. There are two methods of bamboo bending; the hot bending method and the cold bending method.

Hot Bending Method:

Using the hot bending technique there are two ways of making curved bamboo, the immersion technique and the combustion technique. When bamboo is heated to a temperature which will cause it be soft and flexible, it will be easier to bend. Once the bamboo cools down again it keeps its new form. The different hot bending method techniques refer to the different ways of achieving the temperature. For the immersion technique, a large tub is filled with lukewarm water, then the bamboo poles are placed in the tub for a long period of time, usually overnight but it depends on the size and thickness of the bamboo. The bamboo is then bent and fixed into the desired shape and left to dry for 1-3 days. The results of the immersion technique are a smooth curvature and texture, and the mechanical properties remain the same as before it was bent, the same tensile and compressive strength .The combustion technique involves adding head straight to the bamboo pole using a flame torch or heat gun. It is important to gradually heat the pole rather than burn it, using this technique the bamboo can sometimes split if there is too much pressure or if the heat is applied to quickly. The combustion technique results in a smooth curvature and texture, sometimes the bamboo will change colour as a result of the direct heating. The mechanical properties also stay the same (Maurina, 2015). 
Fig 7.2. Bamboo construction technique Diagram 


\section{Bamboo}

\section{Cold Bending Method:}

Hot bending methods require time and other tools, where as cold bending methods are achieved easier. There are two ways of making curved bamboo using cold bending techniques, slashing the bamboo or bundling the bamboo. For the slashing technique the bamboo is slashed V-shaped using knives. Once the $v$ shaped slashes are made in the poles they can be bent and fixed into the desired shape by lashing or adhesive. The bundling technique involves split or smaller bamboo members that are then curved into the desired shape and then bundled together and tied. The results of this technique are a smooth curve, but the actual texture is rougher than the other methods. The mechanical properties have also changed, the curved bamboo still has the same tensile strength as the unbent bamboo. However it has a decrease in its compressive strength (Maurina, 2015).

Using all of these different techniques have different aesthetic outcomes which need to be considered when using this material in my design. Other factors that need to be considered are the access to the different tools needed to carry out the techniques.

General Bamboo Construction:

For standard bamboo construction there are general rules that must be followed. It is important to avoid all bamboo that has cracks as it lowers the resistance. All bamboo used should be seasoned or older than three years, previously cured, air dried, and treated with immunizers. All cuts and joints that need to be made into the bamboo must be made properly and on bamboo with an appropriate diameter and wall thickness. The bamboo used as beams or screeds should be cut in such a way that there is a knot at each end or next to it. Otherwise the vertical loads transmitted by columns could cause the horizontal members to be crushed (Lopez, 1981). 
Fig 7.3. Traditional Betawi Architecture

Fig 7.4. Traditional Betawi Architecture Closer Details 


\section{Traditional Betawi Architecture}

The traditional Betawi house differs according to the location, and the occupant's affordability. The traditional Betawi house can be categorized into three distinct types, specifically the Gudang, joglo, and Bapang. The Gudang house is a simple rectangular building with little decorations. It has either a hipped or gable roof with a complex structure, and usually consists of two rooms. The Joglo house is usually a square plan and has an 'umbrella' type of roof structure. The Bepang house has a folded roof shape which is said to resemble a traditional Indonesian dress. In general all types of the traditional Betawi house have a standard, simple and functional structure with a wooden or bamboo frame (Funo et al., 2005).

Luar Batang is known to be one of the oldest historical Kampungs in Jakarta and some of the traditional Betawi features still clearly present amongst the architecture. In my design it is important to acknowledge the traditional architectural forms of the area to maintain the community connection and fit in on the site. 
Fig 7.5. Sharma Springs

Fig 7.6. Rooftop bamboo structure

Fig 7.7. LUUM Temple 
Bamboo is such a versatile material, there is such a range different factors to consider when forming design ideas. The final aesthetic can be anywhere between an organic and a rigid structure. Looking at examples of how other people have designed with bamboo gives me an idea of how to the different construction techniques are actually manipulated to meet the needs of the design.

The use of bamboo encourages the inhabitants of the space to be closer to nature. Positive features of using bamboo as the main construction material include keeping the room's cool, pleasant to look at and touch, and a reduced carbon footprint. Bamboo is an effective material to be used in warm tropical climates because of the natural ventilation and insulation. Techniques have been developed so large complex forms are achievable, such as prefabricated trusses which make larger spans possible (CLALC, 2017). 

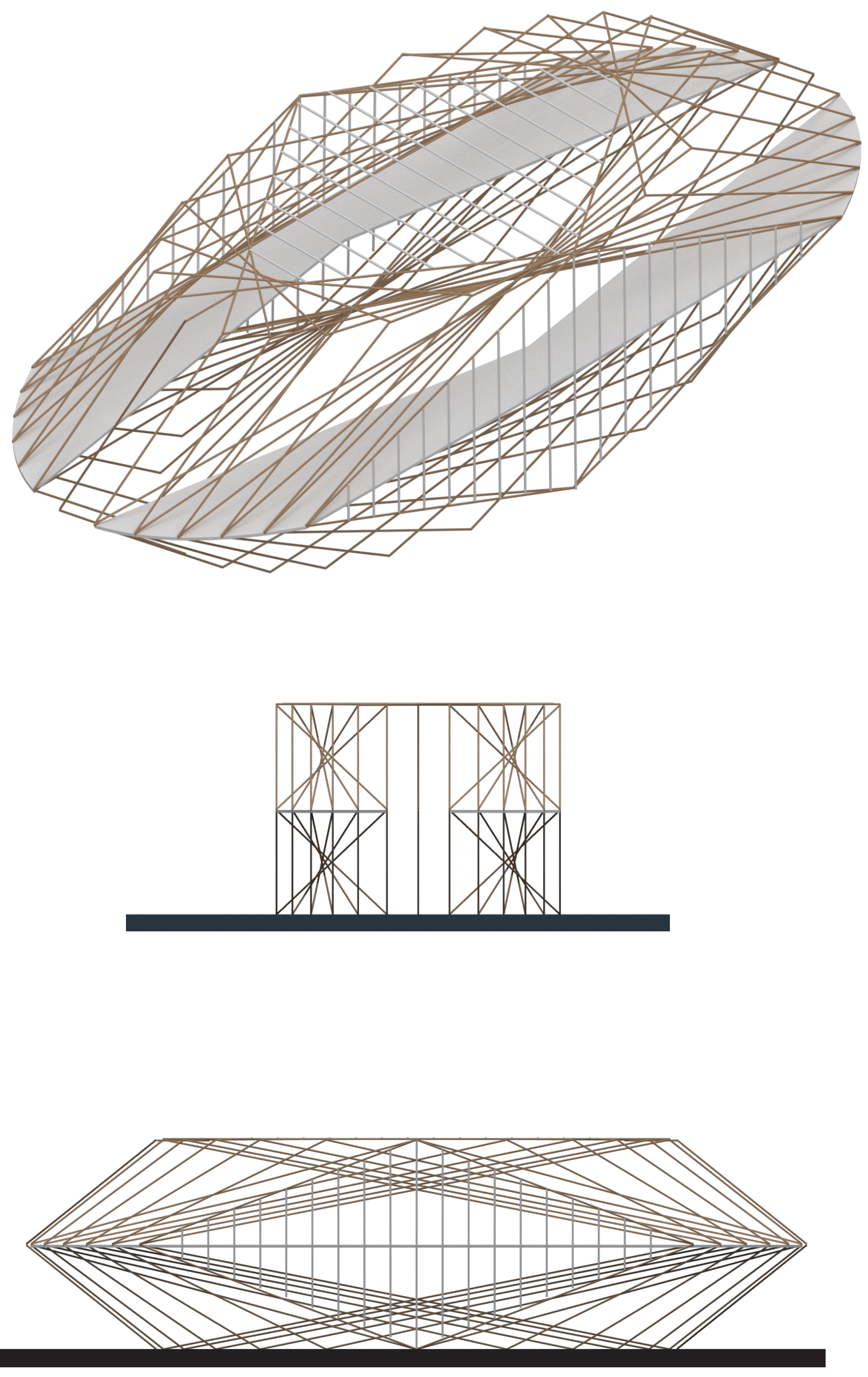

Fig 7.9. Digital Material Exploration 1 
Direction: Exploration of how singular members can come together to close off a space, the idea behind this form is to have a central open space being the main focus. As the main intention is to provide a space for the community to come together, the surrounding structure must allow for a large central opening.

Positives:

- Provides a large open central space.

- Has a smaller building footprint on the ground.

- Has a mezzanine floor, providing space for observation, and unique elevated point for public access that is not otherwise offered on the site.

- Successful investigation shows how singular bamboo members can create a closed off space

Negatives:

- The angles on the side of the form would result in spaces that would be inaccessible.

- No clear entrance or exit.

- Would require large amount of panelling to properly protect form the harsh conditions, and it is unclear where the openings might be.

- Top of the form is flat, which is inappropriate for large amounts of rainfall. 

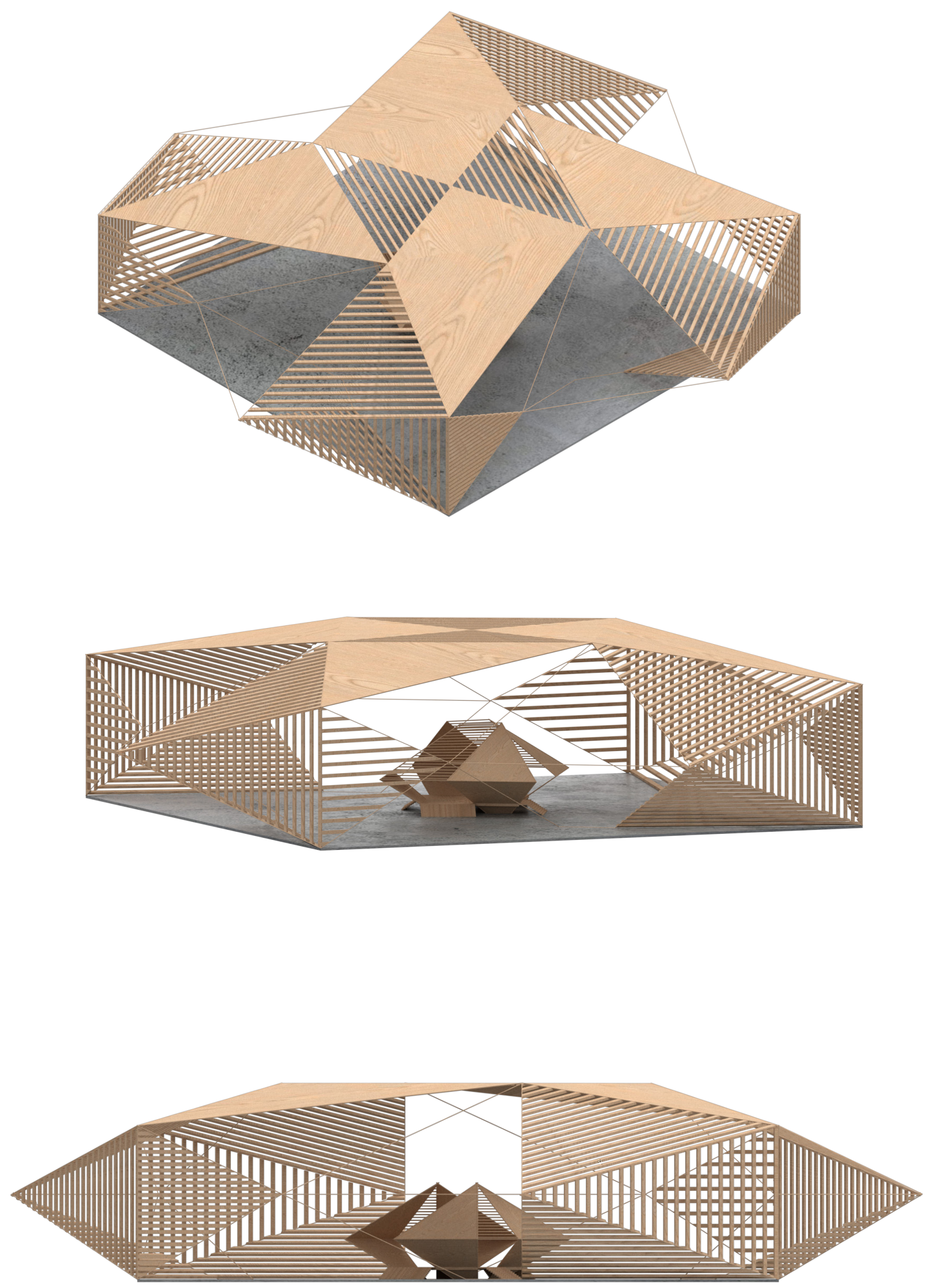


\section{Digital Material Exploration 2}

Direction: Exploration of how an open air structure can be used to define a covered area, with a further enclosed space within. Investigating the relationship between solid bamboo panels and sections of bamboo louvres to define the space and allow different levels of light in.

Positives:

- Has entry access from all sides.

- Maintains visual connections across the site by being able to look through the elevations.

- Angle of roof panels, allow for rainwater to runoff easily.

- Louvres allow for an abundance of natural light into the open air structure while providing protection from the wind

Negatives:

- Solid roof panels will need some support, which would affect the amount of open space beneath.

- There is no main entrance, so it would be unclear when initially approaching where to enter.

- Angled sides of the form create unusable space 

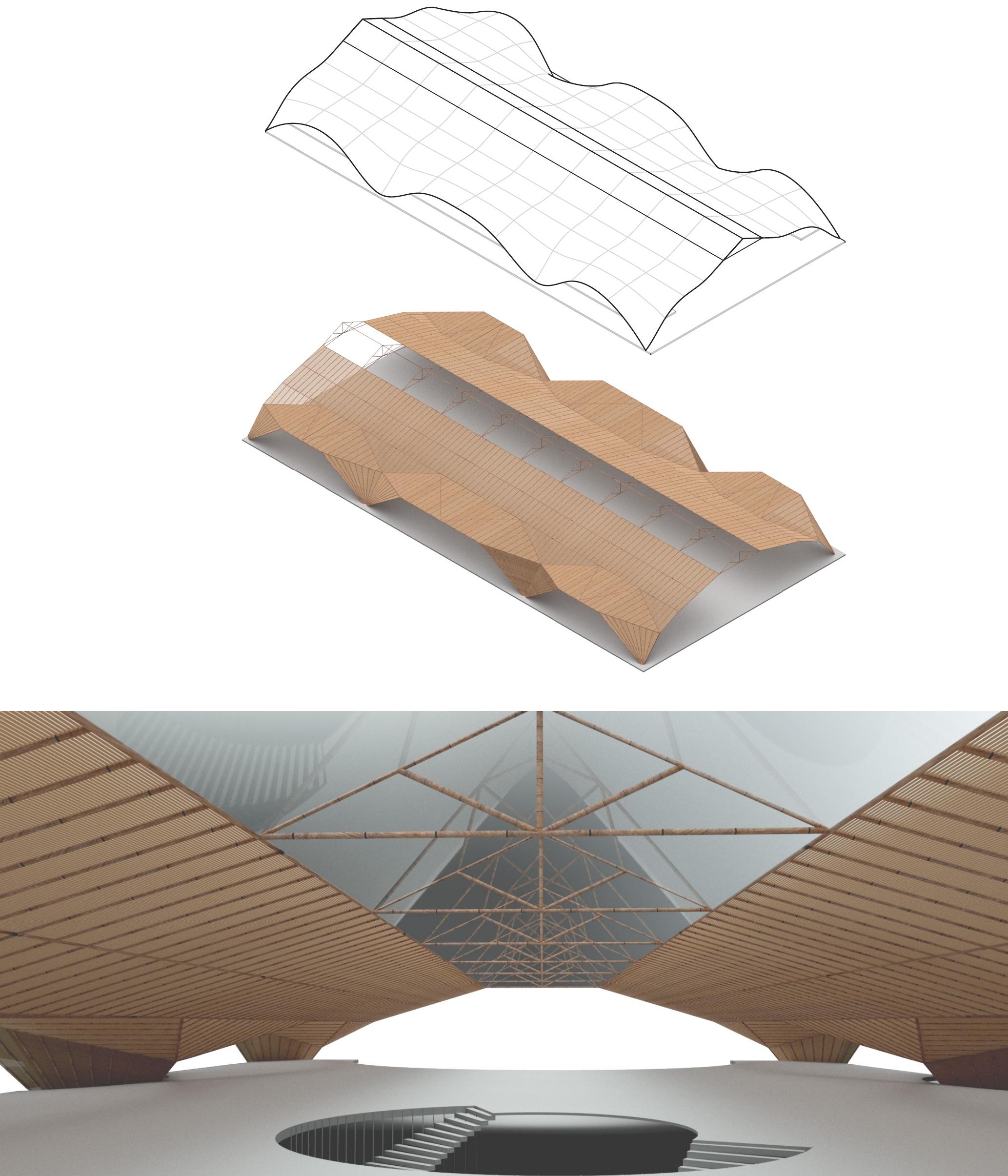


\section{Digital Material Exploration 3}

Direction: Exploration of open air bamboo structure which has a traditional Indonesian architectural influence with the umbrella like roof over the interior footprint. Focusing more on how the form might be able to be made out of bamboo. With some main thicker members making up most of the structure, and smaller thinner members in between.

Positives:

- Contrasting experience from the upper level compared to the lower level. Lower level is more open and exposed.

- Roof angles make it easy for rainwater to runoff and be collected.

- Open lower level encourages people passing by to interact with the space.

Negatives:

-No clear main entrance.

- Central opening would let too much light in for a warm Indonesian climate.

- Large span structure would need some other support which would affect the open space underneath.

- Open ground floor would be almost completely exposed to prevailing winds. 

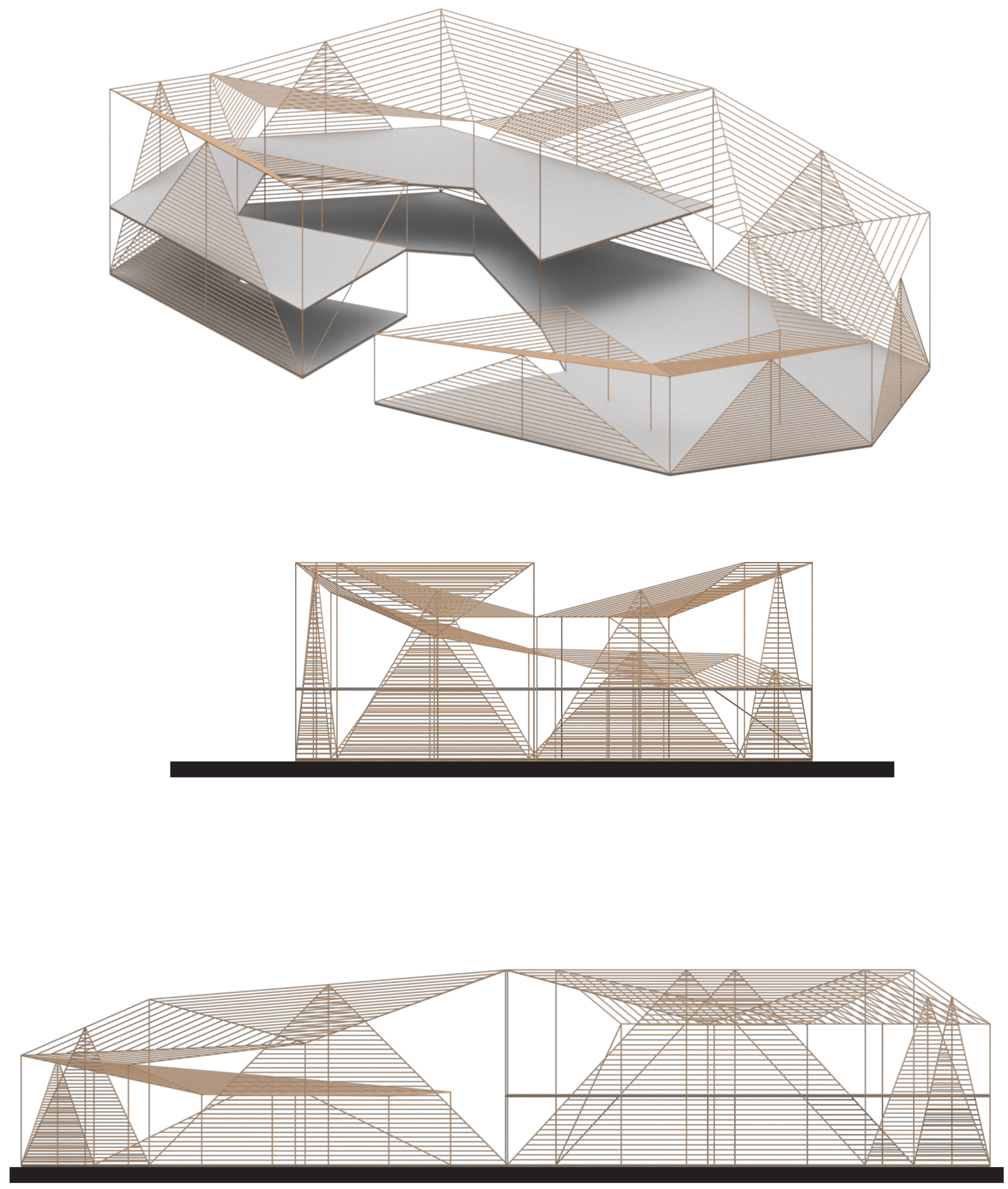

Fig 7.12. Digital Material Exploration 4 


\section{Digital Material Exploration 4}

Direction: Exploration of bamboo creating a blurred line between the open and closed, looking at how spaces could be closed off with different angles and different densities of bamboo members. This exploration also investigates different heights and angles as if it were the initial bamboo structure for a building.

Positives:

- creates an enclosed outside space within the shape which the interior spaces could spill out into.

- Interesting sight lines through the form when looking at it in elevation.

- The roof angles all face towards the central area making it possible for rainwater collection, if this is to be the initial bamboo structure for a roof.

- Level change allows for a range of different spaces to be included in the programme.

Negatives:

- It is unclear what are full openings and what the areas of bamboo louvres are.

- Only has one access point to the internal area.

- Would need some full covered bamboo panels for walls to stop too much wind, rain and light getting in. 


\section{Waterproofing Bamboo Roofs}

In tropical climates such as Indonesia the slope and pitch of a roof is very important to allow for the high amount of rainfall to run off the roof easily. If the roof is at a reasonable slope and pitch, bamboo is a material that can be used to construct a water tight roof using a specific technique. The bamboo all first needs to be coated in 2-3 layers of rubber tree oil to help protect from moisture. The roof is then constructed from six layers. First is an under structure consisting of a woven bamboo net. Then over that is a layer of interlocking split bamboo stems/ shingles. Next is a second layer of structural bamboo on which the outer roof is fixed. A layer of split bamboo is installed on that outer roof. Next is a layer of thick sheets of linen soaked in tar. And finally an outer layer of split bamboo is overlaid, and this is further treated with another layer of rubber oil (CLALC, 2010).

Bamboo roof structure

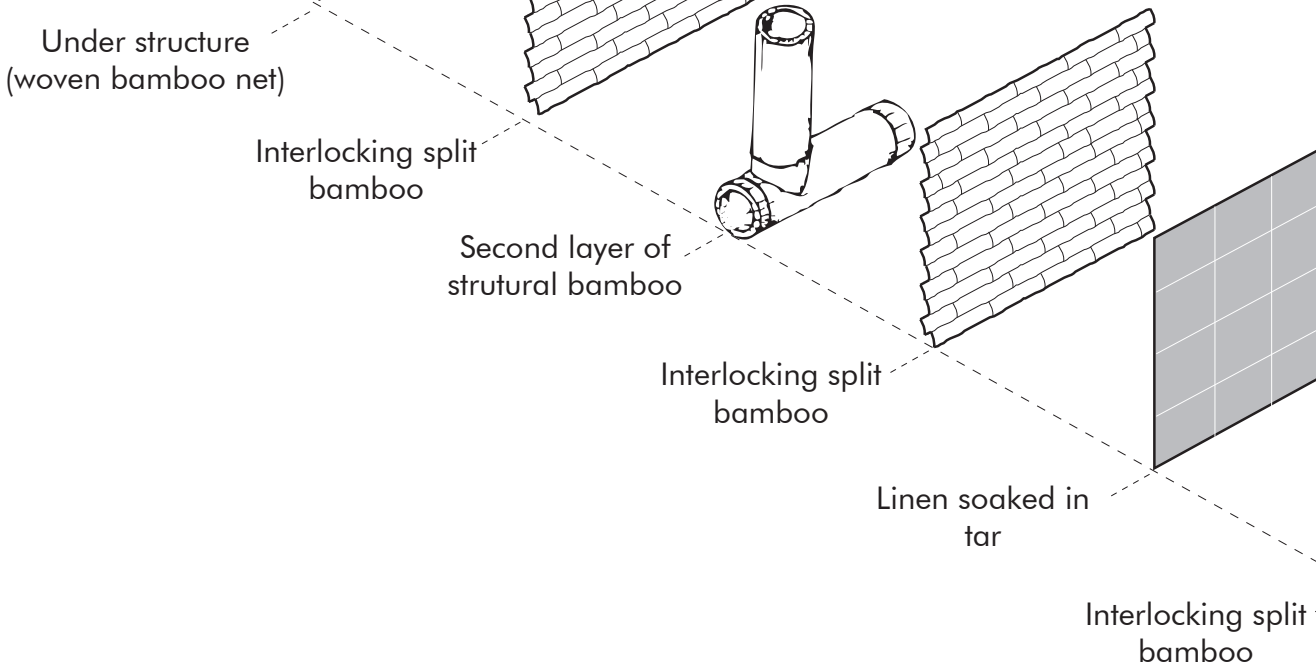




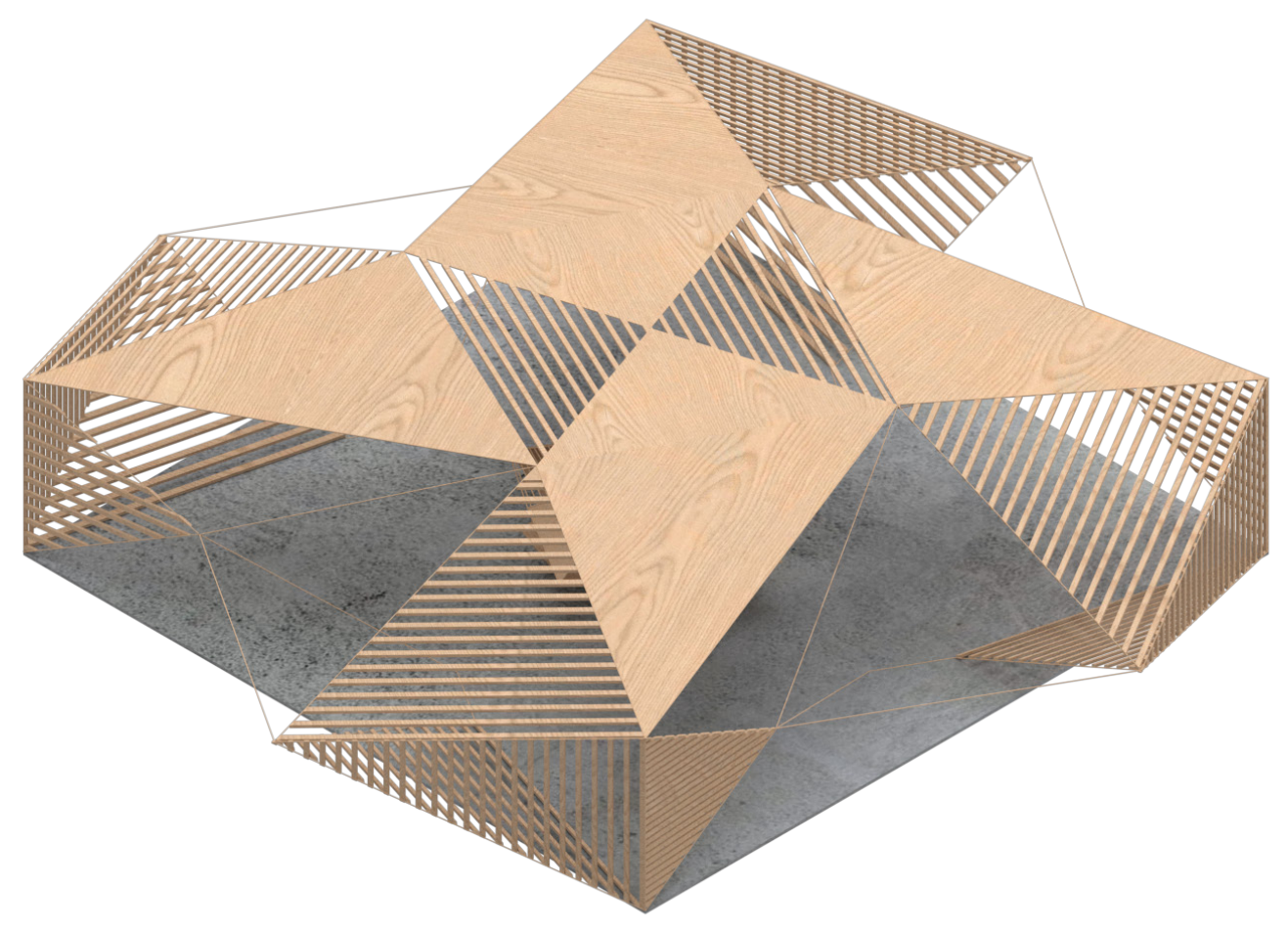

Fig 7.15.Digital Material Exploration 2 


\section{Conclusions}

Material Exploration selected to develop: Digital Material Exploration 2. Understanding the properties of bamboo are what drove the different material explorations, exploring forms with the certain physical limitations of bamboo in mind. Forms incorporating singular bamboo members at different spacing's, with solid panels made up of bamboo members spaced very close together. The material explorations are influenced by the extensive material research. Which helped develop an understanding how different construction techniques are utilised, and how to use materiality to express traditional features of the area.

From the digital material explorations I found that the features of bamboo work well to form open air structures allowing a lot of light in between the individual bamboo members. It then becomes possible to have enclosed spaces within the open air structure if necessary. So the exploration I have selected to be the basis of my conceptual research is digital material exploration 2 . For the conceptual research this exploration will be revisited with more of an architectural approach rather than just focusing on the material use. Materials helped with the digital design process, using the physical characteristics of bamboo, and construction technique as a guideline when producing a digital form. This resulting digital form then becomes a strong base for architectural concepts. 
8.0 Concepts 
Ground

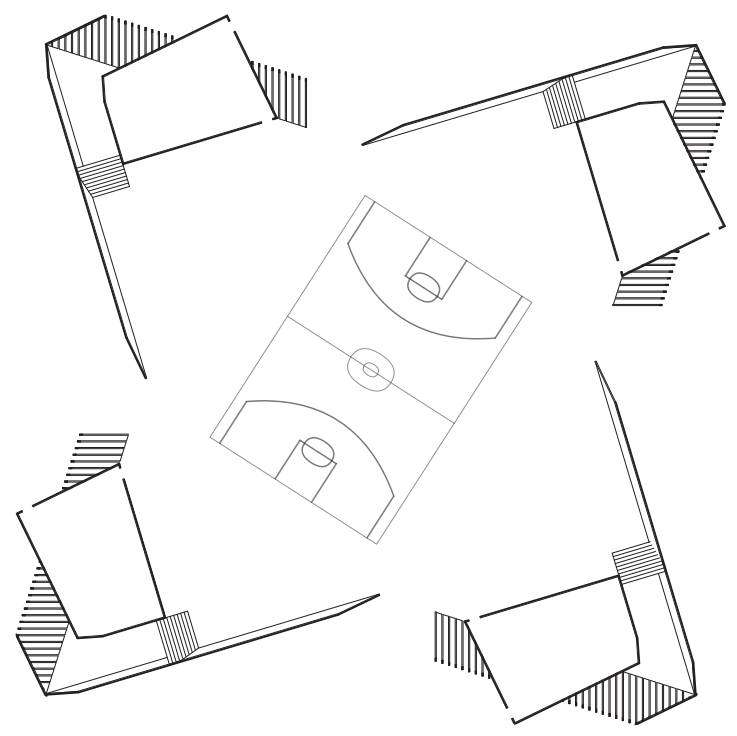

Level 1
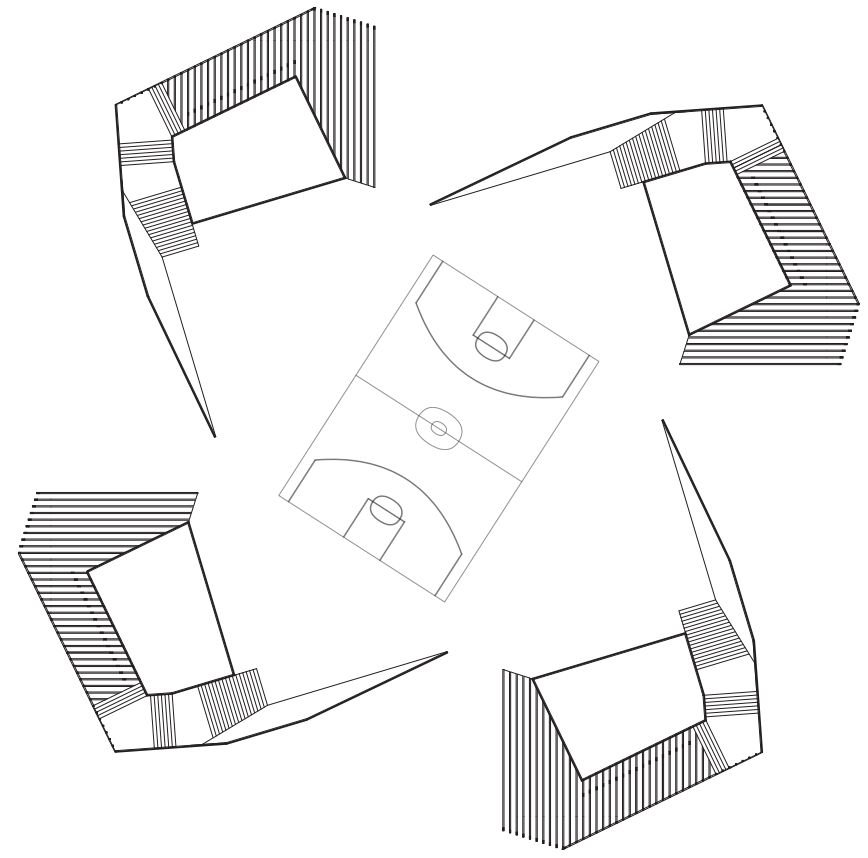

Level 2

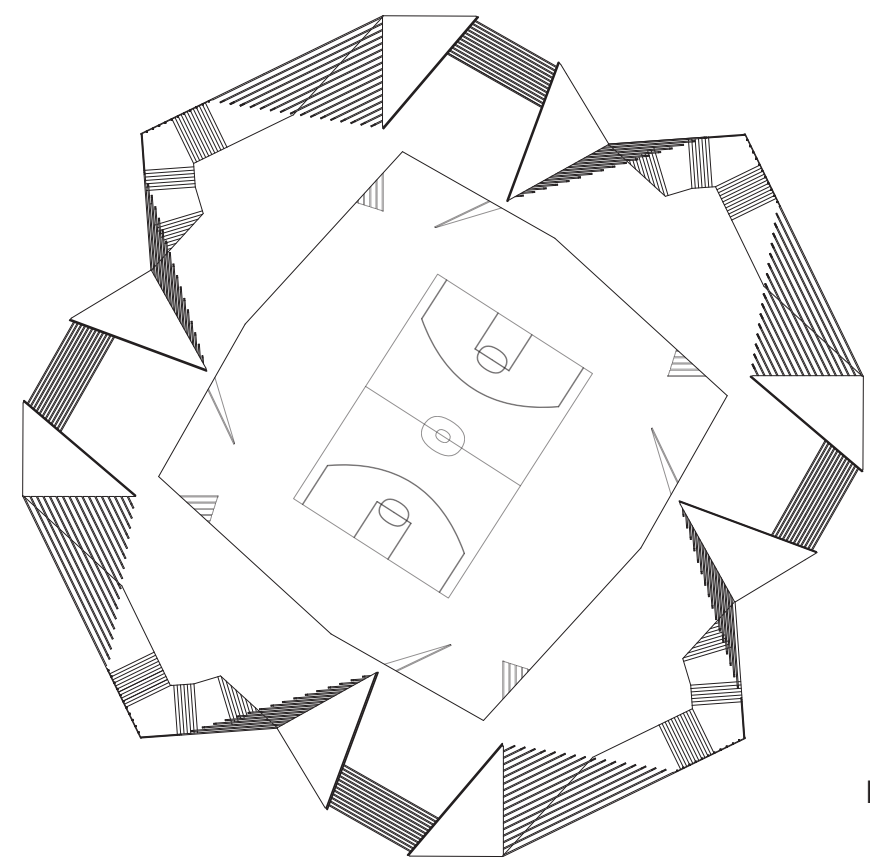

Fig 8.1. Concept 1 - Plan views 


\section{Concept 1}

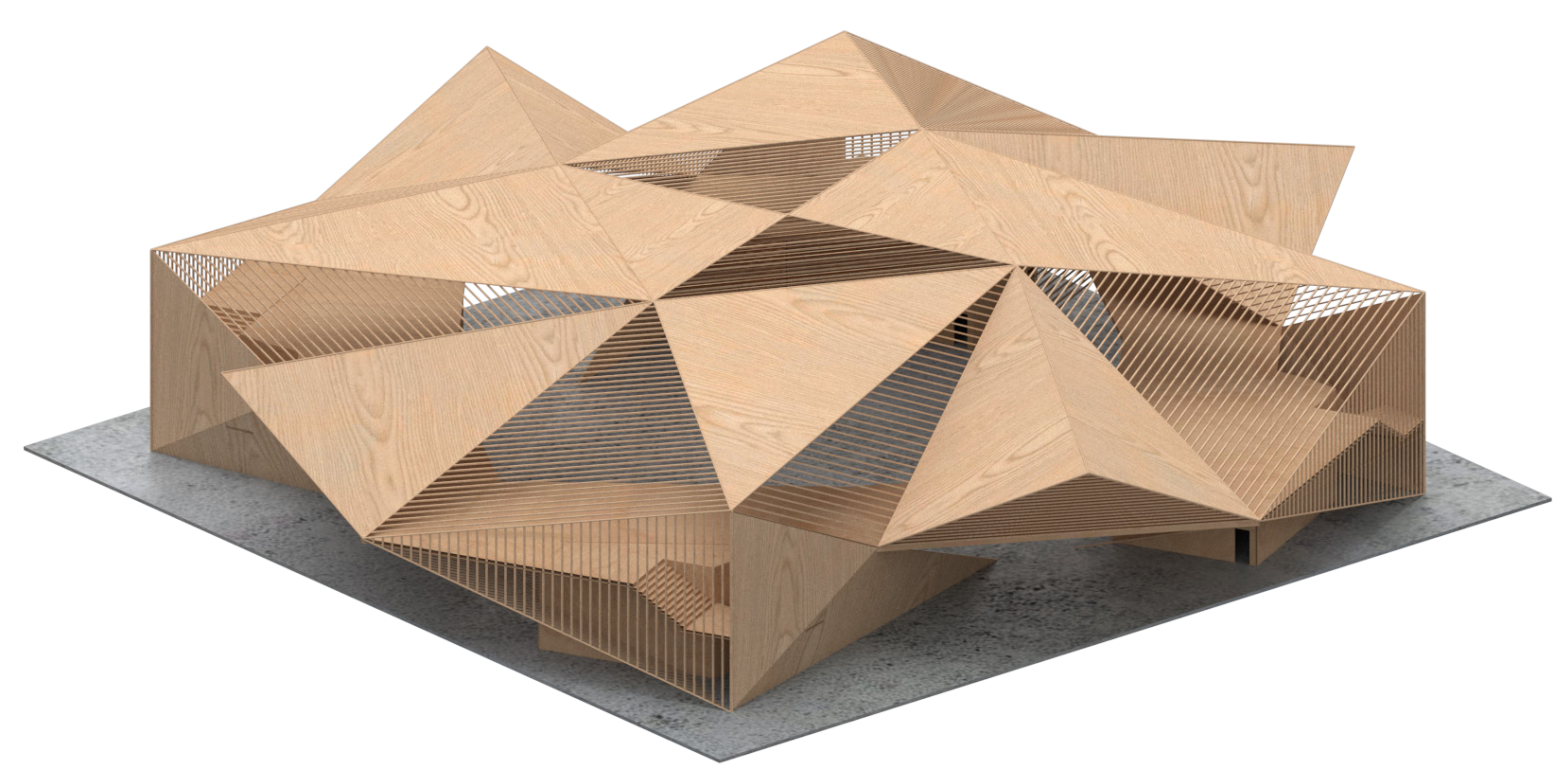

Fig 8.2. Concept 1 - 3D visualisation

Direction: This initial concept is a development of the digital material exploration 2. Continuing the idea of using sections of full bamboo panels and louvres to allow for natural ventilation and different levels of light into the building. The open air structure is focused around a multiuse communal space available for community gatherings or sports, with separate enclosed spaces around the outside. There is also a concourse to observe the communal space from a different level.

Positive:

- Provides a large area for community gatherings and sports

- The unique form stands out from the surrounding architecture, but still acknowledges the traditional features through the materiality and pointed triangular edges.

- Concourse level provides an open raised area for observation.

- Accessible from all directions.

\section{Negatives:}

- Roof louvres allow too much light and rain in over the communal space.

- It is unclear where you enter the space from the outside.

- Does not provide much separate enclosed space for other necessary facilities which support the open community space.

- Rainwater runoff from the roof would be unpredictable and hard to collect. 
Ground

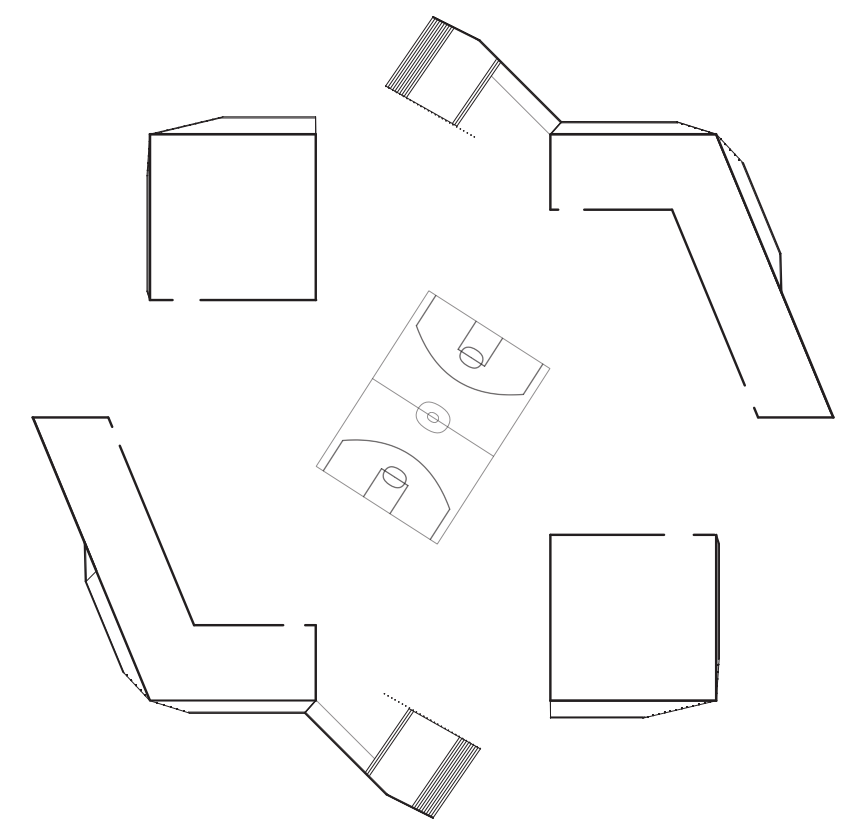

Level 1

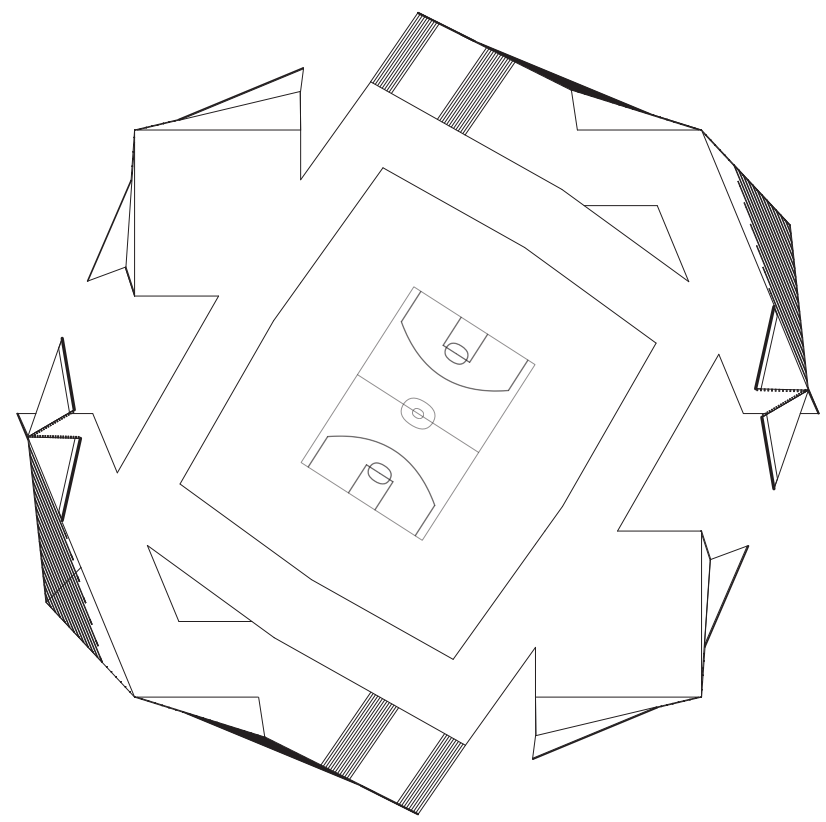

\section{Roof}

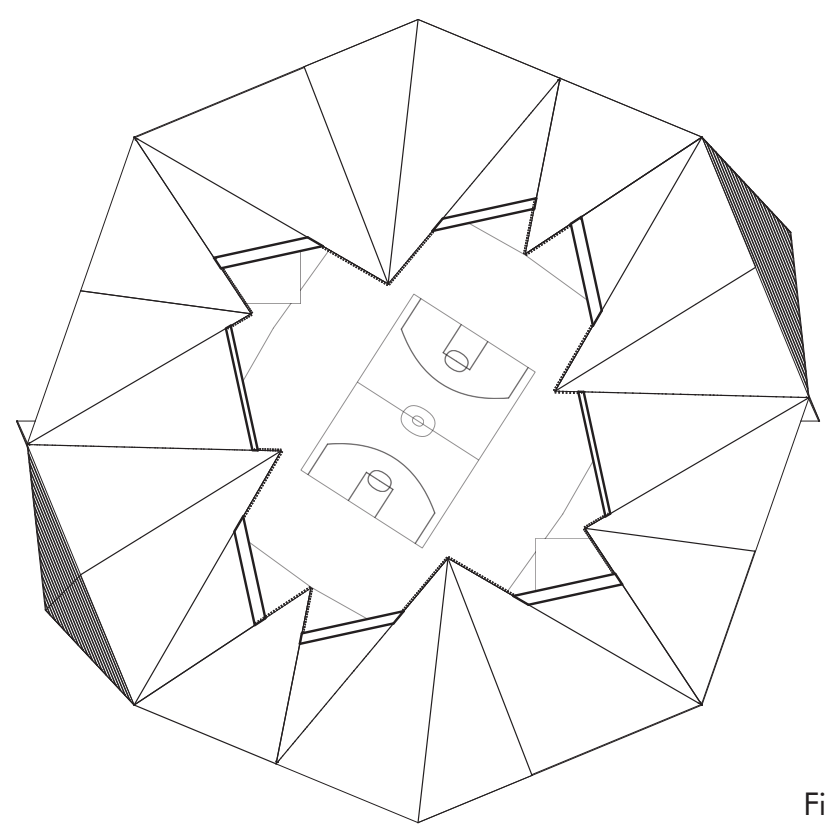

Fig 8.3. Concept 2 - Plan views 


\section{Concept 2}

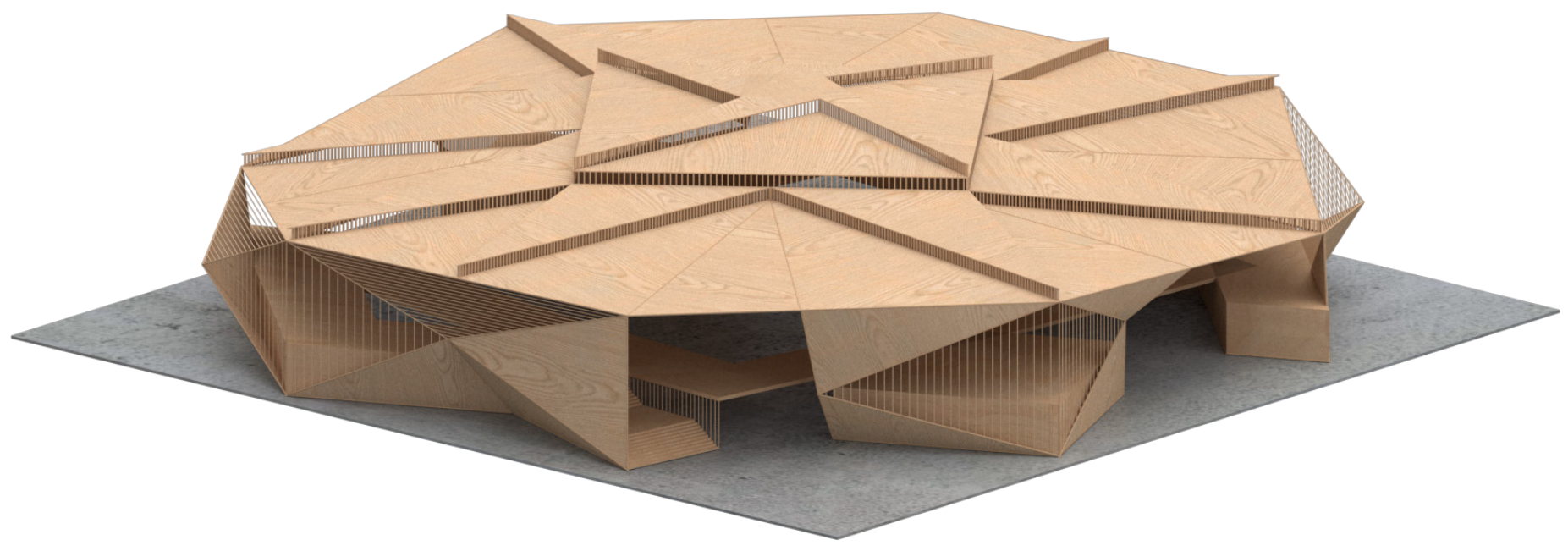

Fig 8.4. Concept 2 - 3D visualisation

Direction: Different approach to the roof form, thinking more about how to keep the rain out during the wet season of Jakarta, but still allowing for natural ventilation during the warm dry season, so has areas of just louvres on the roof. The overall shape of the form is intended to direct the users to the exits from inside the space.

Positive:

- Provides a large open area for community gatherings and sports

- Roof provides large amount of cover from the rain during the wet season but still well ventilated with louvres integrated between the roof panels.

- Clear openings in the exterior façade which allow the entrances to be understood once the building is approached

- Larger amount of separate enclosed space to support the communal area.

Negative:

- Nothing to signify the main entrance.

- Roof is too flat for significant amounts of rainwater.

- Ground level is vulnerable to flooding which is a known threat on the site with the foundations on ground level. 


\section{Ground}

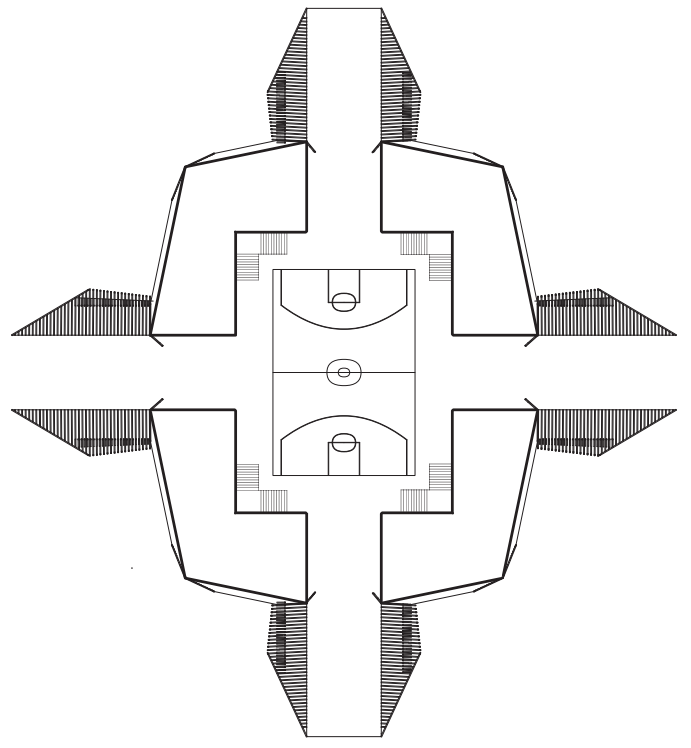

Level 1

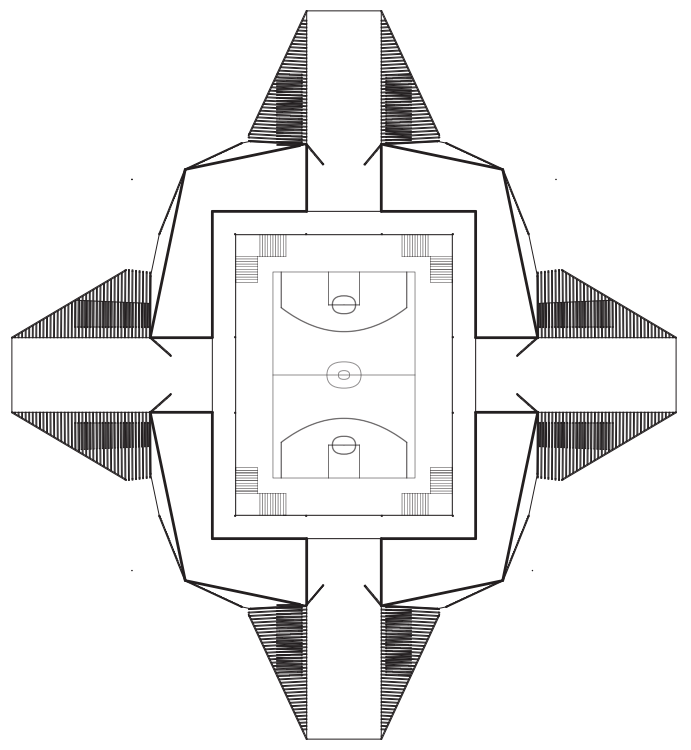

Roof

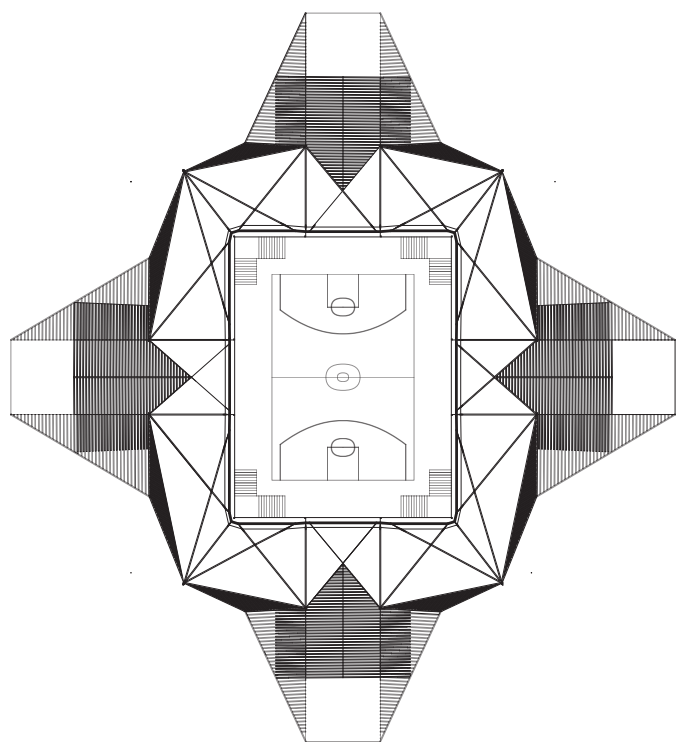




\section{Concept 3}

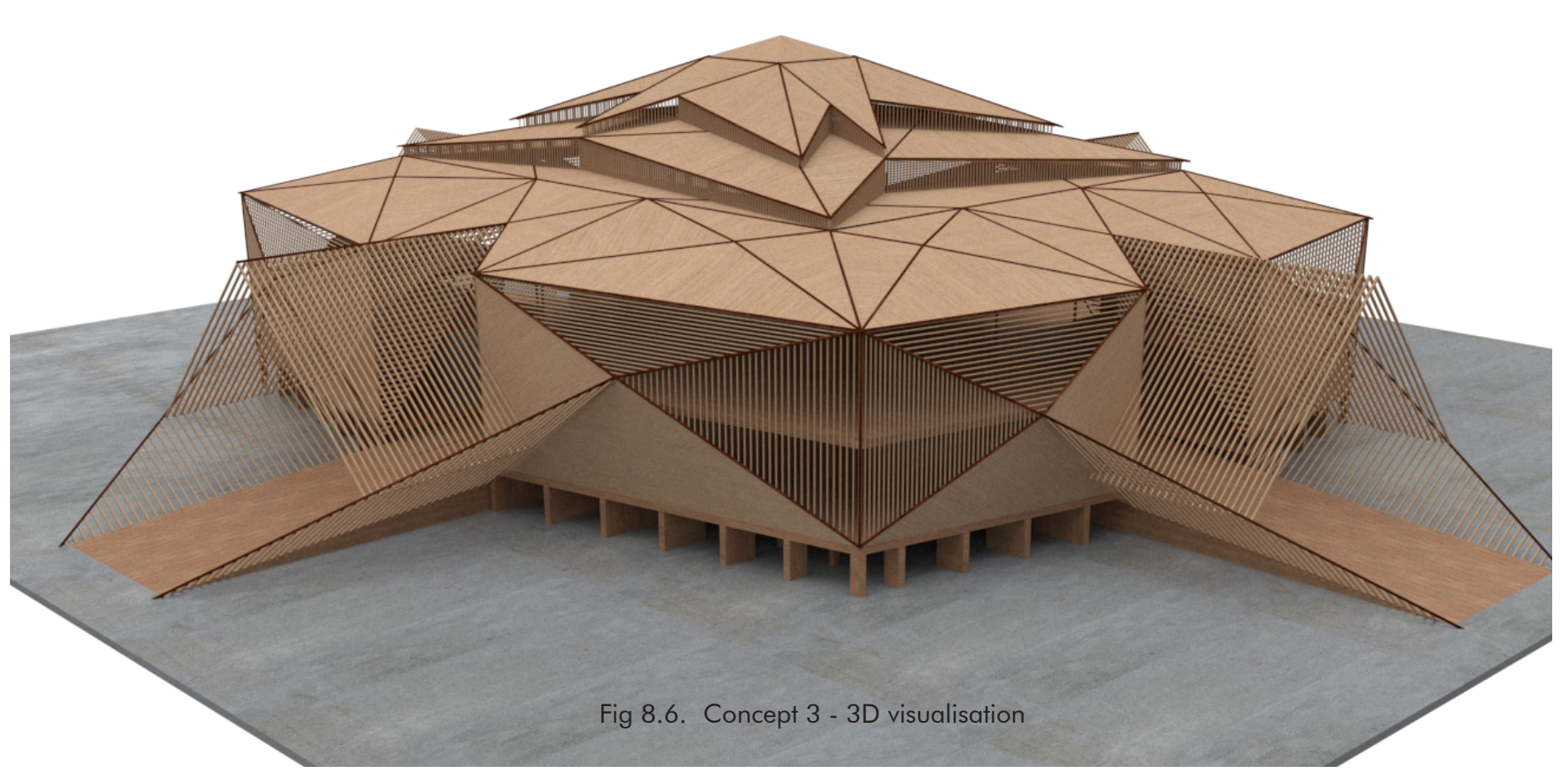

Direction: The intention for this concept was to investigate a smaller building footprint by reducing the open communal space to just the size of a multiuse sports court. This lead to an overall simplified floor plan with four identical size corner interior rooms. The entrances were also exaggerated and the overall form had more of a traditional influence.

Positive:

- Entrance points are clear.

- Raised on piles to account for high amounts of groundwater.

- Roof has a steep pitch to allow for high amounts of rainwater to runoff easily

- Roof still accounts for natural ventilation through louvres.

- Structural bamboo members are emphasised using a darker shade of bamboo.

- Strong influence of traditional Indonesian architecture of the area.

-Reduced building footprint size.

Negative:

- Smaller open communal space becomes more sports orientated and less multi-use with its reduced sized.

- Unclear which is the main entrance.

- Entire form is significantly symmetrical and lacks variation. 
Ground

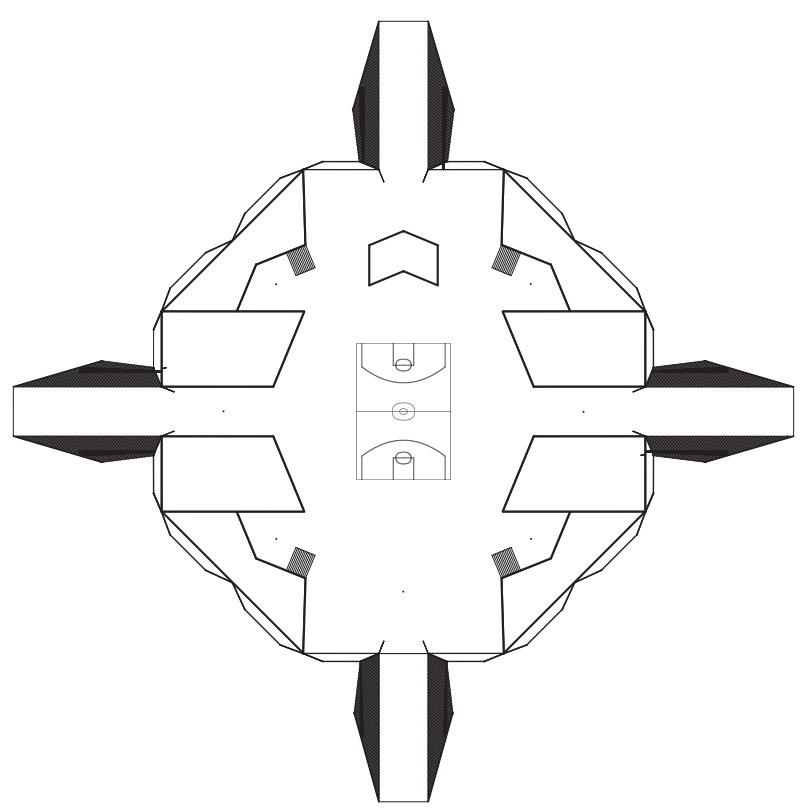

Level 1

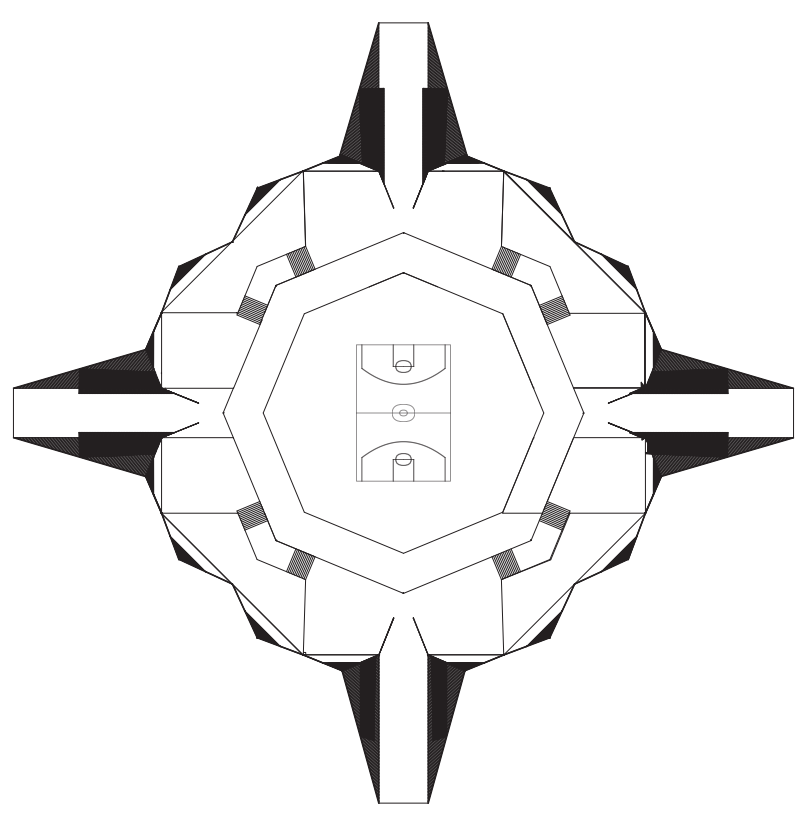

Roof

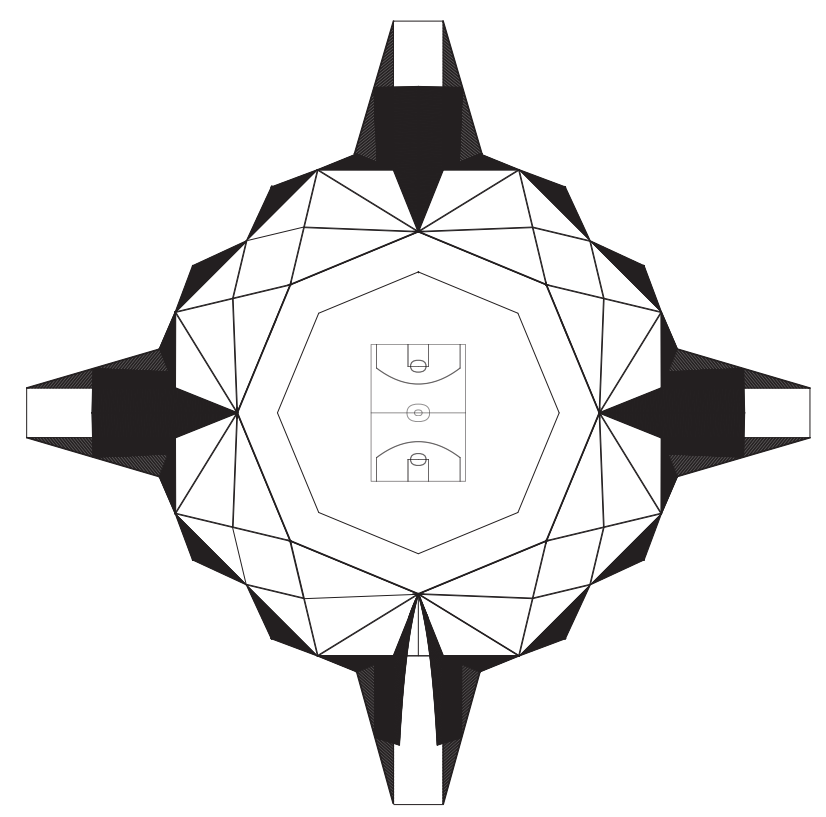




\section{Concept 4}

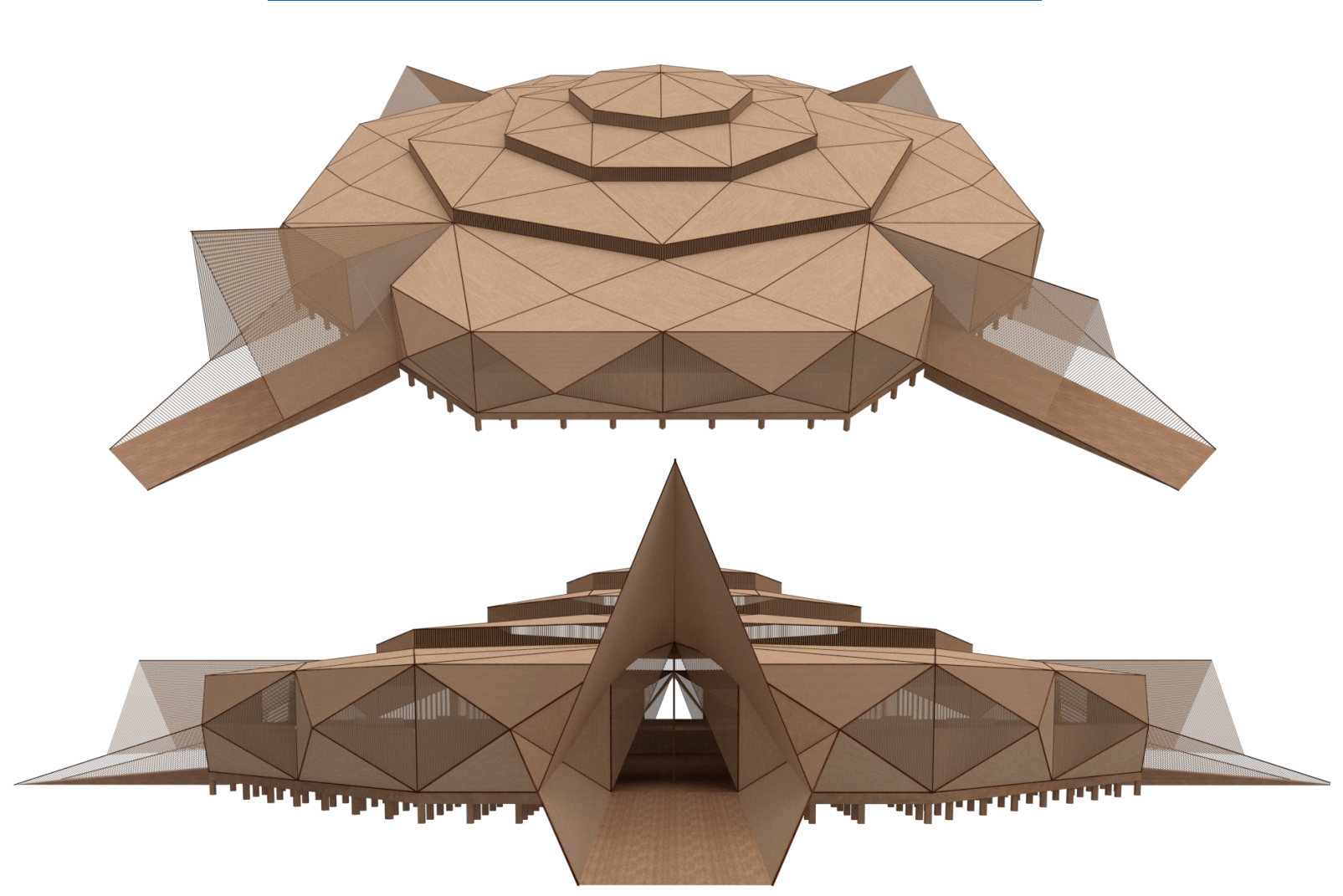

Fig 8.8. Concept 4 - 3D visualisation

Direction: Increase the size of the open communal space to make it more multi-use. Have a more organic overall form and more emphasis on the entry space and the main entrance itself. The interior levels have two stories to them, and all the upper stories are linked with a concourse that goes around the whole building.

\section{Positive:}

- Provides a large open area for community gatherings.

- Roof pitch allows for water to drain easily

- Main entrance is clearly identified

- Strong traditional Indonesian influenced architectural features.

Negative:

- Repetitive façade the same around the entire exterior of the design, the only change is the emphasised main entrance.

- Overall form is significantly symmetrical and lacks variation.

- Interior spaces are unordinary shapes which would make it difficult to organise programme. 
Ground

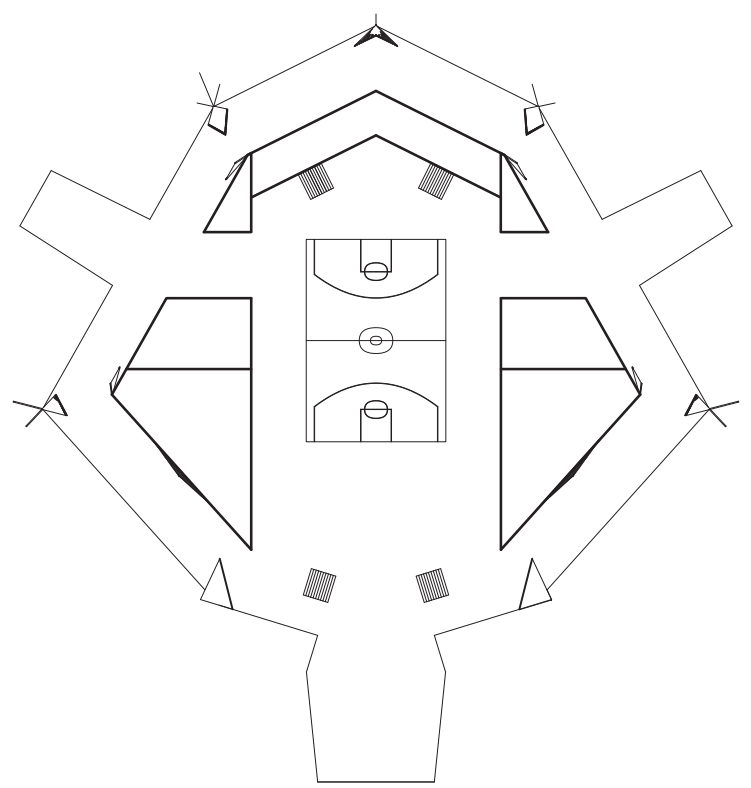

Level 1

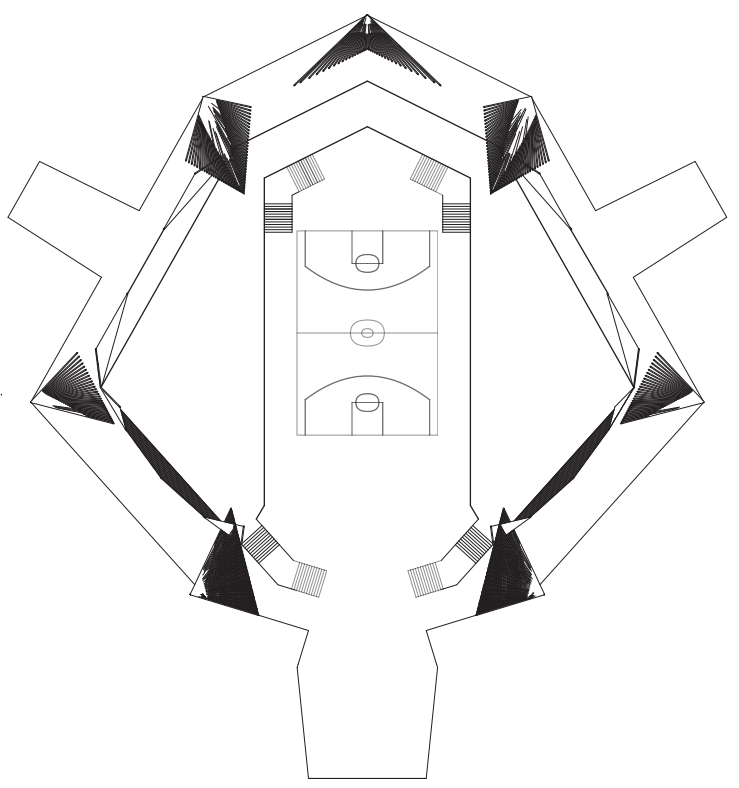

Roof

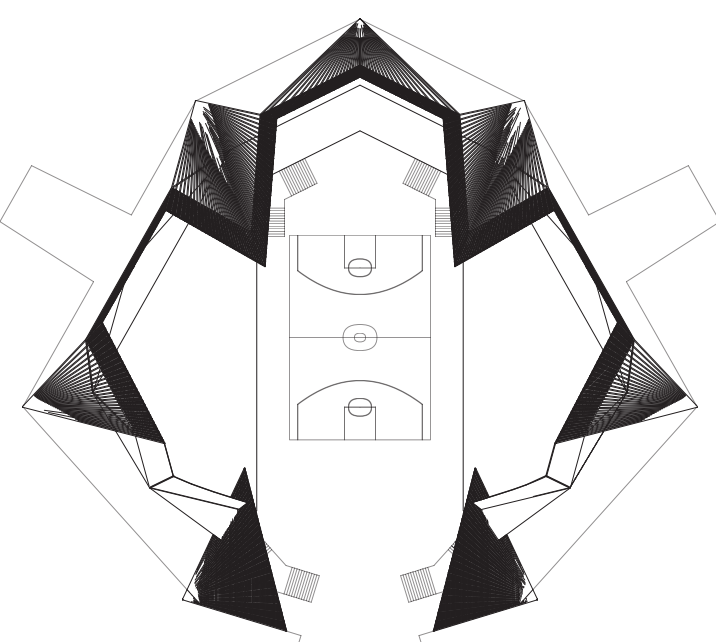




\section{Concept 5}

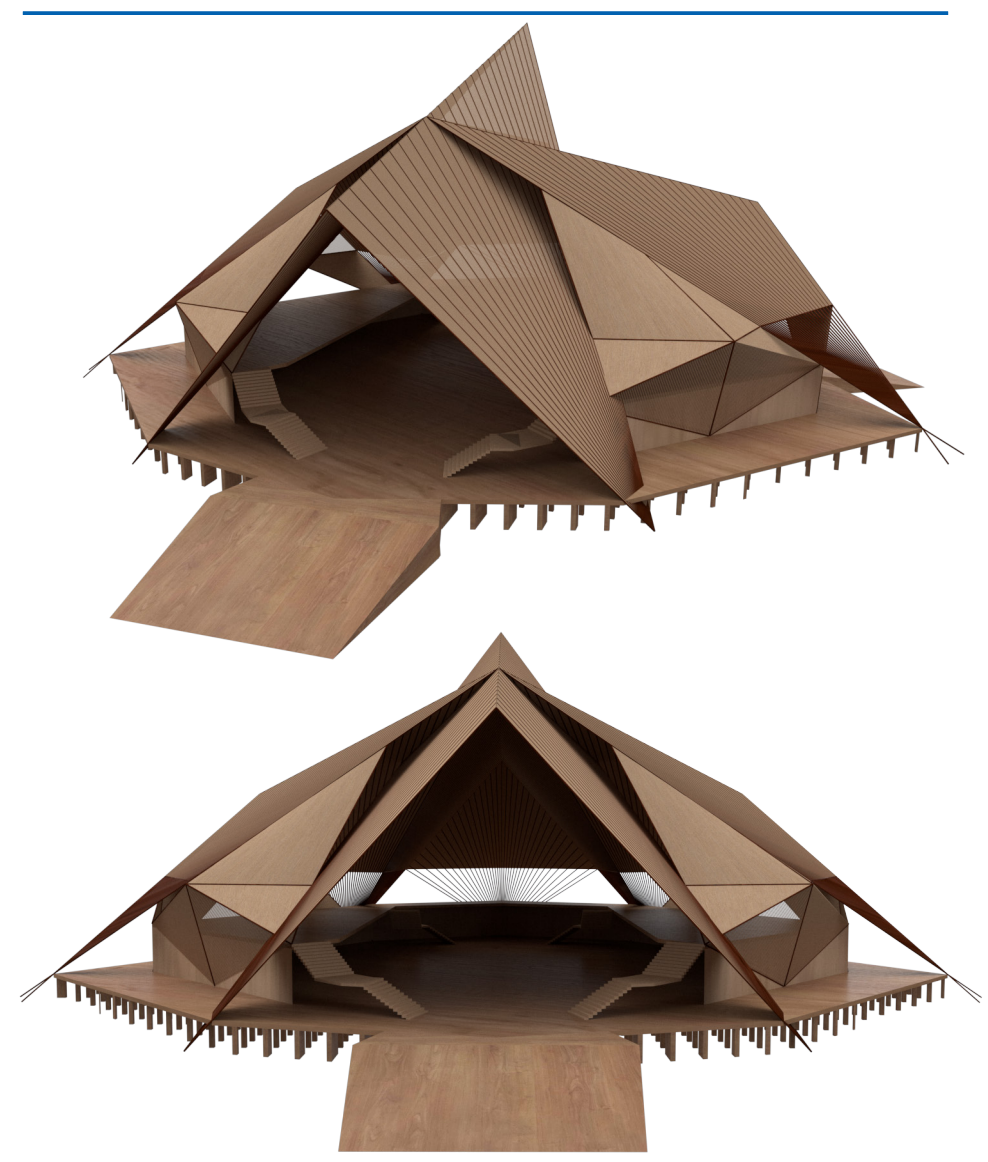

Fig 8.10.Concept 5 - 3D visualisation

Direction: The idea driving the form of this concept was the traditional Betawi architectural feature of the 'umbrella' like roof. So this design consists of an open air roof structure which has variation in the panels to allow for ventilation. The roof structure is completely separate from the floor and the internal spaces.

Positive:

- Roof clearly signifies the main entrance.

- Roof has a high pitch for rainwater to runoff easily.

- Roof has openings to allow for natural ventilation.

- Provides a large open area for communal gatherings.

Negative:

- Interior floor to roof height is unnecessarily high.

- Basic entrance ramp, does not fit with the overall aesthetic of the rest of the building.

- Internal rooms have unordinary shapes which would make it difficult to organise programme. 

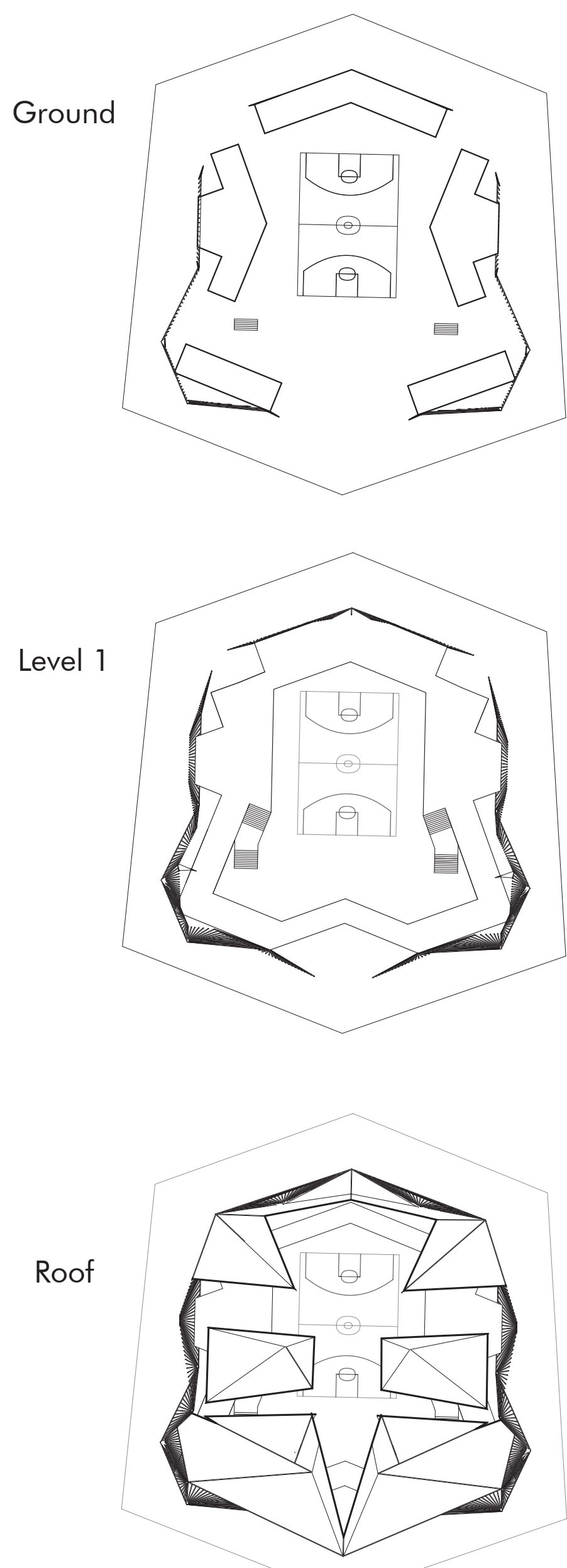


\section{Concept 6}
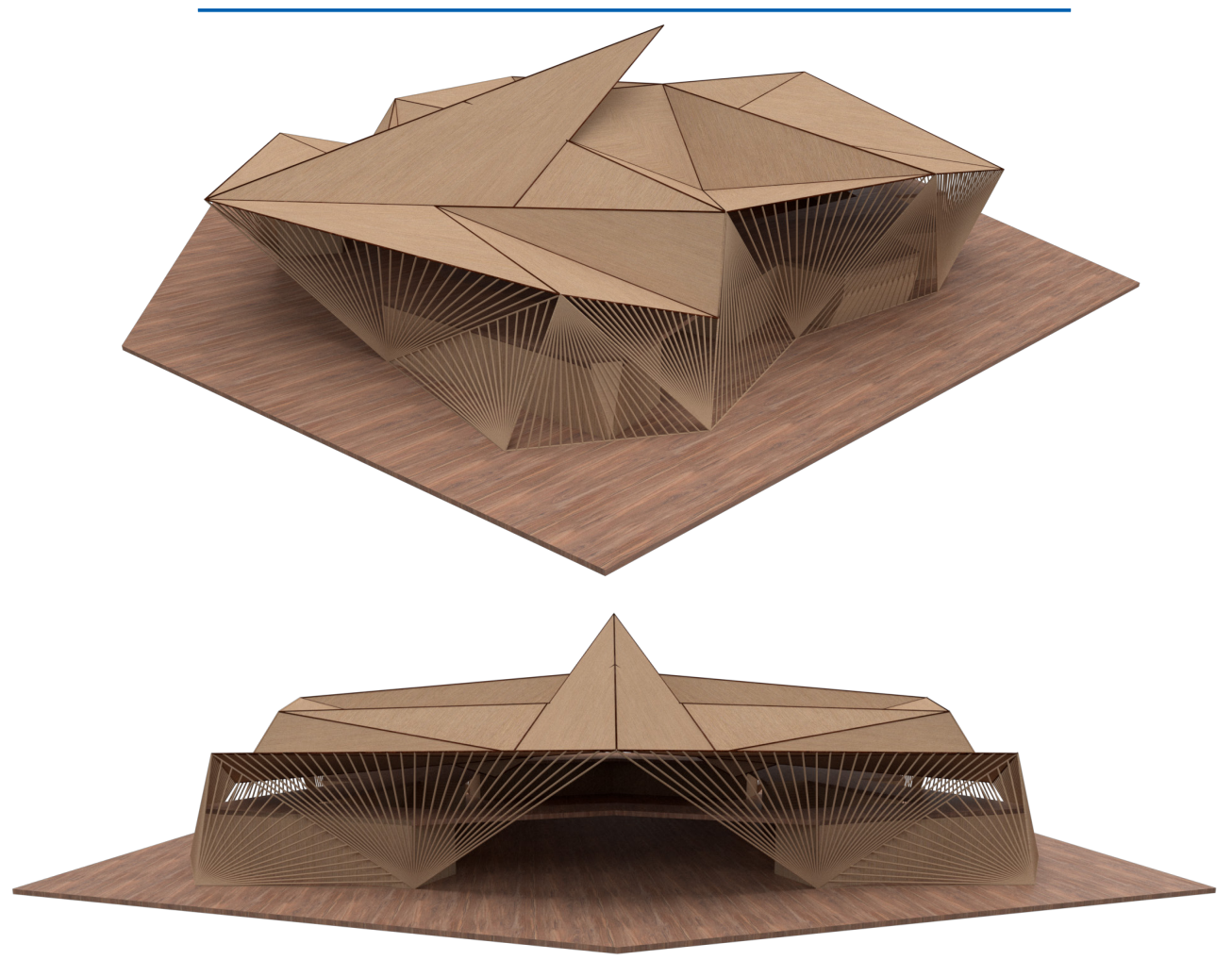

Fig 8.12. Concept 6 - 3D visualisation

Direction: The roof form is intended to have the same architectural language as the walls. The walls are where all of the natural light is let in, as well as the natural ventilation. The roof form is designed to keep the rain out over the central court space and acknowledge the main entrance location.

\section{Positive:}

- Roof form is an appropriate height for a communal multi-use space.

- The main entrance can be clearly identified.

- The interior spaces are all appropriate shapes.

- Concourse level provides an open raised area for observation.

\section{Negative:}

- Having the walls completely made of louvres means there is no control of the amount of light and noise that is let in.

- Louvre walls do not provide much protection from the weather.

- Wall angles create inaccessible areas.

- Roof angles mean water will pool and be drained in the centre of the building rather than the sides.

I have selected this concept to continue through to the development stage because it has the most potential to meet the design criteria successfully and includes all most of the successful features of all the other concepts. 


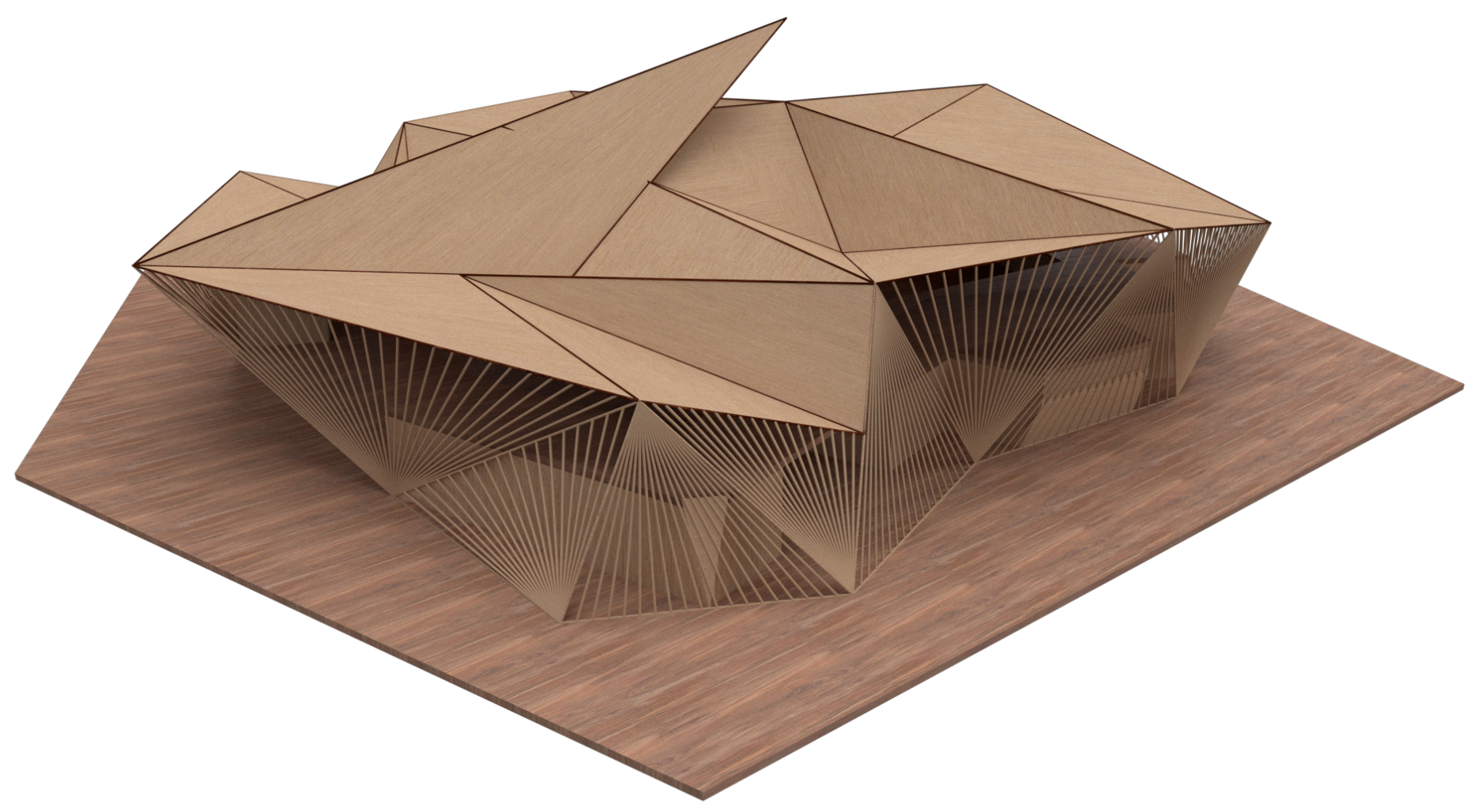

Fig 9.1. Concept 6 
9.0 Developed Design 
$\oplus$
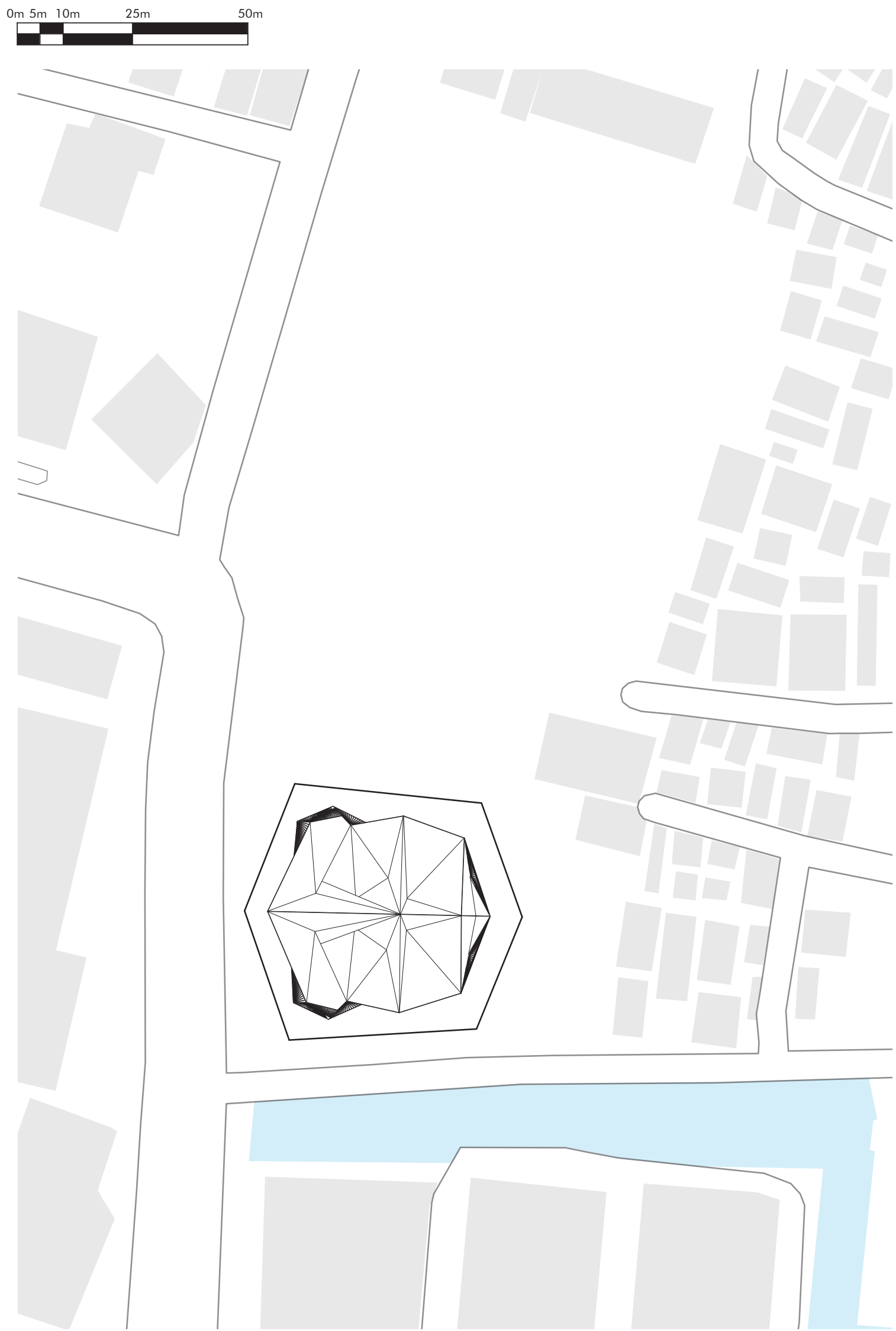

Fig 9.2. Concept 6 in site context 


\section{Jakarta Pevailing Wind}

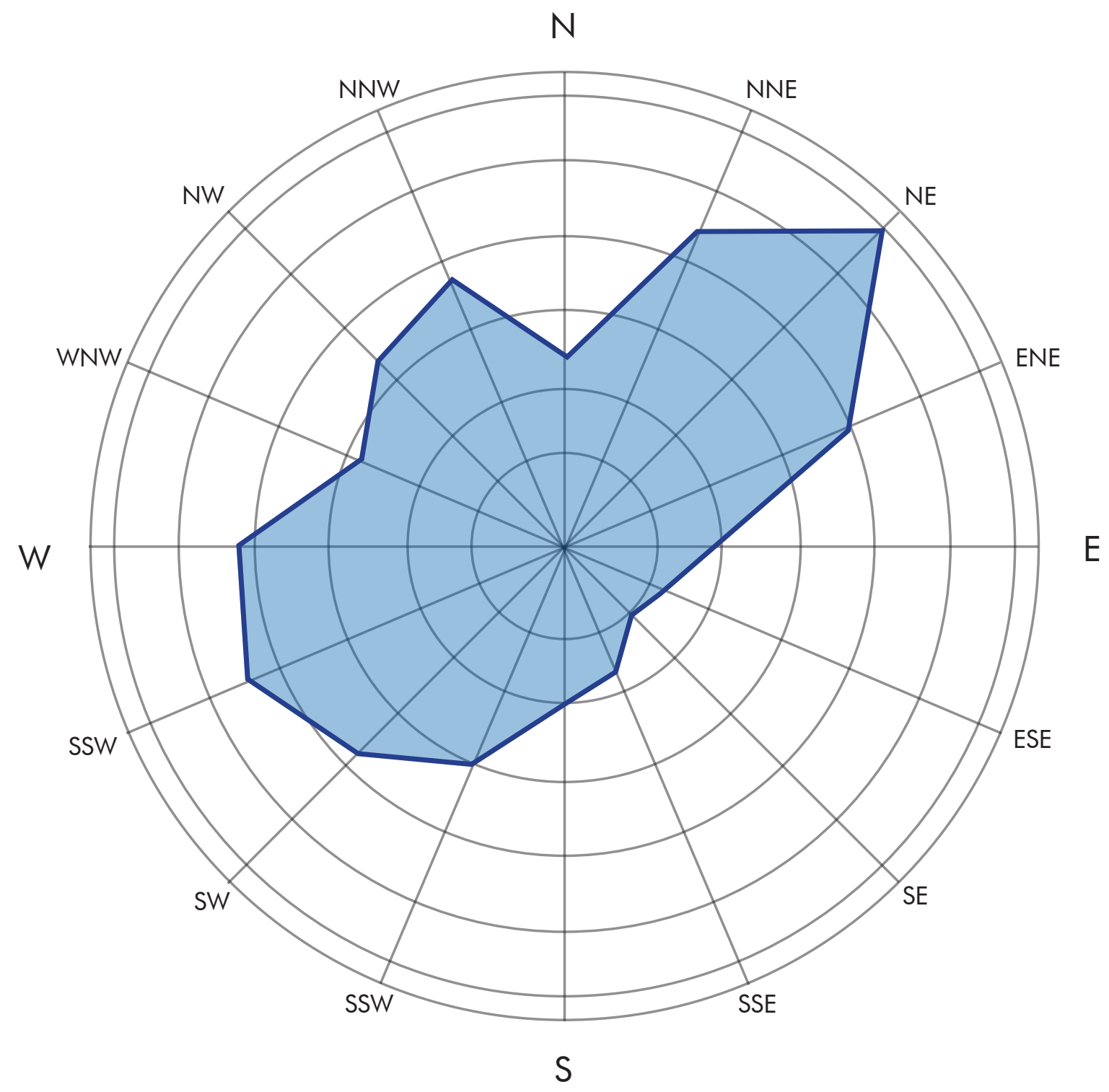

Fig 9.3. Jakarta Wind Map

Data for this graphic sourced from (Windfinder, 2019) 

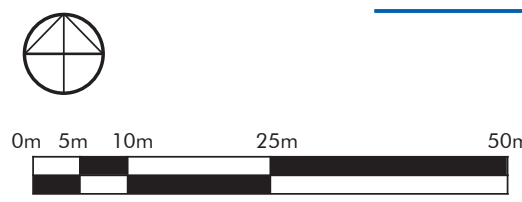

Ground level
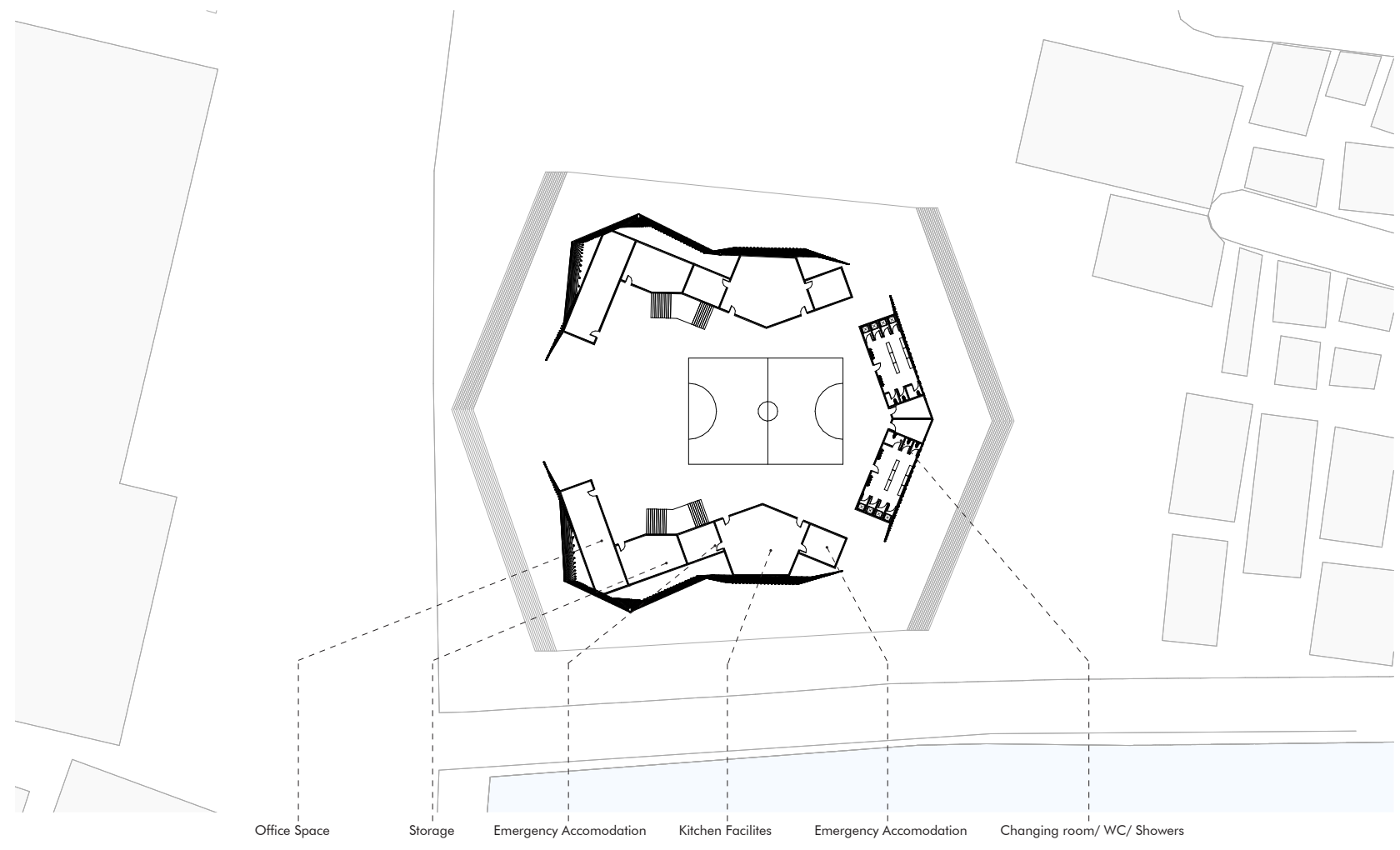

Level 1

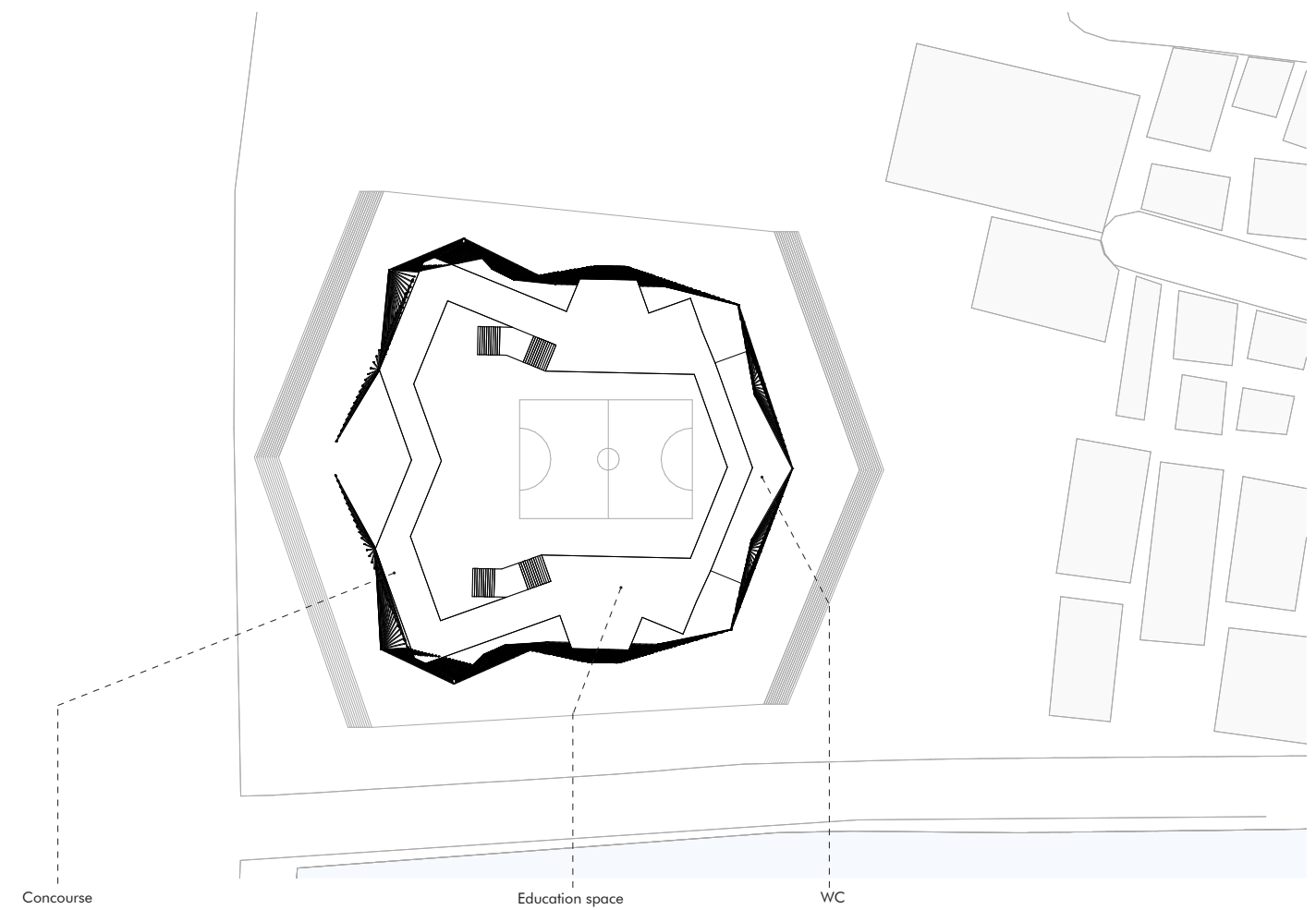

Fig 9.4. Development - spatial planning 


\section{Initial External Form Devlopment}
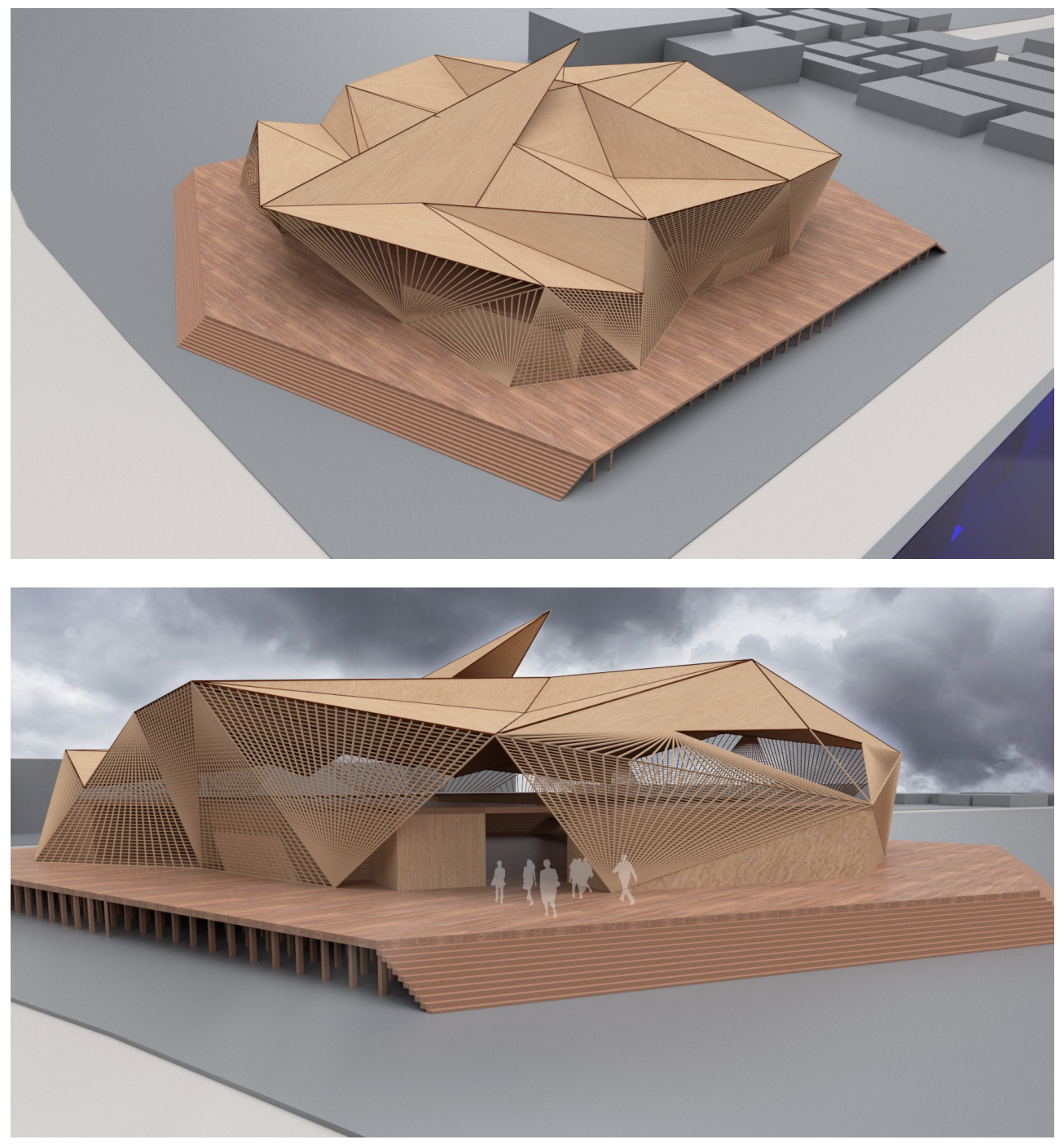

Fig 9.5. Development - spatial planning

Investigating the selected concept (concept 6), positioning it on site the immediate risk is for flooding, so the first significant change made is to raise the building up on piles.

The openings in the plan allow for the wind to enter the building helping with natural ventilation.

Looking at the building in plan, it is clear the arrangement of the interior spaces results in some unusable areas, the interior needs to be better linked with the exterior façade form. 

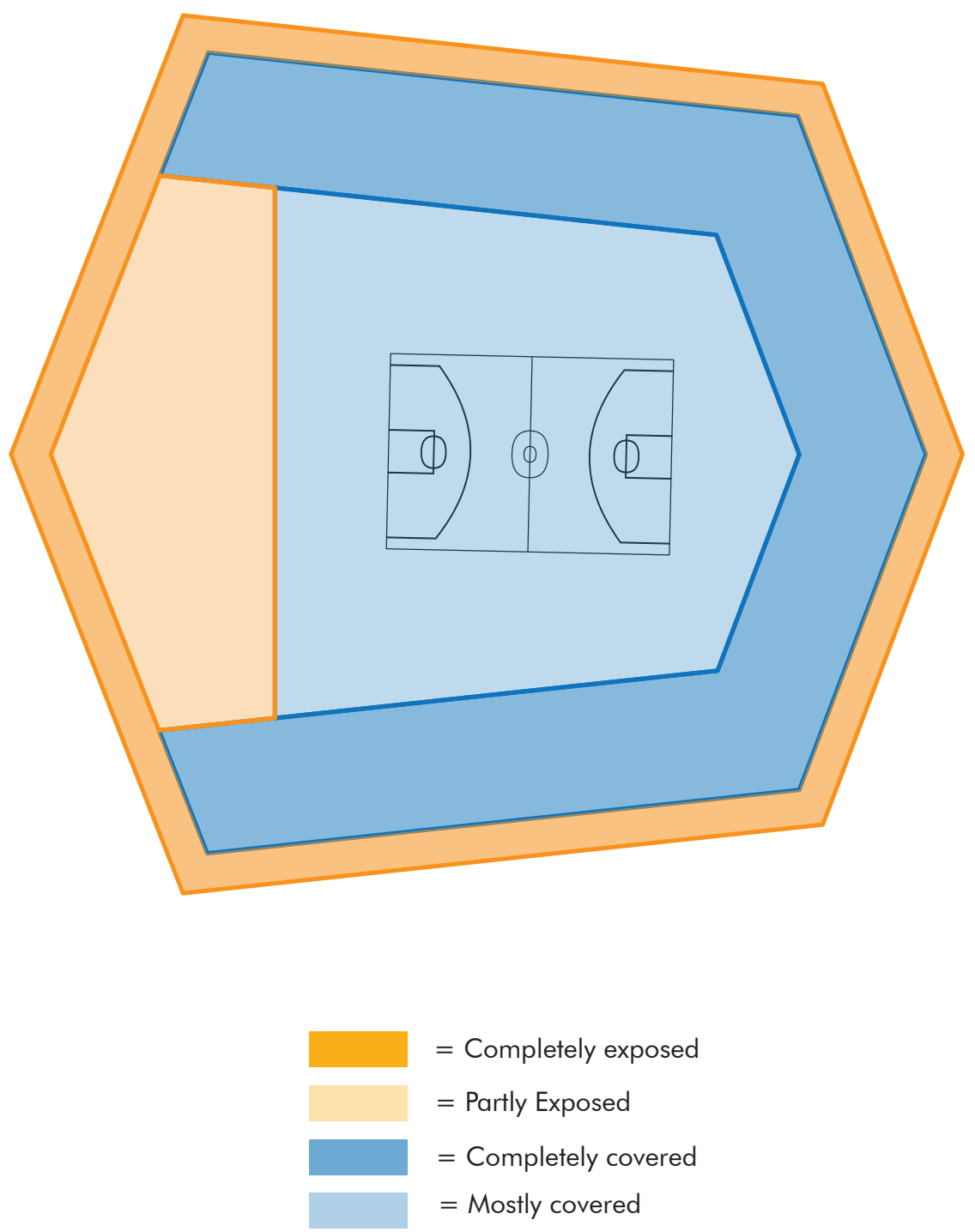


\section{Dry Zones}

Developing the interior layout of the design, the space is split up into four zones with varying levels of exposure to the wet weather conditions. Ranging from completely exposed to completely cover.

\section{Completely Exposed:}

The zone completely exposed goes around the full exterior shape of the building. Giving users of the building the opportunity to walk around the outside of the form uninterrupted.

Partially Exposed:

The partially exposed zone is the main entrance to the building. Due to the size of the large opening some covering protects from the rain but this area will still be wet if there are heavy rains. Not just from direct rain into the space but mostly from the feet of the users.

\section{Completely Covered:}

The completely covered zone is the main interior space around the outside of the open communal area. This zone is completely separated from the other spaces and is completely resistant sealed from the outside conditions. The construction will have to be different and separate from the open air external roof structure.

Mostly Covered:

The mostly covered zone is the open communal space. This space is at the centre of the building so is protected from direct rain, but at the right wind angle rain moisture could still get in, and water from the feet of the users. 


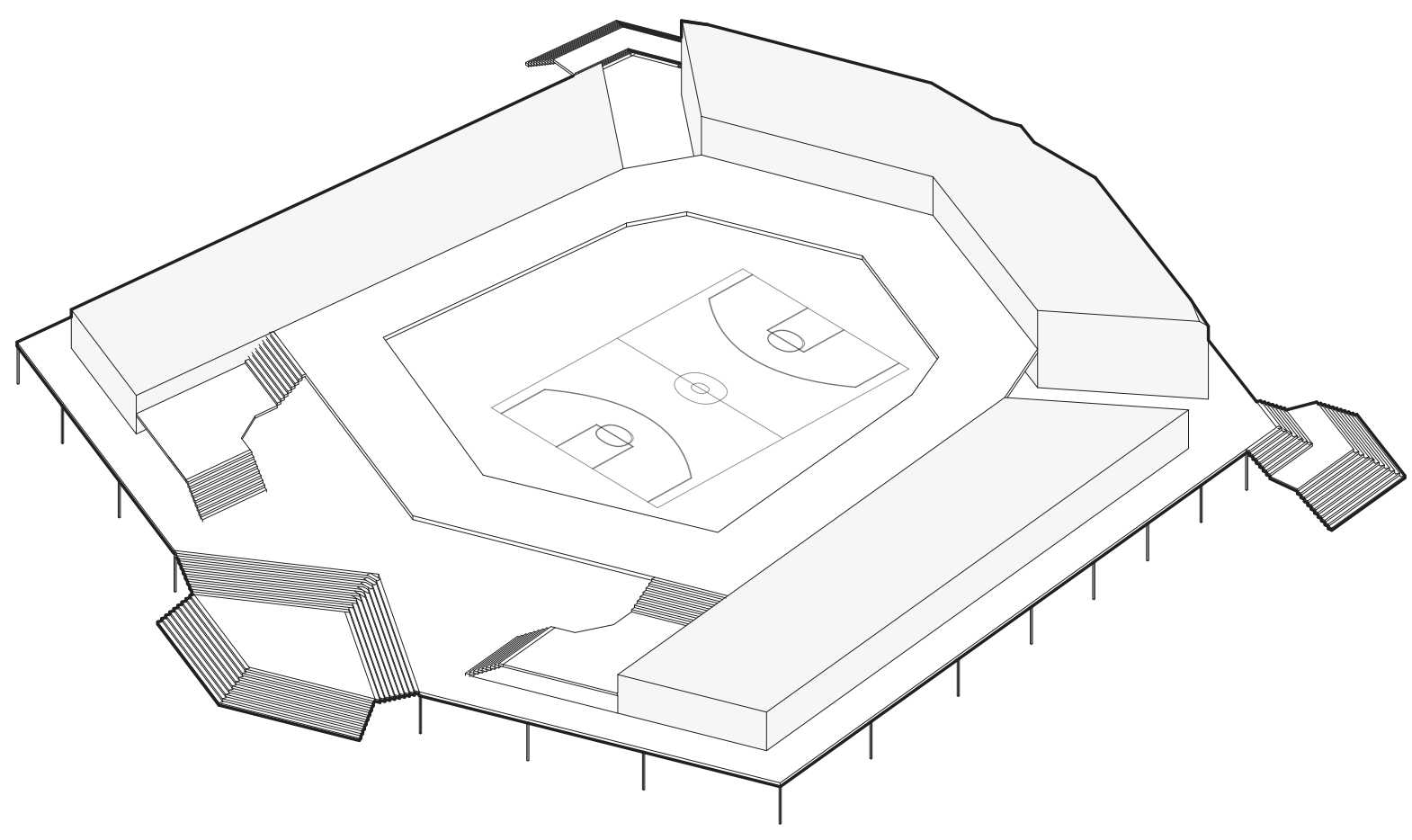

Fig 9.7. Development - Base

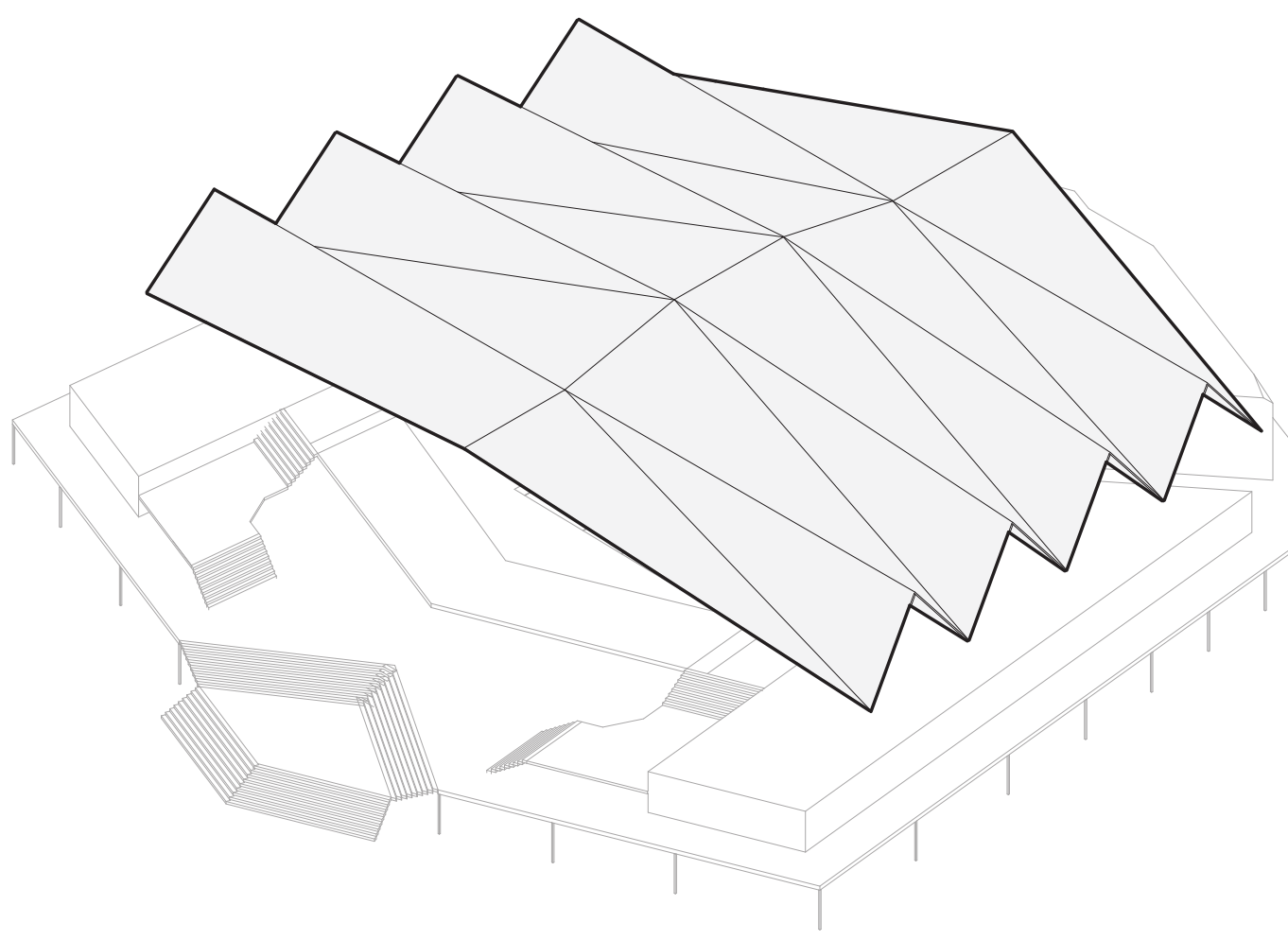

Fig 9.8. Development - Roof 


\section{Design Development - Base}

- Raised the base level by $2.7 \mathrm{~m}$ to allow some flood water resistance, provide some space for community interaction at the ground level.

- Internal spaces supporting the open communal space are of a more linear form to make dividing up the uses more efficient.

- Upper level concourse is simplified to give access to open upper level areas and still be a viewing point for the open communal space.

- Developing the design of the roof, the triangular panels are arranged in a way that better controls the rainwater runoff.

- The rainwater runoff is directed down to specific points which make it easier for collection.

- This arrangement of roof panels is also intended to have sections that are open and with higher angles to allow for natural ventilation. 


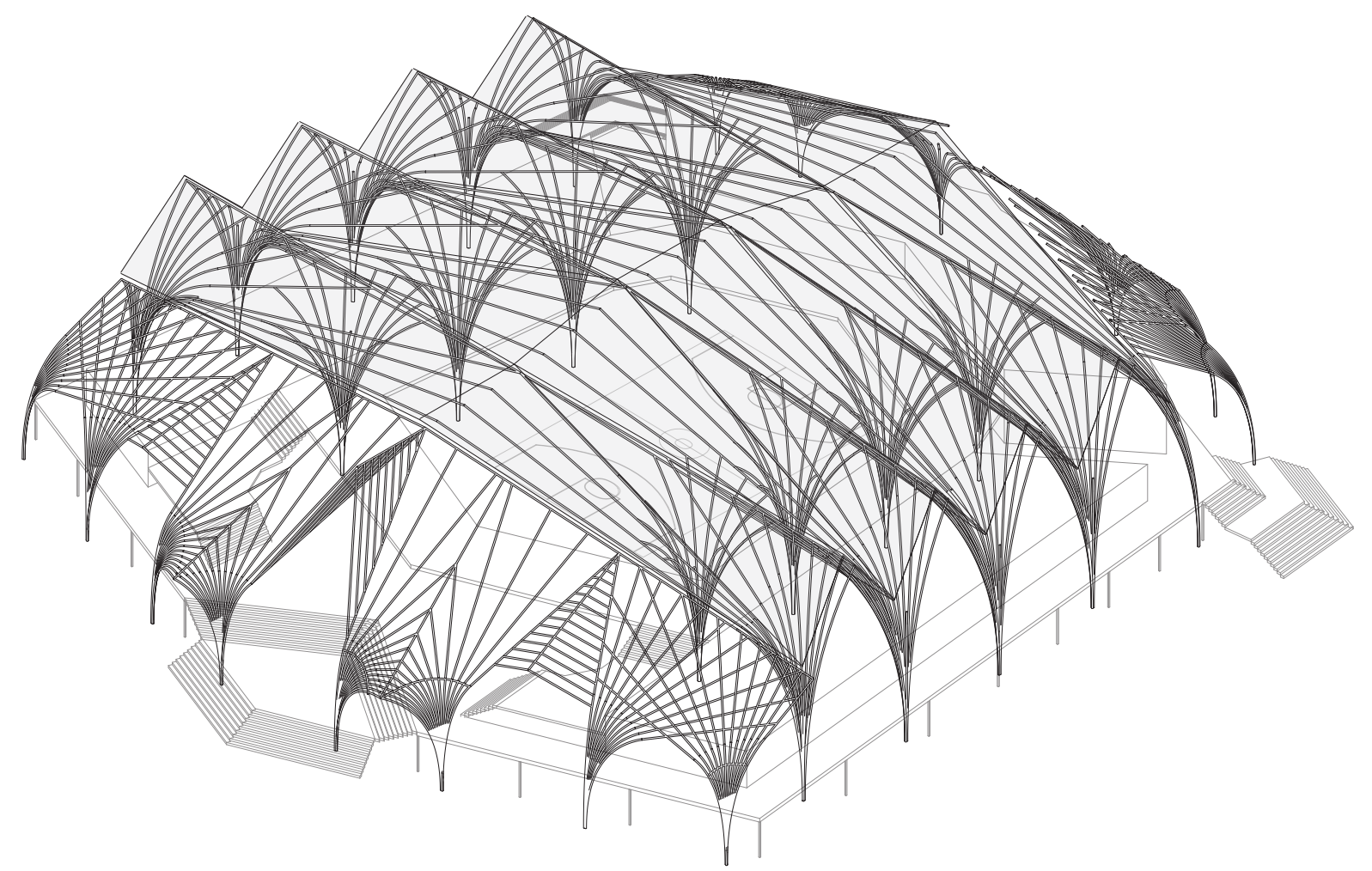

Fig 9.9. Development - Roof suooprt

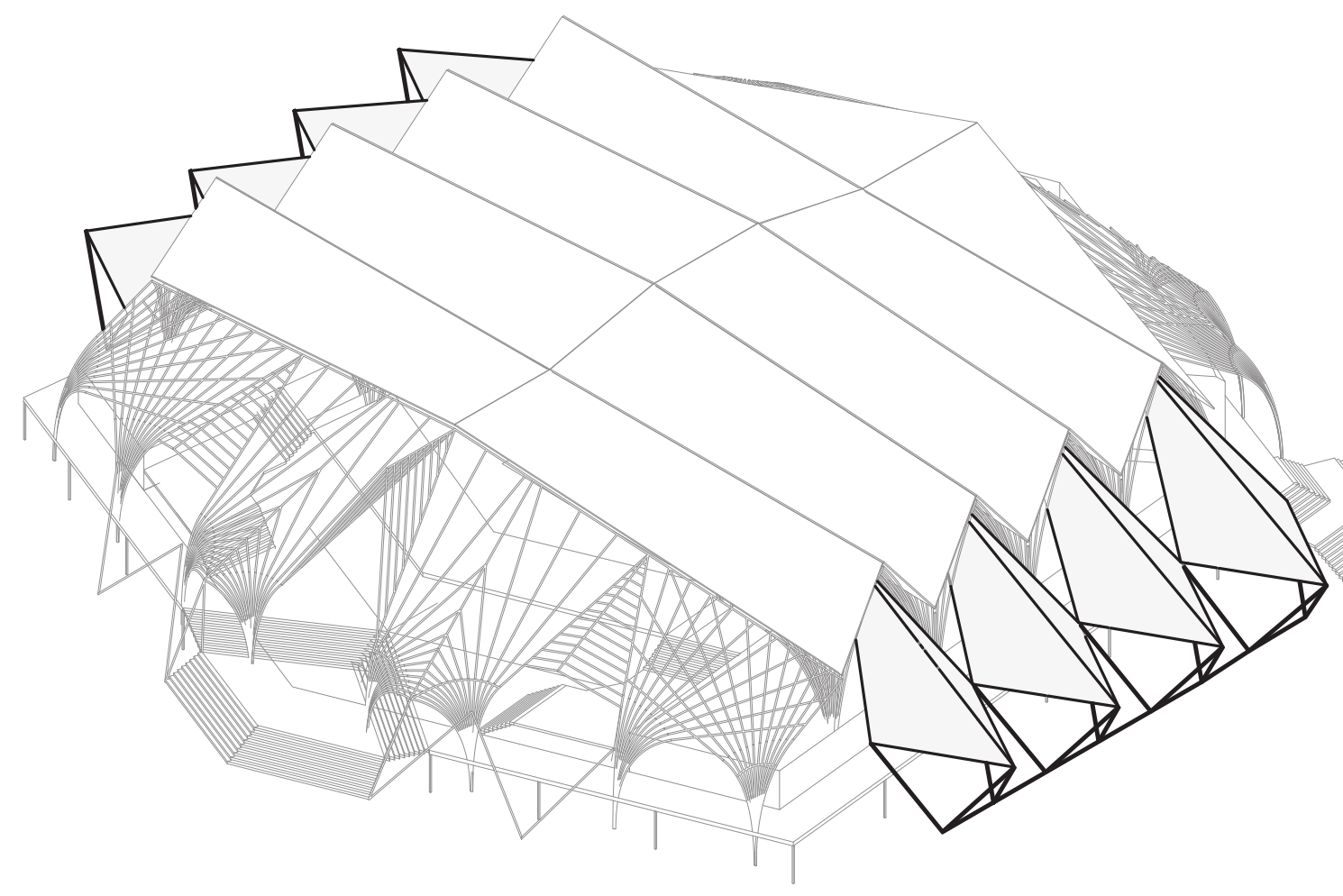

Fig 9.10. Development - Exterior walls 
- Bamboo structure to support the roof form using cold bending techniques to achieve the desired shape.

- Designed to account for pipes required for water collection.

- Acknowledges traditional Indonesian features and traditional construction techniques and materials by using bamboo.

Design Development - Exterior Walls

- Wall form still allows for large amounts of light to be let into the building. Also allowing for natural ventilation.

- The shape acknowledges the roof shape, and is supported from the ground outside of the building footprint to provide shade and more protection from the wind at ground level.

- Provides some protection to the exterior walkway the surrounds the level 1. 

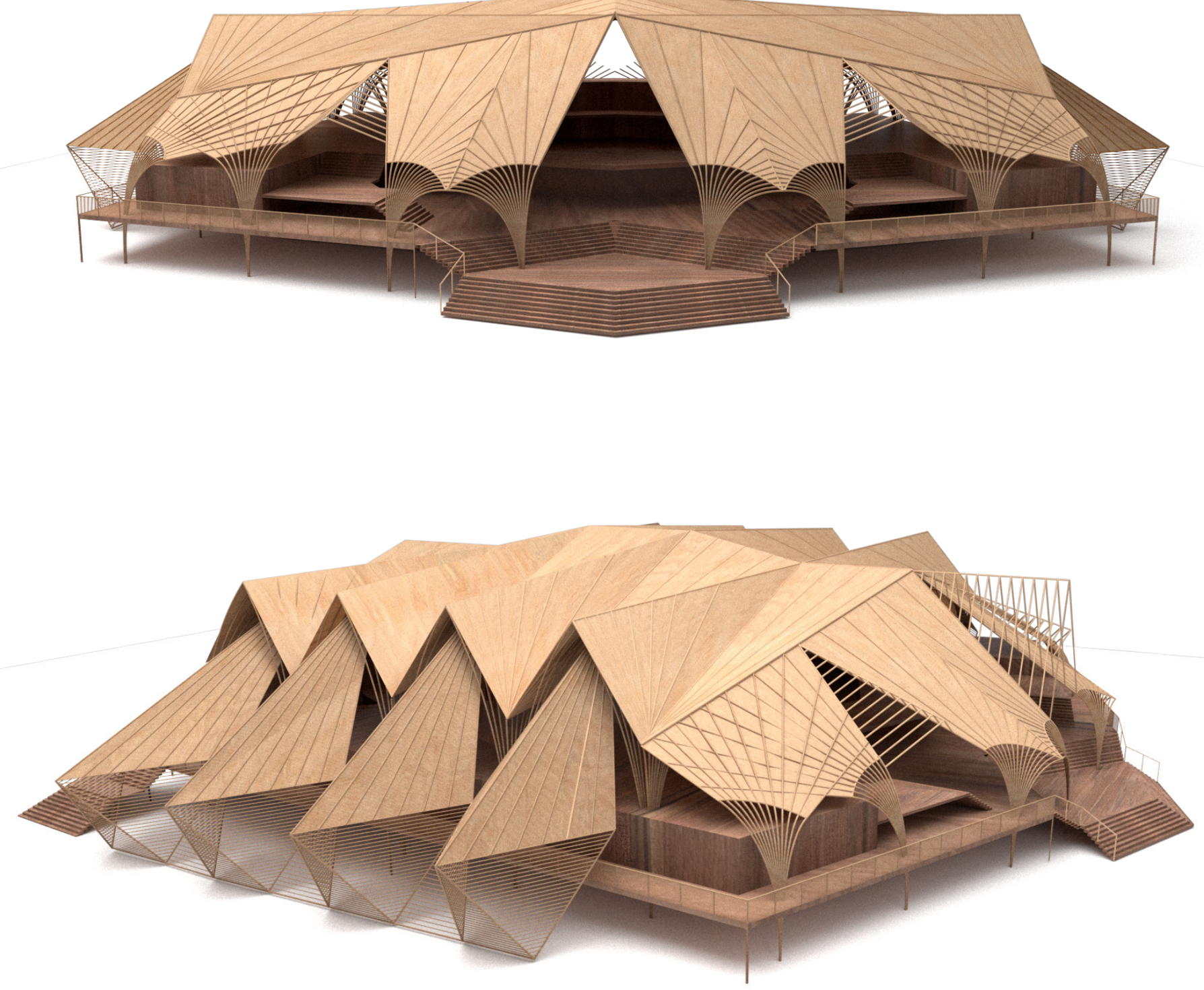

Fig 9.11. Development - 3D visualisation 


\section{Solar Power}

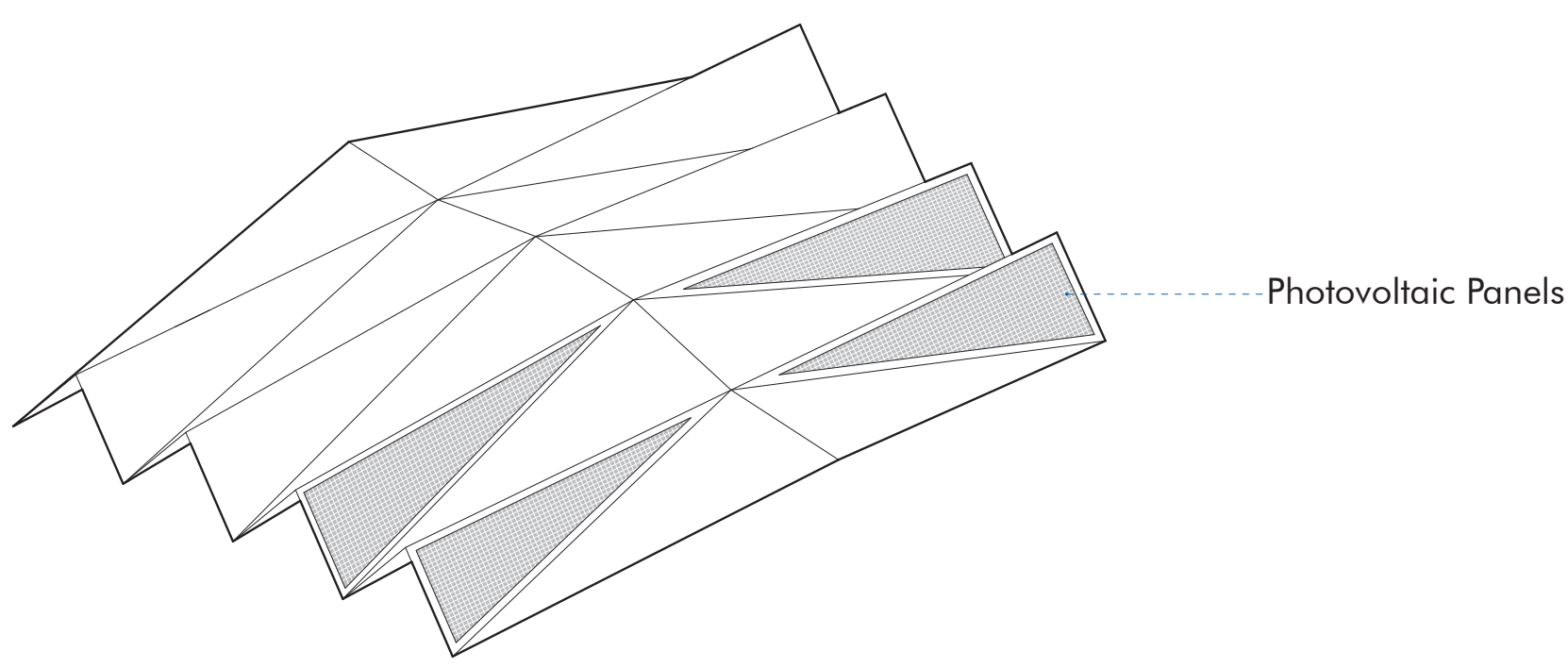

Fig 9.12.Development -Roof solar power

To maintain a reliable source of power, the design has photovoltaic panels on the roof which are able to support the buildings energy service needs. The panels are positioned on the roof in a way to minimise wind lift, being set below the roof ridges with some clearance from the edges (Dower, 2018).

The design incorporates $388 \mathrm{~m} 2$ of solar panels with a solar output of $140 \mathrm{kWh} /$ m2/year. Which means there will be 54,320 kWh of electricity produced on an annual basis. Based on a comparison to a standard European village town hall, this will be enough to independently maintain lighting and other miscellaneous electricity needs. The energy is collected in a large scale battery storage to store excess power generated (OLA Consulting Engineers, 2019). 

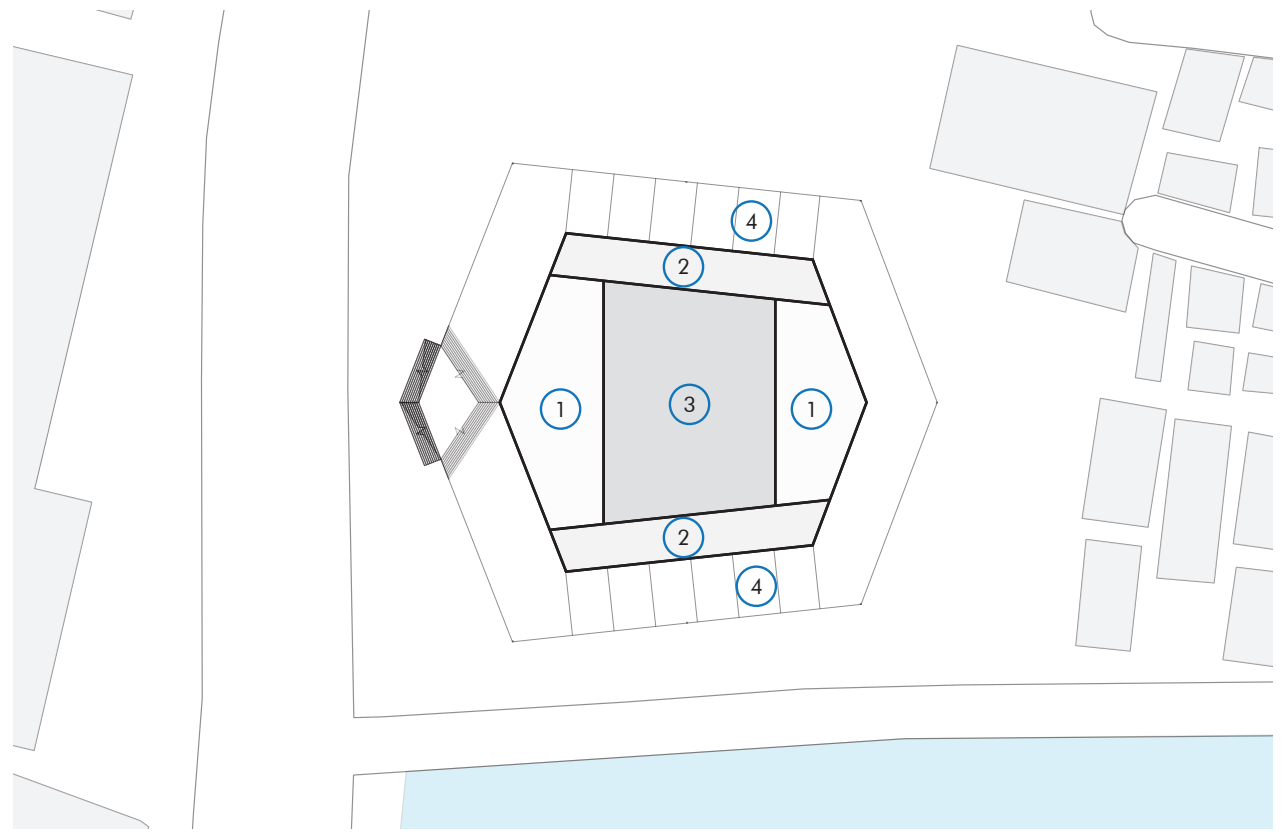

Level 1

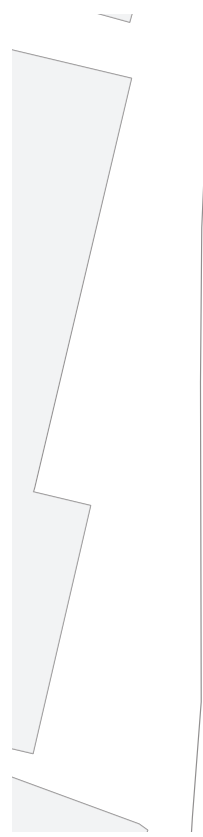

Level 2

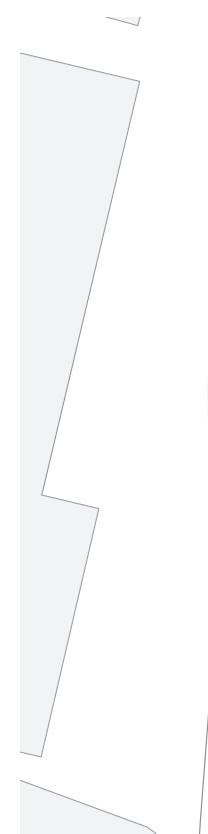

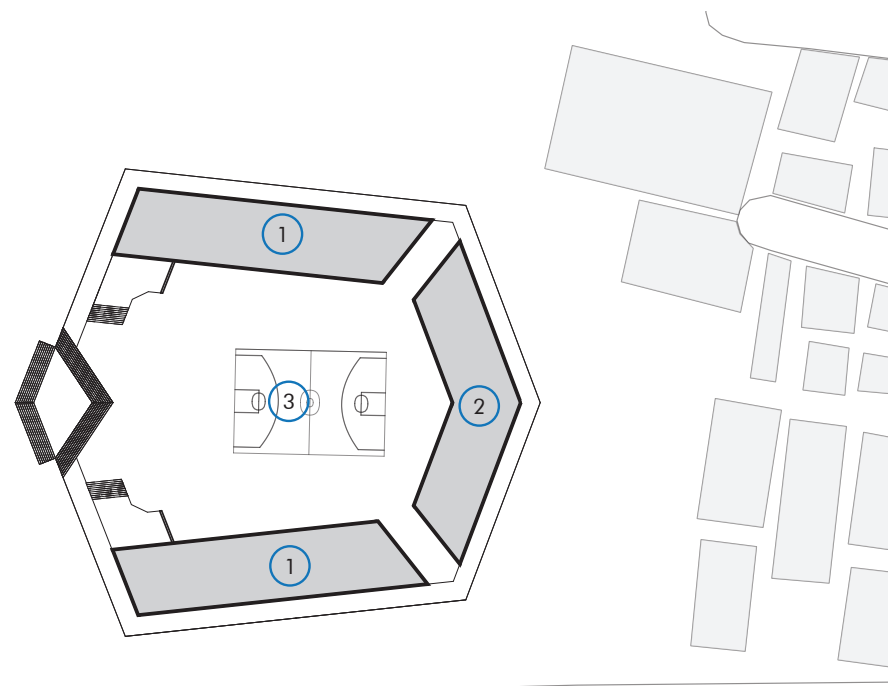

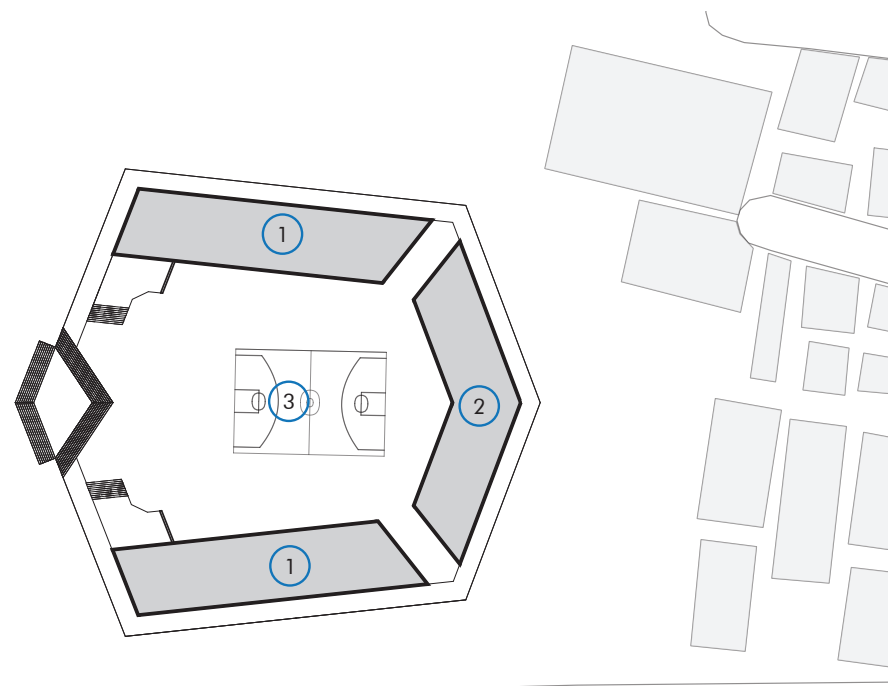
(1) Classroom
(2) Communal Kitchen
(3) Open Multi-use community space
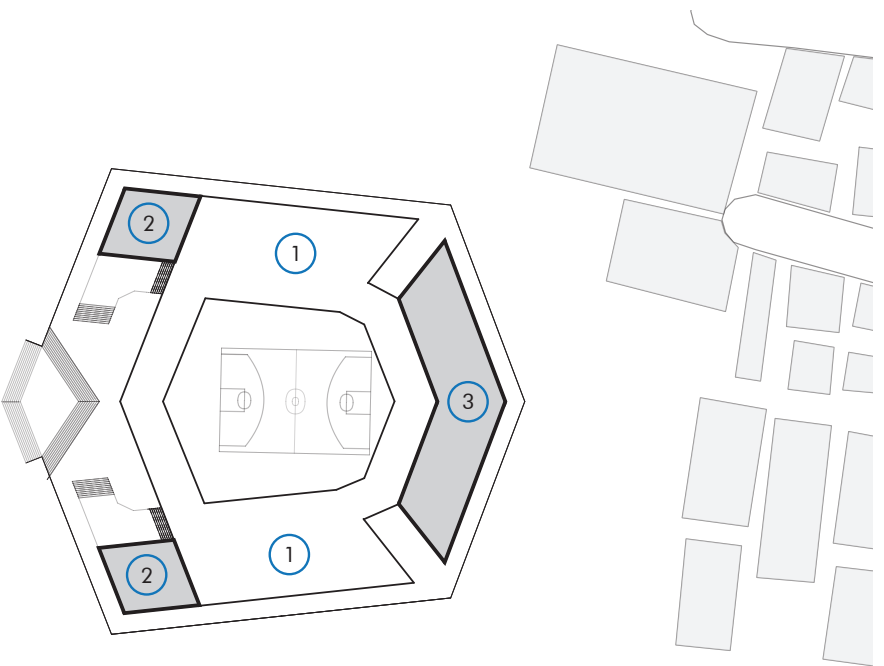

(1) Open teaching space

(2) WC

(3) Emergency Accomodation 
Ground Level

- Public sanitary services to be accessed from the front and back of the building, providing toilets, showers, and clean running water to residents of the area.

- Support space is area that can be used for storage supporting the space for business.

- The business space is designated area with provided foundations can be altered depending on the user's needs.

- A relatively large space will be needed for building services to account for the water filtration system, and the power storage battery to store the solar energy.

$\underline{\text { Level } 1}$

- Main open communal space takes up most of the level, space is intended to have a wide range of use from sports games to community gatherings.

- Enclosed classrooms which have the opportunity to spill out into the open communal space if needed.

- Communal kitchen also has the option to extend out into the open communal space, directly linked to all the entrances into the space.

Level 2

- Open teaching space, an alternative to the enclosed classroom on level 1, can be used as an area for more hands-on learning.

- Toilet facilities to support second level.

- Emergency accommodation in the case of residents unexpectedly becoming without a home, provide facilities to live for a short period of time while other accommodation is organised. 


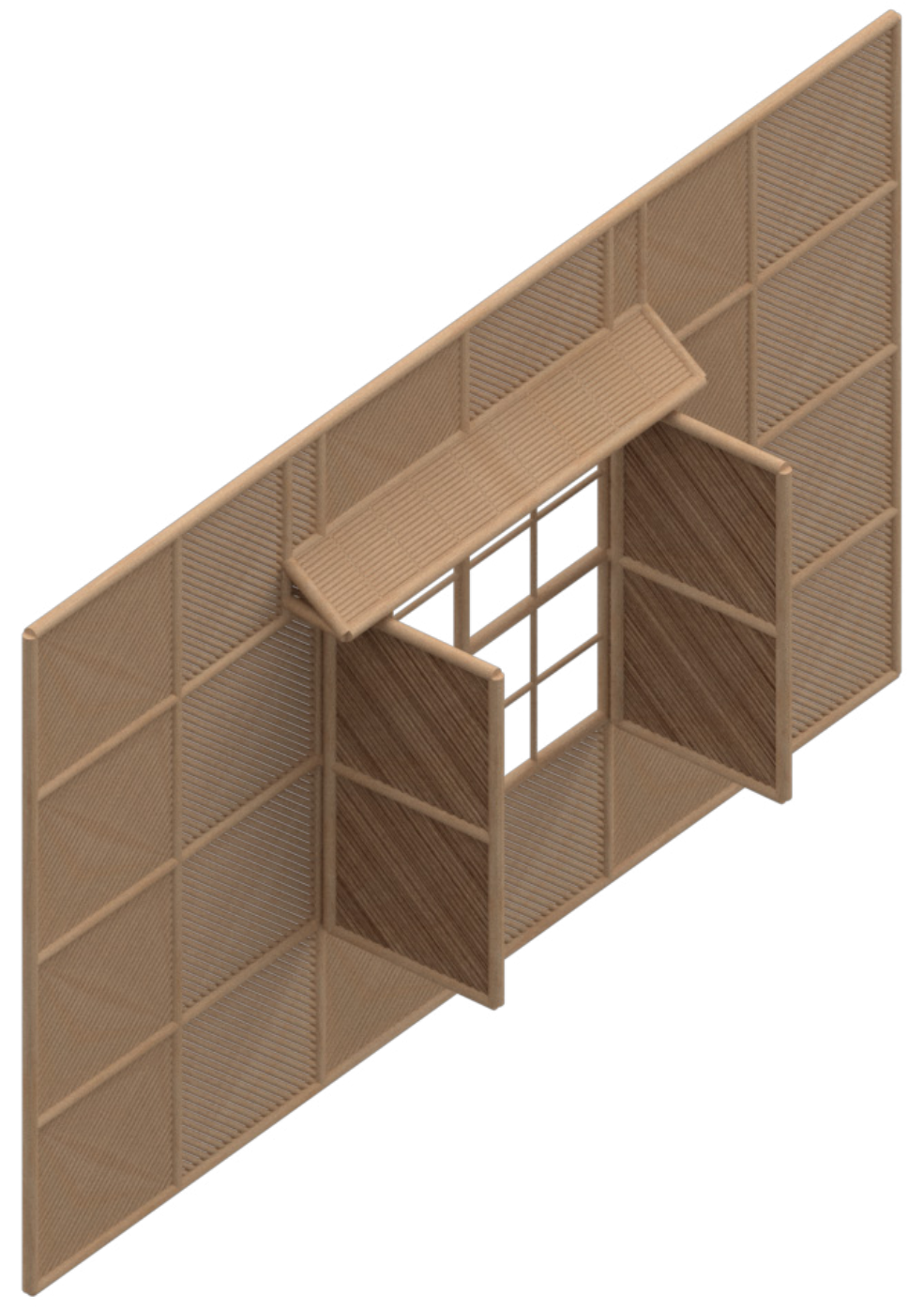

Fig 9.14. Development - Bamboo wall opening 


\section{Design Development - Openings}

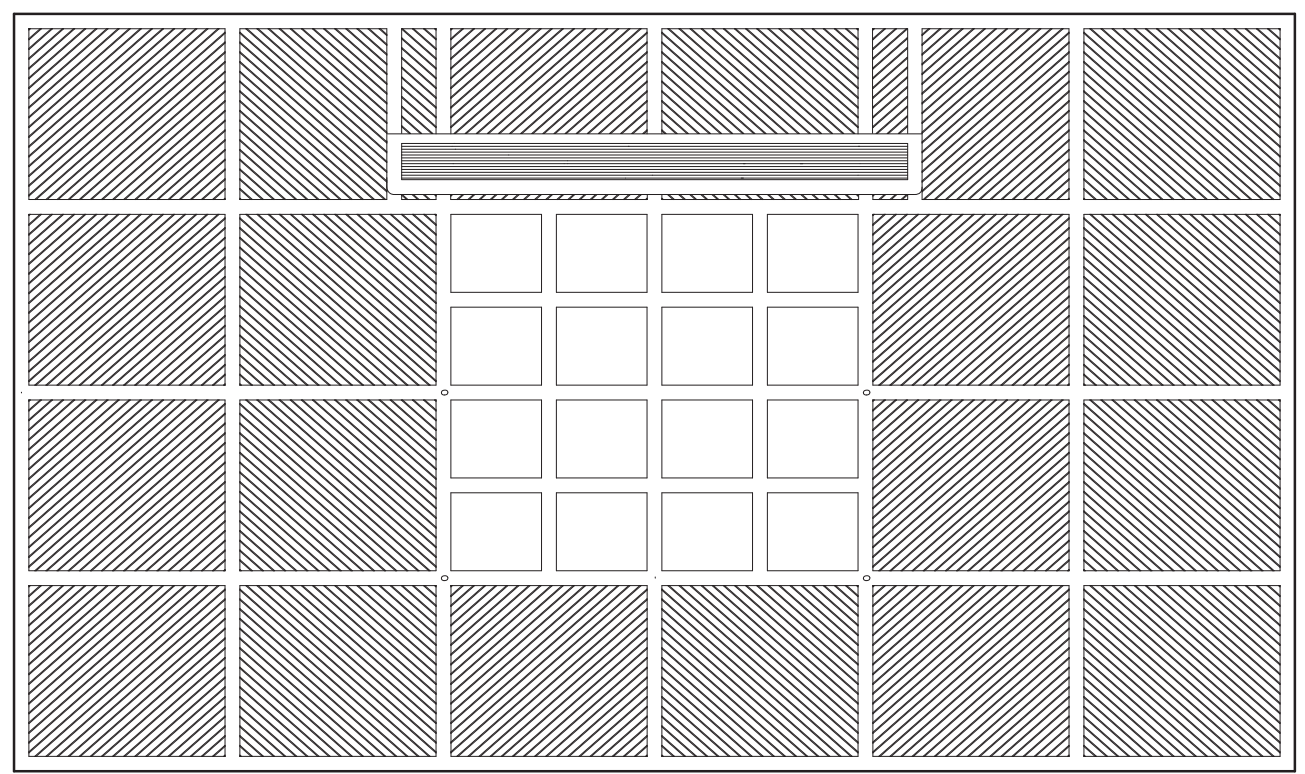

Fig 9.15. Development - Bamboo wall opening diagram

Even though the main interior spaces need to be water tight, there still needs to be the opportunity for natural light to be let into the space through openings. For a wall constructed of bamboo there are simple areas of the wall panelling that are hinged, allowing them to be pinned open to let light in. The panels which can be opened are designed to be part of the wall when closed, making it hard to identify where the opening is from the outside. To stop water seeping in through the top of the opening there is a small eave, directing the small amount of rain that will be in contact with the interior wall away from the opening. 

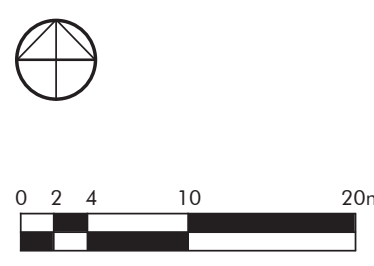

Ground Level

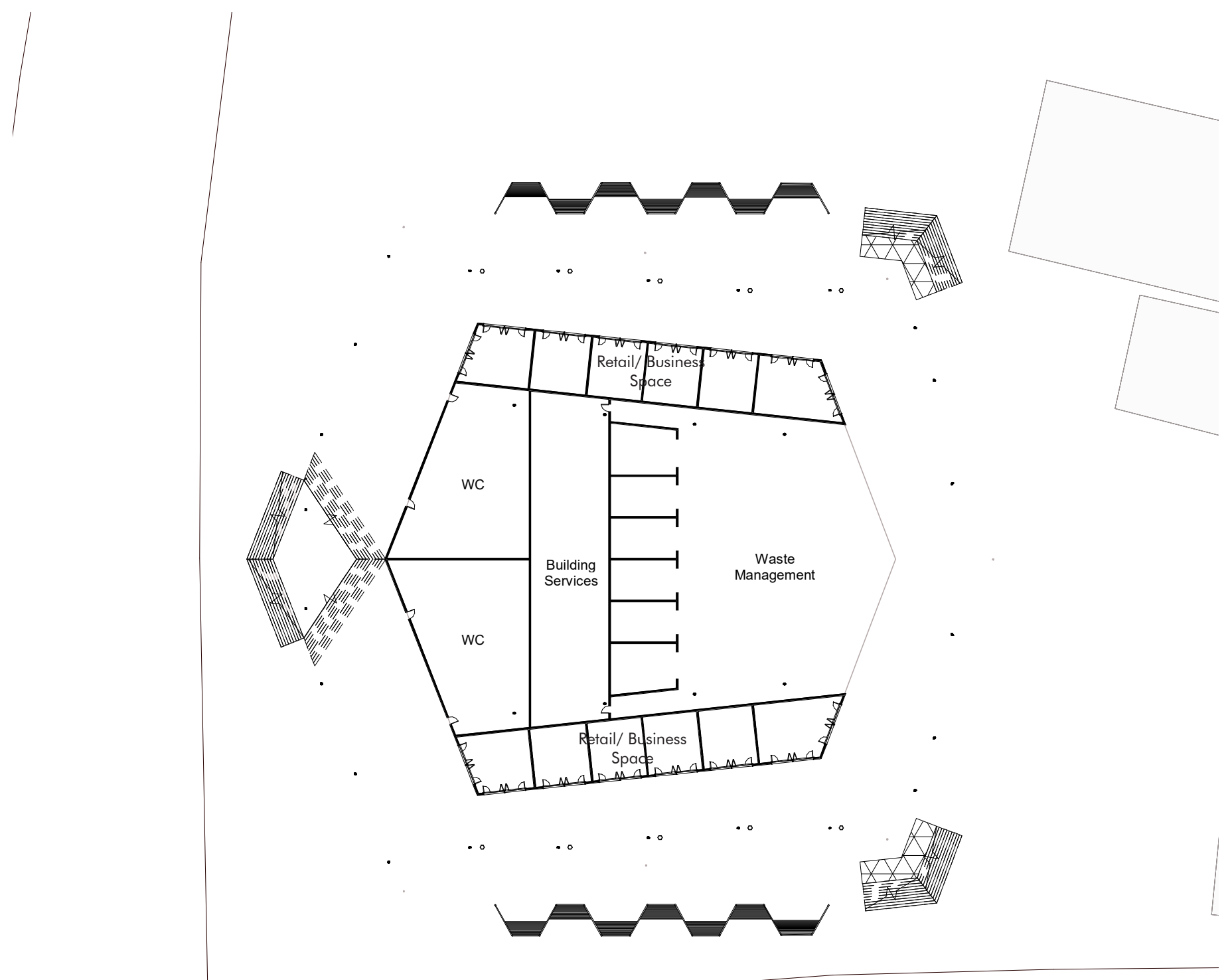

Fig 9.16. Development - Ground Level 
Design Features:

- Ground floor includes a waste management facility to encourage recycling in the community. It will just be for dry recyclable waste. It would not be suitable to process organic waste due to the poor hygiene associated with it, and the large numbers of people expected to use the building.

- Building services compact into a smaller space, featuring water treatment and solar power storage.

- Covered walkway on the sides of the design, encouraging people to walk through the site. Past the business spaces.

Critical Analysis:

- The designation of space is successful. A large amount of space is needed for the waste management area to allow for vehicles and large numbers of people to be able to move in and out of the space easily. A reasonably large amount of space is available for the WC to accommodate not just users of the space, the members of the public too.

- The spaces designated for retail and business do not give much opportunity for variation in the way they are set up. There is not much freedom or the ability to personalise due to the confined enclosed space, the basic framework could be all that is necessary for the business owners. 
$\theta$

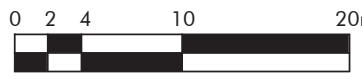

Level 1

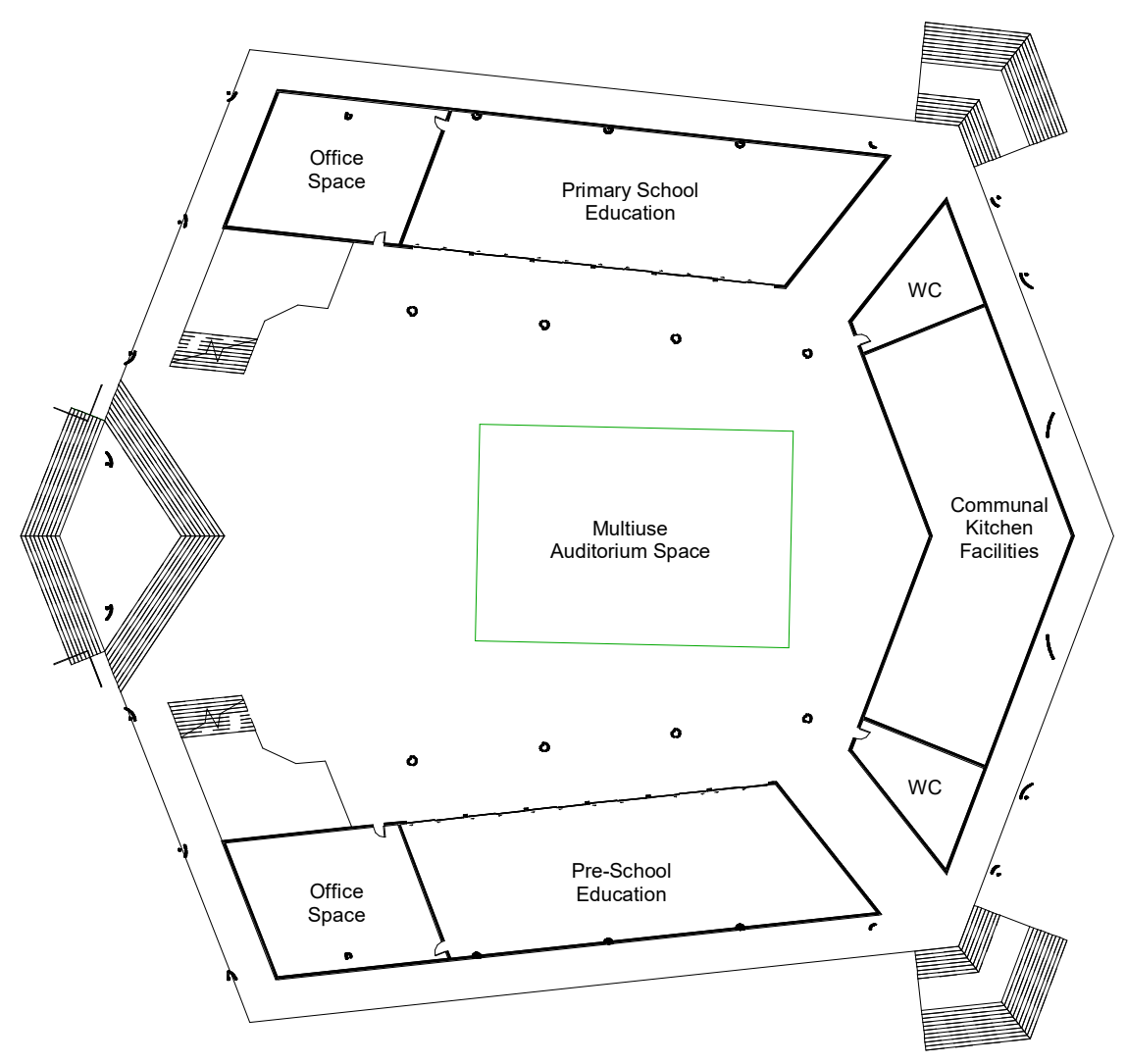

Fig 9.17. Development - Level 1 


\section{Spatial Planning}

Design features:

- Level 1 focuses around an open multi use auditorium space, uses can range from community gatherings to a sports court.

- Two educational spaces which can also utilise the open central area, being able to expand the classroom into the space for large meetings if necessary.

- Office spaces to support the educational spaces.

- Communal kitchen facilities included, can be utilised as part of the educational spaces to help provide the children with food.

Critical Analysis:

- The spatial arrangement has resulted in the two secondary entrances which are not very inviting for people to enter the space, as at the top of the entry stairs is narrow corridor.

- Having the spaces arranged around an open area gives all the areas more flexibility in the occupancy limit. Giving versatility depending on the necessary function required of the space

- There is no disability access to this level, there needs to be a ramp of some kind. 


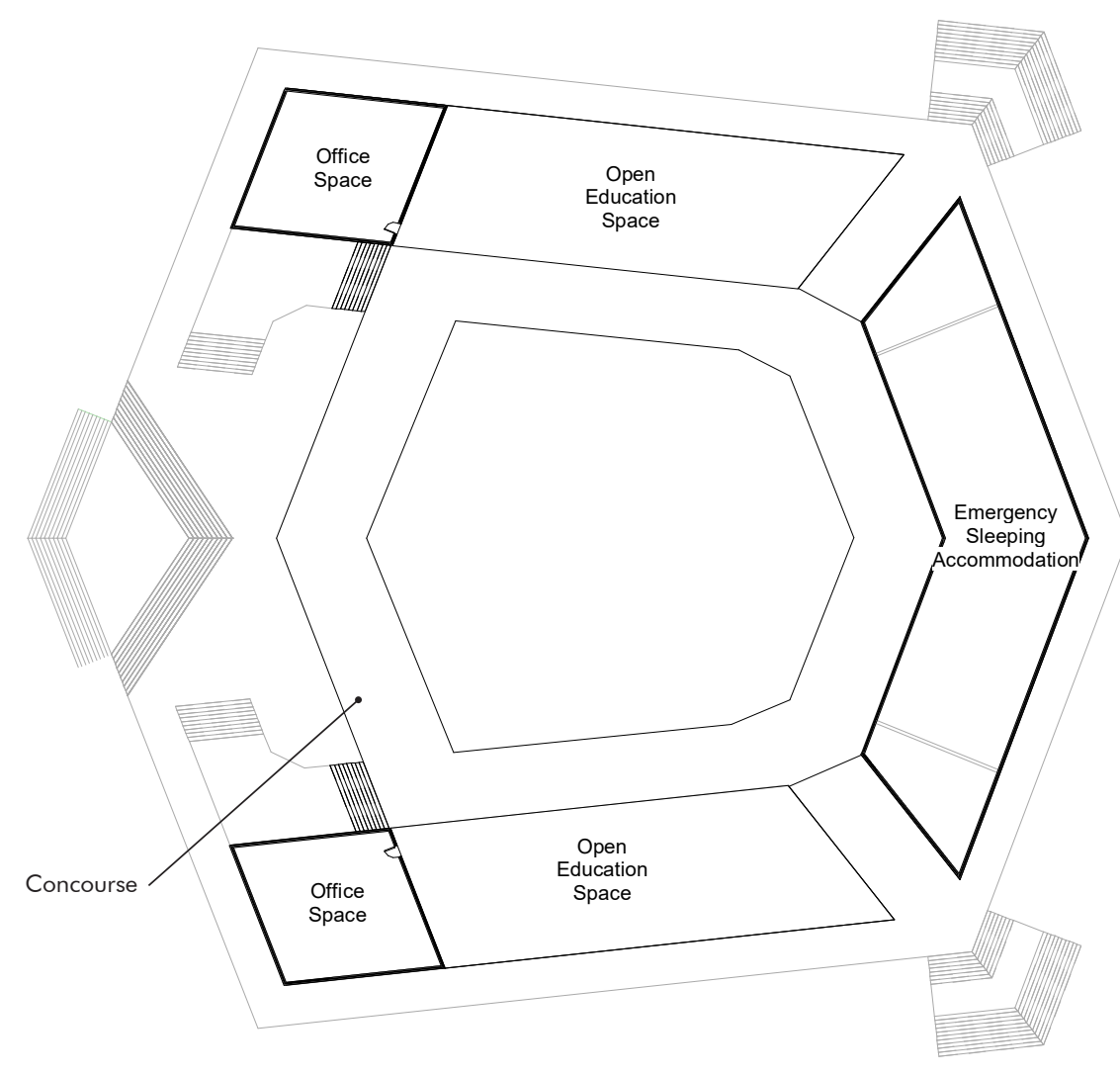

Fig 9.18. Development - Level 2 
Design features:

- Concourse provides circulation to level 2, and goes around the open meeting space providing an elevated view and observation point.

- The open education space is for more hands on teaching, such as teaching the bamboo construction techniques used in the building design so the community has the knowledge to help with maintenance, or use the techniques on their own houses.

- On this floor there is access to the emergency accommodation block, which is intended to help house new residents to the area, or those in need of temporary accommodation in the face of a natural disaster.

Critical Analysis:

- Although the concourse provides an elevated area for viewing and observing, there is no available places to sit and be out of the way of those using the concourse as circulation.

- There needs to be some WC facilities on this floor, could be part of the emergency accommodation block. 


\section{Design Development - Interior Form}
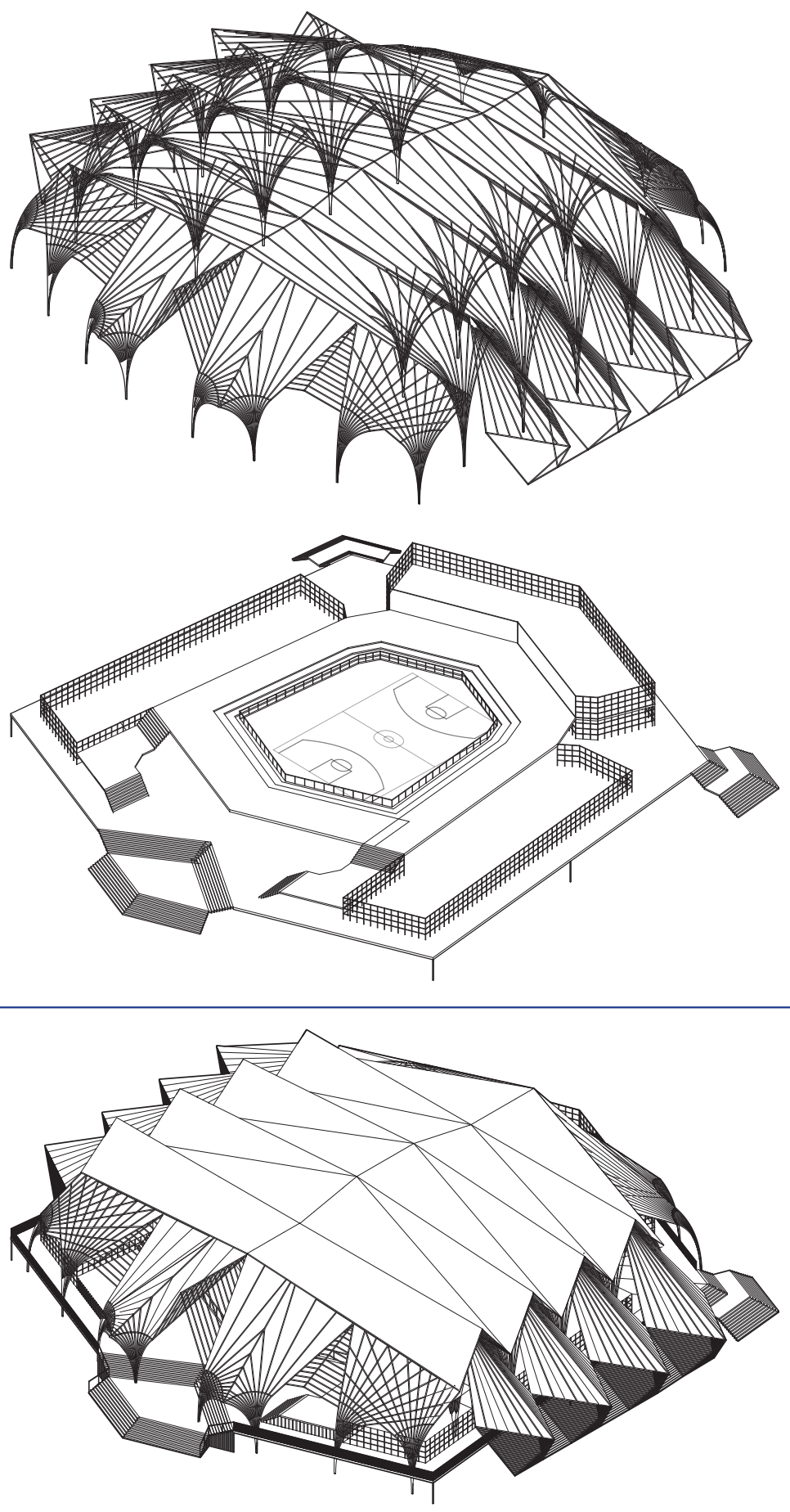

Fig 9.19. Development - Interior form

Design Changes:

- Interior arrangement opens up at the two secondary entrances

- Bleacher seating added to the concourse.

- Interior wall constructed with lightweight treated bamboo. 


\section{Design Development - Structure}

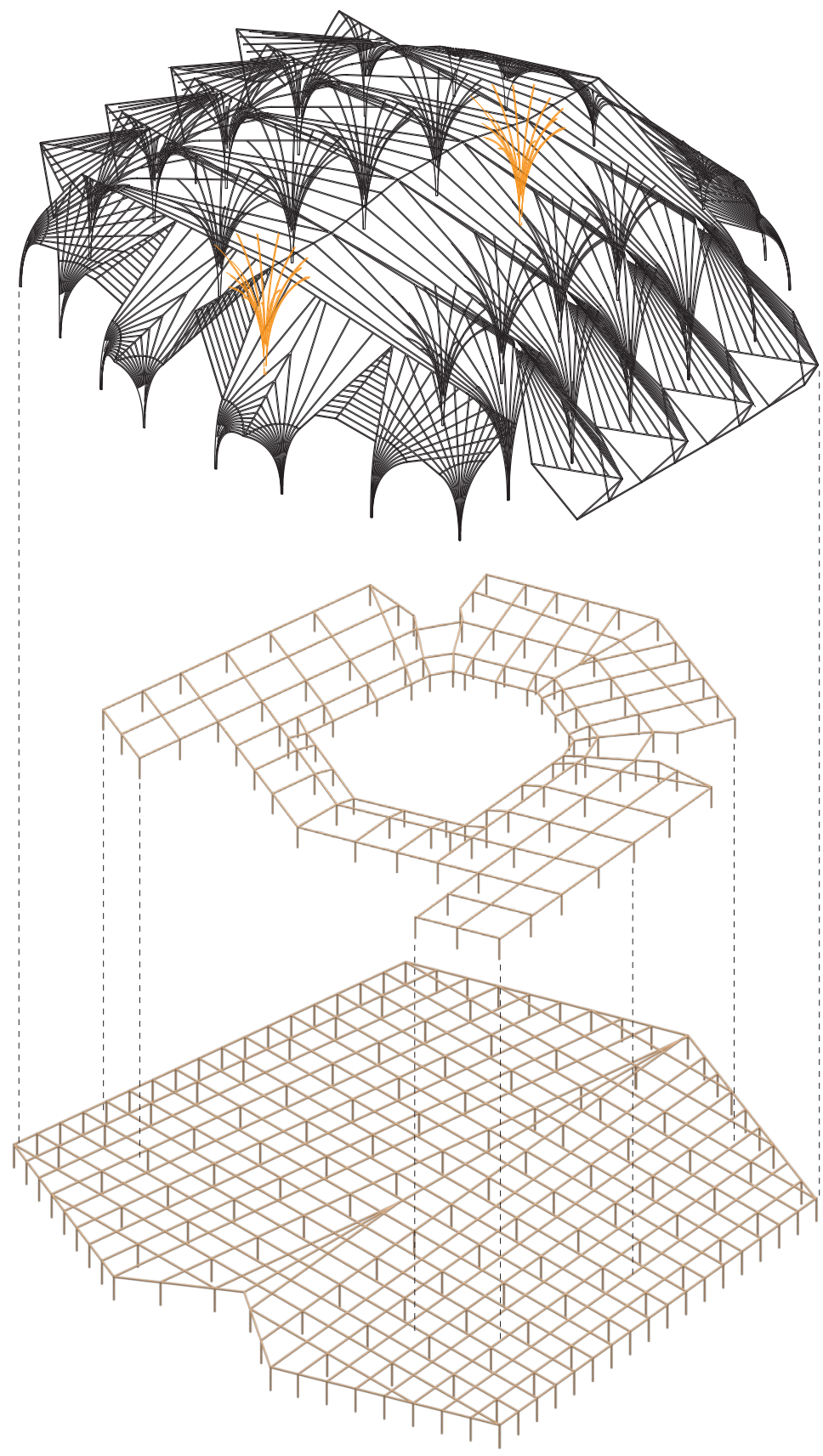

Fig 9.20. Development - Structure

Structure:

- Floor support structure is separate from the roof support structure. Constructed of $360 \times 63 \mathrm{~mm}$ laminated timber beam members which have a continuous maximum span of $6.9 \mathrm{~m}$, if the structural qualities of the beam are of the same qualities as hySPAN LVL (CarterHoltHarvey, 2011). With support columns that are $150 \times 150 \mathrm{~mm}$. The structural grids of the two levels are slightly different.

- More support is added to the roof structure at the front and back of the form, to ensure ensure the large span is able to be held up. From looking at precedents of other large span bamboo structures with lightweight roofs, it will work. 


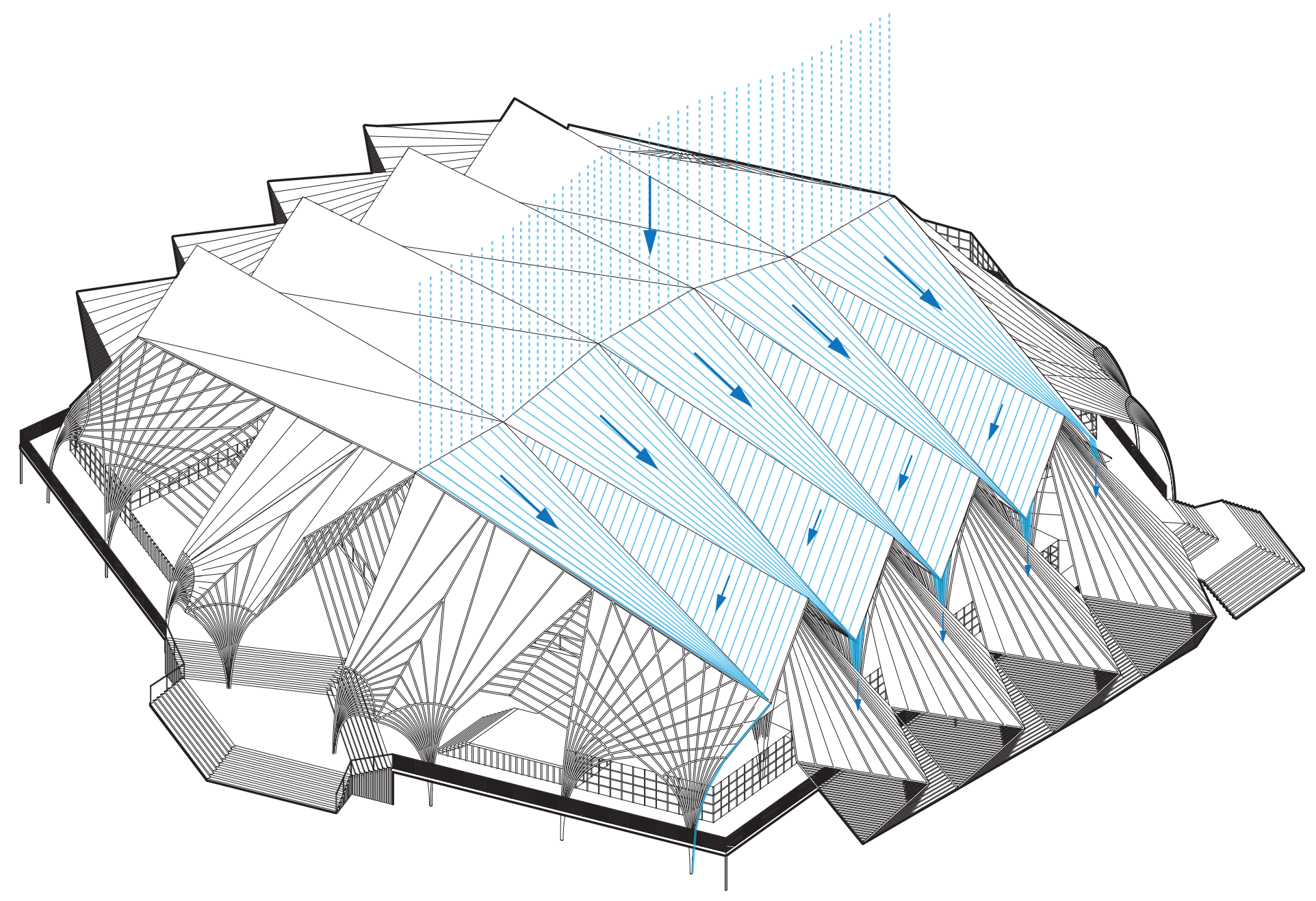

Fig 9.21. Development - Rainwater runoff diagram 1 


\section{Rainwater Management}

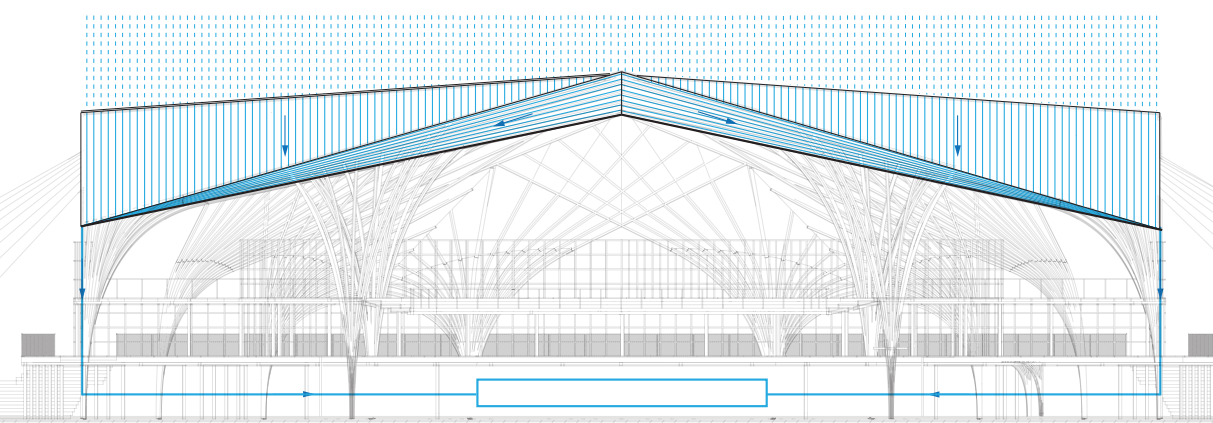

Fig 9.22. Development - Rainwater runoff diagram 2

The roof form is designed to direct the rainwater runoff to points where it is able to be collected. The water is collected through down pipes to the ground level where it is pumped to the services area of the building. It is then processed through metabolic network reactors, which is a way of treating wastewater using natural fibres (Biopolus, 2018). Once the water is cleaned it is then pumped and used throughout the building in the kitchen and bathrooms. The filtration system is also able to treat used grey water so the wastewater from the kitchen and bathrooms can also be reused in the case of water shortages. 


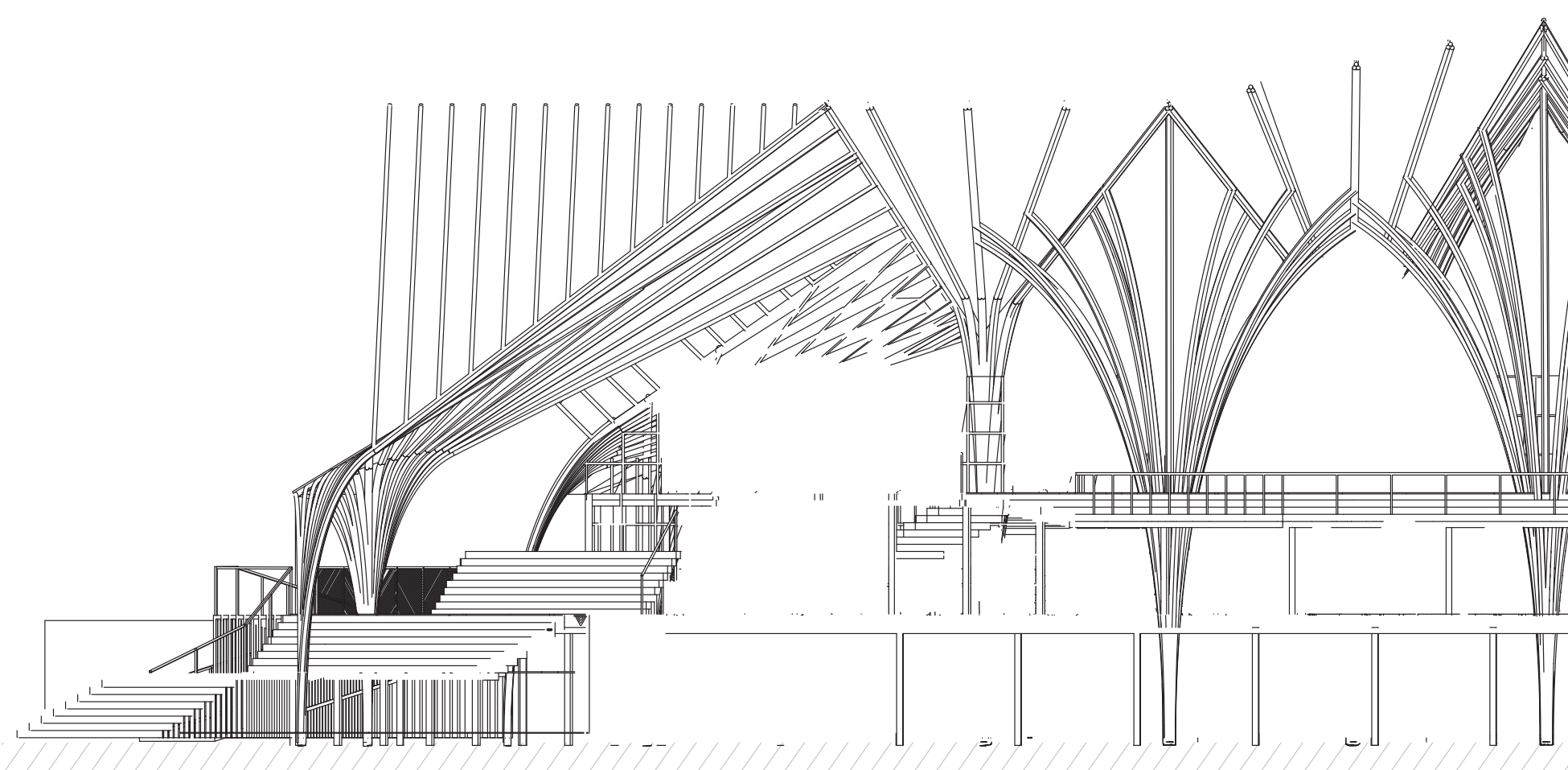




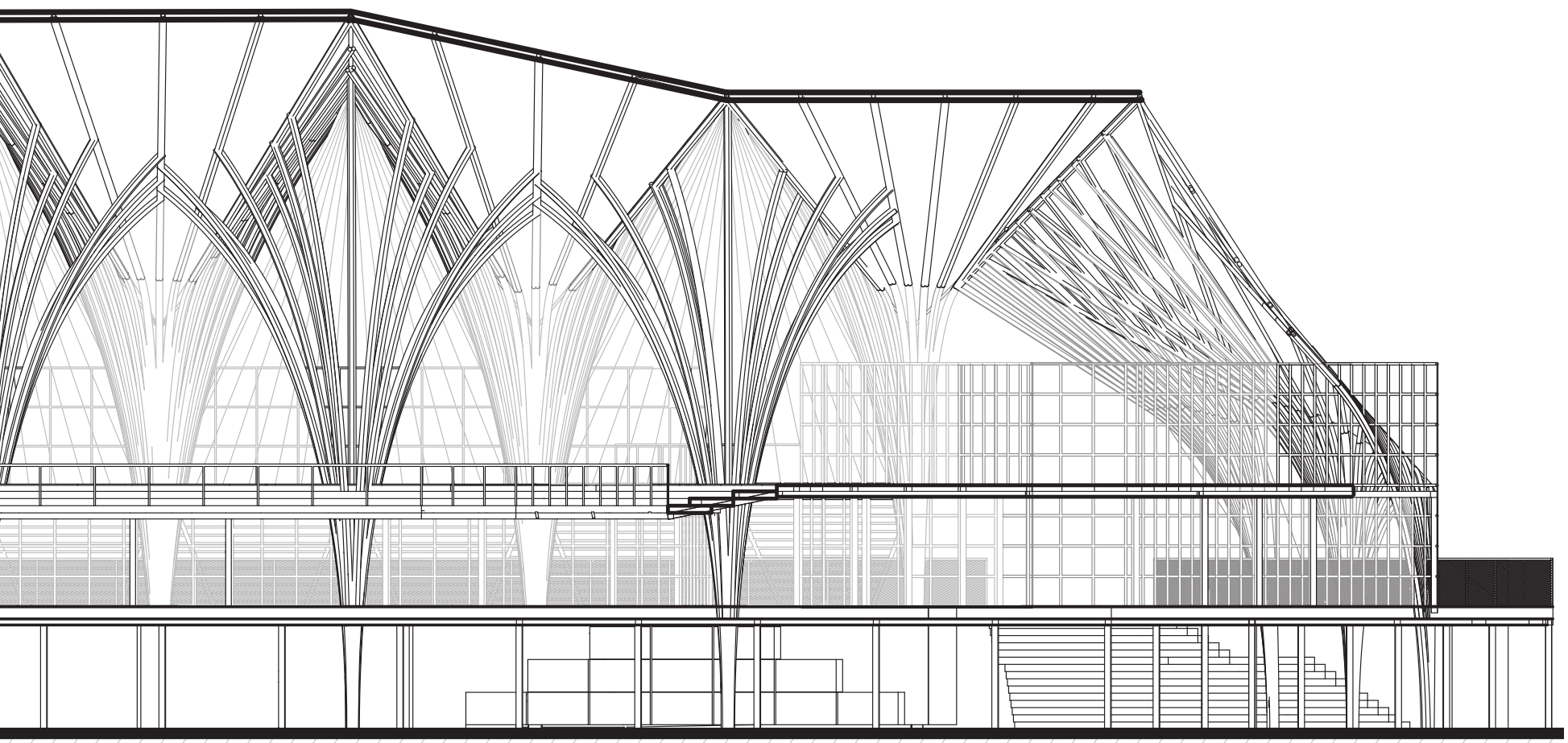

Fig 9.23. Development - Full design section AA

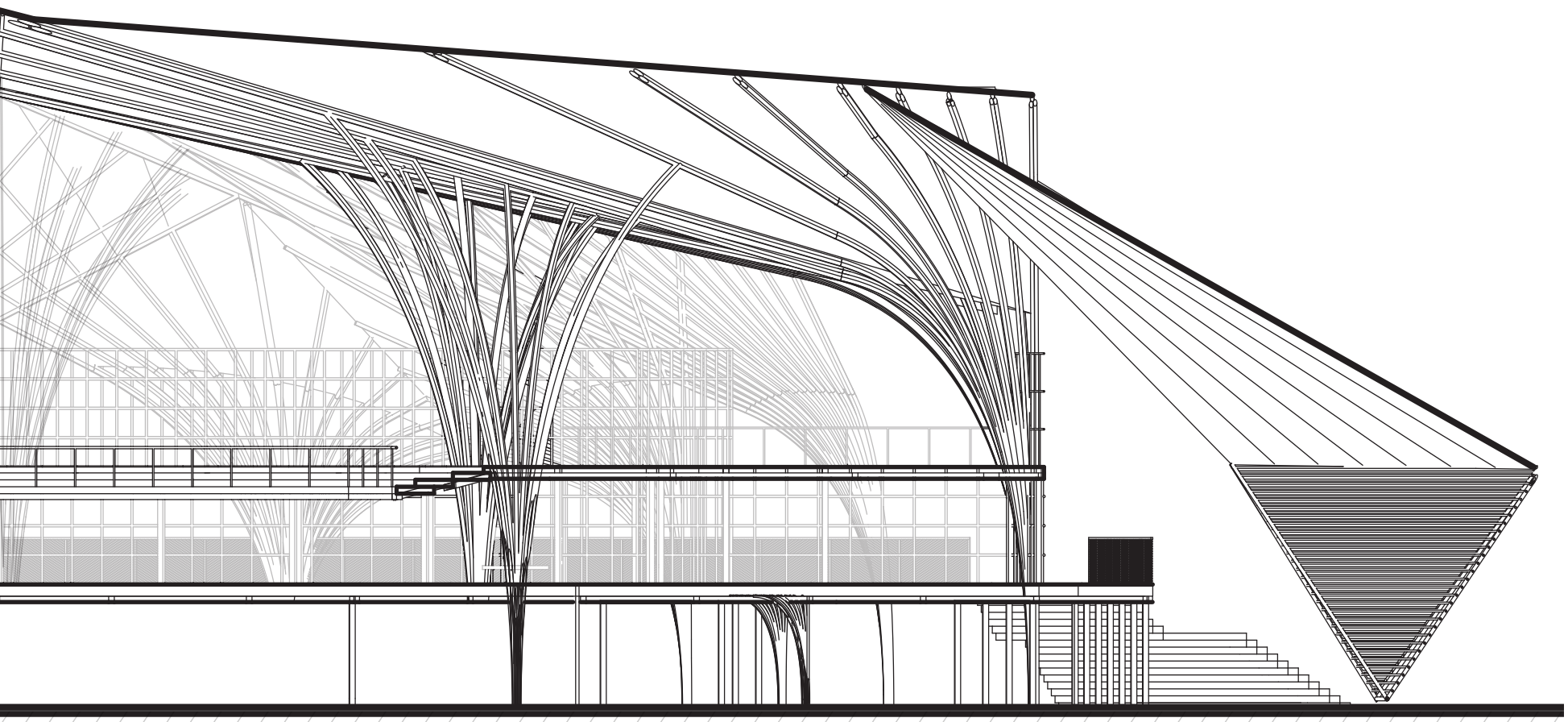

Fig 9.24. Development-Full design section BB 


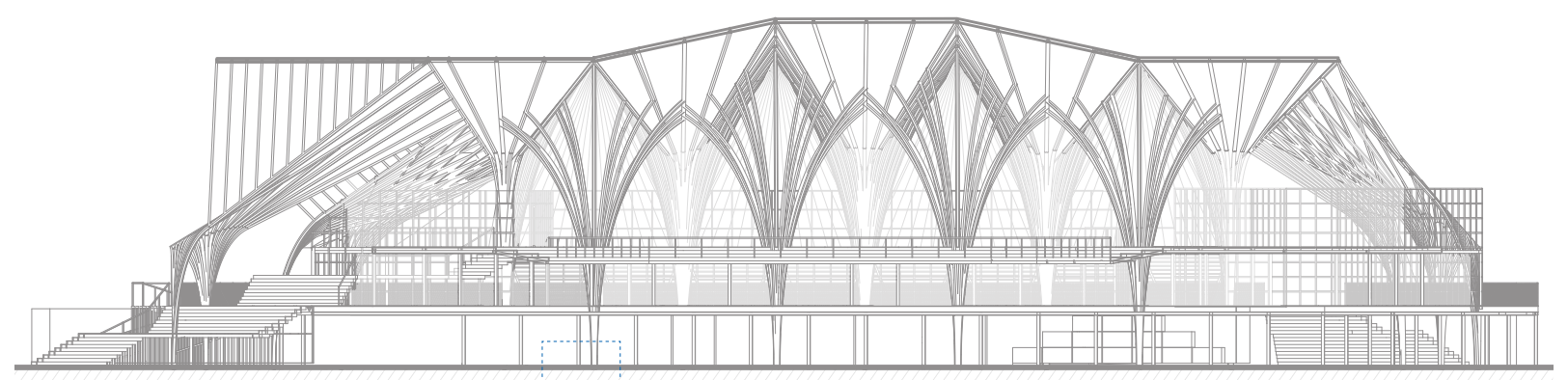

Fig 9.25. Development - Full design section AA

Mortar Entry

Hole

Concrete Floor

Slab

Steel Re-bar

Moisture Barrier

Damp Proof

Membrane

Precast Concrete

Footing

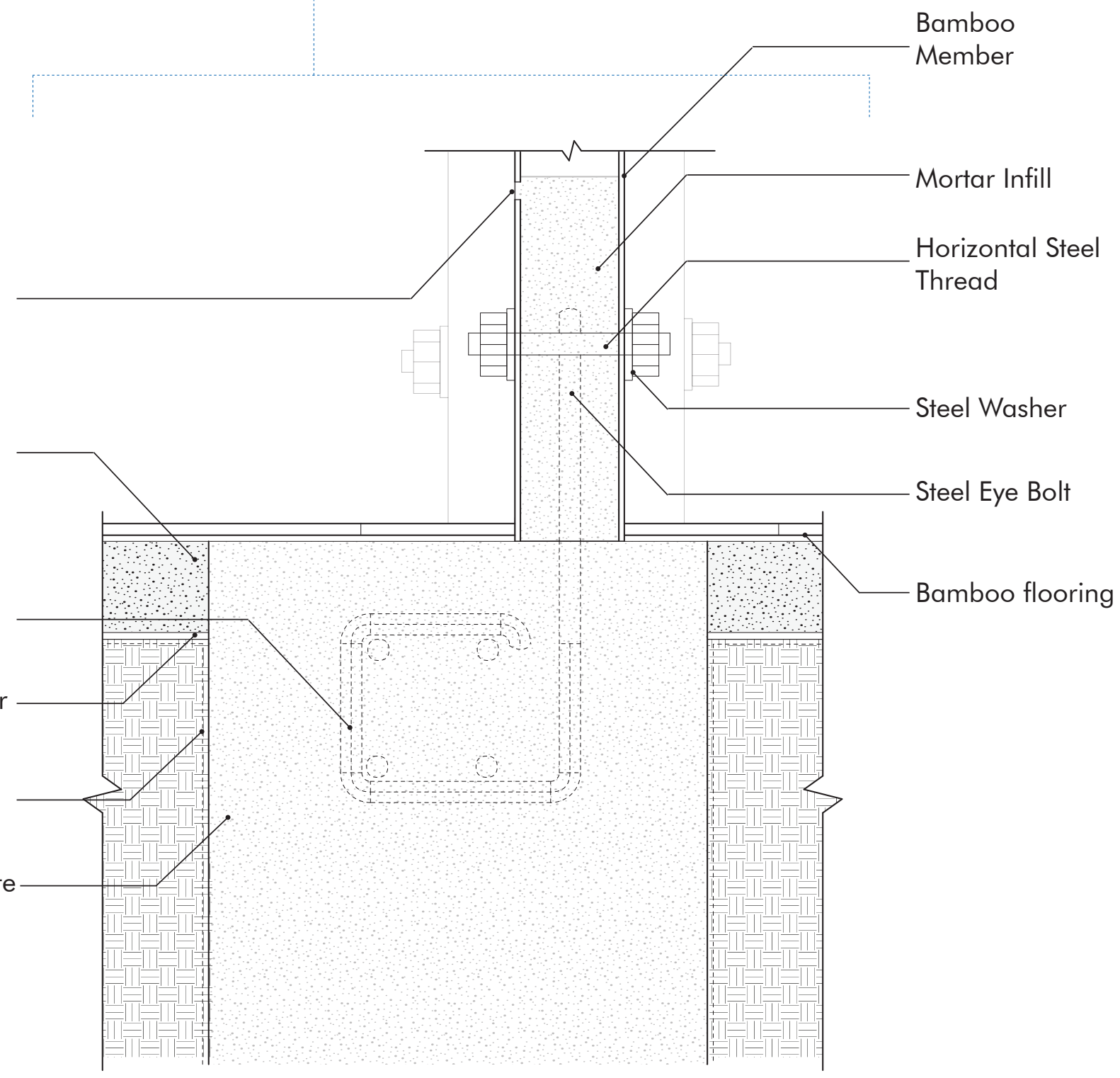

Fig 9.26. Development - Foundation construction detail 


\section{Construction Technique}

Bamboo Post secured to a concrete footing internally

Fig 9.27. Bamboo Foundation

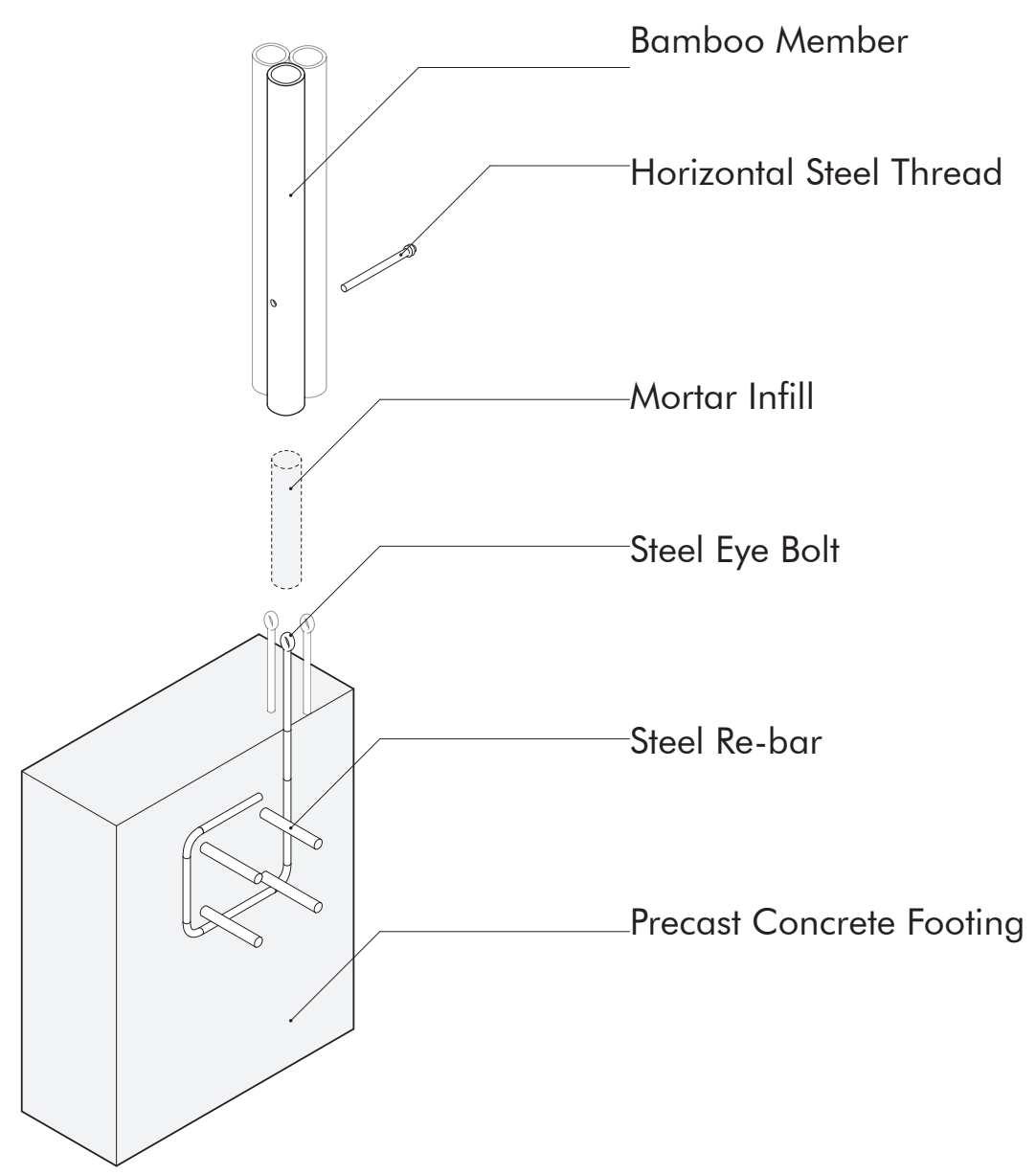

Fig 9.28. Bamboo Foundation 3D visualisation 


\section{Bamboo Construction Detail - Roof}

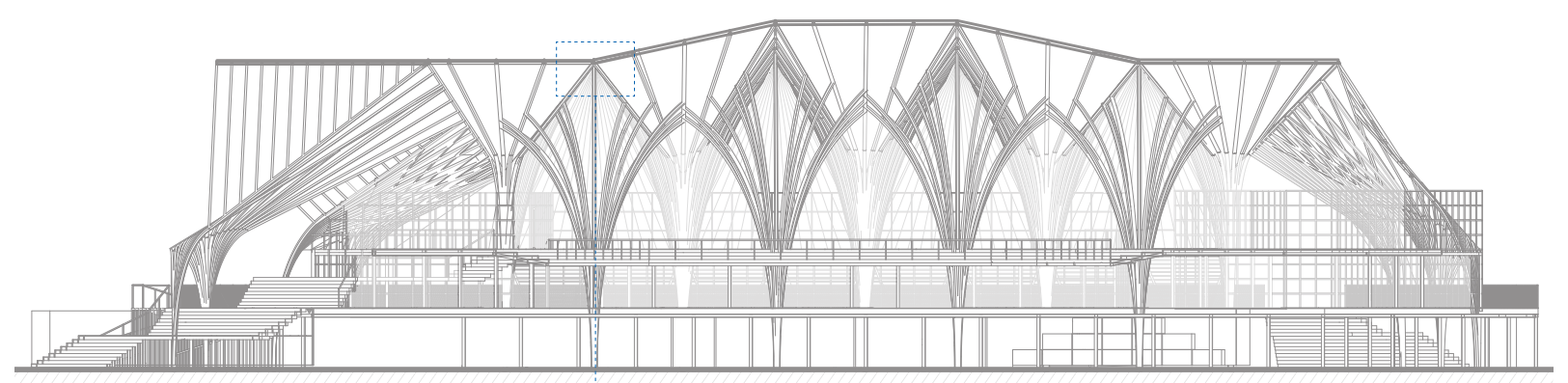

Fig 9.29. Development - Full design section AA

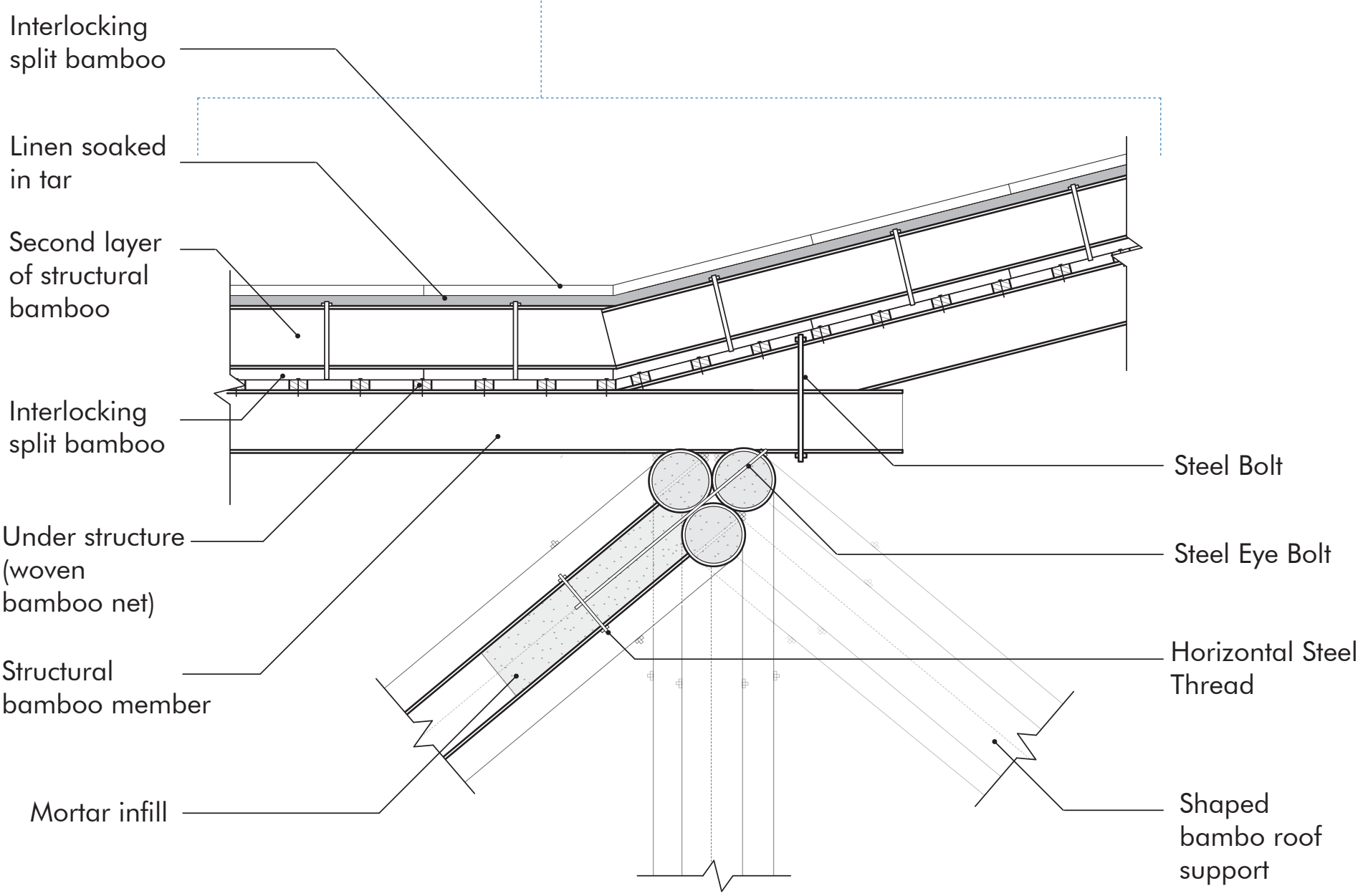

Fig 9.30. Development - Roof construction detail 


\section{Construction Technique}

Orthogonal Mortar Infilled Steel Eyebolt Connection:

Fig 9.31. Bamboo connection

Fig 9.32. Bamboo fishmouth connection 


\section{$\ominus$}

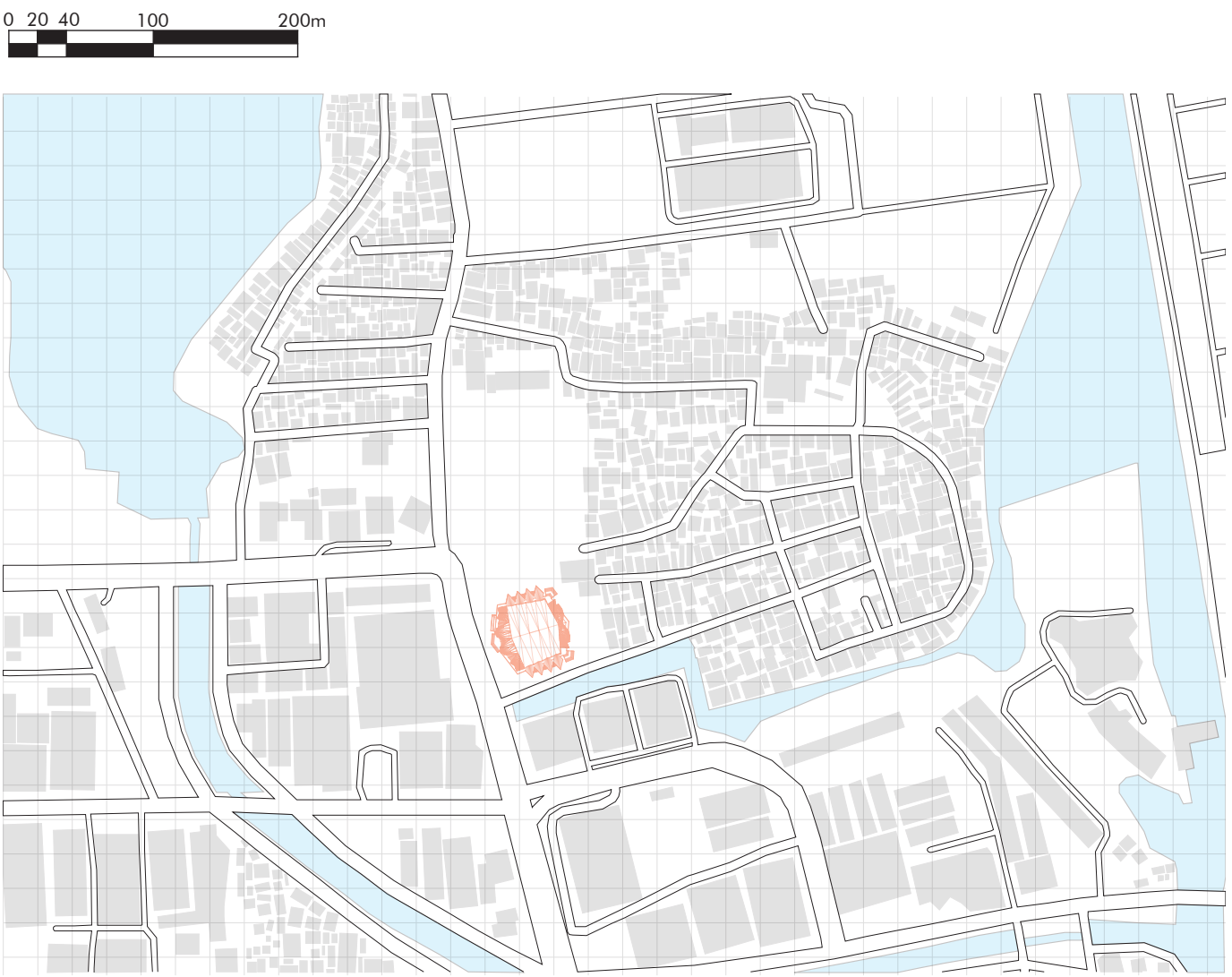

Fig 9.33. Final design on site 


\section{Conclusion}

The design outcome consists of strategies that follow the design criteria. Necessary infrastructure improvements are achieved by providing the public with a waste management facility keeping the streets cleaner. Clean water is also collected and publically available through the communal kitchen and shower facilities. The existing architecture and traditional features of the area are expressed in the exterior form of the building. The bamboo structure has traditional high pointed arch features and an 'umbrella' type roof which are features of the local Betawi houses of Jakarta (Funo et al., 2005). Facilities that are available and of benefit to the community as a whole are provided through the communal open space, the community kitchen, and education spaces. These are facilities that the community is able to gather in large numbers, supporting existing social connections. The spaces within the design are intended to be multi-use, such as the open community space being able to be used as an auditorium or a sports court, and the class rooms being able to spread out into the open communal area. The designated retail space is intended to just provide the framework to give the user of the space opportunity to personalise it however they want depending on their needs. The design helps to achieve social sustainability in the face of environmental threats by having the core of the building raised above the ground level, and providing an emergency wing which includes emergency accommodation. 


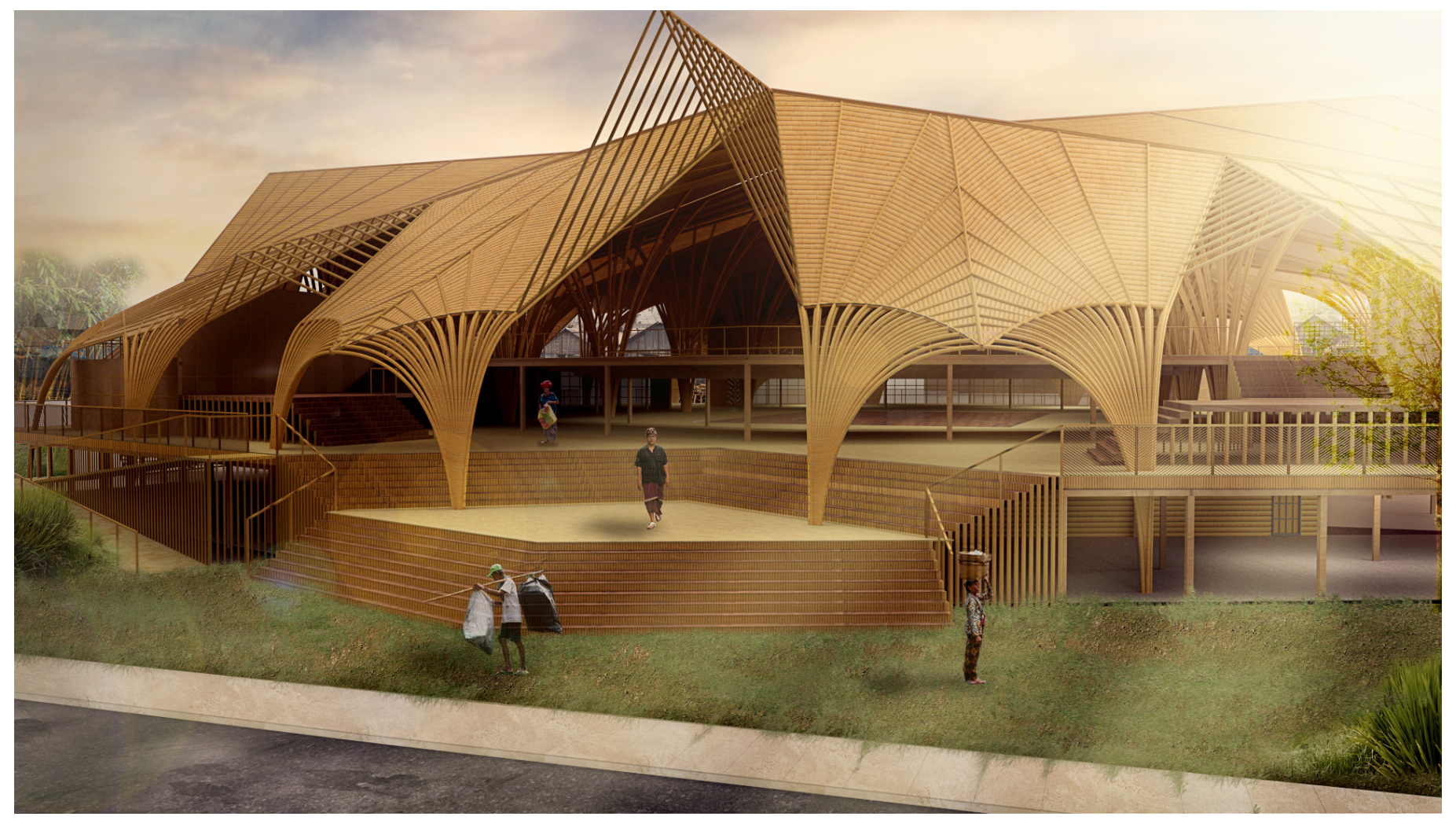

Fig 10.1. Final design visualisation 
10.0 Final Design 
Ground level Floor Plan
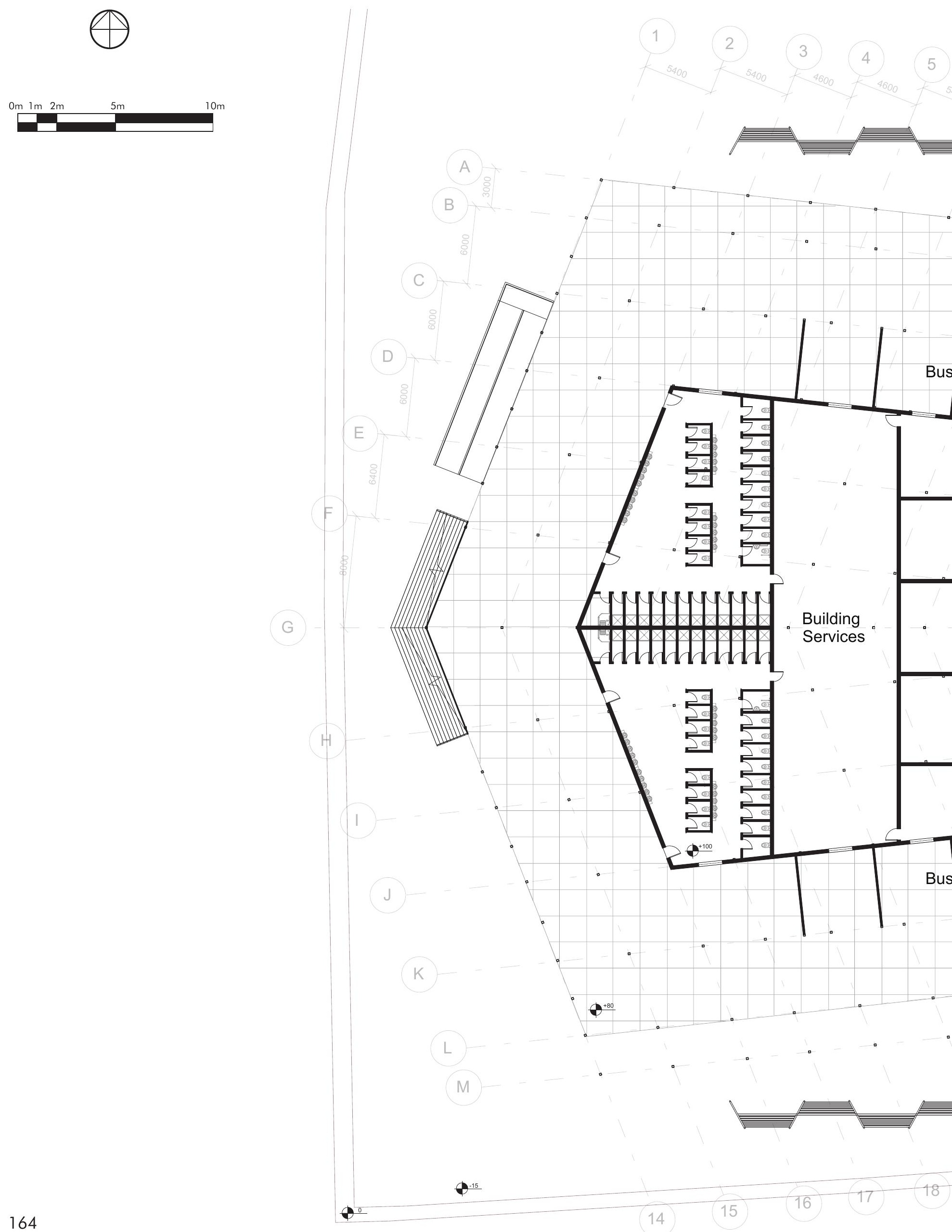

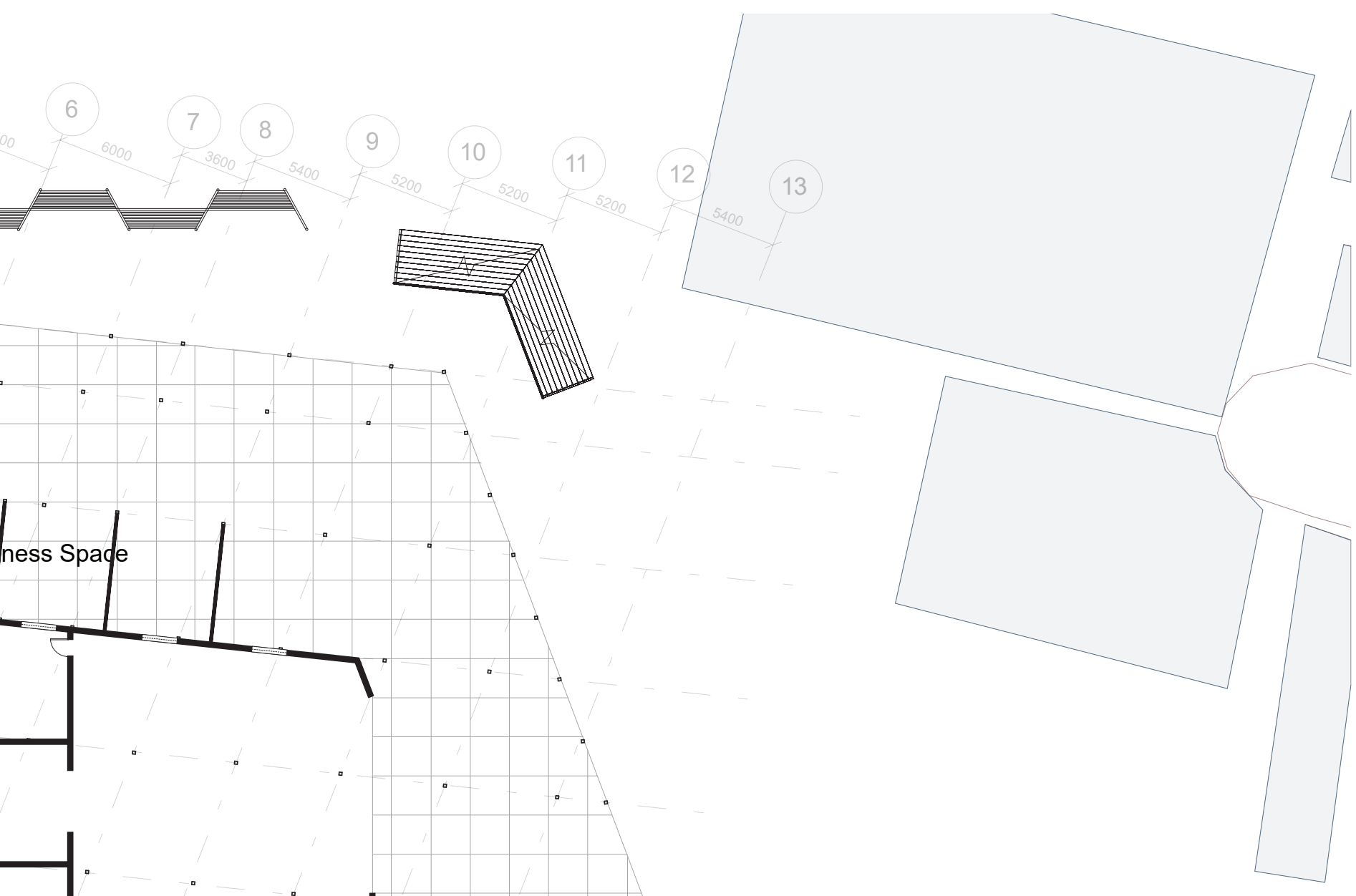

ness Sp
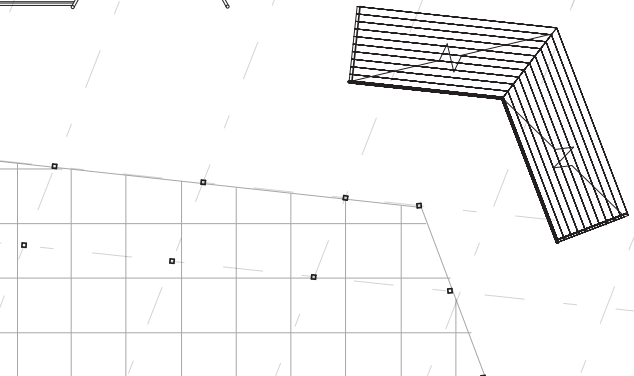
level 1 Floor Plan

$\oplus$
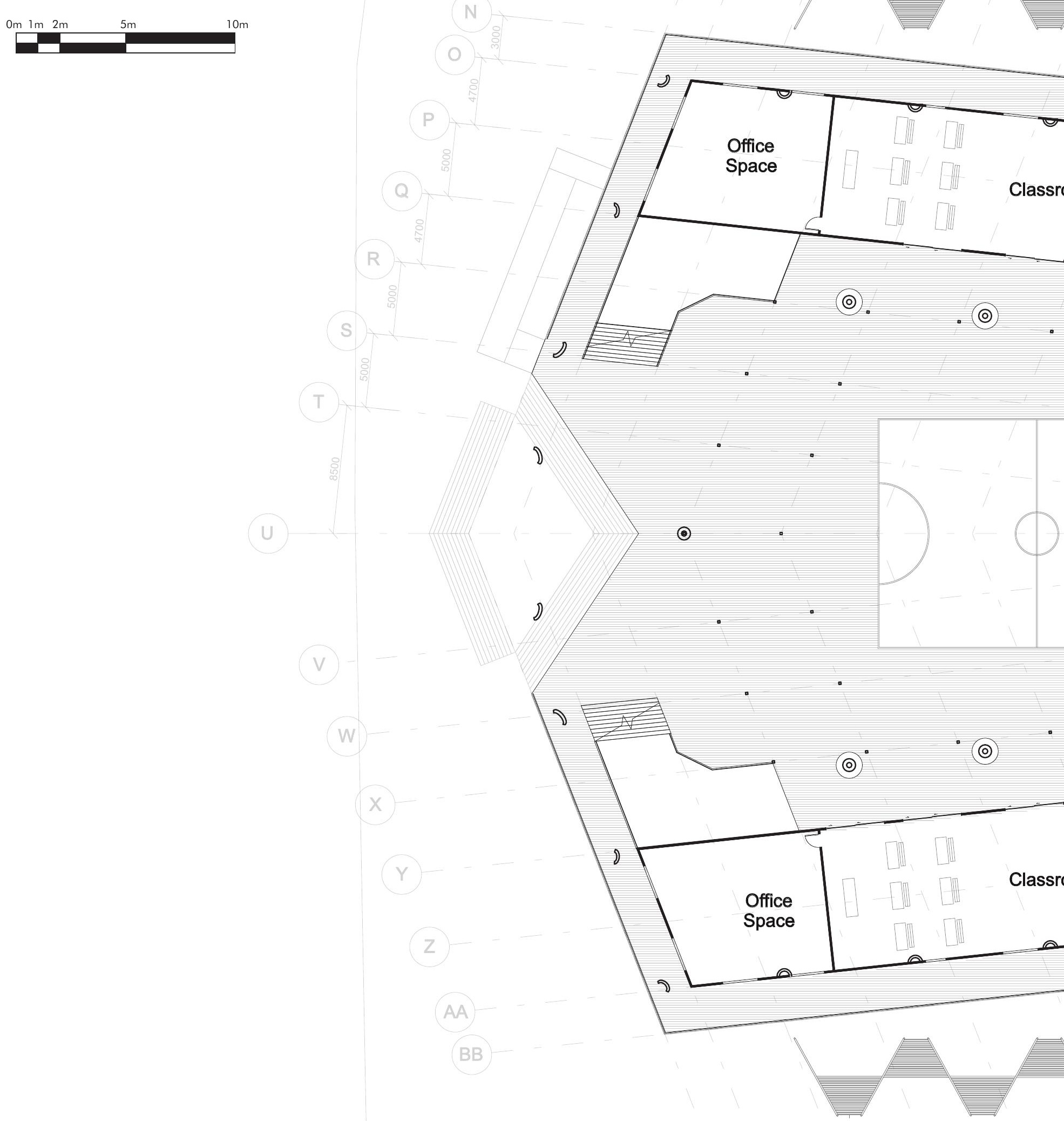

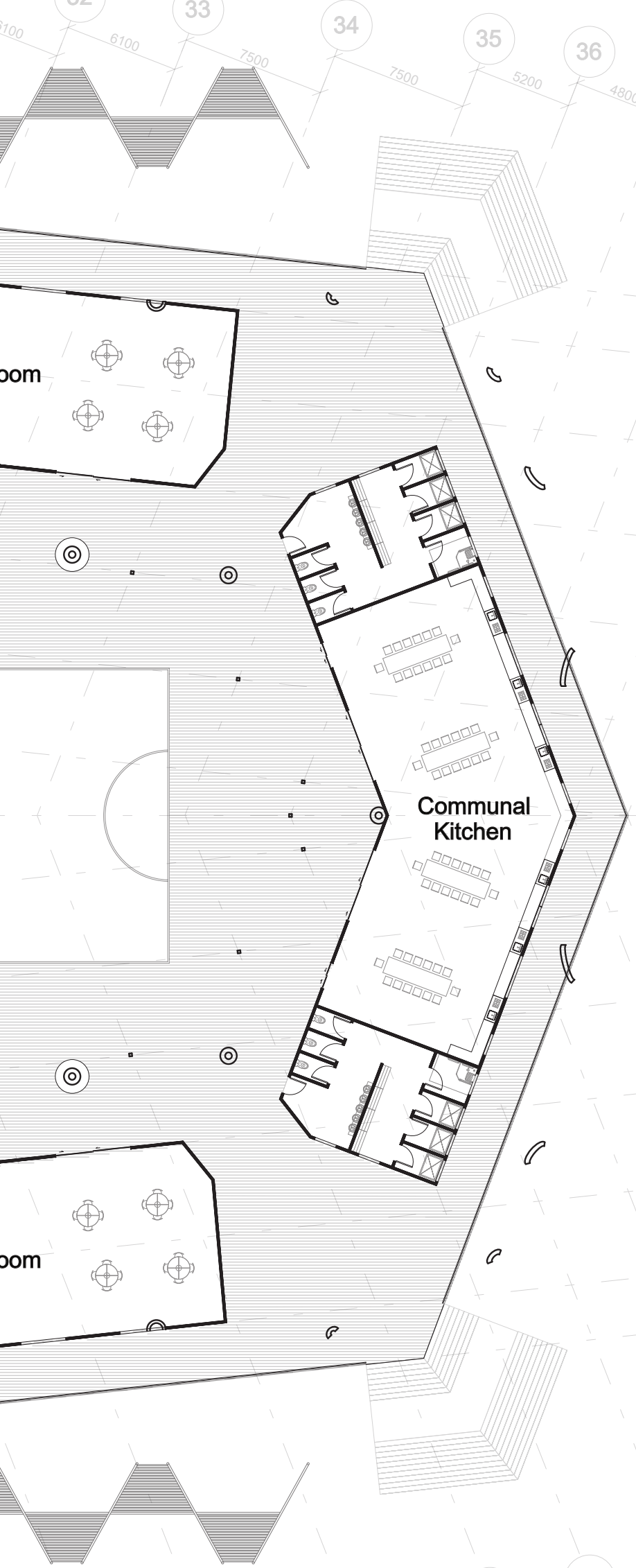

46 
level 2 Floor Plan
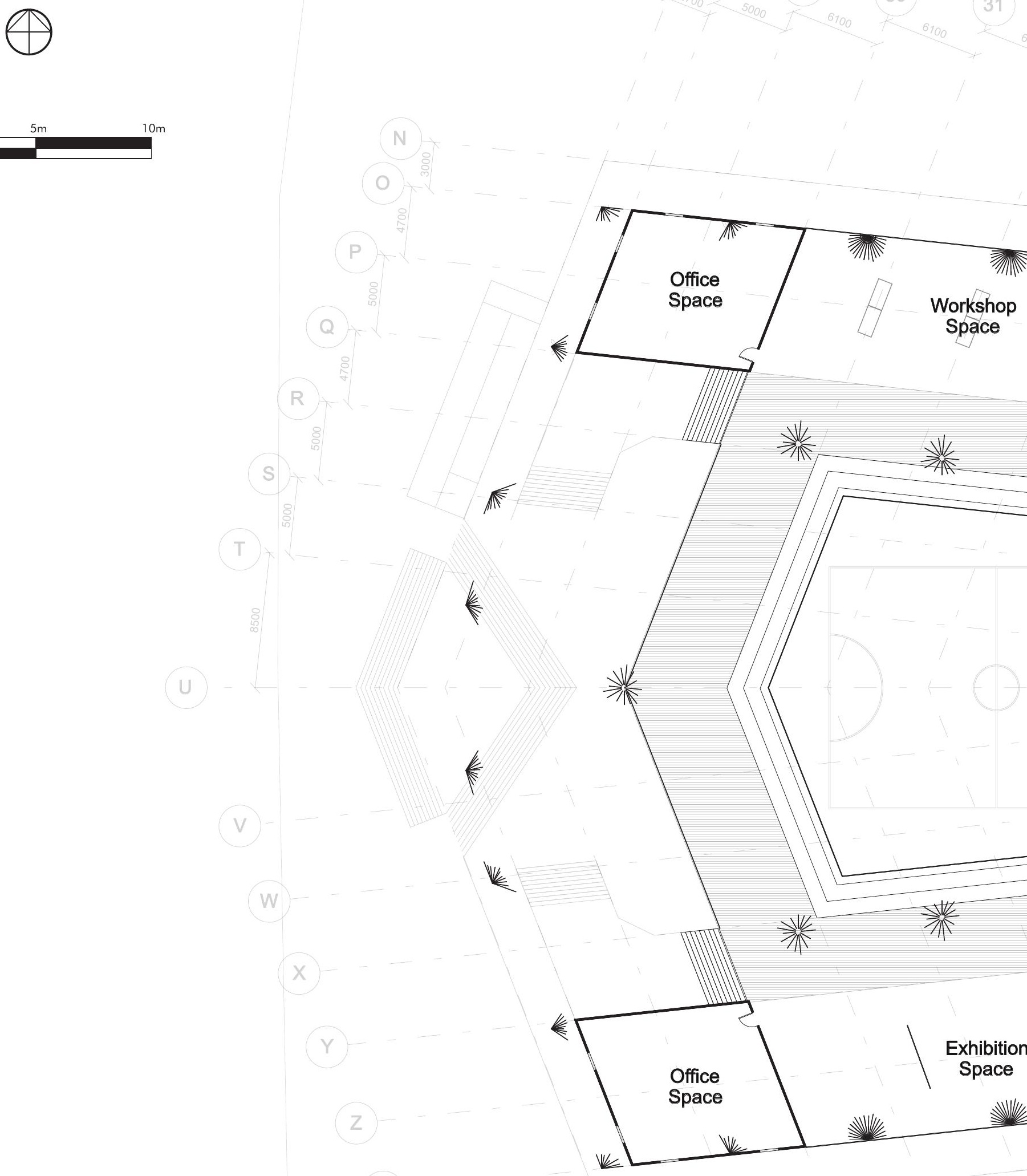
32

33

34

35

36

$37 \quad 38$

$38 \quad 3940$

A

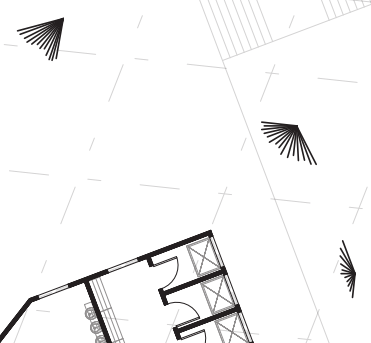

*
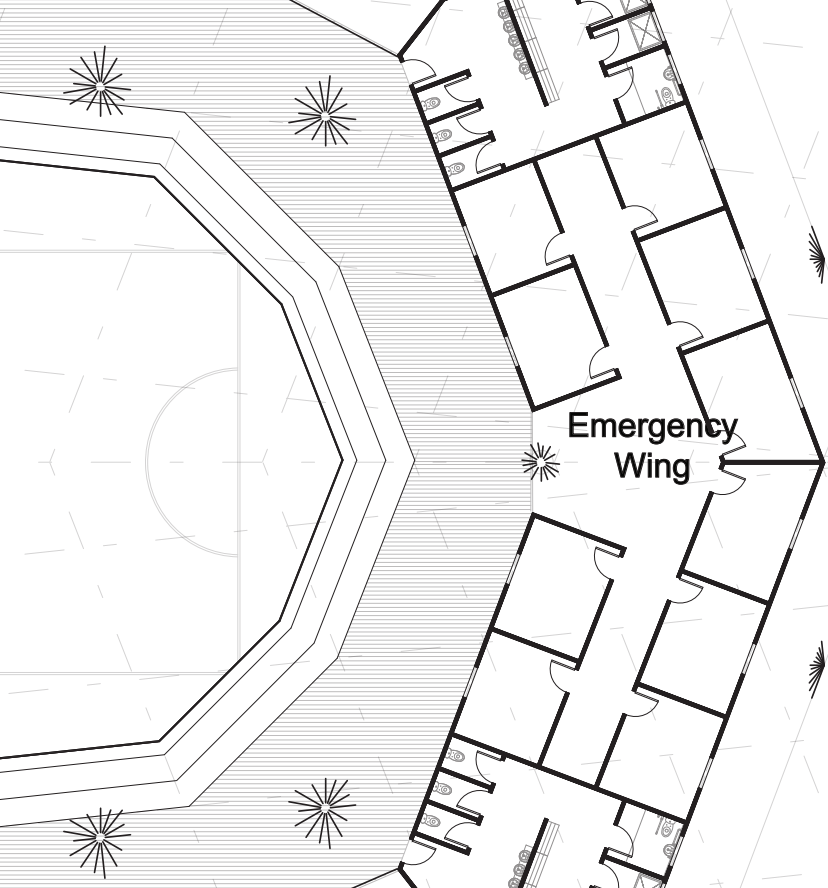

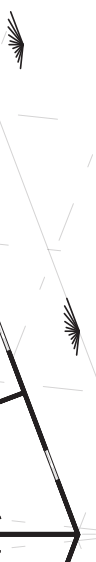

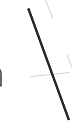

光 Wing

$+$

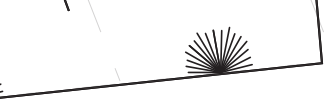

46

50

51

52

5354

48

49

47

Fig 10.4. Level 2 floor plan

169 


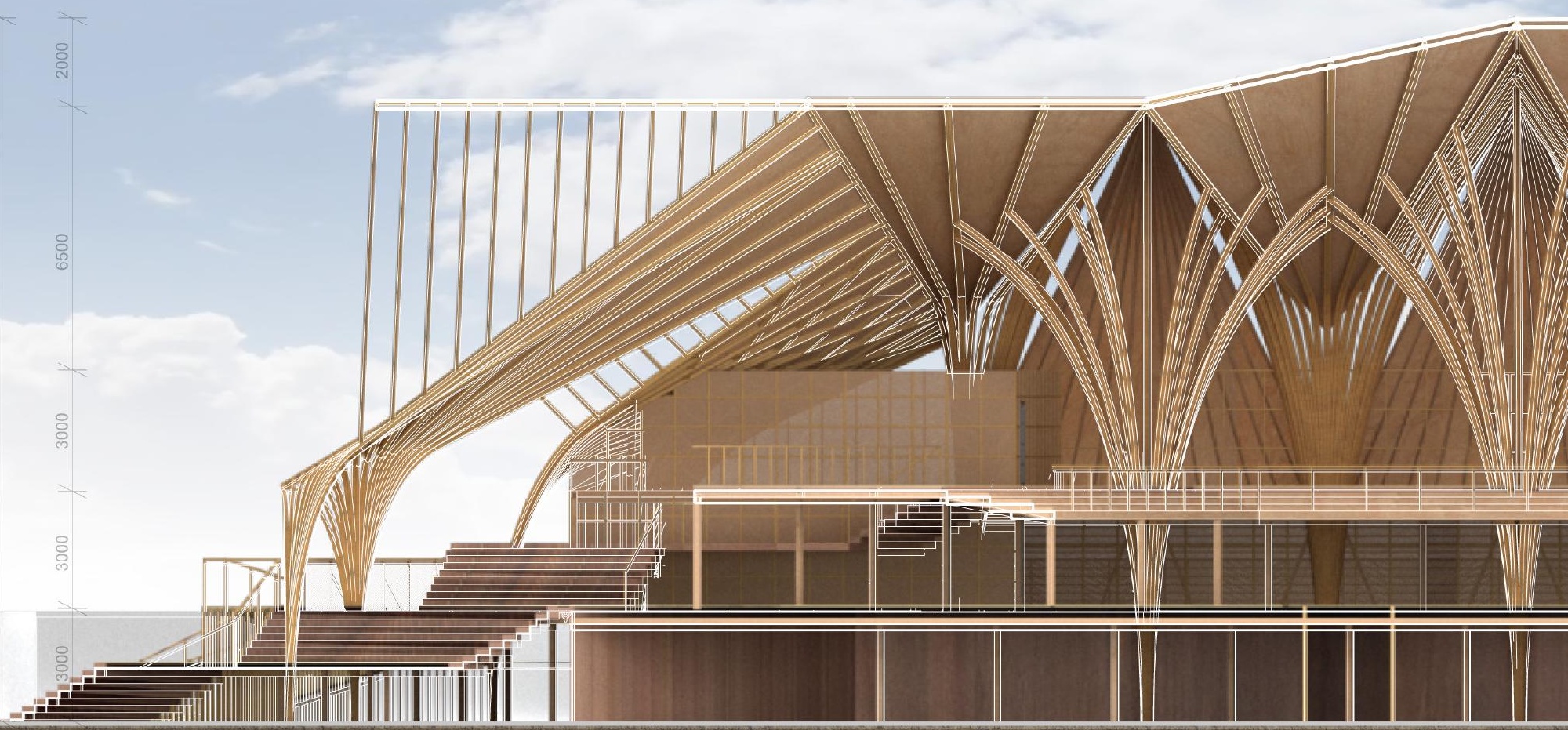

$0 \mathrm{~m} 1 \mathrm{~m} 2 \mathrm{~m} \quad 5 \mathrm{~m}$ 


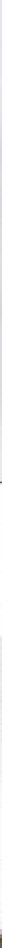


Section

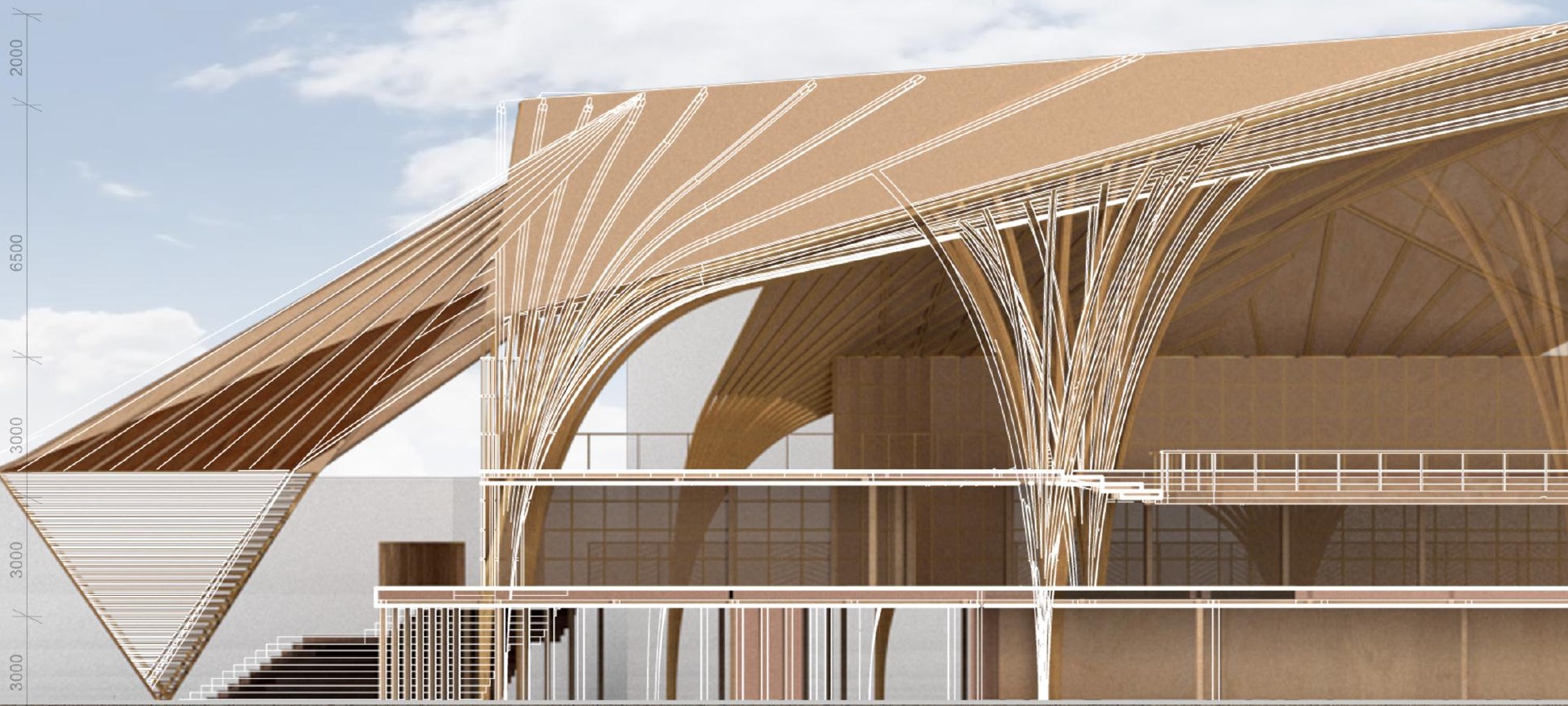

$0 \mathrm{~m} 1 \mathrm{~m} \mathrm{2m}$ $5 m$

- 


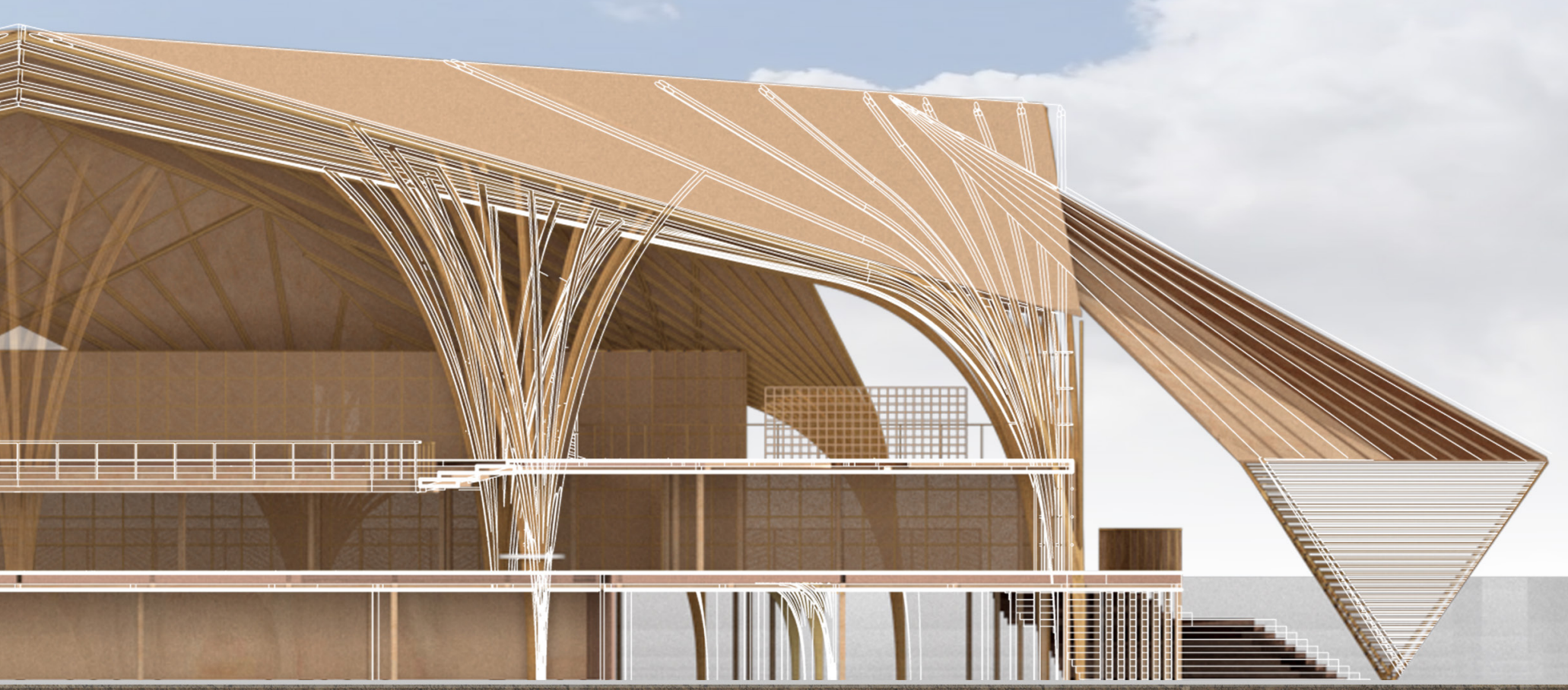




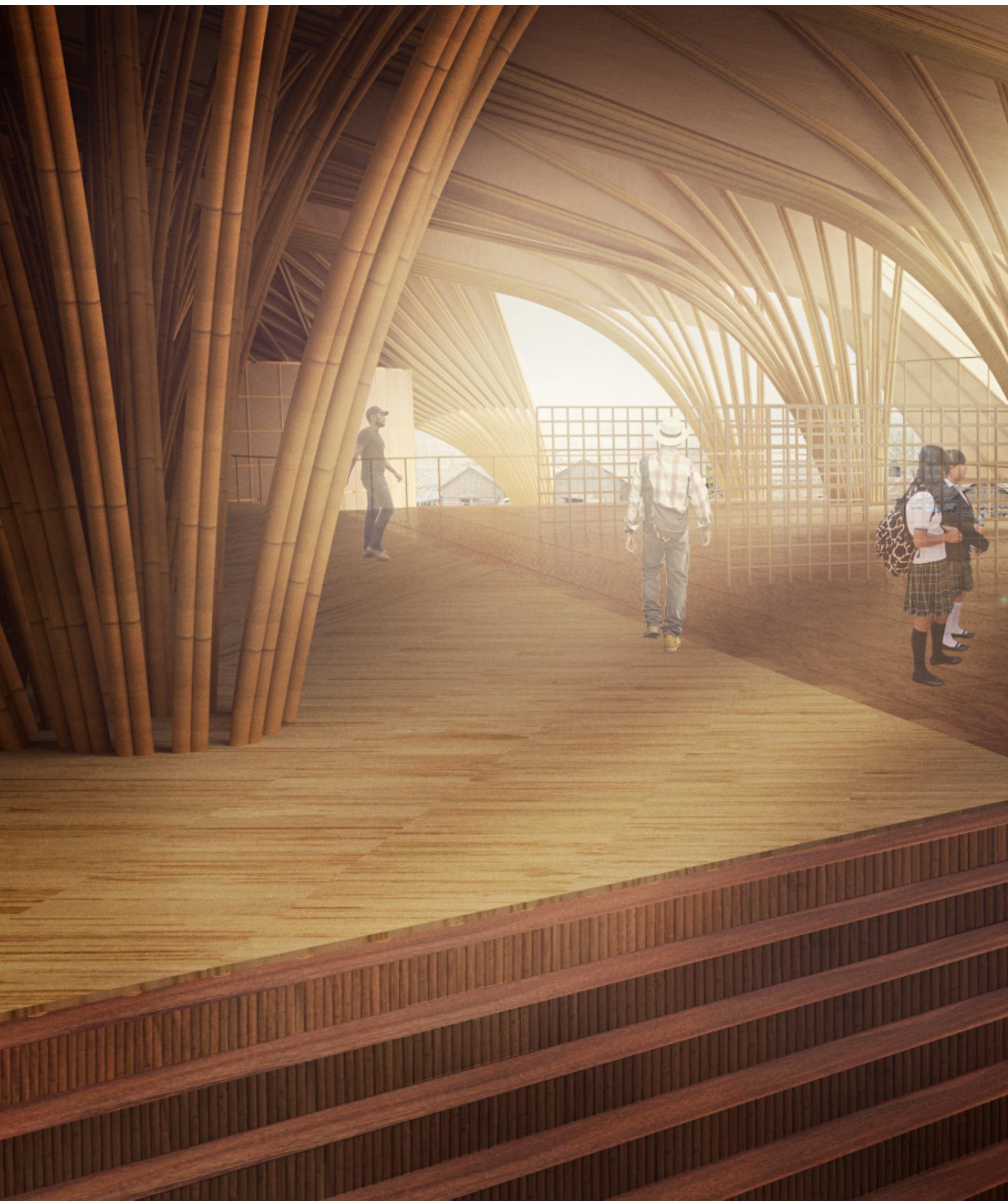




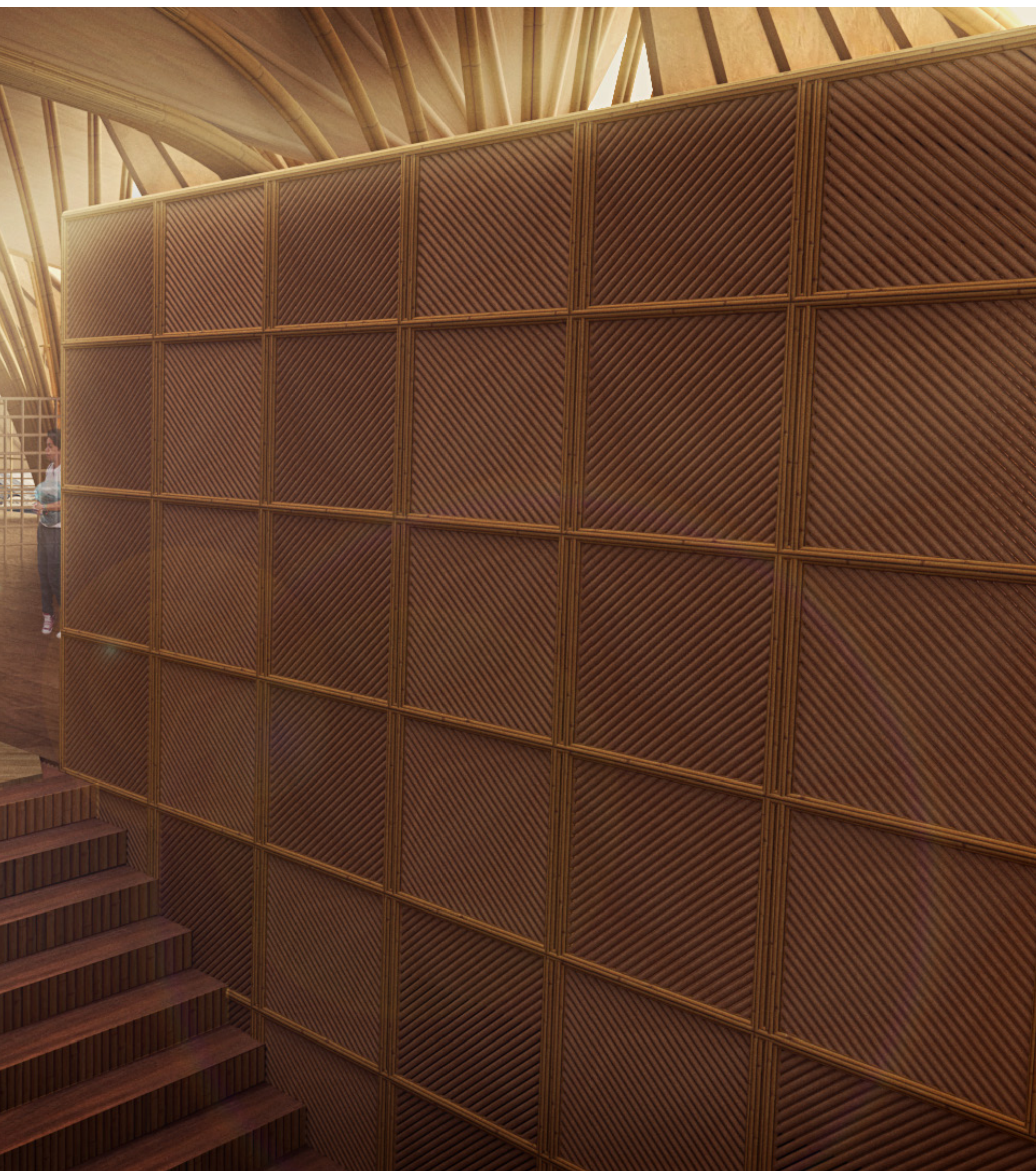




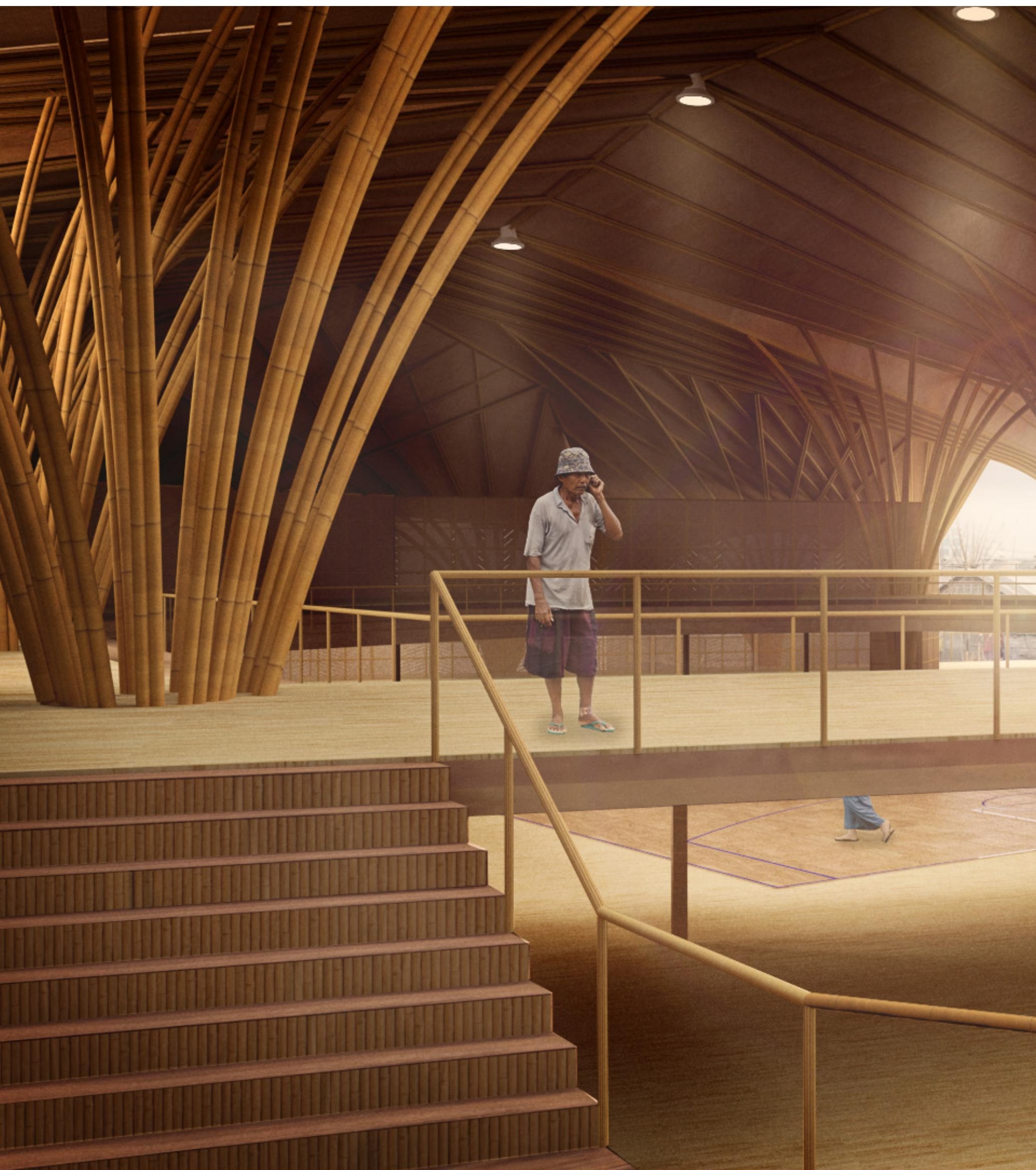




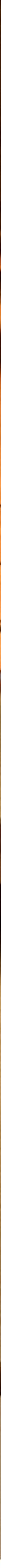




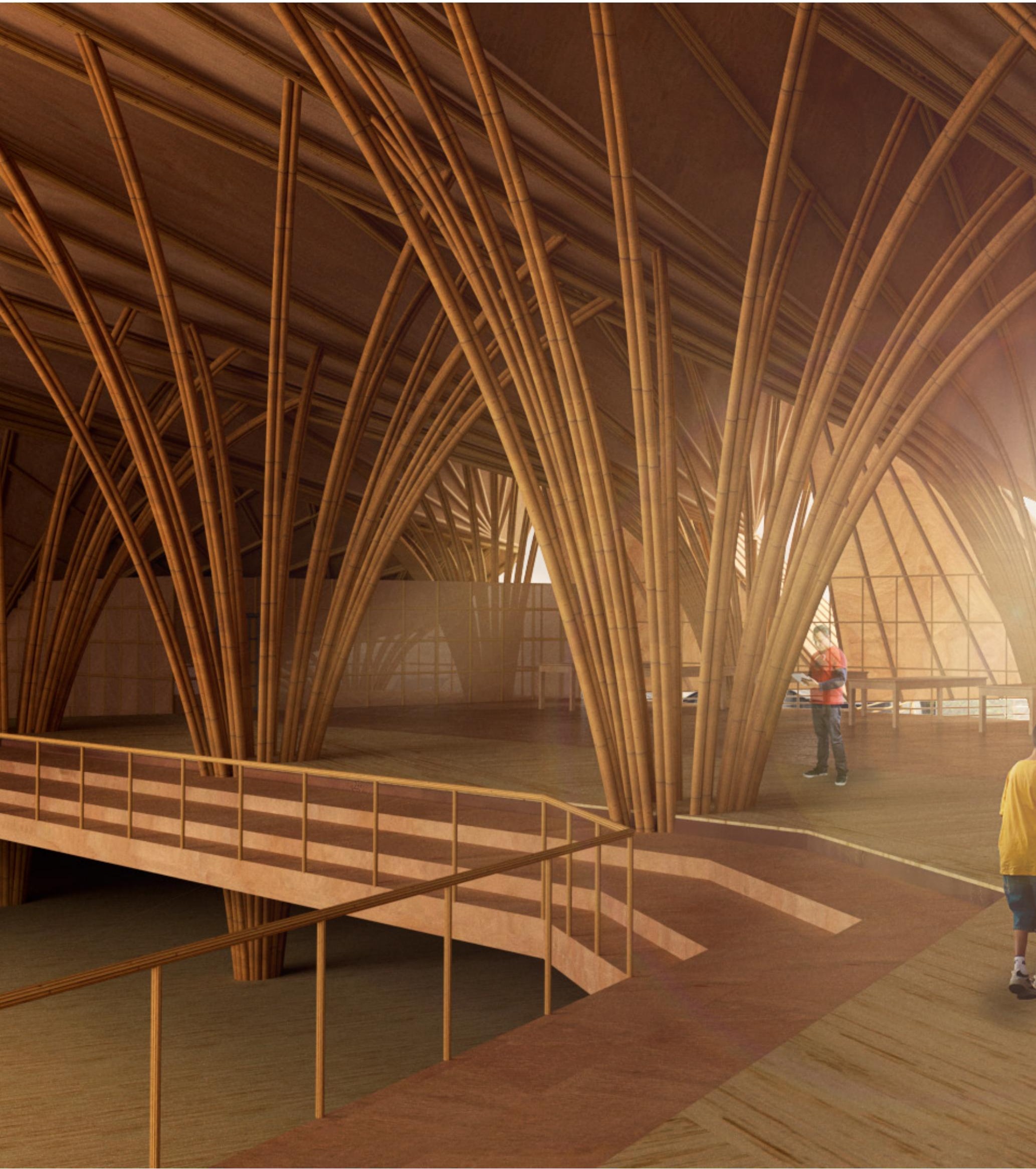




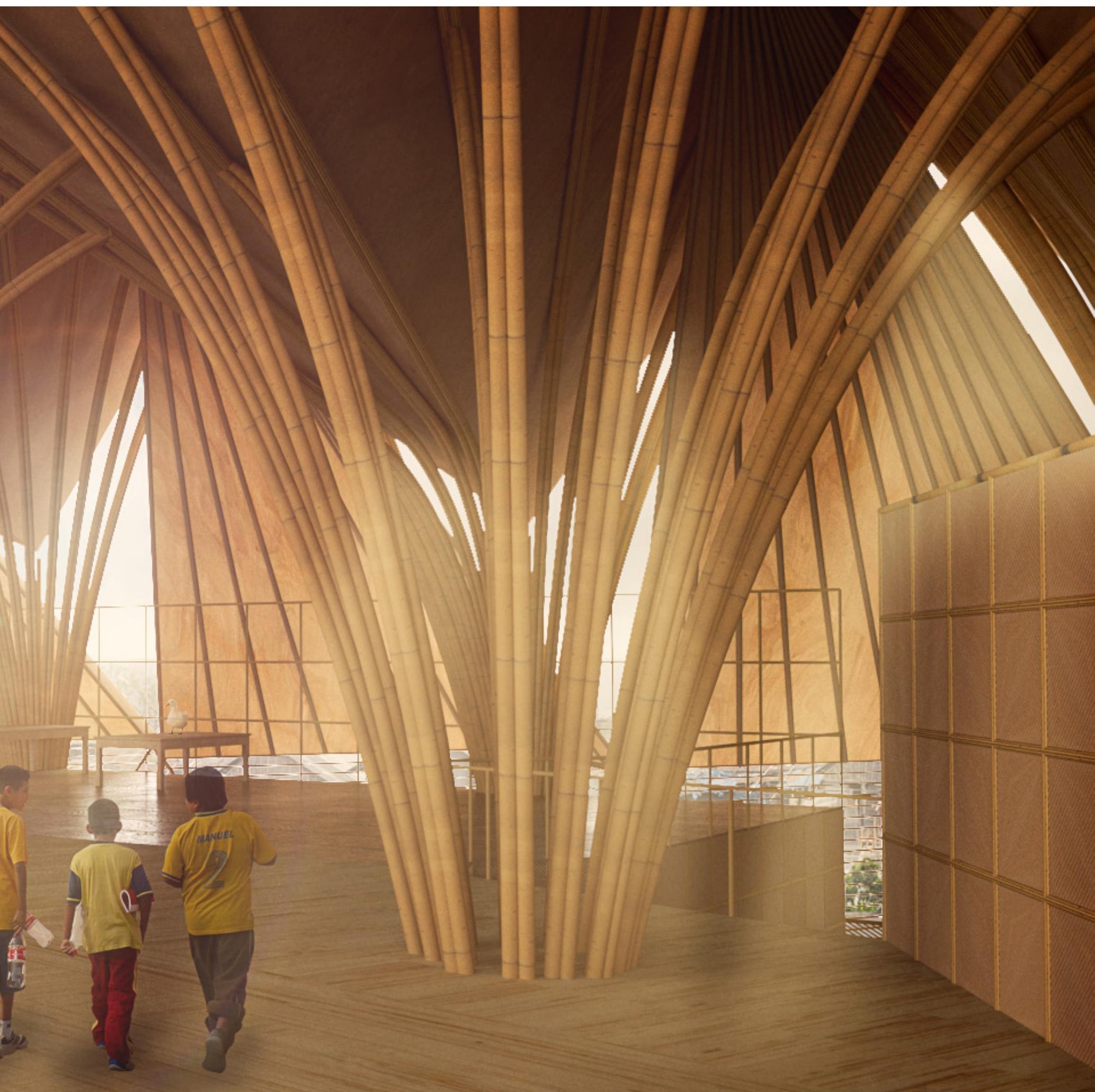




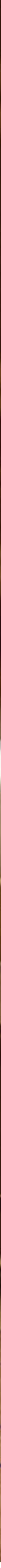




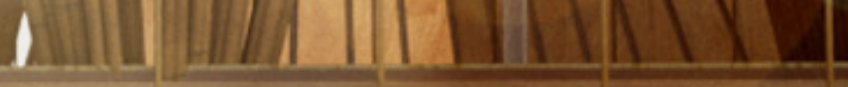
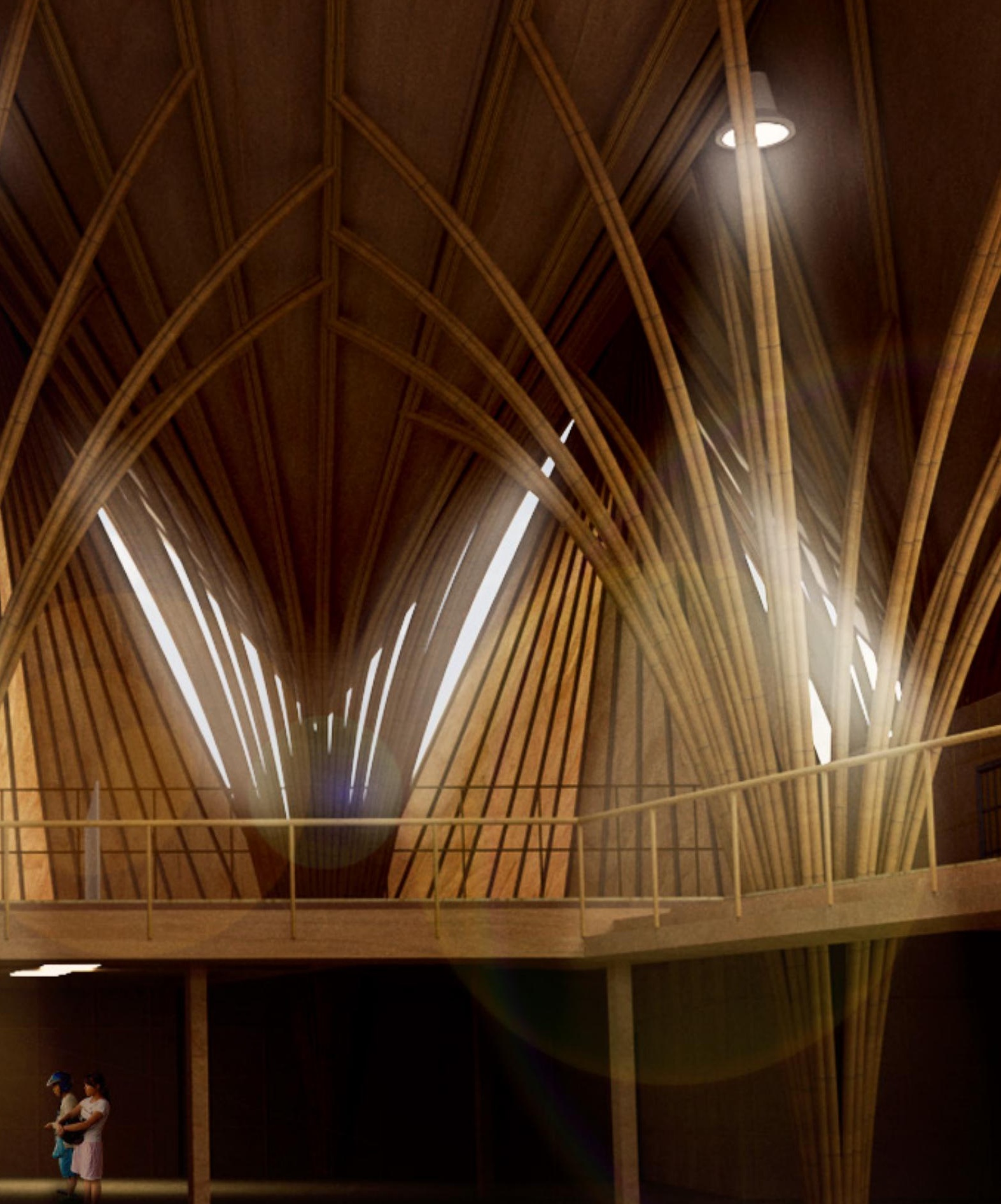


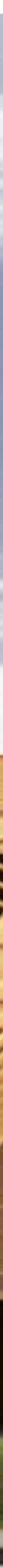


11.0 Conclusion 


\section{Findings}

- Residents of the informal settlements of Jakarta are content in the houses they have. So the design approach for a successful architectural intervention to relieve social stress in the informal settlements will support the existing community connections through a communal building rather than an individual housing design.

- Natural local materials with influence of the traditional architecture of the area, resulting in a unique building form using simple bamboo construction techniques.

- Open space available for community gatherings are a rarity among informal settlements due to their lack of forward planning, providing this space helps maintain and improve the community bonds.

- A multi-use design, the spaces are flexible to meet the specific needs of the community at different times, such as the open communal space also has lines to be used as a sports court.

- Having the facilities of the community centre spread over multiple levels allows the core of the building to remain functional and as a place of refuge when facing the environmental threats of the site, such as flooding. 


\section{Critical Reflection}

The strategies used to tackle the main issues were successful because the design criteria was developed as a result of four different stages of the research. This was the site analysis, literature review, initial precedent study, and the first design review. Extensive testing was done to develop a conceptual design that would meet the design criteria. Starting with initial sketches and digital masses, to investigate spatial arrangements. Then an extensive material study exploring the range of forms given the physical properties and limitations of bamboo. Leading to digital conceptual testing that explores a series of forms, investigating interior arrangements simultaneously with external design. The resulting developed design successfully supports the existing social connections by providing a space where the community can come together, and improve the quality of life through providing necessary infrastructure and services. However there are some parts of the design with minor issues, such as; the response to site environmental threats, programme, materiality, the open air structure, and the retail spaces. If the research were to be continued, perhaps at $\mathrm{PhD}$ level, it would be necessary to acknowledge the following minor issues.

Response to Site Environmental Threats:

The design responds to the significant environmental threat the site faces, which is flooding. The immediate flood threat is acknowledged through the way the core programme of the design is raised on the upper levels. This allows the community centre to continue to function as a meeting place or as emergency accommodation. In the event of a flood the areas of the design that will become damaged and unusable are the, public toilet and shower facilities, the retail spaces, and the waste management facility. These are all facilities placed on the ground level because they are expendable when facing a natural disaster. There are alternative shower and toilet facilities on the other levels of the building, people safety is more important than the goods attempting to be sold, and the waste management centre will not be able to function regardless with roads being flooded. The most important space on the ground floor is the services area. This is the area that the solar energy is stored and the water is filtered and pumped throughout the building. The services are located here to keep them away from the public using the building however this makes it prone to damage in the case of a flood, and extra precautions would need to be made to make sure the building will still be able to function properly.

\section{Programme:}

The programme and designation of space in the design is based on the case study and precedent research. Taking influence from other community based designs and how other designers approached a similar problem in other informal settlements. The final programme developed as a result of what would be most beneficial for the Luar Batang community. This resulted in a place for the community to gather, teaching facilities, toilet facilities, an emergency wing, and a waste management area. These spaces all have a degree of being multi use, and can be adapted to meet specific needs if necessary, such as the teaching space being able to open out into the communal space. Resulting the design to have a familiar adaptive quality to the informal constructed houses of the area. There was some programme that the case studies included that I did not include in my final design, and still could have been beneficial but would require further research, such as a library, or dance studio. 


\section{Critical Reflection}

Materiality:

The material limitations and properties of bamboo played a significant role in the outcome, of the final form. The form was strongly influenced by an extensive bamboo material study resulting in the unique interior and exterior features of my design. Although the traditional architectural features of the area were taken into account when developing the design the dominating feature and overall aesthetic is driven by the bamboo construction and the traditional features do not have much emphasis.

Open Air Structure:

The intention of the design is to benefit the surrounding community by providing facilities that are otherwise unavailable to some residents, such as toilet and kitchen facilities. The design is an open air structure that is accessible all hours of the day and night which makes it vulnerable to vandalism, or unwanted animals taking up residency. The trust is placed in the community to ensure the space is used respectfully. As the building is purely for the community's benefit it is assumed the community will work together in this sense, but there is still a chance it could be misused. Another alternative would be to organise with the governing body of the area to help provide maintenance and security services.

\section{Retail Spaces:}

A prominent feature of the residents of the informal settlements in Jakarta is the home businesses they run, usually in a makeshift space at the front of their homes. On the lower level of the design there are designated areas which provide the framework to set up retail spaces. Depending on the success of the shops that develop there will be varying foot traffic that would be unpredictable. If the businesses in the spaces become successful there might be some times of the day that there will be too many people in the area to pass through easily.

\section{Potential Applications}

This design experiment could be used as a starting point for kampung improvements throughout Indonesia. The design result uses simple bamboo construction methods that would be able to fit in to other sites in Indonesia given there is enough area available. The community centre design could become a central hub for the ever adapting informal community, which moves and changes with population numbers. Therefore encouraging more organisation to the current random layouts of the communities. With the emergency section of the design including temporary accommodation, it makes it easier for new members of the area to integrate into the existing community. Given more time for the investigation to be continued, more research could focus on the multi-use aspect of the interior spaces, developing the design into an adaptive structure that can easily meet the needs of other informal settlements with different deficiencies. 


\section{Limitations}

Site Visit:

The inability for me to visit the site proved to be a major constraint during my research. This prevented any direct discussion with the current residents of the area, meaning there was no research through participatory design which could have strengthened the final design result. In an attempt to compensate for my lack of personal site experience I obtained a detailed understanding of the site through site analysis. Relying heavily on satellite images, photographs, research papers on the area, articles, and books. Although I was able to still develop an understanding of the site conditions and appearance my research would have strongly benefited from a physical experience of the site myself obtaining a real understanding of the residents and their culture. To account for the lack of direct discussion with the current residents of the area, in my research I looked at research that others had done, and took into account the people responses.

Lack of Information:

For research involving informal or unofficial dwellings, there is a distinct lack of information on the population statistics and the buildings themselves. Without an official population number it made it difficult to obtain and understanding of how many people are residing in Kampung Luar Batang, leading the research to be based off a rough population density per hectare. The houses constructed within the informal settlement often change size and shape depending on the resident's needs. This meant there is no official data of the building footprints or heights. To make my maps and digital models I estimated the existing buildings based on satellite images. 


\section{Conclusion}

Jakarta is a city which has over 2 million people that live below the poverty line, and generally in informal settlements that have high population densities, substandard dwellings and inadequate infrastructure. Although these informal communities have strong social connections, the overall quality of life is low.

This research has investigated how an architectural design can support the existing community connections, relieving social stress and improving the lives of residents within the informal settlements of Jakarta, specifically focusing on Kampung Luar Batang. The design criteria was developed after an extensive site analysis, literature review, precedent study, and an initial design review in front of a panel. The design criteria focuses on improving the conditions of Kampung Luar Batang without relocating the current inhabitants from their homes. The design criteria includes: providing necessary infrastructure improvements, acknowledge the existing architecture including the traditional features, Provide facilities to be available and of benefit to the community as a whole, Give opportunity of personalisation of space, assist in social sustainability of the community in the face of environmental threats. During the design process sketches and digital modelling were used to produce community orientated design iterations following the design criteria and attempting to meet the aims of the research.

The proposed solution consists of community orientated open air bamboo structure that provides necessary services to the residents of Kampung Luar Batang. Supporting the existing social connections by providing a place for the community to come together, and providing necessary infrastructure to the area through sanitary facilities and a waste management service. 


\section{Works Cited}

2018 SEED Awards. (2018). Retrieved June 4, 2019, from https:// designcorps.org/seed-awards-about/

Absor, M. U., \& Utomo, I. D. (2017). School-to-work transition of young people in Greater Jakarta: The determinants of success. Asian Population Studies, 13(3), 306-326. https://doi.org/10.1080/17441730.2017.13516 86

Akhmat, G., \& Khan, M. M. (2011). Key interventions to solve the problems of informal abodes of the third world, due to poor infrastructure. Procedia - Social and Behavioral Sciences, 19, 56-60. https://doi.org/10.1016/i. sbspro.2011.05.107

Alzamil, W. (2017). The urban features of informal settlements in Jakarta, Indonesia. Data in Brief, 15, 993-999. https://doi.org/10.1016/i. dib.2017.10.049

Baldwin, C., \& King, R. (2018). Social Sustainability, Climate Resilience and Community-Based Urban Development: What About the People? https://doi. org/10.4324/9781351103329

Biopolus. (2018). Technology-Metabolic Network Reactors. Retrieved April 26, 2019, from http://www.biopolus.net/technology/

Block, I. (2017, December 28). Urban-Think Tank develops low-cost housing for South African slum. Retrieved April 18, 2019, from Dezeen website: https://www.dezeen.com/2017/12/28/empower-shack-urban-think-tanklow-cost-housing-khayelitsha-south-africa/

CADMapper. (2019, May 21). Jakarta Data.

CarterHoltHarvey. (2011). HySPAN; Span Guide for Residential Framing. Retrieved from http://www.5startimbers.com.au/downloads/HYSPAN-EWPSPAN-GUIDE-FOR-RESIDENTIAL-FRAMING.pdf

Chandel, S. (2013). Black Bamboo Community Center for the people of Yogyakarta, Indonesia - Planet Custodian. Retrieved June 26, 2019, from http://www.planetcustodian.com/2013/09/23/2154/black-bamboocommunity-center-for-the-people-of-yogyakarta-indonesia.html

CLALC. (2010). Waterproofing Bamboo Roofs. Retrieved August 28, 2019, from Bamboo Earth Architecture-Chiangmai Life Construction website: https://www.bamboo-earth-architecture-construction.com/in-the-news/ waterproofing-bamboo-roofs/

CLALC. (2017). Panyaden International School Sports Hall / Bamboo Architecture. Retrieved October 22, 2019, from Bamboo Earth Architecture-Chiangmai Life Construction website: https://www.bambooearth-architecture-construction.com/portfolio-item/panyaden-internationalschool-sports-hall/ 
Das, R. (2012). Sustainable Urban Drainage Systems-A possible solution to the problems of Flash Floods in New Delhi, India.

Davis, M. (2006). Planet of Slums. London, UNITED KINGDOM: Verso. Designbuild X Change. (2018). Center for Culture and Ecology Quiané designbuild X change. Retrieved September 20, 2019, from https://www. dbxchange.eu/node/1565

Dower, B. (2018). A Comprehensive Guide to Solar Energy Systems. Elsevier Inc.

Fairs, M. (2009, May 5). Incremental Housing Strategy by Filipe Balestra and Sara Göransson. Retrieved March 21, 2019, from Dezeen website: https:// www.dezeen.com/2009/05/05/incremental-housing-strategy-by-filipebalestra-and-sara-goransson/

Funo, S., Ferianto, B. F., \& Yamada, K. (2005). Considerations on Typology of Kampung House and Betawi House of KAMPUNG LUAR BATANG (JAKARTA). Journal of Asian Architecture and Building Engineering, 4(1), 129-136. https://doi.org/10.3130/jaabe.4.129

Gabriel, R. (2016, November 22). Inside Luar Batang, a Slum at the Center of the Anti-Ahok Movement. Retrieved May 2, 2019, from Vice website: https://www.vice.com/en_asia/article/bm85mz/inside-luar-batang-a-slumat-the-center-of-the-anti-ähok-movement

Gasper, R. J. (2015, October 19). DKI Jakarta: Informal Settlement Mapping. World Bank.

Google Earth. (2019, May 21). Luar Batang, North Jakarta.

Google Maps. (2019, May 20). Jakarta.

Hadiwinoto, S., \& Leitmann, J. (1994). Jakarta. Cities, $11(3), 153-157$. https://doi.org/10.1016/0264-2751(94)90056-6

Irawaty, D. T. (2018). Jakarta's Kampungs: Their History and Contested

Future (UCLA). Retrieved from https://escholarship.org/uc/item/55w9b9gg

Kamh, Y. Z., Khalifa, M. A., \& El-Bahrawy, A. N. (2015). Comparative Study of Community Resilience in Mega Coastal Cities Threatened by Sea Level Rise: The Case of Alexandria and Jakarta | Elsevier Enhanced Reader. https://doi.org/10.1016/j.sbspro.2015.12.007

Kimmelman, M., \& Haner, J. (2017, December 21). Jakarta Is Sinking So Fast, It Could End Up Underwater. The New York Times. Retrieved from https://www.nytimes.com/interactive/2017/12/21/world/asia/jakartasinking-climate.html, https://www.nytimes.com/interactive/2017/12/21/ world/asia/jakarta-sinking-climate.html 
Konovas, K. (2016). Renacer de Chamanga Community House | Jidipi. Retrieved November 15, 2019, from https://architectures.jidipi.com/ a139229/renacer-de-chamanga-community-house/

Lastra, A., \& Pojani, D. (2018). 'Urban acupuncture' to alleviate stress in informal settlements in Mexico. Journal of Urban Design, 1-14. https://doi. org/10.1080/13574809.2018.1429902

Lopez, O. H. (1981). Manuel de Construccion con Bambu. Universidad Nacional de Colombia.

Maurina, A. (2015, July). Curved Bamboo Structural Element. 46-56. Jatiluhur, West Java, Indonesia: Parahyangan Catholic University.

Meinhold, B. (2012). Klong Toey Community Lantern is a Multi-Use Sustainable Social Center in the Heart of Bangkok. Retrieved May 9, 2019, from https://inhabitat.com/klong-toey-community-lantern-is-a-multi-usesustainable-social-center-in-the-heart-of-bangkok/

Ochieng, A. (2016, May 24). The urban waste problem-And tech solutions [Text]. Retrieved April 26, 2019, from http://cleanleap.com/urban-wasteproblem-and-tech-solutions

Oktarina, F. (2018). SHARED SPACE AND CULTURE OF TOLERANCE IN KAMPUNG SETTLEMENTS IN JAKARTA. https://doi.org/10.5614/sostek. itbj.2018.17.3.9

OLA Consulting Engineers. (2019). Village of Hastings-on-Hudson Municipal Greenhouse Gas Analysis and Action Plan Energy Audit Report (No. NVOH0001.00). Retrieved from https://www.hastingsgov.org/sites/ hastingsonhudsonny/files/uploads/2019-03-15_voh_energey_audit_draft_ report.pdf

Parvin, M., \& Begum, A. (2018). Organic Solid Waste Management and the Urban Poor in Dhaka City. International Journal of Waste Resources, 08(01). https://doi.org/10.4172/2252-5211.1000320

Post, T. J. (2015). Sinking Jakarta, frail dike make North Jakartans worried. Retrieved April 24, 2019, from The Jakarta Post website: https://www. thejakartapost.com/news/2015/10/21/sinking-jakarta-frail-dike-makenorth-jakartans-worried.html

Saraf, S. (2015). WaterHubs: Infrastructure for Urban Slums. Retrieved April 26, 2019, from China Water Risk website: http://www.chinawaterrisk.org/ opinions/waterhubs-for-urban-slums/

Simone, A. (2014a). ENDURANCE: Risking the Familiar. In Jakarta, Drawing the City Near (pp. 209-242). Retrieved from https://www.jstor.org/ stable/10.5749/i.ctt7zw6g5.8

Simone, A. (2014b). Introduction: Rehearsal for an Urban Commons in Jakarta. In Jakarta, Drawing the City Near (pp. 1-22). Retrieved from https://www.jstor.org/stable/10.5749/i.ct7zw6g5.4 
Subroto, I. L. (1993). Preservation of Kampung Luar Batang, Sunda Kelapa, North Jakarta. 14.

Sunpath sun position and sunlight phases calculator. (2019).

Retrieved April 12, 2019, from http://www.sunpath.in/\#/-

6.1516,106.8257,11/2019.06.21/10:46

Tilley, L., Elias, J., \& Rethel, L. (2017). Undoing ruination in Jakarta: The gendered remaking of life on a wasted landscape. International Feminist Journal of Politics, 19(4), 522-529. https://doi.org/10.1080/14616742.20 17.1364907

Van Voorst, R., \& Padawangi, R. (2015, August 21). Floods and forced evictions in Jakarta. Retrieved November 14, 2019, from New Mandala website: https://www.newmandala.org/floods-and-forced-evictions-injakarta/

Walker, K. (2016). Flood-prone affordable homes empower slum residents. Retrieved May 9, 2019, from Design Indaba website: https://www. designindaba.com/articles/creative-work/flood-prone-affordable-homesempower-slum-residents

Watson, D., \& Adams, M. (2011). Design for Flooding: Architecture, Landscape, and Urban Design for Resilience to Climate Change. Hoboken, New Jersey: John Wiley \& Sons, Inc.

Weather and Climate. (2019). Weather and Climate information for every country in the world. Retrieved May 14, 2019, from https://weather-andclimate.com/

Wethmann, C., \& Beardsley, J. (2008). Harvard Design Magazine: Improving Informal Settlements: Ideas from Latin America. Retrieved September 5, 2019, from http://www.harvarddesignmagazine.org/issues/28/improvinginformal-settlements-ideas-from-latin-america

Winayanti, L., \& Lang, H. C. (2004). Provision of urban services in an informal settlement: A case study of Kampung Penas Tanggul, Jakarta. Habitat International, 28(1), 41-65. https://doi.org/10.1016/S01973975(02)00072-3

Windfinder. (2019). Wind speed averages and directions for Cengkareng Airport/Jakarta. Retrieved from https://www.windfinder.com/windstatistics/ cengkareng_airport_jakarta 


\section{Source of Figures}

All figures not listed are by author.

Fig 1.1.

Creatival images. (2018). Aerial View of Jakarta Capital City from

Drone [Online image]. Retrieved from https://www.pond5.com/stock-

footage/87331341/aerial-view-jakarta-capital-city-drone.html

Fig 1.2.

Kompas. (2016). Suasana permukiman di Luar Batang [Online image].

Retrieved from https://kilasdaerah.kompas.com/sulawesi-utara/ $\mathrm{read} / 2016 / 03 / 28 / 20143381 / D i s e b u t . A d a$. Rencana.Penggusuran.

Kampung.Luar.Batang.Ini.Kata.Lulung

Fig 2.3.

Google Maps Satellite View (2019). Jakarta [Online Image]. Retrieved from https://www.google.com/maps/place/Jakarta,+Indonesia/@-

$6.1277802,106.7977685,10744 \mathrm{~m} /$ data $=! 3 \mathrm{~m} 1 ! 1 \mathrm{e} 3 ! 4 \mathrm{~m} 5 ! 3 \mathrm{~m} 4 ! 1 \mathrm{~s} 0 \times 2 \mathrm{e} 69 \mathrm{f} 3$ e945e34b9d:0x5371 bf0fdad786a2!8m2!3d-6.2087634!4d106.84559

Fig 2.12.

AKS Machinery Importer (2013). AKS Head Office Jakarta [Online Image]. Retrieved from http://www.aksjakarta.com/company_profile

Fig $2.18 \& 2.19$.

VICE. (2016). Inside Luar Batang, a Slum at the center of the Anti-Ahok Movement [Online Image]. Retrieved from https://www.vice.com/en_asia/ article/bm85mz/inside-luar-batang-a-slum-at-the-center-of-the-anti-ahokmovement

\section{Fig 2.20}

Tilley, L., Elias, J., \& Rethel, L. (2017). Kampung Akuarium life remade on the rubble of the ruined neighbourhood [Online Image]. Retrieved from https://doi.org/10.1080/14616742.2017.1364907

Fig 2.21.

Funo, S. (2005) House Types [Online image]. Retrieved from https://doi. org/10.3130/jaabe.4.129

Fig 2.22.

Google Earth. (2019). Jakarta street photography [Online image]. Retrieved from https://earth.google.com/web/@ 6.18483323,106.84625462,10.40111946a,43725.06556221d,35y,0h,0† ,Or

Fig 4.1.

Fairs, M. (2009). Incremental Housing strategy by Filipe Balestr and Sara Goranson [Online image]. Retreived from https://www.dezeen. com/2009/05/05/incremental-housing-strategy-by-filipe-balestra-and-saragoransson/

Fig 4.2.

Harvard Design Magazine. (2008). Improving Informal Settlements: Ideas from Latin America [Online image]. Retrieved from http://www. harvarddesignmagazine.org/issues/28/improving-informal-settlementsideas-from-latin-america 
Fig 4.3.

Dezeen. (2017). Urban-Think Tank develops low-cost housing for South African slum [Online image]. Retrieved from empower-shack-urban-thinktank-low-cost-housing-khayelitsha-south-africa.html

Fig 4.4.

Desifn Indaba. (2016). Flood-prone affordable homes empower slum residents [Online image]. Retrieved from https://www.designindaba.com/ articles/creative-work/flood-prone-affordable-homes-empower-slumresidents

Fig 4.5.

Inhabitat. (2012). Klong Toey community lantern is a multi-use sustainable social center in the heart of Bangkok [Online image]. Retrieved from https:// inhabitat.com/klong-toey-community-lantern-is-a-multi-use-sustainablesocial-center-in-the-heart-of-bangkok/

Fig 4.6.

CWR. (2015). Waterhubs: Infrastructure for Urban Slums [Online image]. Retrieved from http://www.chinawaterrisk.org/opinions/waterhubs-forurban-slums/

Fig 4.7.

Biopolus. (2018). Technology: Metabolic Network Reactors [Online image]. Retrieved from https://www.biopolus.net/technology/

Fig 4.8.

Das, R. (2012). Cross Section of unlined, partially lined, and lined drains [Online Image]. Retrieved from https://www.researchgate.net/ publication/228327252

Fig 5.1.

CoCoon. (2018). DesigBuild Studio Chamanga/ Ecuador at Hoshule Munchen [Online image]. Retrieved from http://cocoon-studio.de/portfolio/ desigbuild-studio-chamanga-ecuador-more-information/

Fig 5.2.

Designbuild X Change. (2018). Centre for culture and ecology Quiane [Online image]. Retrieved from https://www.dbxchange.eu/node/1565

Fig 5.3

Konovas, K. (2016). Renacer de Chamanga Community House Actemos Ecuador [Online Image] Retrieved from https://architectures.jidipi.com/ a 139229/renacer-de-chamanga-community-house/

Fig 5.4.

Planet Custodian. (2013). Black bamboo community center for the people of Yogyakarta, Indonesia [Online image]. Retrieved from https://www. planetcustodian.com/black-bamboo-community-center-for-the-people-ofyogyakarta-indonesia/2154/ 
Fig 5.5.

Watson, D., \& Adams, M. (2011). Porous concrete or asphalt section [Drawing]. In Design for flooding: Architecture, Landscape, and urban design for Resilience to Climate Change. New Jersey: John Wiley \& Sons, Inc.

\section{Fig $7.1 \& 7.2$}

Lopez, H. L. (1981). Elaboracion de tableros de esterilla [Drawing]. In Manuel de Contruccion con Bambu. Columbia: Estudios Nacional de Columbia, Ltda

Fig 7.3.

Fadilla, R. (2018). Houses of Indonesia [Online image]. Retrieved from https://nowjakarta.co.id/magazine-issue/design-for-living/houses-ofindonesia

Fig 7.4.

Jogolo, R. (n.d.). Bagian-bagian dari [Online image]. Retrieved from http:// rumahjoglo.net/bagian-bagian-dari-rumah-joglo.html

Fig 7.5.

QUARTZ. (2015). Sharma Springs [Online image]. Retrieved from https:// qz.com/367284/spectacular-bamboo-architecture/

Fig 7.6.

Designboom. (2018). Rooftop bamboo structure [Online image]. Retrieved from https://www.designboom.com/architecture/vtn-architects-bambooclub-cafe-vietnam-vinh-06-21-2018/

Fig 7.7.

Bejar, C. (2019). LUUM temple with sweeping catenary arches made from bamboo [Online Image]. Retrieved from https://www.designboom.com/ architecture/co-lab-luum-temple-catenary-arches-bamboo-06-21-2019/

Fig 7.8.

Cosi, A. (2017). Panyaden International School [Online image]. Retrieved from https://www.bdcnetwork.com/school\%E2\%80\%99s-sports-hall-createdentirely-bamboo

Fig 7.13.

CLALC. (2010). Waterproofing bamboo roofs [Online image]. Retrieved from https://www.bamboo-earth-architecture-construction.com/in-the-news/ waterproofing-bamboo-roofs/

Fig $9.27 \& 9.32$

Bielma, C. (2017). TN \#92 Bamboo for Construction [Online image]. Retrieved from https://www.echocommunity.org/resources/ff7fbabb-149c$4 \mathrm{e} 34-9 \mathrm{c} 8 \mathrm{c}-12 \mathrm{dd} 558859 \mathrm{f} 2$

Fig 9.31.

Cabanas, G. (2018). Final eyebolt connection design with cement mortar infill and steel and plastic washers [Online image]. Retrieved from https:// www.researchgate.net/figure/Final-eyebolt-connection-design-with-cementmortar-infill-and-steel-and-plastic-washers_fig 17 _331960255 
